\title{
CHRONIC LOW BACK PAIN AND THE CONSTRUCTION OF ILLNESS IDENTITIES IN WOMEN FROM KUWAIT
}

\author{
NOOR HADI ABDAL
}

A thesis submitted in partial fulfilment of the requirements of the University of Brighton for the degree of Doctor of Philosophy 2015

University of Brighton 


\begin{abstract}
Chronic low back pain (CLBP) has been identified as a prominent health problem and a major cause of disability. Recent research has focussed on providing a better understanding of subjective experiences of people with CLBP; however, emphasis continues to be geared towards the physical restrictions associated with CLBP. There is a scarcity of literature that considers the relation between self and identity, and people's experiences with CLBP. Moreover, studies have concentrated on the experiences of people in Western contexts; to date, no studies have been carried out in Middle Eastern sociocultural contexts including Kuwait. Finally, there is a deficiency of studies that focus on the particularity of the experiences of women with CLBP and the impact on identity. This is the first study that investigates how women with CLBP construct illness identities in Kuwait.

This study adopted a constructivist grounded theory methodology using dimensional analysis. In line with the grounded theory (GT) approach, data collection and analysis took place concurrently. A longitudinal study design was adopted. Semi-structured interviews were used to investigate women's perspectives on their experiences with CLBP in relation to their socio-political and cultural context. Eleven women were recruited from three musculoskeletal outpatient clinics in Kuwait. Initially, five women were purposively sampled. A follow up interview was conducted with four of those women one year after the initial interview to investigate any changes in their experiences. Subsequently, six women were theoretically sampled with the aim of comparing the influence of age, educational level, marital status, socioeconomic status and time on women's illness experiences.

The findings of this study offer the first explanatory theory of the construction of illness identities of women with CLBP in Kuwait. Women's identities can be seen as part of a continuum from oppressed at one end to liberated at the other. Salience of oppressed identities was associated with periods of exacerbation of CLBP and passive coping behaviours. Appearance of liberated identities was accompanied with episodes of remission of CLBP and active coping approaches. Changes in women's social circumstances, thoughts and feelings over time were related to changes in the identities they portrayed, and changes in their manifestation of CLBP and illness experiences. The substantive theory developed through this study has implications for clinical practice, education and research, and may inform physiotherapy professional development activities in Kuwait.
\end{abstract}




\section{Table of Contents}

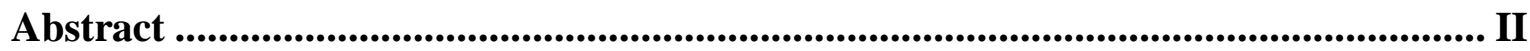

List of Tables ................................................................................................................

List of Figures........................................................................................................ VIII

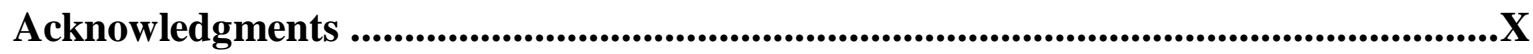

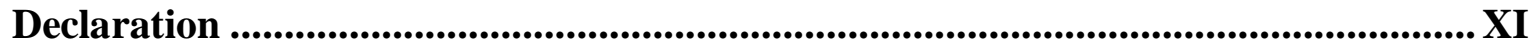

Thesis Structure ............................................................................................................

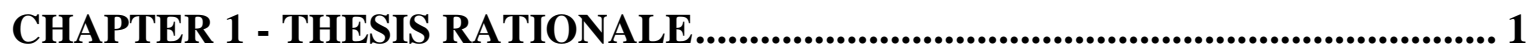

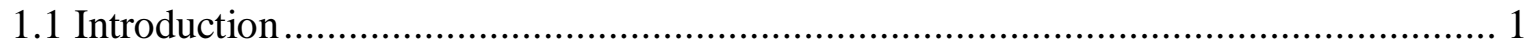

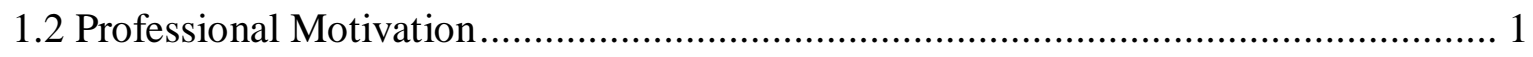

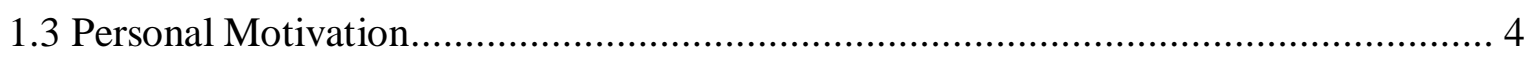

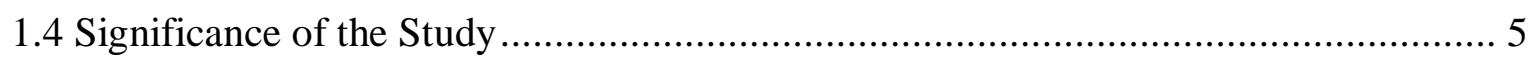

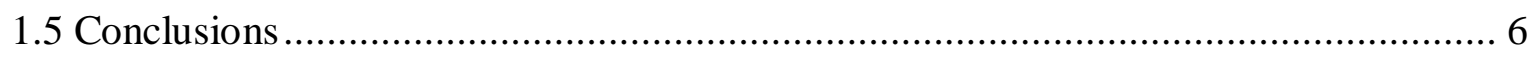

CHAPTER 2 - DEVELOPMENT OF WOMEN'S ROLES IN KUWAIT ................. 8

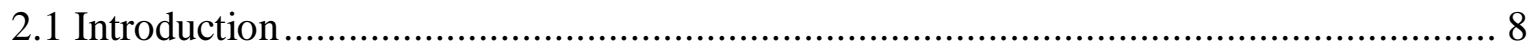

2.2 Geographical and Historical Background of Kuwait ........................................... 8

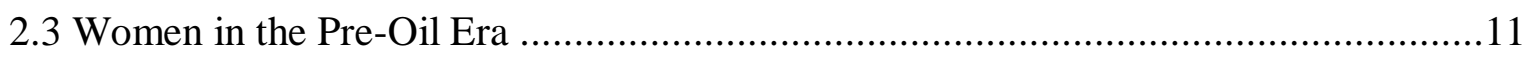

2.4 The Post-Oil Era: Modernisation and the Roles of Women ...................................13

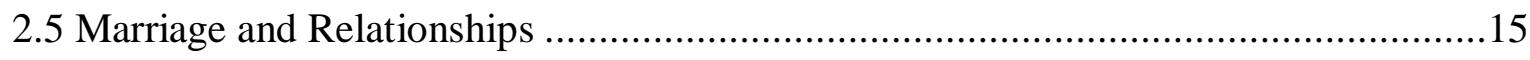

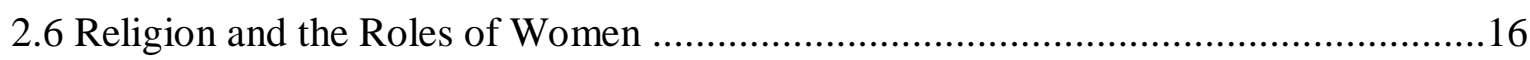

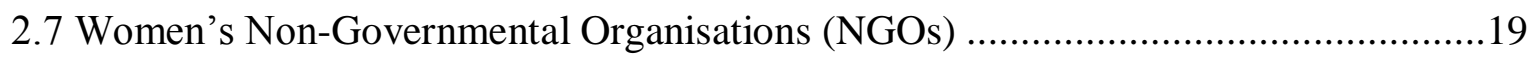

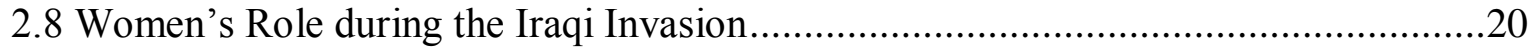

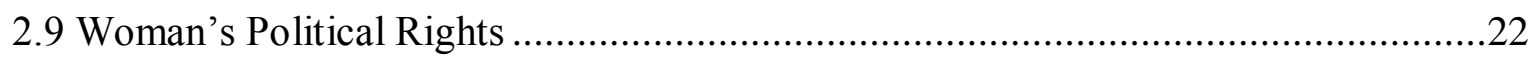

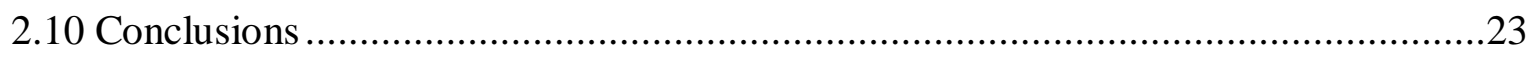

CHAPTER 3 - LOW BACK PAIN CONCEPTS AND MANAGEMENT ...................25

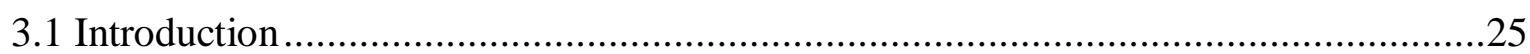

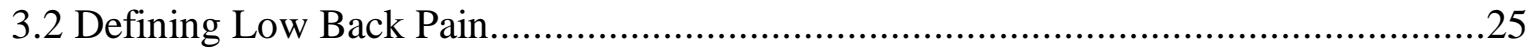

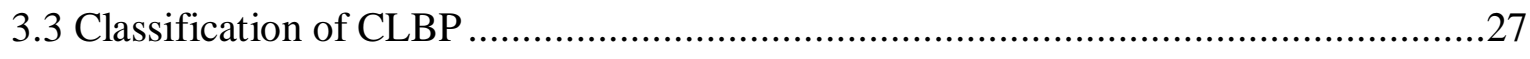

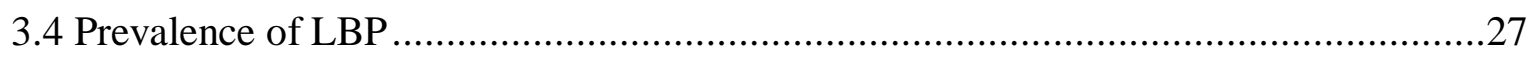

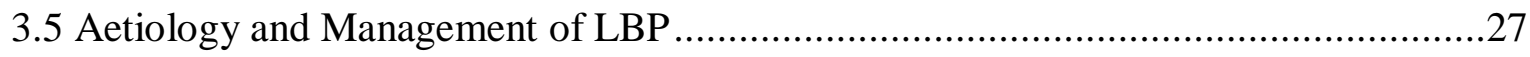

3.6 Pain Perspectives and a Biopsychosocial Approach to CLBP ...................................30

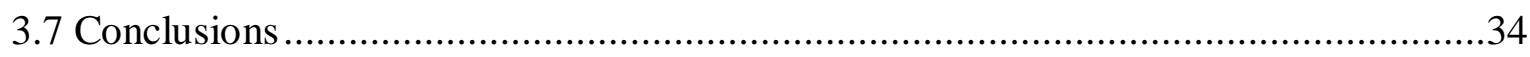

CHAPTER 4 - CHRONIC ILLNESS, SELF AND IDENTITY ...............................35

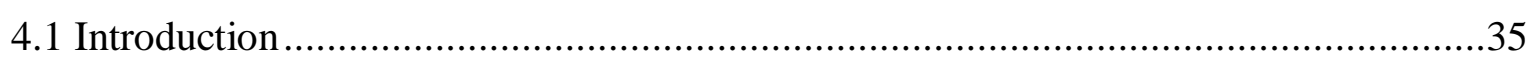

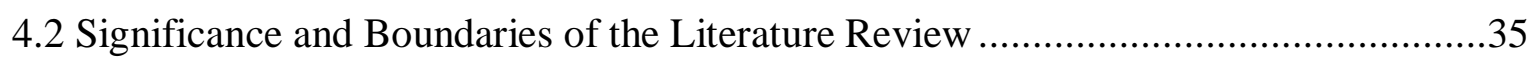

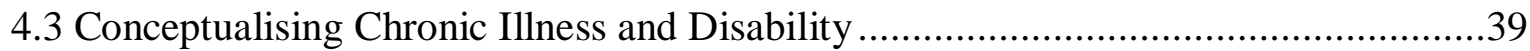

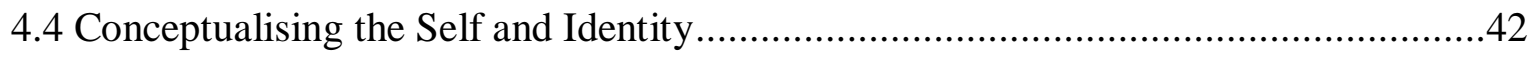




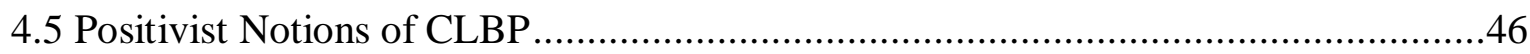

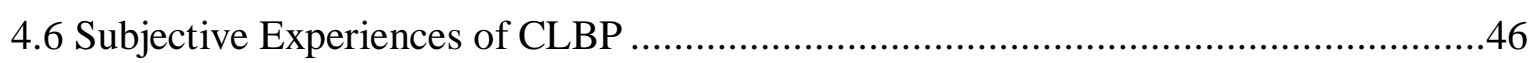

4.6.1 Perspectives of Clinical and Self Management amongst Patients with CLBP...47

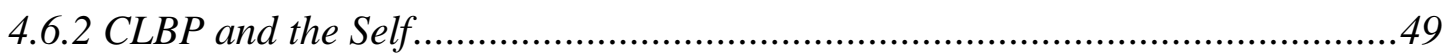

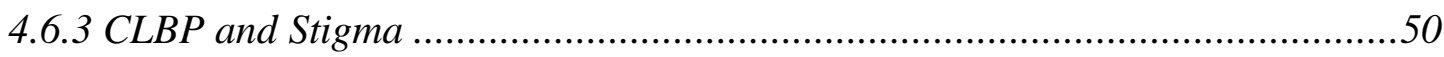

4.6.4 Illness Behaviours amongst People with CLBP ..........................................52

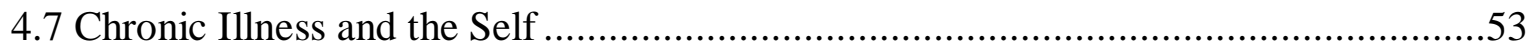

4.8 Illness Behaviours amongst People with Chronic Pain and Illness ............................59

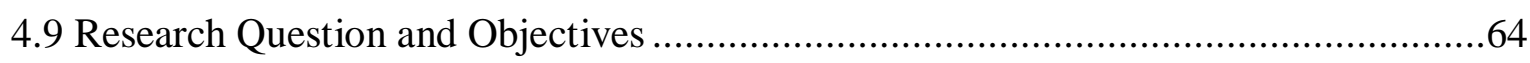

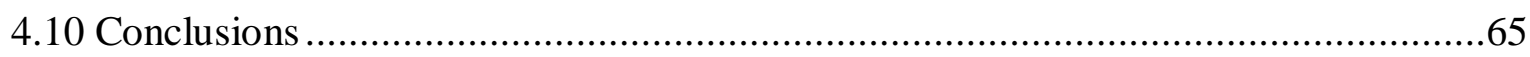

CHAPTER 5 - METHODOLOGY ................................................................67

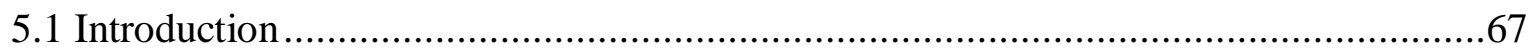

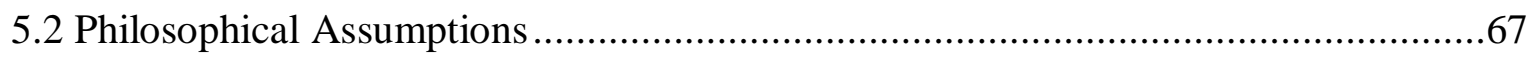

5.2.1 Ontological and Epistemological Positions ..............................................67

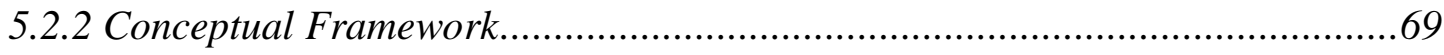

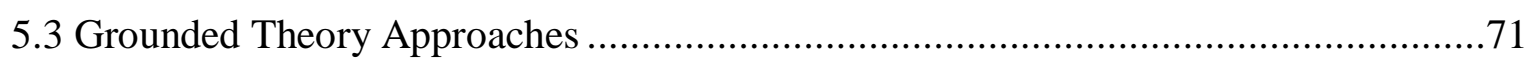

5.3.1 The Development of Grounded Theory and the Rationale for Adopting a Constructivist Grounded Theory Approach............................................................ 71

5.3.2 An Overview of Grounded Theory and Dimensional Analysis Methods ............77

5.3.3 Congruence of Dimensional Analysis with the Constructivist Approach to

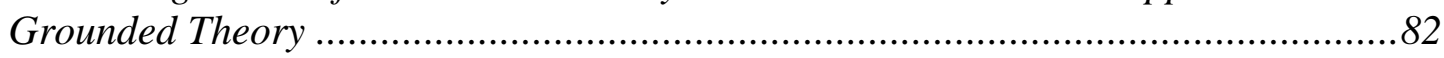

5.3.4 Motivations for Adopting Dimensional Analysis ........................................8 87

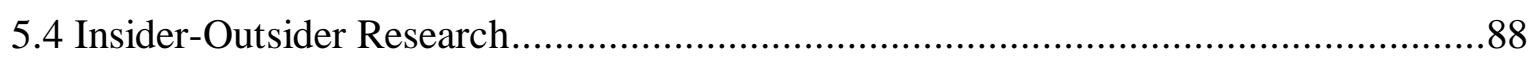

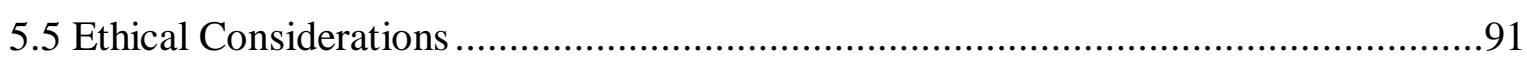

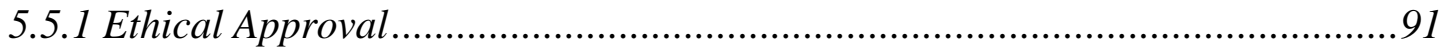

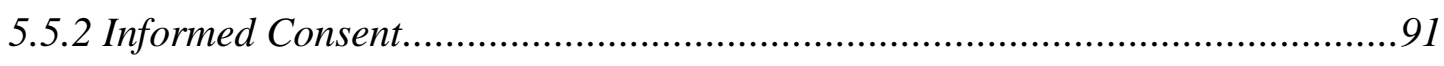

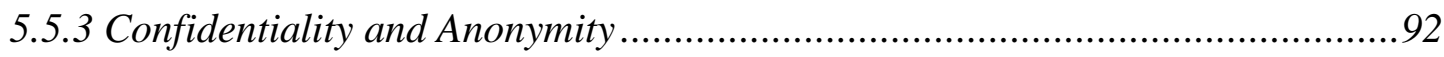

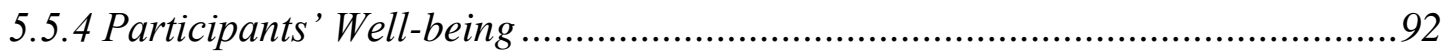

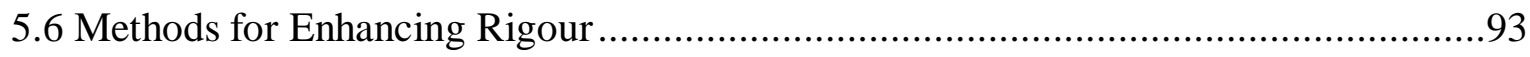

5.6.1 Criteria for Evaluating Grounded Theory Research ....................................93

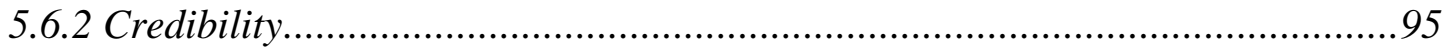

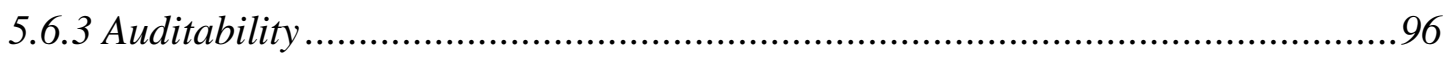

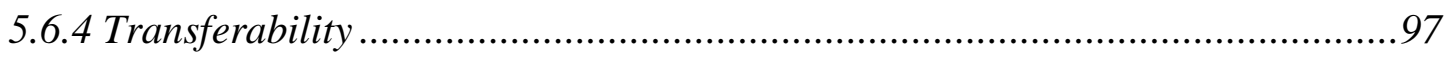

5.6.5 Dependability and Confirmability .......................................................... 98

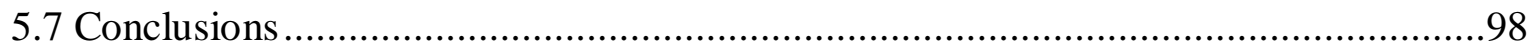

CHAPTER 6 - METHODS .............................................................................100

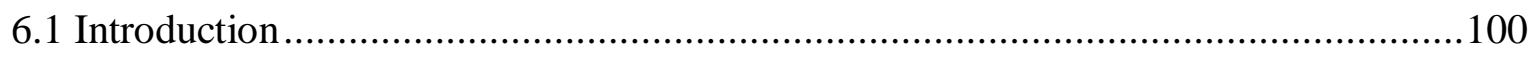

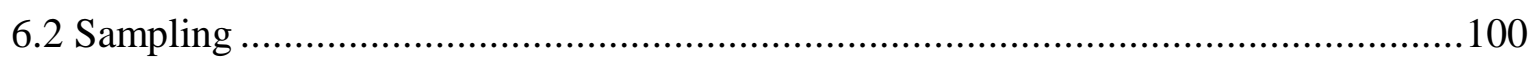

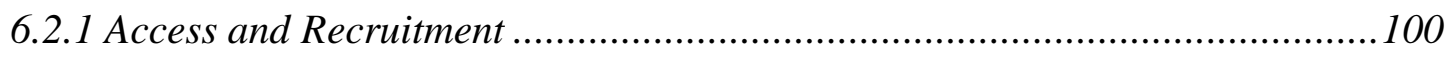

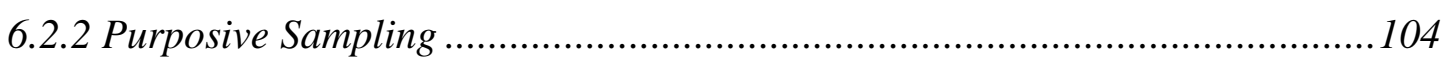

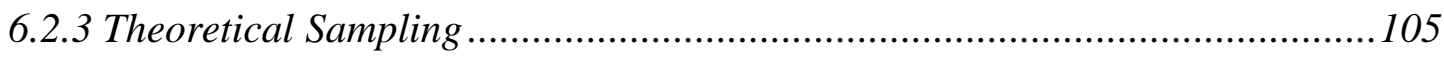

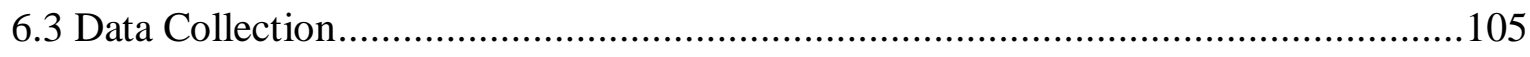

6.3.1 Interview Procedure .............................................................................. 108 


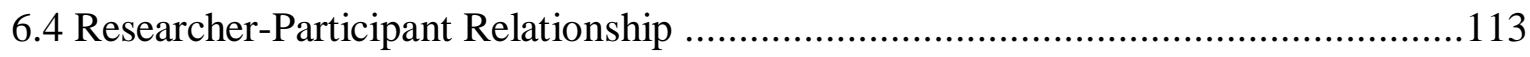

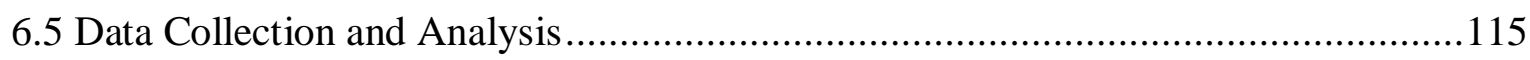

6.5.1 Data Collection - Initial Interviews ........................................................116

6.5.2 Early Analysis of Initial Interviews ............................................................ 116

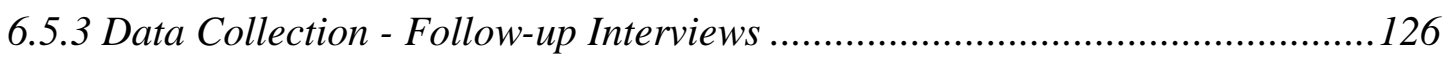

6.5.4 Data Analysis of Follow-up Interviews.................................................... 130

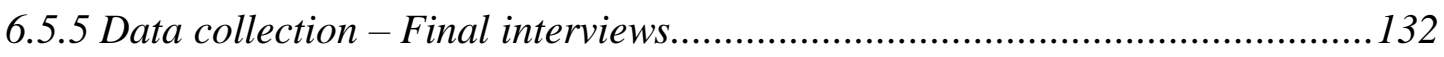

6.5.6 Data Analysis of Final Interviews ............................................................. 133

6.5.7 Finding the Central Organising Dimension and Integration......................... 140

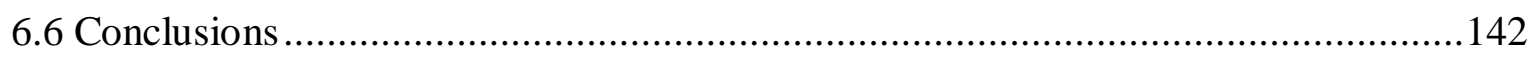

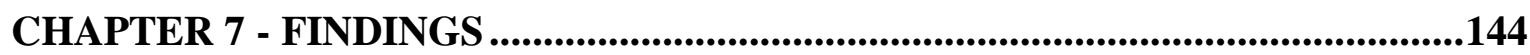

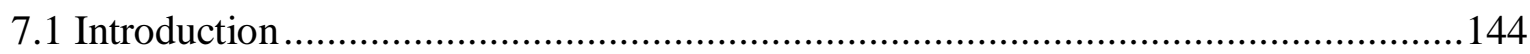

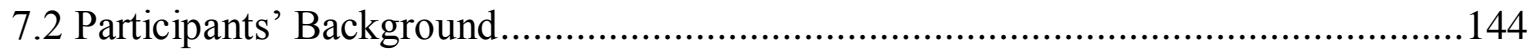

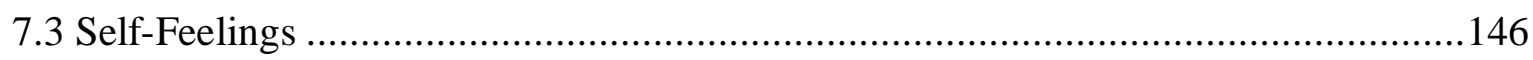

7.3.1 Educational Attainment and Occupational Status......................................... 146

7.3.2 Marital and Family Support ................................................................ 150

7.3.3 Social Communities, Networks and Social Norms ......................................153

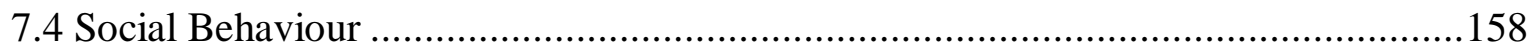

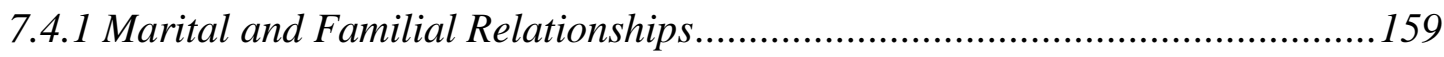

7.4.2 Social Communities and Networks .............................................................. 163

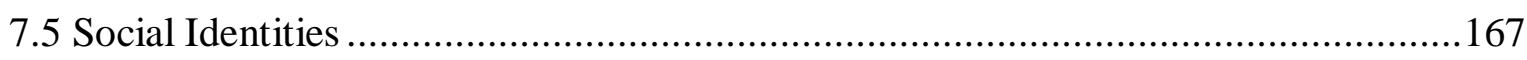

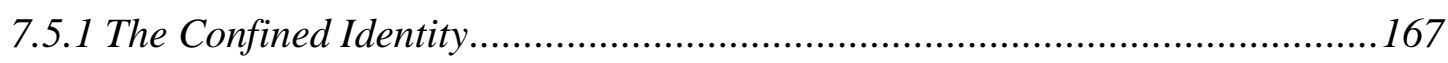

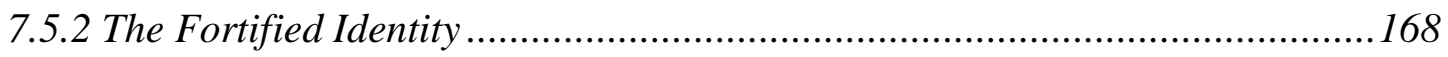

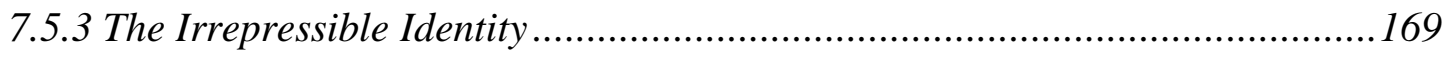

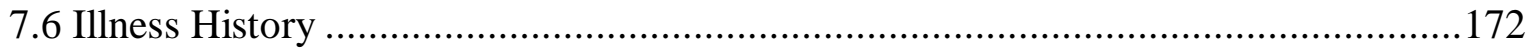

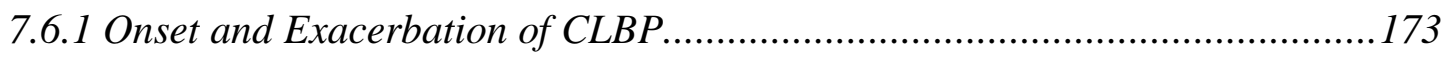

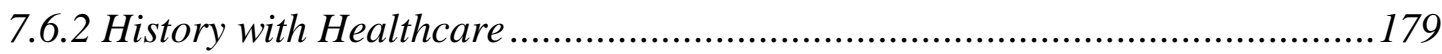

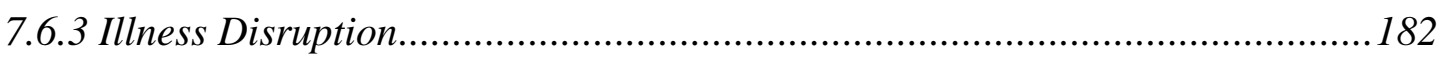

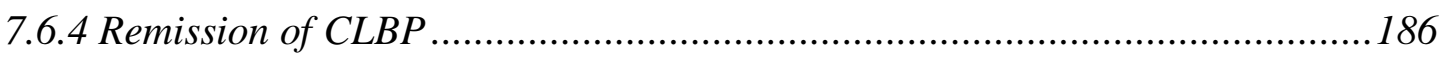

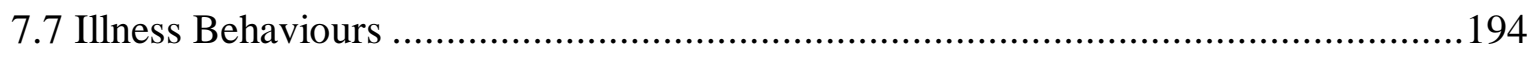

7.7.1 The Confined Identity and Coping with CLBP .............................................195

7.7.2 The Fortified Identity and Coping with CLBP ..............................................198

7.7.3 The Irrepressible Identity and Coping with CLBP ......................................201

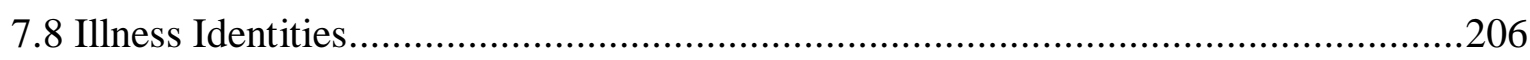

7.8.1 The Submitter Identity ............................................................................206

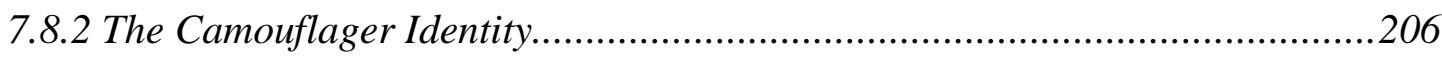

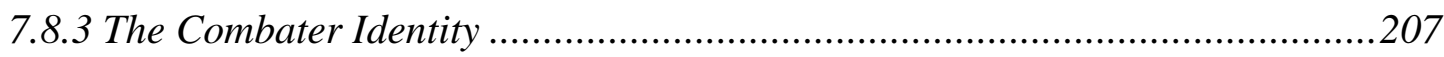

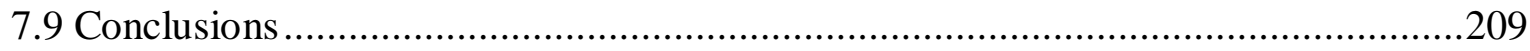

CHAPTER 8 - DISCUSSION …..................................................................................211

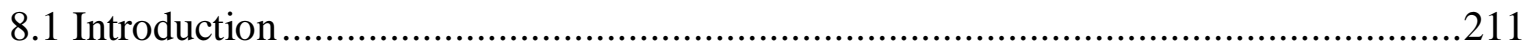

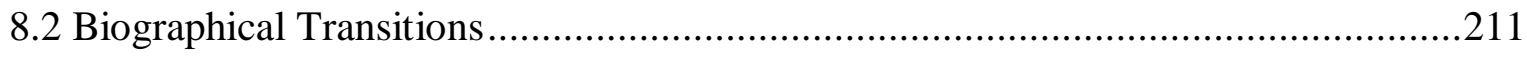

8.3 Social Identities, Social Support and Women with Chronic Illness..........................214

8.4 Illness Identities and Coping with Chronic Illness.............................................217 
8.5 Chronic Illness as a Subjective Experience, and Experiences with Healthcare..........219

8.6 Living as Wives and Mothers, and Suffering from Chronic Illness ..........................221

8.7 Exacerbation and Remission of Chronic Illness .................................................223

8.8 Biographical Transitions and Women's Experiences with Chronic Illness ...............226

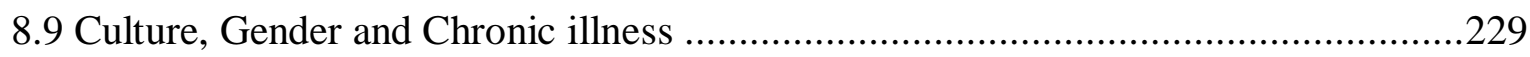

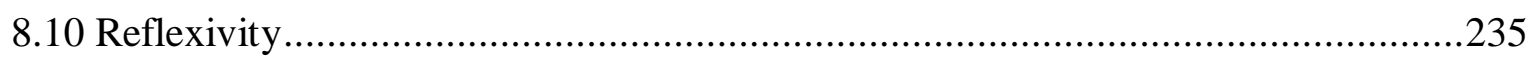

8.10.1 During the Research Process .............................................................2235

8.10.2 Insights Gained from the Research Process............................................237

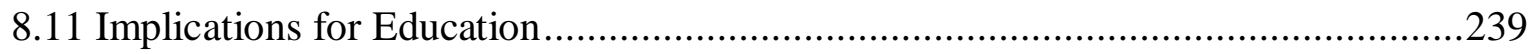

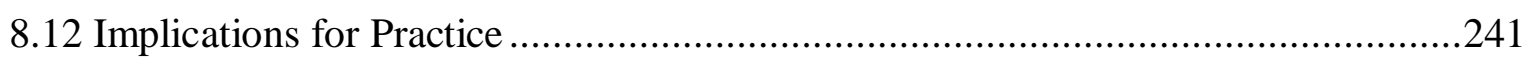

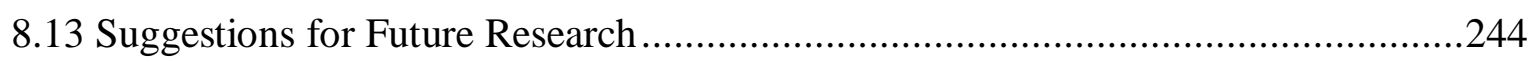

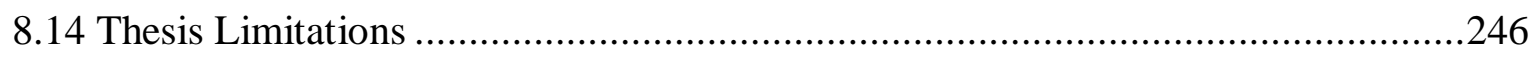

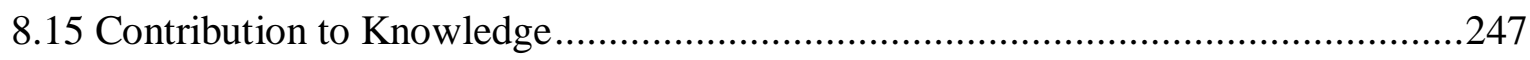

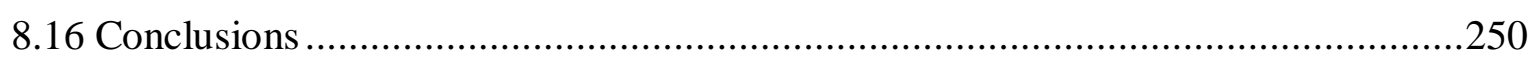

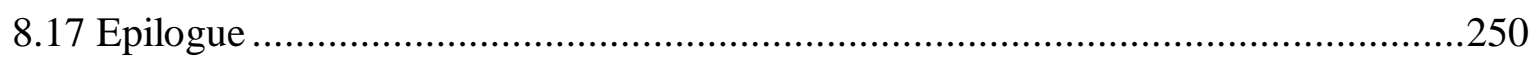

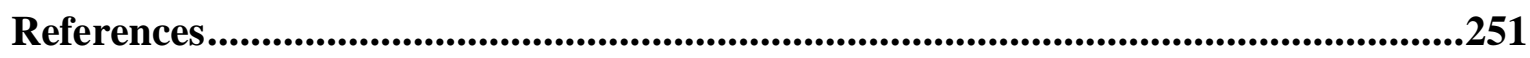

Appendix 1 - Position of the Literature and Development of the Conceptual Framework in this Study ..........................................................................................2272

Appendix 2 - Faculty of Health and Social Science Research Ethics and Governance

Committee, University of Brighton Ethics Committee Approval ................................273

Appendix 3 - Kuwait Institute for Medical Specialisations and Ministry of Health Ethical and Study Approval (English and Arabic versions) .........................................274

Appendix 4 - Participant Information Sheet, Consent Form and Participant Contact

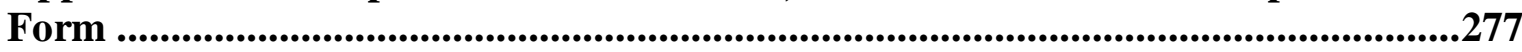

Appendix 5 - The Participant Information Sheet, Consent Form and Participant

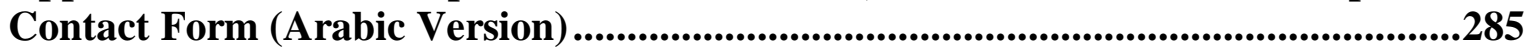




\section{List of Tables}

Table 4.1: Studies related to the impact of CLBP on self and identity

Table 4.2: Perspectives emphasising the multifaceted nature of chronic illness and disability

Table 4.3: Current understandings of chronic illness and identity and areas in need of consideration in future research

Table 5.1: Variations between the constructivist and objectivist GT approaches .76

Table 6.1: Participant's background, sampling and recruitment 102

Table 7.1: Summarising women's social conditions 146

Table 7.2: Summarising the distribution of women amongst the three social identities ..170

Table 7.3: Duration of CLBP and diagnosis 173

Table 7.4: Summarising the distribution of women amongst the three illness identities..208

Table 8.1: Support and rebuttal of the theoretical model by the literature and the novel contributions resulting from this study 


\section{List of Figures}

Figure 2.1: Map of Kuwait 9

Figure 2.2: The governorates of Kuwait 10

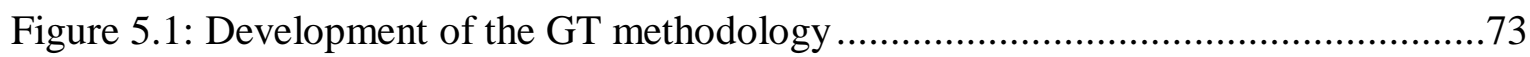

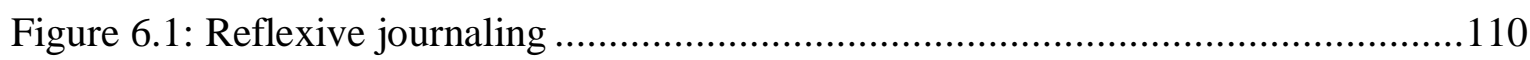

Figure 6.2: Interview guide used for the initial interviews.........................................116

Figure 6.3: Labelling distinctive dimensions of Elham's interview and reflexively challenging presumptions

Figure 6.4: Recalling similarities and variations across the data 120

Figure 6.5: Labels applied to physical restrictions as described by the women 120

Figure 6.6: Excerpt from a reflexive memo concerning the challenges faced and decisions made to manage them

Figure 6.7: Excerpt from an analytical memo illustrating ideas about emotional and family aspects of CLBP experience from Tahani's interview

Figure 6.8: Variations in women's perspectives regarding the approaches of healthcare professionals

Figure 6.9: Variations in women's illness behaviours 123

Figure 6.10: Dimensions and properties generated in the early analysis 125

Figure 6.11: Focused interview guide used during follow-up interviews 128

Figure 6.12: Analytical memo on the significance of the temporal dimension and its relevance to the other dimensions

Figure 6.13: Integrative interview guide used during final interviews

Figure 6.14: Analytical memo raising emotional dimension to perspective

Figure 6.15: Analytical memo demonstrating the constant comparative method of analysis

Figure 6.16: Analytical memo elucidating patterns in the data through the constant comparative method of analysis..... 136

Figure 6.17: Defining the characteristics of women's identity construal. 138

Figure 6.18: Early experimentation with the explanatory matrix to portray the process of biographical transition

Figure 7.1: Illustrating the relation between women's social conditions and emotional states

Figure 7.2: Illustrating the construction of women's social identities 
Figure 7.3: Emphasising the association between women's emotional state and perceived pain intensity

Figure 7.4: Emphasising the association between women's social and illness behaviours .205

Figure 7.5: Illustrating the process of biographical transitions ..... 209

Figure 8.1: Clinical reasoning strategies .240 


\section{Acknowledgments}

My first thanks goes to Allah for giving me the strength, patience and perseverance to carry out this research study.

My supervisors, Dr. Nikki Petty and Dr. Kay Aranda, have been wonderful mentors, and I would like to express my sincerest appreciation to them both. I would like to thank you for giving me the freedom to learn, encouraging me to explore my research interests and for allowing me to grow as a researcher. Your advice and guidance throughout my research journey have been invaluable.

During my time at the University of Brighton I was fortunate to meet several people who have guided me and who have been there for me. Special thanks go to Professor Julie Scholes, Dr. Abeer Al-Tamimi and Dr. Sanaa Madi.

Thanks are also due to the government of Kuwait for sponsoring my doctoral studies, and to the Ministry of Health for providing me access to conduct my research. I am also grateful to Dr. Saud Al-Obaidi, my local advisor, for providing me with ample support, as well as facilitating the process of participant recruitment and data collection.

My deepest gratitude goes to my parents, Eman and Hadi, for supporting me throughout all the stages of my life and education, and for all of the sacrifices that you've made on my behalf. Your prayers for me have sustained me thus far. Thank you for your love, support and patience throughout the long hard hours spent on this $\mathrm{PhD}$. Your love and support are immeasurable and appreciated more than I could possibly express in a few short sentences.

Thanks also to my sister, Dana, for her support and technical advice, and to my brothers, Hassan and Mohammed, for always being there for me. To my aunts, for their endless love and for always cheering me on. I would also like to thank all of my friends who supported me and motivated me to strive towards my goal.

To all the women who participated in this study, of course, this work would have not been possible without you. Thank you for giving of yourselves so freely and generously. It is my hope that I have adequately conveyed your experiences. 


\section{Declaration}

I declare that the research contained in this thesis, unless otherwise formally indicated within the text, is the original work of the author. The thesis has not been previously submitted to this or any other university for a degree, and does not incorporate any material already submitted for a degree.

Signed

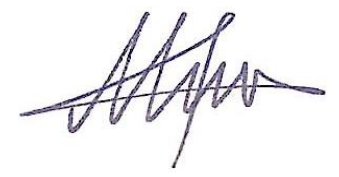

Dated

$10-05-2016$ 


\section{Thesis Structure}

This thesis consists of eight chapters. A brief overview of the content and structure of the thesis, and a synopsis for each chapter is presented.

\section{CHAPTER 1 - THESIS RATIONALE AND OVERVIEW}

The professional and personal rationales for the study are described. The significance of the study is also discussed.

\section{CHAPTER 2 - DEVELOPMENT OF WOMEN'S ROLES IN KUWAIT}

A geographical and historical overview of Kuwait, the context in which the study is set, is introduced. The chapter concentrates on the roles of women in Kuwait, in line with the cultural, social, economic, and political developments that have taken place in the country since the discovery of oil.

\section{CHAPTER 3 - LOW BACK PAIN CONCEPTS AND MANAGEMENT}

Insight into definitions, classifications, prevalence, aetiology and physiotherapy management of low back pain is presented. The biomedical and biopsychosocial models of healthcare as approaches for managing chronic low back pain are also discussed.

\section{CHAPTER 4 - CHRONIC ILLNESS, THE SELF AND IDENTITY}

The theoretical concepts and positions that guided this study are discussed. The chapter focuses on the concepts of self and identity in relation to chronic illness in general, and CLBP in particular, and provides a critical stance of current research and understandings.

\section{CHAPTER 5 - METHODOLOGY}

The methodological approach adopted in this study is discussed. The chapter emphasises the relevance of the constructivist GT approach using dimensional analysis to epistemological and ontological assumptions guiding this study. Ethical measures and measures taken to ensure methodological rigour of this study are also presented. 


\section{CHAPTER 6 - METHODS}

The methods employed to collect data and derive meaning through analysis, in line with the iterative nature grounded theory, are presented. This chapter commences by outlining the strategies used in this study to access, recruit and sample participants. An explicit and detailed account of the data collection methods and dimensional analysis procedures employed is presented. The process is illustrated with data excerpts, different types of memos used during data collection and analysis as well as reference to the relevant literature.

\section{CHAPTER 7 - FINDINGS}

The findings of this study are presented in this chapter which commences by providing context for the findings through presenting the backgrounds of the study participants. Thoughout, each aspect of the theory generated is supported using quotations from the interviews with participants and these serve as supportive evidence for the theoretical claims proposed. The key conceptual relationships which form the constructed theory is illustrated by the way in which the data is organised.

\section{CHAPTER 8 - DISCUSSION}

This chapter engages the theoretical explanation of the data with the literature. It theoretically compares and contrasts the emergent substantive theory with relevant formal theories and other empirical research in the substantive area. The chapter also proposes theoretical links between the findings of the present study and earlier work, and highlights the original contribution of this research. The chapter continues by considering my final reflections on the research journey, some insights I gained and impacts I had on the study. Finally, the contribution of this to the physiotherapy knowledge base and the implications of the findings for practice, education and further research are discussed. 


\section{CHAPTER 1 - THESIS RATIONALE}

\subsection{Introduction}

The purpose of this study was to obtain a theoretical insight into how the Kuwaiti sociocultural context influences the construction of illness identities amongst women with chronic low back pain (CLBP). This chapter will present the rationale of the thesis by clarifying the professional and personal drivers for conducting this research study.

\subsection{Professional Motivation}

I have gained numerous experiences and knowledge while studying at Kuwait University as an undergraduate student, working as a physiotherapist at the Jaber-Al Ahmad Armed Forces Hospital in Kuwait, and undertaking my Master's degree and subsequently $\mathrm{PhD}$ at the University of Brighton. These experiences were influential in shaping and developing my interest in pursuing a research study which gives voice to women's daily experiences of living with chronic illness. How my professional experience and knowledge shaped my perspectives is discussed below.

The biomedical emphasis of my undergraduate education was considerably influential on the perspectives that shaped my clinical practice. Soon after I graduated from Kuwait University, I started practising as a physiotherapist at the Jaber-Al Ahmad Armed Forces Hospital. It is a general hospital, which provides healthcare services to Kuwaiti veterans and their family members. Due to the conservative nature of the Kuwaiti culture, female physiotherapists generally manage female patients, and therefore my experience was mainly with women. The majority of women I worked with suffered from a variety of chronic musculoskeletal problems, with CLBP being one of the most common ones. 
During my clinical practice, I became aware of the limits of biomedical reasoning, particularly when I managed patients with chronic conditions. The influence of being trained under the biomedical school of thought led me to focus on identifying physical symptoms. However, during my assessment, I sometimes realised that the patient was not showing any physical signs, and any physical test I used did not provide signs of physical impairment. In line with the homogeneity, generality and physiological emphasis of biomedical explanations of illness that I was accustomed to, I followed a routine of treatment with every patient that suffered from CLBP, rather than individualising my treatment to the specific patient. This was mainly because I felt the 'real' issues that arose from the patients' illness were not something I had been trained to manage. Although sometimes the patient would be dissatisfied, I was unsure of what more I could have offered.

Reflecting back on the issues that arose while I attempted to manage women with CLBP, I realised that in most cases, my approach was insufficient. I remember a particular patient, who was happy with her sessions with me and was gradually improving. One day she was late, and due to high workloads and busy schedules, I had no choice but to reschedule her appointment. She became upset and asked to change physiotherapists because she felt that I was inconsiderate about her circumstances. In other instances, patients would focus on discussing their social circumstances and difficulties they faced in their lives, rather than the pain itself. It was experiences like those that made me realise the emphasis that women placed on their social circumstances, and their need to voice them despite the physical nature of their treatment sessions.

As I progressed in my practice, I realised several other things. I became aware of women's constant disappointment and dissatisfaction with the healthcare they received in general, and physiotherapy in particular. Working in close proximity with male physiotherapists and regularly discussing patients' conditions and management, I also became aware of the 
fact that chronic pain and illnesses were considerably more prominent amongst female patients in comparison to male patients in our department.

The conditions of my clinical practice and realisations I made while working with women with CLBP raised several questions. I wondered how women's perspectives and their social circumstances might impact their experiences and behaviours towards chronic illnesses. I also questioned why there was a difference between the types of conditions experienced by women in comparison to men. Those questions made me aware of my duty as a healthcare professional, to be sensitive to women's circumstances outside the realms of healthcare, and to develop a more holistic understanding that captured the subjectivities of women's experiences with chronic illness.

After two and a half years of clinical practice, I was offered a scholarship to pursue my postgraduate education. I commenced my master's education at the University of Brighton and embarked on a journey of critical appraisal. While my biomedical training was focused on homogeneity, being introduced to the concept of critical appraisal made me aware of the importance of understanding different perspectives. Using the GT approach for my dissertation opened my eyes to the potential of qualitative research in capturing emic perspectives and developing an understanding of participants' views. Exploring physiotherapists' perspectives about quality of care made me aware that physiotherapists working in all sorts of settings and regions emphasised the importance of taking social variation and cultural understandings into consideration to provide better quality care.

As a doctoral student, I have had an opportunity to develop an understanding of various epistemological standpoints. In particular, I was drawn to the social constructionist epistemology, which suggests that individual's perspectives and experiences are constructed through their views, social realities and their selves. Moreover, I further developed my understanding of the GT approach, particularly with regards to how it can 
be adopted to construct a theory, which juxtaposes multiple stories of people involved in the study; moreover, I understood how I could illuminate the daily realities of women living with CLBP through this epistemological standpoint and methodological approach.

The experience and knowledge I gained throughout my academic and clinical journeys motivated me to explore women's subjective experiences. Providing such an understanding would inform physiotherapists and other clinicians about the detailed nature and variation in women's experiences in order to assist them in devising recommendations for more holistic physiotherapy services in Kuwait. This led me to the concept of identity, and the exploration of it in the sociocultural context of Kuwait amongst women with CLBP. In Kuwait, there is a growing need to understand how social and cultural influences may impact women's wellbeing and behaviours. The subjectivities of women's chronic illness experiences in Middle Eastern societies remains under investigated. Accordingly, it is timely to explore women's perspectives about their chronic illness experiences in Kuwait, a geographic region that has scarcely been addressed in the scope of mainstream academia.

\subsection{Personal Motivation}

I am a Kuwaiti female, in my twenties. Having lived in Kuwait for most of my life, I took the impact of cultural and social understandings for granted. It was not until I moved to the UK in 2008 to pursue my postgraduate education that I became aware of the considerable impact of cultural variation on the behaviours of people in general, and women in particular. As the years passed, I became increasingly aware that this was more than an academic experience for me; it was a life experience. As I became more exposed and accustomed to the culture in the UK, I found myself selectively embracing ideologies and understandings that were new to me. I watched myself evolve in line with a continuous amalgamation of sociocultural ideologies I had grasped as a Kuwaiti woman and a 
physiotherapist living in Kuwait, and subsequently as a Kuwaiti woman and postgraduate student living in the UK. I realised how my understandings of the social context around me impacted on my perspectives and worldviews, my values and expectations, and even my feelings and behaviours.

As well as the high prevalence of CLBP amongst women that I treated, watching my mother suffer from CLBP for many years was also a driver that triggered my interest in investigating this condition. While my mother and all those women complained of pain in their back, I did not understand why there was variation and in their manifestations of pain, their coping behaviours, and the benefit they gained from physiotherapy treatment.

My own life experiences along with my mother's experience with CLBP ignited my passion for understanding how the variation of social experiences of women impacted on their realities and experiences with CLBP.

\subsection{Significance of the Study}

Conceptualisations of the pain phenomenon have been largely influenced by theoretical notions and research based on the Cartesian dualism which dominates Western medicine. Cartesian philosophy, proposed by the French philosopher René Descartes, produced dichotomies resulting in mind/body divides, which have been suggested as restricting healthcare management of chronic pain and illness (Bendelow, 1993). This philosophy has also been suggested to favour and legitimise 'visible', physical pain over intangible, emotional and mental suffering (Chandler, 2013).

This 'medicalisation' of pain has led current literature and healthcare to emphasise the physical and physiological detriments encountered by individuals suffering from chronic pain and illness. Nevertheless, the pain experience both shapes and is shaped by people's day-to-day social and emotional experiences. Therefore, shifting the emphasis to people's 
subjectivities and validating lay manifestations of chronic pain is vital in order to develop more effective, patient-centred management approaches.

In terms of CLBP, research and management approaches have repeatedly emphasised the physical and functional restrictions faced by individuals, with scarcely any consideration of the impact of other factors, including social variation and wider cultural discourses. Moreover, there has been a scarcity of literature considering the experiences of individuals living in Middle Eastern, Arab societies. An in-depth exploration of CLBP experiences and the diverse social situations in which they are intertwined within a non-Western context is essential in order to broaden current understandings. This is turn will aid in developing holistic healthcare approaches which are more perceptive to sociocultural variation.

\subsection{Conclusions}

This chapter discussed my professional and personal backgrounds and perspectives in order to be transparent about how they have influenced my studies, and provided a rationale for conducting this study. It has been suggested that a researcher's biography influences their methodological decisions (Charmaz, 1990), and therefore it is necessary to clarify how prior knowledge may impact the research process to enhance the rigour and quality of findings (Cutcliffe, 2000). Nevertheless, it was also important to ensure that my personal experiences and views did not impede the process of attaining rich data from the participants (Charmaz, 2009), making it essential to manage any preconceived ideas. This has been managed throughout the data collection and analysis process, by distinctly documenting reactions from the actual data and scrutinising my research decisions throughout the research project.

The following chapter provides a historical and contextual account which demonstrates the development of the roles of women in Kuwaiti society. The chapter sets the scene for the 
theory presented in Chapter 7, and provides some contextual background to the wider cultural discourses which influenced the shaping of women's CLBP experiences and identity construals. 


\section{CHAPTER 2 - DEVELOPMENT OF WOMEN'S ROLES IN}

\section{KUWAIT}

\subsection{Introduction}

This chapter demonstrates the development of the roles of women in Kuwait in line with social, economic and political advancements that have taken place in the country since its establishment. The chapter commences with a geographical overview and an outline of the early development of Kuwait. It moves on to clarify the impact of tribal ideologies and patriarchal authority on the roles of women. It then explains the developments associated with the discovery of oil and modernisation, and their impact on the roles and opportunities for women in Kuwait. This information has been presented to provide context for the study findings (Chapter 7), by illuminating some cultural norms and practices that influenced the construction of illness identities amongst women with CLBP in Kuwait.

\subsection{Geographical and Historical Background of Kuwait}

Kuwait is one of the smallest countries in the Middle East, covering a total area of approximately 17,818 square kilometres (slightly smaller than Wales), and its terrain is almost entirely flat desert plain. It is located in the north-eastern corner of the Arabian Peninsula, bordering the Persian Gulf to the east, Saudi Arabia to the south and west, and Iraq to the north and west (Figure 2.1). 


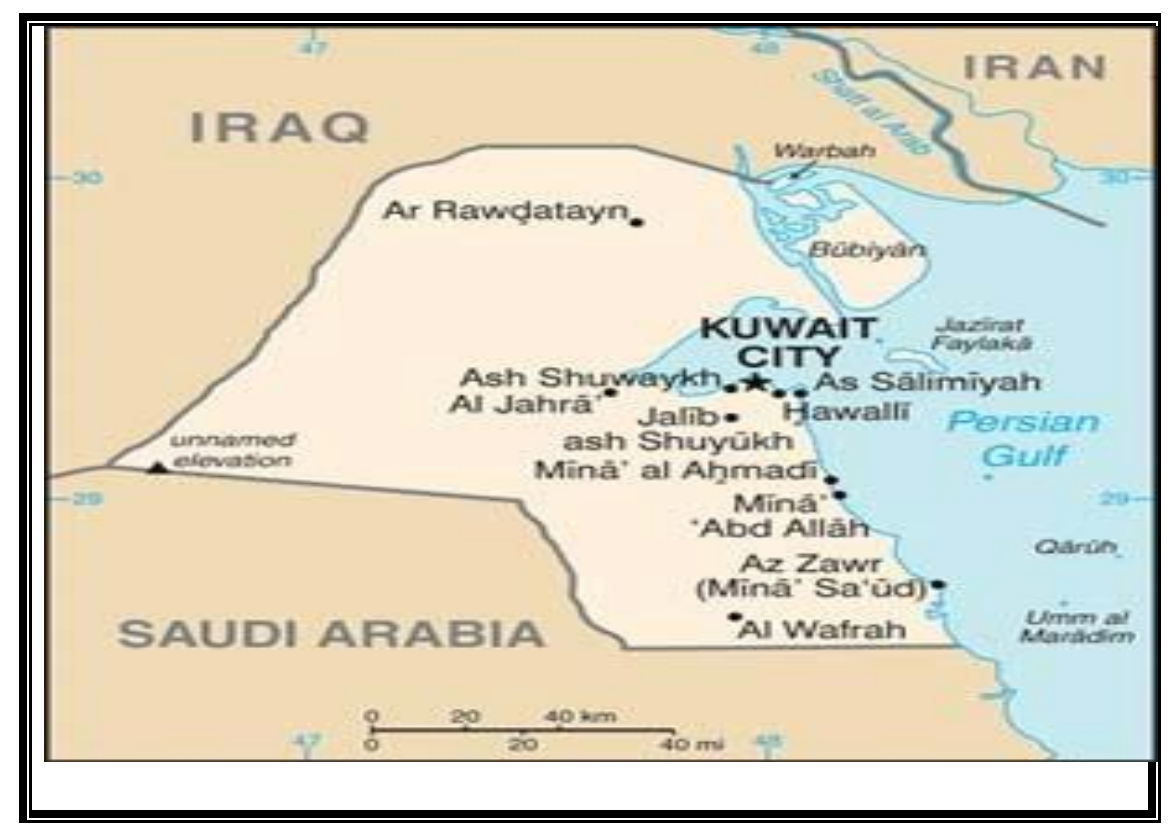

Figure 2.1: Map of Kuwait

Kuwait was founded in the early eighteenth century when a group of nomadic families migrated to the Persian Gulf from Saudi Arabia. They settled in the area due to the availability of water, which was utilised to join a trading network with neighbouring families. The name Kuwait is believed to be derived from kut, the Arabic word for fort, since the families built one to protect the early settlement (Winstone and Freeth, 1972). One of those families, the Al-Sabah family, became the ruling family in Kuwait.

In the 1920s, the Kuwaiti economy depended on fishing, pearl diving, seafaring, boat building, herding and trade (Al-Sabah, 1980). Families lived close to one another, each in their own neighbourhood. They provided jobs for much of the community and supplied the ruling family with a regular income in the form of customs duties (Tetreault and AlMughni, 1995).

The discovery of oil in 1938 was a turning point for Kuwait, leading to economic, cultural and population progression, and developments in industry, education, and healthcare services. In 1953, the country's economy prospered, as it became the largest oil exporter in the Middle East. New Kuwait rose and buildings in old neighbourhoods were replaced 
with new houses, which were built along the modern highway system, in accordance with plans devised by foreign architects. Kuwait was divided into six governorates: Al-Ahmadi, Al-Asimah (Al-Kuwait), Al-Farwaniyah, Al-Jahra, Hawalli, and Mubarak Al-Kabeer (Figure 2.2). The new governorates introduced new boundaries based on nationality, age cohort and family status. Hawalli, for example, was the neighbourhood where many expatriates resided in Kuwait. Bedouin families were concentrated outside the city centre, in Jahra, around the oil town of Ahmadi and along the south coast. Those boundaries were not concrete; the neighbourhoods were mixed in that they included families who did not conform to the mode of that area. In older neighbourhoods, older buildings remain alongside more modern houses. Nevertheless, residential segregation both shapes, and is shaped by, Kuwaiti politics and culture.

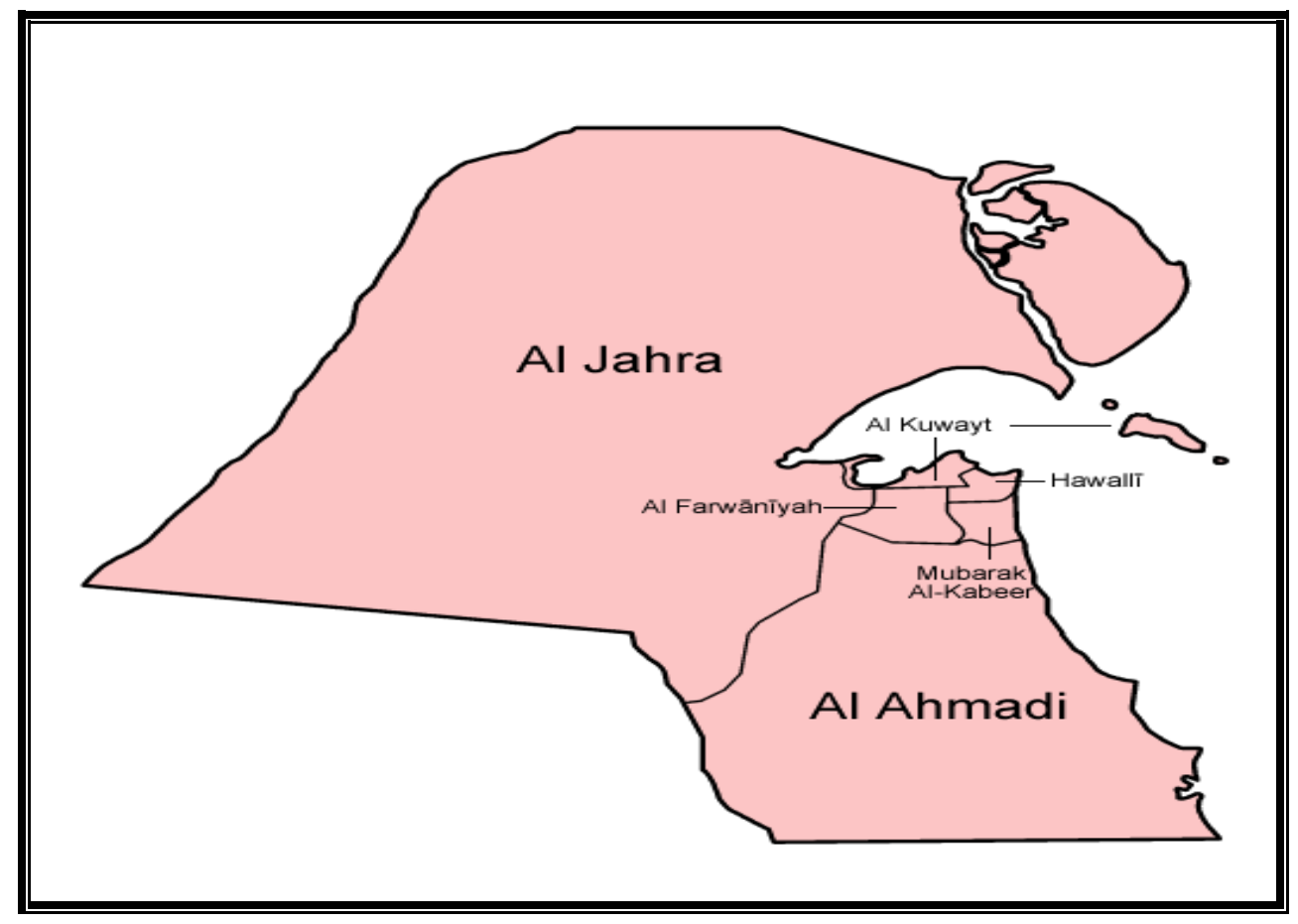

Figure 2.2: The governorates of Kuwait

An overview of the historical development of Kuwait before the discovery of oil, and the changes and advancements that took place after oil was discovered in the country has been 
presented. The following sections portray how those developments impacted on the roles of women in Kuwait.

\subsection{Women in the Pre-Oil Era}

Before the discovery of oil, the Al-Sabah family and a number of important merchant families controlled Kuwaiti society. In order to preserve their status, these families established a tribalist ideology based on an entrenched system of paternal and patriarchal norms and age and gender hierarchies (Tetreault and Al-Mughni, 1995).

Under the influence of this patriarchal order, the fortress around Kuwait impacted on the lives of women; they were isolated from the outside world. Women were generally accustomed to conservative practices, where a woman's place was seen to be within the private/domestic sphere. It was only acceptable for women to socialise within homes and seeing women in public was considered to be inappropriate. Men who could afford to provide for their wives and unmarried daughters and sisters, felt there was no need for the women to go to work and they should therefore devote themselves to home life.

The society believed that education was only a necessity for males, as this would enable them to attain employment that will secure an income to provide for their wives and children. Women's education was based on basic religious studies until adolescence, at which point they would be married off to a suitor chosen by their male relatives. Nevertheless, women did work from within their households. Their work included sewing clothes, raising poultry, teaching the Qur'an and some even gave their husbands the money they made to buy goods from abroad (Al-Kazi, 2011).

While the majority of Kuwaitis accepted those hierarchies, a number of male authoritarian figures from merchant elite families, who had been educated abroad, developed an opposition movement against the oppressiveness of the ruling family. Their relatively cosmopolitan lifestyle was associated with them developing more tolerant perceptions of 
women's roles. The opposition included lobbying the government in line with their beliefs that women should be educated, employment opportunities for women should be enhanced and the boundaries of patriarchy should be surpassed by ensuring access to education for girls (Tetreault, 1993; Al-Kazi, 2011).

Women who were fortunate to have already been educated abroad started writing articles in newspapers on issues that concerned them including the veil, and women's access to education and employment. A new female consciousness arose, which commenced with women protesting against wearing the abbaya (a black over garment). In 1961, the government granted women the permission to go to work without being veiled (AlMughni, 2001). During this time, women were confined to working for government departments, which provided gender-segregated occupations including the Ministry of Education and the Ministry of Health and Social Affairs (Al-Kazi, 2011). Nevertheless, protests from merchant class families who held senior government positions opened new avenues of work for women in the national broadcasting station and the Foreign Ministry in 1962 (Al-Mughni, 2001). Better job opportunities gave women greater freedom such as driving their own cars. With modernisation, there were evident changes in the social and family system in Kuwait, and the roles of women (Al-Kazi, 2011).

Conservative, tribal ideologies and patriarchal authority confined the roles of women and limited their educational and employment opportunities during the pre-oil era. This gendered hierarchy was challenged by male authoritarian figures and educated women from merchant families. Continuous protests and lobbying initiated changes including better job opportunities and greater freedom for women. The next section explains how the development of women's roles continued to flourish after the discovery of oil in Kuwait. 


\subsection{The Post-Oil Era: Modernisation and the Roles of Women}

The commencement of oil exportation in 1946 brought with it changes that not only impacted on the economy of Kuwait, but also the country's social and political life. Change in the social and political order was influenced by a vast amount of foreign workers who were attracted by the economic expansion; this resulted in Kuwaitis becoming a minority in their country (Tetreault \& Al-Mughni, 1995). Kuwait has witnessed various waves of immigration due to its resources. Following the discovery of oil, foreign workers started interacting more in work domains; furthermore, additional migrants from different parts of the world (Egypt, Jordan, Palestine, Lebanon and others) came to work in Kuwait. The country had a population of approximately 3,632,009 of which only 1.16 million were Kuwaiti citizens (32\% of the total population), and 2.47 million were non-Kuwaiti nationals (27\% Arabs, 37\% South Asians, 4\% others), making the non-citizens outweigh the nationals (Public Authority of Civil Information, 2011, U.S. Department of State, 2012). The importance of improving the education and health systems led to the dependence of the Kuwaiti government on non-Arab nationals as a work force. More migrants moved from other parts of Asia and Africa. In effect, Kuwait became a multicultural land, where people from many nationalities and with various social values integrated to form what is known today as Kuwaiti society.

Social and political changes associated with the diversification of Kuwaiti society led to considerable transformation in the roles of women. Since education was provided free of cost to Kuwaiti citizens, it was easily accessible to women; this led to the gradual reduction of illiteracy amongst women to minimal rates (Shah, 2004). Today, literacy rates have risen to as high as $95 \%$ amongst women in Kuwait, and almost two-thirds of university graduates, or 67\%, are women (Al-Hamli, 2013). 
Increasing levels of educational attainment aided a gradual increase in work participation, from 2\% in 1965 to 43\% in 2013 (Shah 2004; Al-Hamli, 2013). Employment opportunities for women have broadened, enabling them to play a significant role in the country's development. They have many more choices in comparison to women in some neighbouring countries, as they can work as lawyers, own and manage their own businesses and work in sectors where they have male colleagues (Metcalfe \& Rees, 2010). Women in Kuwait represent $52.6 \%$ of medical doctors, $55.9 \%$ of lawyers and economists and $74.5 \%$ of health professionals, such as X-ray and nuclear medicine personnel. There has also been an increase in Kuwaiti businesswomen to 25.6\% (Al-Kazi, 2011)

Those changes accompanying modernisation associated with the oil economy challenged gender relations; they were also associated with the emergence of Islamist movements to counteract this social change. In the absence of political groups and reliable secular alternatives, these political groups became popular. Their claim was that the Islamic identity was in danger, while in fact it was the patriarchal authority that was being challenged. During the 1980s and 1990s, those groups gained a foothold in the Kuwaiti parliament; their agenda was to undermine gender perspectives in public policies (AlKazi, 2011).

The post-oil era and modernisation were associated with diversification of cultural ideologies and practices in the Kuwaiti society, and in turn, a transformation in the role of women. This transformation included higher educational attainment, an increase in work participation and broader employment opportunities, which enabled women to play a significant role in the country's development. An enhancement in women's roles led to the emergence of extremist Islamic movements claiming to preserve an endangered Islamic identity, with a political agenda to undermine gender perspectives in public policy. 
The information provided thus far portrays a continuous clash between societal perspectives in favour of the development of women's roles in Kuwait, against perspectives which endorse the preservation of patriarchal norms and undermine women's rights. The following section demonstrates how those opposing ideologies impacted on societal expectations in regards to the roles of women in marriage and relationships.

\subsection{Marriage and Relationships}

Increasing university education and employment opportunities meant that women were more commonly commuting in venues which were non-segregated, providing opportunities for them to become romantically involved, and in some cases married, following their families' consent. Marriage without the approval of both families is considered socially deviant behaviour and can cause parental admonishment and either temporary or permanent severing of relationships (Shah 2004).

While improvements in education and employment opportunities offered women a choice of who to marry, this choice was undermined by gendered legislation. Though it is acceptable for Kuwaiti men to marry non-Kuwaiti women, Kuwaiti women who marry a foreigner are marginalised both by society and by the government. Since citizenship is passed from father to son, when a Kuwaiti women has children with a non-Kuwaiti husband, they are not entitled to Kuwaiti citizenship and are denied political, economic and social protection to which Kuwaitis are entitled (Tetreault \& Al-Mughni, 1995).

Both non-marriage and divorce are seen to be social problems. Media portrayals as well as societal perceptions emphasise the roles of women as wives and mothers to be a priority. They are expected to combine those roles with their role as employees if they were working; however, a role in the work force is not seen an alternative to their domestic and childbearing roles. Culturally, divorce is stigmatised and divorced women are viewed to be unfortunate (Shah, 2004). 
Improvements in educational and employment opportunities enhanced women's choice in deciding whom to marry. Nevertheless, legislation influenced by patriarchal authority undermines this choice. Moreover, conservative ideologies which prioritise women's domestic and childbearing roles over their employment, and which marginalise nonmarried and divorced women, prescribe how women are expected to behave in marital relationships. The next section illuminates variations in religious ideologies and how various interpretations led to different manifestations of the roles of women in Kuwait.

\subsection{Religion and the Roles of Women}

As well as the variety of social values and practices brought by the large number of ethnic groups living in Kuwait, Kuwaiti citizens are further classified into three distinct groups, adding to the diversity of the Kuwaiti culture. The first group includes the Arabs who descended from urban Arab tribes from Najd in Saudi Arabia, such as 'Utub', 'Ejman', 'Awazim', 'Bani Khalid', 'Rishayda', 'Enouz' and many others (Taqi, 2010). In the early days of the establishment of Kuwait, these tribes made up most of the Kuwaiti population (Dashti, 1997). This group also includes other nomadic tribes, whose people are known as Bedu, or Bedouin. The second group includes Arabs who came from Iraq and the eastern part of Saudi Arabia (Hasawi) and Bahrain. The third group is referred to as the Ahwaz and the Ajamis, who are the people who migrated from Iran.

All Kuwaiti citizens are Muslims, and while the national census does not distinguish between Sunni and Shi'a adherents, approximately $70 \%$ of citizens, including the ruling family, belong to the Sunni branch of Islam. The remaining 30\% of Kuwaiti citizens are Shi'a (U.S. Department of State, 2012). Among expatriates, there are an estimated 450,000 Christians, 300,000 Hindus, 100,000 Buddhists, and 10,000 Sikhs (U.S. Department of State, 2012). Christians, Hindus, Sikhs and Buddhists are allowed to build places of worship or other religious facilities. Christian families practise their own 
religious rituals with complete freedom in the churches found in Kuwait. In accordance with the Kuwaiti constitution, these groups are allowed to practise and can engage in religious activities, provided that no prejudice may occur against Islam (Kuwait Government Online, 2011).

In Islam, there are different worldviews regarding the roles of women. Islamic orthodoxy urges the inclusion of women in politics, in line with the teachings of Muhammad (PBUH) which stated that both men and women deserve equal and just treatment and that both had to approve his leadership in order for it to be legitimate (Zepp, 1992). After the leadership of Muhammad (PBUH), his principals in regards to the roles of women and their place in political life were shaped differently within the context of a variety of traditions and cultures in the Middle East. Different groups of clergy developed various interpretations in regards to women and their place in society (Ayubi, 1992). Among Sunnis in Kuwait, some follow the Saudi Arabian (Najd) school that believes that women must be separated from public life both socially and politically, while others follow the Egyptian (Alazhar) school and/or the worldview of the Muslim Brotherhood, which believes that women should be more involved politically. Among Shi'as in Kuwait, some follow the Iraqi (Najaf), school, which does not support women's political involvement and others follow the Iranian (Qom) school that endorses the growth of Islamic states, such as Iran where the constitution guarantees women's political rights (Rizzo et al., 2002).

Prominence of religious practices in Islam also depends on whether practices are dictated by the Qur'an or by the Hadiths. The Qur'an is considered the most authentic source for Islamic principles and practices. The Hadiths on the other hand, are documentations of the words, deeds and habitual practices of the Prophet Mohammed, which have been passed down orally across the generations, and which Muslims refer to as ideals for their behaviour and conduct. The emphasis put on the teachings of the Qur'an and Hadiths depends on the various available interpretations. For example, while divorce is sanctioned 
in the Qur'an, the acceptability of divorce in various Muslim communities depends on how it has been culturally interpreted. Julia ana Ridha (2001) suggest that Muslim women in Kuwait believe that gender equality exists in the Qur'an itself. The problem is malpractice and misunderstanding of the sacred text, particularly since women are excluded from clergy groups, which develop and provide interpretations.

Emerson (1996) suggests that orthodoxy refers to religious beliefs, whereas religiosity signifies practices and behaviours. There is a distinction between the ideal, pristine Islam, and the traditional, practiced Islam. In a study by Meyer et al. (1998), which explored the compatibility of Islam with the extension of women's rights in Kuwait, it was found that participants who identified with Islamic orthodoxy supported women's rights. Respondents who favoured Islamic religiosity, on the other hand, such as wearing the veil and traditional clothing as well as sporting beards, did not. Those findings echoed in Rizzo et al.'s (2002) study, which investigated whether Kuwaiti women's groups who supported women's political rights in Kuwait had allies. The findings suggested that orthodox respondents strongly supported the involvement of women. On the other hand, those who valued Islamic appearance or religiosity did not. Moreover, the endorsement or lack of endorsement of women's rights was associated with the school of thought with which respondents were affiliated. For example, participants who followed the Saudi Arabian school of thought did not support women's political involvement; whereas those who followed the Iranian school of thought did.

The religious diversity presented in Kuwaiti society impacted on the roles of women. Dominance of non-nationals in Kuwait with various religious backgrounds, as well as the numerous Islamic schools of thought followed by Kuwaitis, have led to diverse perspectives and expectations in regards to the social and political involvement of women. This has led to a continuum of religious ideologies: one end endorses full participation of women in social and political affairs, while the other advocates separating women 
completely from public life. The next section demonstrates the impact of women's nongovernmental organisations on developing their position in the Kuwaiti society.

\subsection{Women's Non-Governmental Organisations (NGOs)}

In 1963, the first two women's NGOs were developed in Kuwait: the Women's Cultural and Social Society (WCSS), which was developed by merchant class women, and the Arab Women Development Society (AWDS) which was formulated by middle class women. For over a decade, they were the only two entities which lobbied for women's rights in the country (Tetreault et al., 2009; Al-Kazi, 2011). A new feminine ideal was set by those NGOs: namely that of an educated career woman who participated in statebuilding, and who was involved in the government and political arena.

In 1971, the AWDS organised the first women's conference in Kuwait. It discussed a petition that demanded full political rights, the right to equal opportunity in employment, the right of working mothers to child allowances (which were only provided to male heads-of households) and the right of women to be appointment as special attorneys to draft a new family law (Tetreault et al., 2009). In 1994, the WCSS demanded the members of parliament to present a proposal, which outlined the importance of offering government housing to Kuwaiti women married to non-Kuwaitis; the law was passed in 1995. The law stipulates that in the event the mother passes away, the family would only own the house until the daughter marries or the son reached 26 years of age (Tetreault et al., 2009).

Local NGOs, in collaboration with governmental agencies and international NGOs, have worked to economically empower women in Kuwait. In modern times, there are several Kuwaiti women who own and manage their own businesses (Tetreault et al., 2009; AlHamli, 2013). Nevertheless, this economic empowerment is impeded by gendered government policies. For example, laws pertaining to loans given by the Savings and Investment Bank (a governmental institution) are based on gender and not on the capacity 
of a person to pay back the loan. A Kuwaiti man married to a non-Kuwaiti woman can apply for a loan, but a Kuwaiti woman married to a non-Kuwaiti cannot (Tetreault et al., 2009).

The establishment of women's NGOs has created new ideologies pertaining to the role of women in Kuwait. Women became more involved in governmental and political affairs, and more economically empowered. Despite the efforts of those NGOs to develop women's position in society, gendered governmental policies continue to impede this development. This is another demonstration of the conflict between groups supporting the enhancement of women's roles and policies that restrict and limit such advancements. The next section demonstrates the roles that women played during the Iraqi invasion and how this period impacted on their sense of self.

\subsection{Women's Role during the Iraqi Invasion}

When the Iraqi military surpassed the Kuwaiti boarders on the 2nd of August 1990, women played a crucial role in the seven-month resistance. They produced and took charge of circulating al-Kuwaitiya (The Kuwaiti Woman), the underground resistance paper. They were also involved in the underground armed resistance. The abbaya, which was historically used as a gown to conceal women and hide their sexual attributes, was used to hide and distribute weapons and information and became a symbol of national cohesion.

Class distinctions and privileges, as well as customary male protective roles were retracted in the defence of an endangered Kuwaiti identity. Men who worked for the Ministry of Defence, military personnel and young men were perceived to be members of resistance groups and hid in fear of being arrested. In such circumstances, women were at the forefront and in fact were protecting the men (Julia \& Ridha, 2001). 
Women took a central role in providing community needs including food, water, shelter, and health care; they cared for the elderly, orphans, the mentally impaired and the disabled. They ran their households as asylums, stocking them with food, water and homemade gas masks. They visited relatives who were incarcerated, arranged transport for women to visit relatives in prison, and took care of prisoners of war (POWs); some women also became martyrs and POWs. They also traded material goods such a television sets with Iraqi soldiers in exchange for releasing Kuwaiti prisoners (Julia \& Ridha, 2001).

Women's heroic role during the invasion showed that despite a lack of political awareness, they were able to take a firm stand in the struggle to liberate Kuwait. This gave women a new sense of self. They perceived themselves as different people, and felt things inside of themselves that they had not in the past (Badran, 1998). This gave them an incentive to become more active in volunteer work and in the reconstruction of Kuwaiti society. Women volunteered to help other people who were affected by wars and crises, such as civilians in Somalia and Bosnia. Moreover the WCSS organised committees to help individuals who were impacted by the flood that occurred in Kuwait in 1997. Also, coalitions including the Democratic Platform and the Constitution Movement, which were run by men, became open to women members after liberation (Julia \& Al-Ridha, 2001).

Women played a crucial role in the mission to liberate Kuwait from the Iraqi invasion. Customary gendered roles were reversed, where women were at the forefront and male protective roles were deflected. Women's heroic stance during the invasion gave them a new sense of self and an incentive to become more active in reconstructing Kuwaiti society and the country's political affairs. The next section demonstrates how women's position in society developed further after they were granted their full political rights. 


\subsection{Woman's Political Rights}

Since the 1950s, educated men from merchant families have led the campaign for women's rights, in line with their belief that it is a path towards progress and independence (Al-Mughni, 2001). The heroic role that women played during the Gulf War in 1991 brought the issue of women's political rights back to the spotlight. In 1993, the WCSS held the first conference after liberation which focused on gender discrimination; it raised national awareness about the debate on women's rights. Moreover, rallies and protests were held, seminars and lectures were presented, and signed petitions were addressed to the National Assembly. Members of society and members of parliament (MPs) that were in favour of granting women their political rights appeared in the media to show that it was cultural understandings, not the Islamic religion, that was preventing women from participating in the political sphere (Al-Kazi, 2011).

On the other hand, there was some opposition to extending women's rights from particular religious and tribal groups, including their female members. The increasing political power of those groups pertained from the regime's aim to divide the opposition by weakening the secular Arab nationalists through strengthening the Islamic extremists (AlMughni, 2001; Rizo et al., 2002). Extremists overlooked women's role during the occupation and argued that women's primary role was to be a wife and mother and their involvement in politics was forbidden by religious principles.

Women gained their political rights in 2005 , and in elections held in 2010 , three women won and took their positions in parliament along with seven men (Al-Kazi, 2011). Despite the opposition, women's political input continues to grow. Several women that ran and won parliamentary elections have been appointed as ministers for several ministries including the Ministry of Planning and Administrative Development, the Ministry of Health, the Ministry of Education and Higher Education, the Ministry of Commerce and 
Industry and the Ministry of Labour and Social Affairs; some have even been appointed as ambassadors (Al-Suwaheil, 2009; Al-Hamli, 2013).

Continuous rallies, protests and conferences led to women being granted their full political rights. This advancement improved women's position in society; they assumed positions in parliament, and were appointed as ministers and ambassadors. Despite this progression, extremists continue to oppose extending women's rights, as they believe that women's role should be limited to being wives and mothers.

\subsection{Conclusions}

Kuwait is a country which is caught between two opposing philosophies: modernisation and a longing to maintain tradition. Those opposing ideologies have had a significant impact on the development of social, political and religious understandings pertaining to the roles of women in Kuwaiti society. The era before the discovery of oil was characterised by traditional and conservative norms that limited women's access to education, employment and politics. The era after the discovery of oil led to the diversification of Kuwaiti society due to the considerable number of expatriates the country attracted. Moreover, opposition groups challenging traditional tribal ideologies, women's NGOs, and women's role in the Iraqi invasion were all factors that enhanced women's educational attainment, provided them with more senior positions, and ensured them full political rights and participation in political and public life. Despite those developments, the conflict between liberal values endorsing women's rights and the progression of women's position in society, and conservative values, which oppose this progression, remains. The impact of the various ideologies on identity and illness will be elaborated on in the theory presented in Chapter 7.

The following chapter presents a literature review which demonstrates the complexity of the CLBP phenomenon, and the necessity for developing more holistic understandings and 
healthcare approaches to manage this condition more effectively. In particular, it demonstrates the necessity of acknowledging social and cultural variation in developing more effective management approaches for CLBP. This sheds light on the necessity of considering the distinct sociocultural context, as presented in this chapter, when exploring the experiences of women in Kuwait suffering from CLBP. 


\section{CHAPTER 3 - LOW BACK PAIN CONCEPTS AND}

\section{MANAGEMENT}

\subsection{Introduction}

This chapter provides an overview of low back pain (LBP) and CLBP. It includes insight into the definitions, classifications, prevalence, aetiology, and physiotherapy management of LBP. It also discusses the effectiveness of biomedical and biopsychosocial models of healthcare in the management of CLBP. The objectives of this chapter are twofold: first, to demonstrate the adversity and complexity of CLBP, and how this has challenged lay people and clinicians alike; and second, to illuminate the necessity of broadening current understandings and management approaches, by acknowledging the psychosocial and cultural dimensions of people's experiences with CLBP.

\subsection{Defining Low Back Pain}

In the literature, LBP is the common term used to describe pain in the lumbar region; CLBP is differentiated from LBP by the duration of pain. There has been considerable controversy about a precise definition to capture the complexity of LBP. LBP is commonly defined as the area between the bottom of the costal margin (twelfth rib) and the inferior gluteal folds (buttock creases). Some people with LBP complain of pain in their legs, which may be present in addition to, or without, LBP (European Guidelines for the Management of Chronic Non-specific Low Back Pain, 2004). Waddell (2004) defines back pain as a mechanical problem of musculoskeletal origin in which symptoms vary with physical activity and over time, and further highlights that the cause of pain can be any of the spinal structures; therefore, it is difficult to know the exact cause. While the first definition limits the condition to a specific region of the body, Waddell (2004) highlights the difficulty of restricting it to particular regions or spinal structures. 
CLBP has been identified as a leading health problem in the world (WHO, 2003; 2004), and is considered a major cause of disability (Cook and Hassenkamp, 2000; Aceves-Avila et al., 2004; Taimela et al., 2004). Treatment of CLBP has been a challenge, and a solution to the problem has not yet been determined (Ehrlich, 2003). Most approaches used to manage CLBP, including surgery, medication and conservative treatment, such as physiotherapy, have not been proven justifiable and usually fail to provide any permanent relief (Pinnington, 2001; Ehlrich, 2003). People with CLBP have only been considered to be a minority of back pain sufferers. Nevertheless, ineffective management approaches causing recurrent treatment and long-absences from work and social support, have made them responsible for the majority of economic costs associated with back pain and the consumption of large quantities of health care resources (Taime et al., 2004). With regard to physiotherapy, the magnitude of the problem has been demonstrated by the fact that patients with CLBP were found to account for $60 \%$ of referrals to out-patient departments (Callaghan, 1994).

In Kuwait, statistics from the Physical Medicine and Rehabilitation Hospital have shown that approximately 55\% of patients that were referred for physiotherapy treatment in 2010 suffered from CLBP (Physical Medicine and Rehabilitation Hospital, unpublished statistics demonstrating percent of musculoskeletal patients referred to physiotherapy according to diagnosis, 2010). While statistics on surgical and procedural costs inferred by patients suffering from CLBP are not readily available, a large number of patients who undergo surgical procedures continue to seek physiotherapy and medical attention due to the failure of surgeries in providing any permanent relief. Unsuccessful surgical procedures and the recurrent utilisation of healthcare services by patients with CLBP may lead to large economic consumption and load on healthcare resources. 


\subsection{Classification of CLBP}

Conventionally, LBP has been classified according to its duration (Savigny et al., 2009). However, there has been a lack of agreement concerning the time period which signifies chronicity, thereby adding another dimension to the complexity of this condition. CLBP has been defined as pain which lasts longer than 12 weeks (Spitzer and Leblanc, 1987). Believing that it is too late to start thinking about back pain as chronic after 12 weeks, Waddell (2004) contends that 6 weeks is a more appropriate alternative. Waddell's (2004) criterion for determining chronicity of LBP has been followed to recruit women in this study (refer to Section 6.2.1).

\subsection{Prevalence of LBP}

Estimates for the prevalence of LBP vary considerably; in addition, they do not distinguish between LBP of differing durations. However, a global review by Hoy et al. on the prevalence of LBP in the general adult population was published in 2012. It showed a point prevalence of $11.9 \% \pm 2.0 \%$ and a one-month prevalence of $23.2 \% \pm 2.9 \%$ after adjusting for methodological variation. The overall mean prevalence was $31.0 \% \pm 0.6 \%$, the one-year prevalence was $38.0 \% \pm 19.4 \%$, and the lifetime prevalence was $39.9 \% \pm$ 24.3\%. LBP was shown to be a major problem throughout the world, with the highest prevalence among women aged between 40 and 80 years. The study concluded that as the population ages over the coming decades, the number of people with LBP is likely to increase substantially.

\subsection{Aetiology and Management of LBP}

A 'specific' or physiological cause of LBP, such as a vertebral fracture, tumour, infection, inflammatory disease, disc herniation or spinal stenosis, can only be identified in $5 \%$ to $15 \%$ of cases (Nordin et al., 2006; Balague et al., 2007; Krismer and van Tulder, 2007; 
Foster, 2011). In $85 \%$ of cases, no underlying pathology can be determined to explain the cause of people's pain. Such individuals are considered to have 'non-specific' LBP (Nachmenson et al., 2000; Balague et al., 2007; Krismer and van Tulder, 2007; Foster, 2011).

A lack of 'specific' or physiological explanation for $85 \%$ of LBP may be due to the dominance of biomedical perspectives in conceptualising LBP (Koenig et al., 2014). This is particularly problematic for individuals whose pain has developed from acute to CLBP, since it has been acknowledged that psychosocial factors, or what clinicians' term 'yellow flags', such as stress, anxiety, negative mood or emotions, poor work relationships and social support, are associated with an increased risk of CLBP (Koes et al., 2006).

While a number of physiotherapy interventions have evolved over the years to treat LBP, including electrotherapy, traction, manual therapy, exercises and education, there has been very little evidence to support their effectiveness (Pinnigton 2001; Burton et al., 2006; Balague et al., 2007). This may be due to the biomedical philosophy underpinning such interventions, which has been suggested to be ineffective in managing CLBP due to the reductionist perspective of pain (Waddell, 1996; 2004). The biomedical model is based on the principle of mind-body dualism, which poses a theoretical separation between the mind and the body (Engel, 1989). In this model, diseases are classified as organic, pertaining to the body and of physical nature, or non-organic, pertaining to the mind or psychological in nature. Engel (1989) suggests that the fundamental principle of the biomedical approach is the reduction of illness to the lesion, or the physical malfunction in the body. In this approach to healthcare pain is viewed as bodily sensations, which are responses to certain stimuli that can be tested objectively and rationally (Vlayaen and Crombez, 1999; Lillrank, 2003). This approach positions health professionals in a dominant role, and suggests that they are solely responsible for determining the nature of patients' problems (Engels, 1989). Health professionals focus on identifying the disease 
and defining the precise cause through diagnostic procedures, and treating patients by correcting the disturbance (Aceves-Avila et al., 2004).

The biomedical model dominates healthcare systems in general, and physiotherapy practice in particular, and this has been suggested to be the main reason for the challenges faced by practitioners and patients with CLBP (Waddell, 1996; Pinnington, 2001; Bishop and Foster, 2005). While biomedical practice reduces patients' experiences to physical aspects and impairment, diagnostic procedures have been proven to be of little relevance to the severity of pain suffered by CLBP patients (Jensen, 1994; Carragee et al., 2005). Associations between tissue damage illustrated on an MRI and discography testing and back pain episodes have been found to be weak, and no association has been found between disability and the severity of pain (Carragee et al., 2005). Moreover, it was found that numerous people that do not complain of back pain show disc bulges or protrusions on an MRI examination, suggesting that identifying disc bulges in people with back pain may frequently be coincidental (Jensen, 1994). The inconclusiveness of diagnostic tests is another indication that CLBP cannot be limited to physical deficits. Moreover, CLBP has repeatedly been found to have negative impacts on social relationships, social roles, and family duties, as well as work loss and early retirement (Croft et al.1998; Middleton, 2004; Strunin and Boden, 2004; Ghaffari et al., 2006). This suggests the need for management approaches that acknowledge the social impacts of CLBP and people's subjective experiences in order to provide holistic and individualised care. The biomedical model does not take into account the psychological or socially debilitating factors of LBP. However, Waddell (1987) advocates a holistic, biopsychosocial approach, which takes into account a range of factors and its appropriateness for managing CLBP will be discussed in the following section. 


\subsection{Pain Perspectives and a Biopsychosocial Approach to CLBP}

'Pain is never the sole creation of our anatomy and physiology. It emerges only at the intersection of bodies, minds and cultures' (Morris, 1991, p.1).

There are various perspectives that have been proposed to explain the pain phenomenon. Descartes, a French philosopher, was one of the first people to provide a biomedical model of pain (Vlaeyen \& Crombez, 1999). Descartes viewed the mind and body separately, and considered pain to be a reflex of the mind upon nociceptive stimulation of the body (Vlaeyen \& Crombez, 1999). This model views pain as a unidimensional phenomenon, a physiological response to specific stimuli. Melzack and Wall (1988) viewed pain as a multidimensional phenomenon, where the presence or absence of pain is influenced by both central or neurophysiological inputs and also psychological inputs. Moreover, their theory proposes that pain is associated with different causes, and is characterised by different qualities, varying along a number of sensory, affective and evaluative dimensions. This notion was extended by Waddell (2004), who suggested that while psychological and neurophysiological processes may sensitise patients to common bodily symptoms, it is emotions, attitudes and beliefs that turn these symptoms into subjective health complaints. The postmodern perspective rejects the biomedical view that human nature is consistently homogenous, universal and absolute, and negates the proposition that a single theory or model is capable of explaining every illness (Morris, 2000). The view of illness developed by the postmodern perspective has challenged traditional biomedical thinking by claiming that illness is no longer a purely biological state, rather it is partly a construction influenced by cultural interpretations, social influences and personal cognitions (Charmaz, 1983, 1999; Morris, 2000).

Agreement on the prominence of psychological and social influences on patients with CLBP, and negating the notion that CLBP is induced and exacerbated by purely physical 
factors, has been shown within the literature. Psychological aspects, such as a state of anxiety, depression, worrying and being emotionally affected by pain were found to be significantly associated with high paraspinal electromyogram (EMG) reactivity levels (Flor et al., 1985) and pain intensity (Linton, 2000) in CLBP patients; whereas physical factors did not correlate significantly to EMG readings (Flor et al., 1985). Moreover, responses to straight leg raising and prone knee bending were found to be associated with psychological factors rather than physical dysfunction, and at two months after onset of LBP an overlap was found between fear-avoidance and spinal weakness and stiffness (Rose et al., 1995). Fear avoidance beliefs, weak beliefs about personal controllability, and low confidence in the ability to perform normal activities despite the pain have been suggested to be predictors of disability in LBP patients (Vlaeyen et al., 1995; Vlaeyen and Crombez, 1999; Waddell, 2004; Foster et al., 2010).

In terms of social influences, a low socio-economic status has been shown to be significantly associated to higher rates of emotional discomfort and anxiety amongst Nigerian and Caucasian patients with LBP (Egwu \& Nwuga, 2008). A systematic review by Anderson et al. (2009), which critically evaluated the literature on racial and ethnic disparities in pain in the United States, also identified socio-economic status as a risk factor for severe pain-related impairment in daily activities amongst patients with chronic pain. Races and ethnicities also differed in behaviours, with black patients reporting significantly more disability, more symptoms consistent with depression and posttraumatic stress disorder, and more suffering and less control over pain than white patients. In addition, differences in beliefs were found, with African Americans and Hispanics with chronic pain more likely than whites to report using prayer and other religious coping strategies. The evidence demonstrates associations between psychological, biological and social aspects to the experience of LBP. Therefore, the 
evidence supports the proposition that CLBP is a complex multidimensional phenomenon, rather than a being a unidimensional physical reaction to a specific stimulus.

There is literature supporting the implementation of a biopsychosocial approach to managing CLBP in order to provide more effective and desired outcomes (Croft et al., 1996; Jorgensen et al., 2000; Guzman et al., 2001; Harland and Lavallee, 2003). The biopsychosocial model views an illness from a broad perspective by acknowledging the somatic, interpersonal and environmental levels of the illness experience (Fava \& Sonino, 2008). It acknowledges a patient's personal problems, and repositions patients from being submissive to being knowledgeable about their problems and assuming an active role in their health care (Engel, 1989). Price (1996) suggests that a biopsychosocial approach acknowledges patients' experiences in living with a chronic condition by attempting to gain an in-depth insight from patients in order to understand different aspects, such as a patient's motivation and altered patterns of social engagement. In other words, the biopsychosocial model emphasises the patient as the expert, and the importance of understanding the subjective aspects of a patient's illness and disabilities in order to provide sufficient care.

There has been a consensus on the precedence of the effectiveness of multidisciplinary biopsychosocial rehabilitation in comparison to usual care and physical treatment in decreasing pain and disability (Kamper, 2015; Semrau et al., 2015). Despite the agreement on the advantages of implementing a biopsychosocial approach to manage CLBP, this term or concept has been used very loosely, with no agreement or explanation regarding how this can be achieved in CLBP rehabilitation (Taimela et al., 2004). It has been suggested that one reason why physiotherapists have found it challenging to change their approach is the infeasibility of applying research findings into clinical practice (Pinnigton, 2000). This may be attributed to the diversity of perceptions and social circumstances that individuals with CLBP encounter in different cultural contexts and geographical locations. 
Moreover, the available literature has considered the influence of psychological, biological and social dimensions on patients with CLBP as separate entities. Although these studies have provided important building blocks for a biopsychosocial understanding of chronic pain, they are suggested to be incomplete (Koenig et al., 2014). In order to propose a more comprehensive alternative to the biomedical model, the interconnection between social, psychological and cultural factors should be investigated in unison, rather than viewing them separately. In other words, it is necessary to undertake research which aims to explain individuals' perspectives and behaviours in relation to their social situations, practices, and cultural ideologies. It is important to include all three areas of functioning in order to fully understand the heuristic model of CLBP and to best target interventions that address these areas (Koenig et al., 2014).

In summary, CLBP has proven to be a complex, multidimensional condition. There has been a lack of consensus about an exact definition, criteria to determine chronicity, and the prevalence of this debilitating condition. Moreover, the variation in aetiological factors and diagnoses, and the prevalence of 'non-specific' CLBP in the majority of people who suffer from this condition, has led to challenges in providing effective management approaches. While various active and passive physiotherapy approaches are available to manage individuals with CLBP, the biomedical model of healthcare has largely influenced the development of these approaches. Since the biomedical model restricts CLBP to physical and functional limitations, it has been suggested to be an ineffective approach to managing it. Current research has shown the effectiveness of following a biopsychosocial approach, which acknowledges psychosocial factors associated with CLBP. Nevertheless, there remains a lack of consensus about what this approach includes. This may be due to a lack of research which explores how biological, social and psychological factors intertwine in people's experiences with CLBP. Moreover, there has been limited research 
investigating the variation in perceptions and social circumstances of people from different cultural contexts and geographical locations.

\subsection{Conclusions}

This chapter has presented background information on CLBP, and clarified the controversy clinicians' face in understanding this condition and providing effective management. This controversy may be due to a lack of research exploring the various psychosocial dimensions which people from different cultural contexts experience and how they may impact upon their experiences with CLBP.

The following chapter presents a review of the recent literature which has explored the subjective experiences of individuals with CLBP in particular, and chronic illness in general, and identifies how current understandings can be developed. It reinforces the argument presented in this chapter, which highlights the necessity of considering sociocultural factors when exploring the experiences of people with CLBP. Furthermore, it explains how the literature presented thus far has led to the formulation of the research question and objectives. 


\section{CHAPTER 4 - CHRONIC ILLNESS, SELF AND IDENTITY}

\subsection{Introduction}

This chapter discusses the role that the literature has played in this research in light of the grounded theory (GT) approach utilised. It contains a discussion of the main theoretical concepts, which have guided the study. It commences by exploring various perspectives through which chronic illness and disability, the self and identity, can be conceptualised, and clarifies which perspectives guided this study. It then presents a critical stance on the recent literature investigating the subjective experiences of people with CLBP and the self and identity in other chronic illnesses; it also identifies gaps in the existing understandings. The literature reviewed in this chapter and the previous one led to the development of the research question and objectives, presented at the end of this chapter.

\subsection{Significance and Boundaries of the Literature Review}

An essential principle of the GT approach is to abstain from forcing preconceived assumptions and existing frameworks on the data and developing theory (Heath, 2006). This has resulted in some controversy regarding how and when to engage with the existing literature (Dune, 2011; Heath, 2006; McGhee et al., 2007). In the original GT text, Glaser and Strauss (1967) argued against conducting a literature review before data collection and the emergence of the core category; however, this idea has been challenged and subjected to intensive debates. Other authors have suggested that a preliminary review of the literature can be useful in sensitising the researcher to the area that needs investigating and where research may be limited, without necessarily imposing existing theories and knowledge (McGhee et al., 2007).

In line with the constructivist GT approach adopted in this study (refer to Section 5.3.1), the literature was initially consulted to develop and refine the research question and 
objectives (refer to Section 4.9), and to identify gaps in the existing knowledge which this study aimed to contribute to (Charmaz, 2006; 2014). Moreover, developing a 'Research Plan Approval', a requirement of the $\mathrm{PhD}$ process, drove me to develop a preliminary literature review exploring the concepts of chronic pain and illness, identity, and research methods commonly utilised in this area. In this way I was able to develop an awareness of some existing theoretical concepts and research exploring people's subjective experiences of chronic pain and illness, and its impact on their identity construction. This is considered more effective than assuming a stance of "theoretical ignorance to sum up the ways of using literature at the early stages' of GT studies (Henwood and Pidegon, 2006, p.350).

The literature review presented in this chapter was initially undertaken to provide a preliminary overview of the previous research in order to place this study in the context of related work. It was used as a 'conceptual lever' (Schatzman \& Strauss, 1973, p.117) or an analytical tool that provided various theoretical perspectives, which guided me in extending existing knowledge on identity construction in women with CLBP. Nevertheless, the process of writing this chapter involved drafting and re-drafting, and using the analysis of the data to direct the critical stance adopted, in order to develop it in a way that was congruent with the theoretical claims in the theoretical model that was being developed (Charmaz, 2014). In other words, the final version of the literature review was tailored to fit the argument being posed by this research study and substantive theory it yielded (Charmaz, 2014).

During the later stages of data collection and analysis existing theoretical concepts were compared with my interpretations of the data to explore where they illuminated my theoretical constructs, and how the developing theory extended and/or challenged dominant ideas (Charmaz, 2014). Nevertheless, engaging in reflexivity prompted me to be vigilant and constantly challenge whether and to what extent existing theoretical notions helped to explain my data, in order to avoid forcing preexisting assumptions (Charmaz, 
2014). Using the literature in this way at these different stages of the research enabled me to develop my theoretical sensitivity, and to develop abstract and conceptual understandings of the data. An overview of the literature engaged with during the process of data collection and analysis is provided later in Sections 6.5.4 and 6.5.7. As the study progressed, a more focused literature review was conducted to 'enlist the conceptual argument' and 'position the study and clarify its contribution' (Charmaz, 2014; p.310). In this sense, further theoretical insights from the available literature have been included in Chapter 8 of this thesis. An overall summary of how the literature has been utilised in this study is provided in Appendix 1.

The literature was accessed through a variety of options during the course of the study; however, only articles written in English that could be obtained from online or hand searching were utilised. The following online databases were interrogated: Allied Health and Complementary Medicine (AMED), Cumulative Index to Nursing and Allied Health Literature (CINHAL), PubMed, Science Direct, International Bibliography of the Social Sciences (IBSS), Web of Science (WOS) and PsycINFO.

While there are various ways in which the self has been defined or conceptualised, it can be viewed as a complex phenomenon pertaining to, but not limited to, social interaction and behaviour, consciousness, feelings and attitudes (Mead, 1934; Bauermeister, 1986; Stevens, 1996; Lawler, 2014). This may suggest that investigating the self is largely dependent upon understanding subjective experiences. In this sense, this review did not focus on studies adopting quantitative approaches where the aim was to establish causal relationships and detached generalisations. Instead, the focus was on qualitative studies, since the aim of qualitative inquiry is to portray lay perspectives and subjective meanings of lived experience. 
The complexity and eclectic nature of chronic illness has resulted in an immense and diverse body of literature investigating various aspects and concepts pertaining to people's lived experiences. Therefore, it is necessary to be explicit about the criteria that were followed in making decisions about which articles to include and exclude (Randolph, 2009) in this review. The main focus of the search of the literature was to evaluate how the concepts of self or identity have been conceptualised in relation to chronic illness. Moreover, since this study focused on women with CLBP, the search was focused, but not limited to, establishing to what extent the concepts of self or identity have been addressed in the literature pertaining to people with CLBP, and to evaluate to what extent the concept of gender has been investigated. Key words, including qualitative, subjective, CLBP, chronic illness, chronic pain, women, female, self, and identity, were used to identify recent studies that have explored individuals' illness experiences from their own vantage point.

While undertaking this research it became apparent that the concepts of self and gender have been under explored in the recent literature. With the exception of one study in which the impact on self was investigated, Table 4.1 includes those studies where concepts of self and identity were presented as one of the themes of the study rather than as a primary focus. No recent studies were found to have focused on the experiences of women with CLBP. This highlights the need to investigate the impact of contemporary gendered ideologies, as well as current social, economic and political situations on women's manifestations of CLBP. 


\begin{tabular}{|c|c|c|}
\hline Study & Aims/Objectives & Portrayal of Self/Identity \\
\hline $\begin{array}{l}\text { Campbell } \\
\text { \& Guy } \\
(2007)\end{array}$ & $\begin{array}{l}\text { Examined patient narratives of chronic pain to } \\
\text { gain a greater understanding and insight into } \\
\text { their expectations for future treatment, and } \\
\text { contextualise this in relation to current pain } \\
\text { management and medical practices. }\end{array}$ & $\begin{array}{l}\text { Self explained in terms of individual ability } \\
\text { and independence. Psychological impacts } \\
\text { on self-including mood swings considered. }\end{array}$ \\
\hline $\begin{array}{l}\text { Smith \& } \\
\text { Osborne } \\
(2007)\end{array}$ & $\begin{array}{l}\text { Explored the relationship between the } \\
\text { participants' chronic benign low back pain and } \\
\text { their sense of self. }\end{array}$ & $\begin{array}{l}\text { Considered the negative impact CLBP has } \\
\text { on people's sense of self and identity. This } \\
\text { included the struggle to retain a good self } \\
\text { due to disability from pain and social } \\
\text { isolation, and due to uncomfortable feelings } \\
\text { in the presence of others. }\end{array}$ \\
\hline $\begin{array}{l}\text { DeSouza \& } \\
\text { Frank } \\
(2007)\end{array}$ & $\begin{array}{l}\text { Explored and described the physical } \\
\text { consequences of living day-to-day with CBP } \\
\text { and documented the 'insider' accounts of how } \\
\text { this pain impacts on daily activities. }\end{array}$ & $\begin{array}{l}\text { Change in self was explained in terms of } \\
\text { physical activities that the participants } \\
\text { perceived they could no longer perform. }\end{array}$ \\
\hline $\begin{array}{l}\text { Snelgrove } \\
\text { \& Liossi } \\
(2009)\end{array}$ & $\begin{array}{l}\text { Provided a detailed and contextualised } \\
\text { understanding of the meaning of CLBP for } \\
\text { participants with long-standing experiences of } \\
\text { chronic pain. }\end{array}$ & $\begin{array}{l}\text { Participants expressed a dualism of self and } \\
\text { body. Impaired functioning affected } \\
\text { participants' self-esteem. }\end{array}$ \\
\hline $\begin{array}{l}\text { Crowe et } \\
\text { al. }(2010)\end{array}$ & $\begin{array}{l}\text { Explored the impact of CLBP on people's } \\
\text { lives. }\end{array}$ & $\begin{array}{l}\text { Participants talked about their bodies as if } \\
\text { they were not part of their subjectivity and } \\
\text { were external from their sense of self. }\end{array}$ \\
\hline $\begin{array}{l}\text { Toye and } \\
\text { Barker } \\
(\mathbf{2 0 1 0})\end{array}$ & $\begin{array}{l}\text { Explored how patients with persistent } \\
\text { unexplained pain interpret and utilise the } \\
\text { biopsychosocial model. }\end{array}$ & $\begin{array}{l}\text { It was explained that some people fought to } \\
\text { hold onto their preferred selves by } \\
\text { maintaining certain activities such as } \\
\text { camping, while others described a lost battle } \\
\text { where the pain prevented them from being } \\
\text { themselves. }\end{array}$ \\
\hline $\begin{array}{l}\text { Ellegaard } \\
\text { \& Pederson } \\
(\mathbf{2 0 1 2})\end{array}$ & $\begin{array}{l}\text { Investigated how Gestalt therapy, somatic } \\
\text { experiencing, and psychotherapeutic } \\
\text { treatments can influence a patient's capacity to } \\
\text { cope with CLBP when it is coupled with } \\
\text { depression. }\end{array}$ & $\begin{array}{l}\text { Identity explained in terms of physical and } \\
\text { psychological restrictions preventing a } \\
\text { person from their work identity. }\end{array}$ \\
\hline
\end{tabular}

Table 4.1: Studies related to the impact of CLBP on self and identity

\subsection{Conceptualising Chronic Illness and Disability}

The concepts of chronic illness and disability have been dominated by two main perspectives: 1) illness as social deviance - the focus of the literature pertaining to medical sociology (Bury, 1997; Williams, 2003); and 2) illness as social oppression - the heart of 
disability studies, as well as disability political movements in the UK (Shakespeare, 2006; Thomas, 2007).

The roots of the social deviance perspective can be traced to Talcott Parson's sick role theory, which has been suggested to be a functionalist-structuralism perspective that focuses on social order (Bury, 1997). This perspective focuses on the tragedy or suffering acquired by illness, and limits illness to physical or mental impairments. According to the sick role theory, illness is a role that people adopt in order to be exempted from punishment or penalty for failing to fulfil their normal social roles and from carrying any blame for being ill. Moreover, this theory proposes that there are two obligations acquired with the privilege of adopting the sick role: the individual strives to get well as speedily as possible; and the individual seeks the assistance of a medical professional and follows his/her orders (Thomas, 2006). This theoretical position has been challenged as being inadequate to investigate chronic illness experiences, since it assumes that people are disabled by their bodies and neglects the impact of societal restrictions on their disability experiences (Oliver, 2009; Shakespeare 2006; Thomas, 2007). Moreover, it may restrict capturing the complexity of living with chronic illness for the following reasons. First, lay perspectives and subjective experiences of illness are not readily accommodated in what may be seen as a reductionist view of illness limited to the body and impairment. Moreover, it emphasises medical authority in legitimating people's illness experiences and providing treatment, and neglects people's agency in chronic illness management. As a condition progresses towards chronicity, people develop expertise in understanding and managing their conditions. Therefore, there may need to be a shift in power relations, whereby some authority is driven towards people living with chronic illness, their subjective experiences and their active role in managing their conditions.

The social oppression perspective is based on Michael Oliver's (2009) social model of disability, which focuses on economic, environmental and cultural barriers experienced by 
people who are viewed by others as having a form of impairment. Unlike the social deviance perspective, which stems from professionals' perspectives, the social model of disability originates from the perspective of theorists who lived with physical disabilities, including Vik Finkelstein, Paul Hunt and Michael Oliver (Scambler \& Scambler, 2010). In this model, disability is considered to be the result of social barriers or restrictions, including individual prejudice and institutional discrimination (Shakespeare, 2006). It has been argued that this perspective neglects the impact of impairment, and suggests that people are disabled by society, with no impact from their bodily restrictions on their disability experiences (Shakespeare, 2006). This perspective emphasises a social view of illness experiences, and viewing people's experiences solely from this perspective may result in under theorising personal experience. This includes the subjective, emotional and personal aspects of people's experiences (Morris, 1992; Thomas, 2007).

In this study, chronic illness has been interpreted by amalgamating various theoretical perspectives (Table 4.2) through which more holistic explanations of chronic illness that clarify subjective experiences may be grasped. These notions have focused on blurring the biological/social dichotomy suggested by the social deviance and social oppression views of chronic illness and disability. They emphasise the need to view people's subjective experiences as the interplay between macro and micro dimensions, including environmental factors, societal interactions, cultural understandings and context, intrinsic or individual factors, personal identity and emotional states. The theorists, their theoretical approaches and the theoretical assumptions underpinning these perspectives are summarised in Table 4.2 . 


\begin{tabular}{|c|c|c|}
\hline Theorist & Approach/Perspective & Theoretical Assumptions \\
\hline Michael Bury (1997) & $\begin{array}{l}\text { Socio-medical model of } \\
\text { disability (interactionist } \\
\text { perspective) }\end{array}$ & $\begin{array}{l}\text { Understands chronic illness and disability to be } \\
\text { both biologically and socially caused; however, } \\
\text { suggests that more significance or causal weight } \\
\text { is given to the biological aspect (impairment). }\end{array}$ \\
\hline Simon Williams (2003) & $\begin{array}{l}\text { Critical realist } \\
\text { perspective }\end{array}$ & $\begin{array}{l}\text { From this perspective, chronic illness and } \\
\text { disability can be understood as arising from the } \\
\text { interplay between physiological impairment, } \\
\text { structural conditioning and sociocultural } \\
\text { interaction. }\end{array}$ \\
\hline $\begin{array}{l}\text { Tom Shakespeare } \\
\text { (2006) }\end{array}$ & $\begin{array}{l}\text { Interactional approach } \\
\text { (critical realist } \\
\text { perspective) }\end{array}$ & $\begin{array}{l}\text { Defines the disability experience in terms of } \\
\text { intrinsic factors related to the individual and } \\
\text { extrinsic factors in the environment (an individual } \\
\text { and structural focus). }\end{array}$ \\
\hline Jenny Morris (1992) & $\begin{array}{l}\text { Feminist perspective } \\
\text { (making the personal } \\
\text { political) }\end{array}$ & $\begin{array}{l}\text { Emphasises aspects of disability, which she } \\
\text { suggests have been neglected by the social model, } \\
\text { including culture, gender and personal identity. }\end{array}$ \\
\hline $\begin{array}{l}\text { Carol Thomas (1999; } \\
\text { 2007) }\end{array}$ & $\begin{array}{l}\text { Feminist materialist } \\
\text { perspective }\end{array}$ & $\begin{array}{l}\text { Views the body as biological, material and social. } \\
\text { Focuses on the psycho-emotional effect of } \\
\text { disability (the impact of family, friends, health } \\
\text { professionals and others on people's confidence, } \\
\text { self-esteem, emotional well-being and willingness } \\
\text { to take chances). Views those issues as } \\
\text { consequences of being impaired rather than } \\
\text { private troubles that should not be made public, as } \\
\text { may be suggested by the social model. }\end{array}$ \\
\hline
\end{tabular}

Table 4.2: Perspectives emphasising the multifaceted nature of chronic illness and disability

In this study the perspectives which guided the interpretation of women's illness experiences, acknowledged the multidimensional nature of people's experiences with chronic illness (Table 4.2). In other words, CLBP experiences were portrayed in relation to macro processes, including cultural ideologies and societal expectations, as well as micro processes, including women's emotional states and self-perceptions.

\subsection{Conceptualising the Self and Identity}

The concepts of self and identity are challenging to define, as it is not possible to provide one overarching definition of what they constitute, how they develop, and how they function. Nevertheless, it has been suggested that it is necessary to avoid producing a 
single definition because different ways of theorising these concepts develop different kinds of meanings and understandings (Lawler, 2014).

The terms 'self' and 'identity' have been used interchangeably in the literature presented in this chapter, and it has been suggested that there is an overlap between these two terms (Woodward, 2002). In this study, however, the terms have been used to portray different yet interrelated dimensions of the process through which women's illness identities developed, in line with the various understandings proposed by several scholars (Mead, 1934; Goffman, 1959; Woodward, 2002). Woodward (2002) suggested that the choice of term may depend upon the emphasis on the degree of agency exerted by people in the process of constructing themselves. Agency is the active or autonomous role that individuals take in shaping their preferred identities. For example, it is the way individuals interpret cultural ideologies and the value they place on cultural stereotypes that determines how they may shape and alter themselves to fit with the identities they construct (Woodward, 2004). It is suggested that the self emphasises the social and is developed through socialisation and language (Mead, 1934; Stevens, 1996; Lawler, 2104), whereas identity accommodates the interrelationship between the social and personal, and the relationship between agency and of social construction (Goffman, 1959; Woodward, 2002). While this study aimed to investigate the social dimensions influencing women's illness identity construction, Woodward's (2002) notion of identity was chosen in order to consider the impact of social aspects on identity construction but not to neglect agency or the active role of women in identity construction that may be lacking from the term 'self'. However, the term 'self' or 'self-feelings' (refer to Section 7.3) was utilised to refer to the internal dialogue, or women's perspectives, thoughts and feelings, in relation to social interactions and societal expectations. In other words, the term 'identity' was utilised to portray the 'I' (Mead, 1934), or the public representation of who women perceived themselves to be, which they revealed through their actions and behaviours. In contrast, 
the term 'self' was used to refer to the 'me' (Mead, 1934) or the process of internalising social and cultural ideologies and circumstances, and how these influenced how women perceived themselves and their emotional state. A discussion of how these concepts influenced the development of the conceptual framework adopted as the study progressed is presented later in Section 5.2.2.

In line with the epistemological position adopted in this study (refer to Section 6.2), identity was conceptualised through a social constructionist perspective. This perspective provides a theoretical tool which considers both the personal and social attributes involved in the process of making meaning or defining identities. A social constructionist accepts that assumptions about the makeup of a person vary from one culture to another, and an adequate understanding of people can only be gained through their social practices and ideologies (Gergen, 1991). Therefore, adopting a social constructionist perspective in this study was considered appropriate to contribute to and extend existing understandings of identity and CLBP by exploring how social situations and interactions, as well as historical understandings of CLBP, may impact on women's identity construction and explain variation in their behaviours.

In order to conceptualise the construction of women's identities in Kuwait, which has been shown to be a collectivist society (refer to Chapter 2), the position taken in this study was that identity is a social and collective process, rather than a unique and individual attribute and possession (Lawler, 2014). It was assumed that identity is constructed through a social process, intertwined with cultural norms and ideologies, social relationships and interactions, subjectivities, and emotional states. Moreover, it was assumed that women presented with multiple identities, and the emergence of these identities were influenced by their social conditions and circumstances, and varied across time. This position aligns with Mead's (1934) pragmatist and symbolic interactionist perspective in his seminal work on the sociality of the self. For Mead (1934), the self is a relational, processual and social 
entity, developed through communication and language, social relationships and interaction; the self identifies with various objects and symbols, such as cultural norms and traditions. Mead (1934) also emphasises the temporality and reflexive nature of the self, and the multiple selves people present across time and in response to different social situations.

It was also assumed in this study that identity is constructed or developed, rather than it being an innate characteristic. It is developed through social and affective experiences, and through women's behaviours in social interactions and settings. This position is congruent with Goffman (1959) and Butler's (1996) notion of identity as a social performance. This notion suggests that identity is not a question of who people really are; rather, identity is achieved in particular contexts and with constraints, which determine the choice or agency people possess in developing them. Both theorists emphasise that individuals' agency is relative to their social context and which actions it either permits or disallows (Lawler, 2014). The behavioural aspect of identity construal can also be traced back to Bourdieu's (1990) habitus, which he defines as 'embodied history, internalised as a second nature and so forgotten as history' (p.56). In this study it was assumed that women learn how to act and behave through social experiences and interactions, until such actions and behaviours become natural to them or a part of who they are.

The sections presented thus far have described various theoretical notions through which the concepts of chronic illness and disability, and self and identity have been explored. How these concepts have been defined and utilised in this study has also been clarified. The following section provides some insight into early understandings of people's experiences with CLBP. 


\subsection{Positivist Notions of CLBP}

While quantitative studies are not the focus of this review, positivist approaches prominently dominated earlier literature exploring CLBP. Therefore some of the key findings from this literature have been included to demonstrate the essentialist perspectives that have directed theoretical and clinical understandings of CLBP experiences.

Previous research has emphasised individualist views of people with CLBP; they have explained illness behaviours in terms of causal relationships between patients' beliefs and the pain and disability they experience. Experimentalist approaches were utilised to explain pain and disability in terms of certain individual characteristics, such as fear of movement/(re)injury (Vlaeyen et al., 1995; 1999), fear-avoidance beliefs (Vlaeyen \& Linton, 2000; Woby et al., 2004), catastrophising (Mannion et al., 2001), as well as painrelated fear and weak beliefs about personal controllability (Crombez et al., 1999). There may be several deficiencies in this perspective as it undermines the impact of others on people's behaviours, which may portray the idea of individuals as living in isolation, with no impact of the social environment on their behaviours. Moreover, manipulating stimulus conditions in a laboratory environment provides an over simplistic view that fails to consider the complexities of human behaviour. Additionally, it provides a reductionist view of CLBP by focusing on the medical aspects of illness including pain and disability, which has been suggested to be inadequate to capture the complexity of this condition (refer to Section 3.6 and 3.7). The impact of people's subjective experiences on their illness behaviours is not considered.

\subsection{Subjective Experiences of CLBP}

Over the last decade studies have addressed the need to explore insider or emic perspectives, and qualitative approaches have been utilised to provide a deeper 
understanding of individuals' lived experience with CLBP. However, the concepts of self and identity have scarcely been the focus of recent literature portraying the experiences of people with CLBP (refer to Section 4.2). The following sections evaluate recent studies which have explored individuals' perspectives and subjective experiences in order to identify indirect findings which signify characteristics or attributes of self and identity in relation to CLBP.

\subsubsection{Perspectives of Clinical and Self Management amongst Patients with CLBP}

Several recent studies have investigated patients' perspectives, experiences, expectations, beliefs and attitudes towards clinical and self-management of CLBP. Findings from these studies have demonstrated that patients' favoured taking an active role in managing their back pain and expected partnership in their care (Liddle et al., 2007; May, 2007; Slade et al., 2009). Participants emphasised their need for practitioners to consider their life circumstances, to develop a comprehensive picture of their values, preferences and lifestyles, and to listen to their stories. However, they perceived that health professionals were uninterested in listening to them and this led to ineffective episodes of care (May, 2007; Slade et al., 2009). Findings which emphasised partnership in care and considering life circumstances, suggest that future research needs to be geared towards the social dimensions of individuals' subjective experiences with CLBP. This would provide a more holistic understanding of their illness experiences and ensure that they receive more effective care.

The literature also suggested that participants adopted a variety of self-management approaches; including rest during periods when symptoms are exacerbated, a gradual return to normal activity and exercise, heat, massage and pain killers during flare-ups (Liddle et al., 2007; May, 2007; Slade et al., 2009). The importance of self-management 
for people with CLBP suggests that it is necessary to consider how people manage their conditions outside clinical settings, and what alternative management approaches and coping strategies they may adopt. This may provide explanations regarding how subjective experiences, social and cultural ideologies, social roles and social circumstances may impact people's experiences with CLBP and their self-management approaches.

Biomedical and individualist perspectives were highly evident in the literature. Emotional consequences, including fear, anger and depression, were explained as consequences of people worrying about permanent damage to their spine, and stigmatising experiences were explained in terms of distress related to a lack of an accurate diagnosis to explain CLBP to others (May, 2007; Slade et al., 2009). Moreover, the literature did not elaborate on the social dimensions which impacted on people's self-help strategies. While it was suggested that help from family members was resorted to as a self-management strategy, it was not explained how family members helped people manage their CLBP.

Findings from the available literature have repeatedly emphasised patients' agency, portrayed in the tendency of patients with CLBP to demand active involvement in their care and self-management. This may support challenges to the medical model, which has been suggested to exert professionals' dominance over patients (Freidson, 1970), and reveals the need to delegate authority to patients in the management of their conditions. Nevertheless, emphasis on patient agency may be due to the fact that studies were carried out in Western contexts, where values such as taking individual responsibility for one's actions and problems (Bates et al., 1997) are common, and may have influenced participants' perspectives. Moreover, the literature focused on people's perspectives on medical treatment approaches or management approaches prescribed by health professionals, which may reflect the dominance of medical perspectives. 


\subsubsection{CLBP and the Self}

The dominance of biomedical perspectives on the portrayal of the impact of CLBP on the self was evident in the literature. This was apparent in the homogeneity of study samples, where commonality in the experiences of people from similar ethnicity, class and age was assumed. Moreover, there was a dualism portrayed, where the mind and body were viewed as separate entities, and the self was held in separation of the body. Participants described negative impacts on their self-perception and self-esteem, by blaming their bodies for interfering with their ability to maintain their preferred roles (Campbell \& Guy, 2007; Snelgrove \& Liossi, 2009; Crowe et al., 2010). The impacts of illness on the self were described in terms of functional limitations, including sleep disturbance and an inability to carry out manual work, and psychological factors, such as anxiety and feeling mentally inadequate, which impacted people's self-worth and identity.

Findings were also focused on the corporeal pain experience. Studies focused on the physical consequences of living day-to-day with CLBP and the findings were pain oriented. They focused on the unpredictability of pain, participants' increased vigilance to their bodies and movement as a consequence of this unpredictability, and negative emotional consequences, including lowering of mood and anger in response to the perceived physical causes of their CLBP (Snelgrove \& Liossi, 2009; Crowe et al., 2010). Moreover, emotions, including anger, were associated with the exacerbation of pain and a restriction in physical activity; however, how and why such emotions may have developed was not clarified (Ellegaard \& Pederson, 2012).

The available literature provides valuable insight into the embodied experiences of individuals, and the alterations in their sense of self imposed by the physical changes associated with CLBP. However, these findings may be viewed as reductionist interpretations of the self limited to the physical and functional limitations experienced by participants. The mind/body dualism, or separation of mind and body, and objectifying of 
the body, has been suggested to be influenced by cultural and historical assumptions rooted and derived from biomedical perspectives, which focus on visual images and the medicalisation of the interior of the body. These assumptions make seeing into the body central to confirming and normalising patients' symptoms through diagnostic images (Rhodes et al., 1999). Woodward (2002) agrees that illness experiences have been investigated through biomedical and essentialist perspectives, and further suggests that such perspectives classify a collective identity to a certain condition, which may attribute common physical symptoms. It has been suggested that embodied experiences are located in a specific time and space, and certain bodily features are connected to cultural contexts, and social expectations, practices and behaviours (Twigg, 2006; Woodward, 2012). Therefore, broadening understandings of the relationship between CLBP and identity can be achieved by investigating how non-Western cultural and historical assumptions may impact on people's perspectives of their sense of self in relation to the bodily changes acquired from CLBP.

\subsubsection{CLBP and Stigma}

Goffman (1963) considers stigma to be a phenomenon where an individual who has an attribute that is deeply discredited by his/her society is rejected as a result of this attribute. Stigma has been portrayed as a process by which the reaction of others spoils normal identity. In other words, societies establish attributes associated with what they consider to be normal. Therefore, to be socially stigmatised leads to some form of exclusion or the discrediting of people and distinguishing them from other members of society. Such attributes differ depending on cultural, social, and political contexts, and what may lead to social stigma in one society may be considered normal in another. In this sense focusing on contextual factors becomes essential when exploring the impact of social stigma on people's illness experiences. 
The available literature provided insight into the negative impact that stigma can cause for individuals with CLBP, including interference with care-seeking and participation in rehabilitation, as well as difficulties in maintaining their social roles and relationships. Moreover, it highlights the necessity of viewing people as active agents that follow their own management strategies as a means of avoiding stigmatisation (Slade et al., 2009).

The objectified and reductionist view of patients in Western medicine and the influence of the Parsonian sick role on people's understanding of illness (the task of medicine to treat and the task of the patient to follow treatment and get well) was associated with the stigma assigned to doctors by patients as a result of their failure in their duty to diagnose and treat them (Holloway et al., 2007). Similarly, medical professionals assigned stigma to patients for their failure in their duty to reveal a medical diagnosis or respond to treatment. Moreover, it was demonstrated how social conditions, including affluence and family support, helped individuals overcome feelings of self-blame and shame (Holloway et al., 2007).

The literature provides insight into the impact of stigma on people with CLBP, and how it can interfere with seeking healthcare, participation in rehabilitation, socialising with friends and family, as well as maintaining social roles, such as employment. It also portrayed how social support and alternative management strategies that people choose to adopt may reduce the impact of stigma on their experiences with CLBP. Finally, the impact of social and cultural understandings stemming from Western ideologies on the nature of stigmatising experiences faced by patients has been presented. There remains a deficiency of knowledge about the stigmatising experiences individuals with CLBP in non-Western societies face, and what cultural perspectives may impact on such experiences. 
Extending understandings of subjective experiences of CLBP may require adopting broader perspectives, which consider alterations in social circumstances, feelings, social roles and the impact on people's experiences with CLBP. Considering the social construction of gender in various contexts and its impact on variations between the stigmatising experiences encountered and emotional responses of women and men, may be beneficial in building a better understanding of the different experiences between men and women with CLBP.

In summary, the dominance of Western biomedical notions of self and illness are evident in the current literature exploring people's subjective experiences with CLBP. There has been an emphasis on portraying individuals' emotional states and stigmatising experiences through an essentialist lens which reduces their experiences to the physical and corporeal dimensions of illness. Moreover, an exploration of the concept of gender and the impact of social understandings of women's roles on their experiences with CLBP is deficient.

\subsubsection{Illness Behaviours amongst People with CLBP}

Variations in illness behaviours adopted by individuals with CLBP have been explored within the literature. Findings have portrayed both adaptive and maladaptive strategies being utilised to cope with CLBP. Adaptive behaviours include exercise, disregarding or ignoring the pain (this minimised the emotional impact of the pain, psychological detriments and pain-related anxiety, prevented the pain from controlling individuals' lives, and promoted physical activity), as well as being proactive and taking care of oneself. Maladaptive behaviours included being absorbed in the pain and engaging in passive coping strategies, such as catastrophising and fear avoidance behaviours (Busch, 2005; Benjaminson et al., 2007).

While it has been shown that individuals adopt different approaches and behaviours to cope with CLBP, there has been less emphasis on why such variations occur. It has been 
suggested that the choice of strategy combines personal experience and professional recommendations (Crowe et al., 2010). Nevertheless, there has been a lack of focus on variation in social roles and responsibilities, and how such differences may account for or influence the illness behaviours people with CLBP portray.

In summary, the literature exploring the illness behaviours of individuals with CLBP has shown a variation in the strategies people adopt to manage and deal with their pain. However, less emphasis has been directed towards why illness behaviours vary and how social factors, including social interactions, responsibilities and relationships, may influence such variation.

The following section explores how the concepts of self and identity have been conceptualised in the wider literature which has explored the experiences of individuals with various chronic illnesses.

\subsection{Chronic Illness and the Self}

Since recent literature on the lived experience and lay perspectives of people with CLBP has rarely focused on the self, identity and gender, the scope of this literature review has been broadened to explore these concepts in studies looking at various other chronic illnesses. While studies focusing on distinct chronic illnesses have found various experiential features that were distinctive to that particular condition, it has been suggested that the chronic illness experience can be generic (Thorne and Paterson, 2000). For example, the pain and suffering acquired due to both CLBP and fibromyalgia have been found to be associated with similar challenges to people's identities and self-concepts, despite the differing origins of pain (Thorne and Paterson, 2000). Moreover, Charmaz's (1983) key work on the loss of self, which explored the experiences of individuals with various chronic conditions, including cardiovascular disease, diabetes, cancer, multiple sclerosis and lupus erythematosus, found similarities in their experiences, including being 
discredited, burdening others, and experiencing social isolation. Therefore, studies that have focused on the concepts of self and identity in relation to various chronic illnesses were included in this literature review in order to gain a broader understanding of these concepts and perspectives through which they have been portrayed. Due to the eclectic nature and lack of consensus on the definition of the terms self and identity (refer to Section 4.4), it was challenging to identify common understandings amongst the studies included in this section. Therefore, each study is discussed in detail to provide an appreciation of the complexity of understandings of self and identity in relation to chronic illness.

McMormick et al. (2012) presented themes that reflected patients' lived experience with gastrointestinal conditions. The themes presented explained personal and physical factors influencing the self, and how a person understands the self reflexively in terms of his or her biography (Giddens, 1991). This can be illustrated by one of the themes, called person and disease. Here, the authors suggested that the participants reflect on their disease and start questioning why they were the ones that acquired the disease rather than their siblings given they were all from the same gene pool, and on what things they could have done wrong to end up with this condition. In other words, individuals' thoughts on what personal factors may have led to the disease were explained. Moreover, the concepts of self-worth and feeling worthless were interpreted as a consequence of the symptoms of the disease, such as belching and flatulence, which caused shame for the participants during social interactions. While this study focused on lived experience, this concept could have been elaborated to provide an understanding of self-worth in terms of subjective aspects, such as preferred identities and how they may have been affected by acquiring a gastrointestinal condition. An interesting finding was that normalcy was portrayed as a relational concept, where participants compared themselves to others, and factors that 
distinguished them from others impacted their sense of self. This can be demonstrated in the following quote:

I think what makes it so hard is like, when you are sitting down with your family, and you're basically all you see that everybody else at that table can eat all of these other foods, and you are the one that can't. You're like 'What's wrong with me? Why can't I be like my sister or my brother or other family members? Why did I get this one?' (McMormick et al., 2012, p.4)

In a study by Lonardi (2007), one of the objectives was to explore how family representations of chronic headache, an 'invisible disease', impacted on people's identities, self-reliance and social relationships. This study provided valuable insight into the identity negotiation strategies people with chronic illness are involved in. The study focused on negotiations that took place within the close family network. It was suggested that when a patient is in a social environment, which assimilated the presence of the disease, they do not need to adopt an identity strategy and are able to discuss their disease with all those with whom they are in contact, including families, friends, neighbours, employers and colleagues. In other situations, the inner family network accepted the person as ill, whereas the wider or external network, such as employers and colleagues, refused them. In such circumstances a person was able to readily inform family members about their illness; however, in external networks they had to act normal and conceal their identity, or adopt what Goffman (1963) refers to as 'passing,' a strategy to escape stigmatising experiences by avoiding disclosure of illness. While the authors suggested different scenarios where some families accepted a person's condition and helped them, whereas others did not understand what the person was going through and discredited their suffering, they did not explain what may have led to such differences in family responses. An interesting observation in the study findings, which the authors did not elaborate on, was how family members' reactions affected the individual with an illness personally. For example, two participants, who were housewives, explained how their children and 
husbands helped them with house chores; however, the impact of their illness on family members was not considered.

The lived experience of individuals affected by TB and HIV was examined by Daftary (2012) in order to analyse what they thought about their dual illness, and how they characterised their stigmatised experiences in the context of their perceptions and identities. This study demonstrated how social interactions and social constructions of illness (HIV was associated with immoral behaviours and death, while TB was seen as normal since it was very common in the target population in South Africa) influenced people's behaviours. Individuals disclosed having TB more readily, but used the strategy of what Goffman (1963) refers to as 'passing,' where they concealed having HIV since it was viewed as the least desirable identity and invoked the dominant degree of discrimination and stigma. Moreover, it provided valuable insight into the experiences of people with comorbidities. However, analysis at a more macro level may provide a more nuanced understanding of how social and structural factors, such as gender and access to care, may have influenced variations in identity construction and stigma experiences.

Baumgartner (2007) investigated the incorporation of HIV/AIDS into identity over a period of time when the disease transitioned from being classified as an acute, terminal illness to a chronic disease. The findings focused on the identity of being a patient, where a person's life centred on the illness. One of the themes in this study was called 'immersion' which refers to where the HIV/AIDS identity was considered the central identity; according to a quote from one participant the illness was their whole life. The author suggested that at the point of diagnosis people started to incorporate a new personal identity as a person living with HIV/AIDS within the context of a society that stigmatises the disease. However, while the sample included both males and females, it was not clarified whether societal understandings of gender differences and the association with acquiring HIV/AIDS may have led to variations in stigma experiences. Moreover, while 
the sample included both White and African-American participants, it was not clarified whether variations in ethnic backgrounds and ideologies, social context, the area in which they lived or lifestyle choices, may have influenced people's experiences of incorporating HIV/AIDS identity. In other words, the study was oriented towards a collective identity of being a TB and HIV patient, and social factors that may have illuminated and explained variations in illness experiences were not addressed.

In the work of Travers and Lawler (2008) the experiences of self for people with chronic fatigue syndrome (CFS) living in Australia were explored following a GT approach. The theory related to the process of self-renewal and adaptation associated with CFS. The authors explained how living with CFS compromised people's aspiration to adopt preferred identities. For example a health worker was forced to retire and become a house wife due to CFS and she explained how this surprised others, as she would not have assumed this identity had she not been ill, stating:

People who knew me before-I met one recently and she was gob-smacked that I was a housewife because that's not what I'd planned, it's not what I'd envisaged, and it's probably not what I would have done (female, 47 years, previously a health worker, retired due to CFS) (Travers and Lawler, 2008, p.319)

Another example was that one participant felt like she was old, but perceived herself as young, and this shows the discrepancy between participants' feelings and perspective about the self and identity. On the other hand, explaining how age or aging was constructed in the geographical or social context of the study in order to clarify why the participant may have felt this way may have provided a deeper understanding of his/her behaviour. Moreover, guardianship, a defensive mechanism that involved containing emotions and emotional threats, was a dimension in the study that focused on male quotes; whereas another dimension, called progress in grief work, focused on quotes from interviews with females. As the feminist argument suggests, gender is a social construct, and in this sense explaining, for example, whether findings were linked to gender 
dichotomies which relate the male gender with emotional distance and females as emotional (Twigg, 2006), may have provided a richer explanation of the nuances in participants' accounts, and the impact of the social context on their behaviours.

Guise et al. (2010) examined the ways in which sufferers talked about early stroke and the effects this chronic condition has on identity. A social constructionist perspective and a discourse analytic methodology were adopted, where data was collected from focus groups attended by both patients and their carers. This study provided useful insight and explanations pertaining to how patients use discourse or language to lessen the negative impact of identity, as well as the role of carers in identity construction. For example, it was suggested that participants may have mitigated the negative impact on identity associated with a loss of ability, by using humour and diverting restriction to a lack of motivation rather than ability due to the stigma associated with stroke. In another example, it was demonstrated how carers may challenge patients' accounts. While the patient proposed that they no longer carry out tasks due to a lack of energy associated with the stroke, the carer suggested that he was capable of performing the tasks but did not do so due to the fact that he was lazy and lacked motivation. When carers provided their own accounts that highlighted the negative aspects that a stroke sufferer experienced as a result of a stroke, participants displayed sensitivity to this issue. The study provided a valuable insight into the impact of carers on identity construction, and suggested that carers may play a role in maintaining damaged identities. However, participants were all young and aged 55 years or younger. It has been suggested that culture is saturated with ideas about age and aging, where older people are discredited in the sense that aging becomes a stigmatised identity (Twigg, 2006). Therefore, it is necessary to take into account people's social backgrounds and how people from different age groups may face different challenges regarding their sense of self and identity. 
The following section discusses the variation in illness behaviours adopted by individuals suffering from chronic pain and illness.

\subsection{Illness Behaviours amongst People with Chronic Pain and Illness}

The significance of sociocultural variables in shaping people's illness behaviours has been acknowledged in the wider literature exploring the experiences of people with chronic pain and illness. There has been particular emphasis on investigating barriers and facilitators to adopting self-help strategies. Barriers include physical and functional restrictions, depression, fear avoidance and catastrophising thoughts, physicians directing individuals to rely on prescribed medications, and a lack of social support (Jerant et al., 2005; Bair et al., 2009). Moreover, cultural barriers include gendered ideologies which expected mothers and wives to take care of others despite their illness, as well as gatherings and family rituals which focus on feasts, making it difficult for individuals to control their weight (Jerant et al., 2005). Facilitators include relieving depression, and social support from formal services, family and friends (Townsend et al., 2006; Bair et al., 2009).

The literature also sheds light on the impact of social roles and interactions on the illness behaviours that people with chronic conditions portray. Some people struggle to find a balance between their work responsibilities and battling fatigue and pain, whilst others were in despair, no longer being able to cope with pain, which in turn strained their family relationships. Some gave up on many activities and were unable to control their illness, which was often associated with re-evaluation and a loss of social relationships, employment and former identities (Townsend et al., 2006; Sim and Madden, 2008). Other coping strategies included concealing the illness to protect others, and prioritising social roles and responsibilities by preventing the illness from dominating. In other words, individuals' perceptions and belief in personal control has a significant influence on the 
illness behaviours they portray. Moreover, the perceptions and behaviours of others towards individuals with chronic illness have been shown to be influential in shaping their illness behaviours. For example, it has been suggested that when family members view people with illness positively, then this encourages them to feel confident and in control of their illness (White et al., 2007).

In summary, the literature exploring the illness behaviours of individuals with chronic conditions has identified the influence of sociocultural variables, including gendered roles, social responsibilities, and the perspectives and behaviours of significant others on the coping strategies adopted and illness behaviours portrayed. Therefore, it is necessary to explore how such factors may influence the experiences of individuals with CLBP, in order to provide more holistic understandings and devise management approaches which are sensitive to and accommodate individuals' social situations and circumstances. 
Overall, the synthesis of the current literature exploring the subjective experiences of individuals with CLBP, and the concepts of chronic illness and identity has identified some in-depth understandings and illuminated the relevance of people's subjectivities to their illness experiences and identity portrayal. Nevertheless, in order to develop understandings of the construction of illness identities amongst individuals with CLBP in particular and chronic illness in general, several aspects need to be considered in future research. An outline of this synthesis is presented in Table 4.3. 


\begin{tabular}{|c|c|c|c|}
\hline 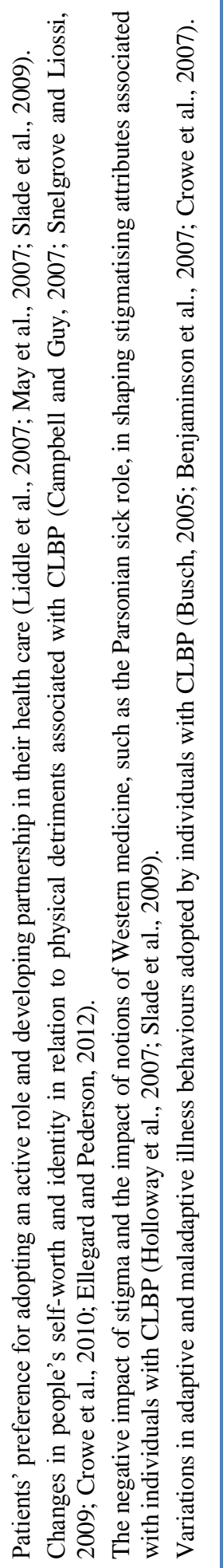 & 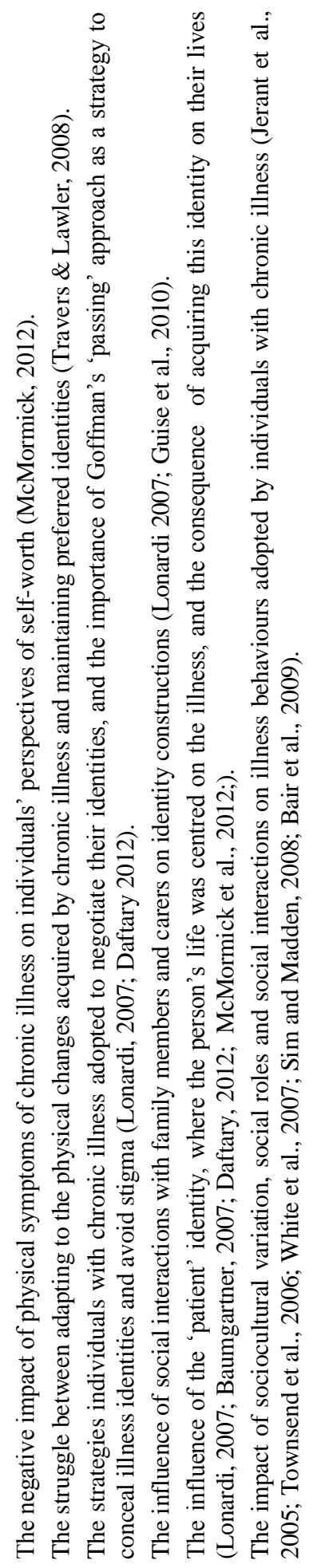 & 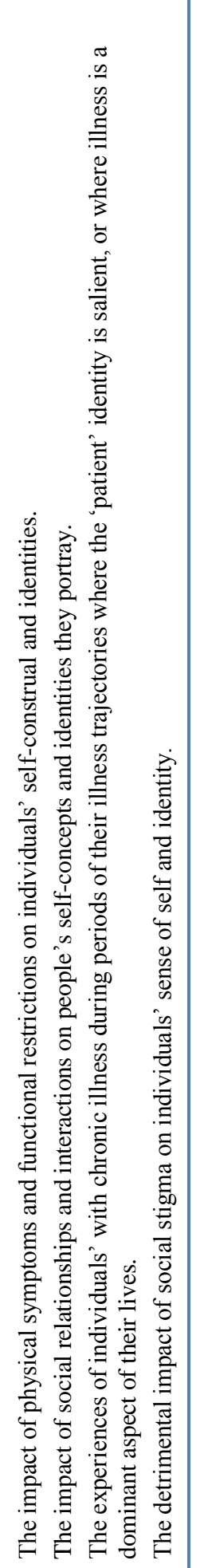 & 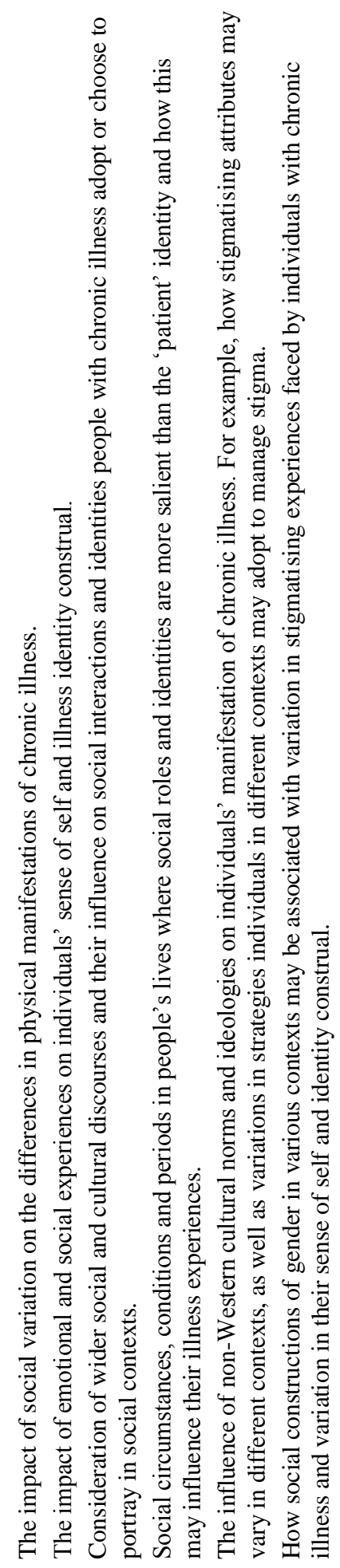 \\
\hline 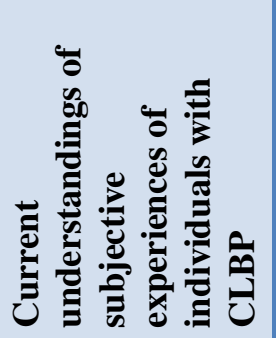 & 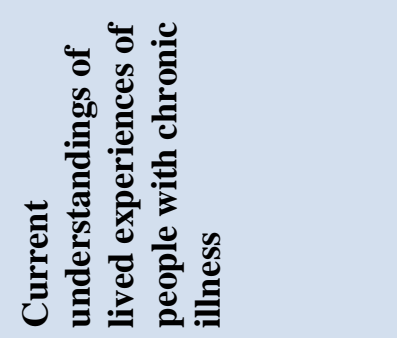 & 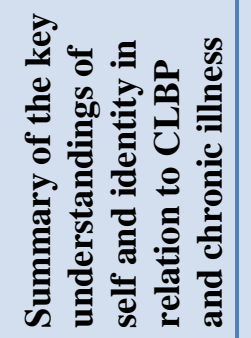 & 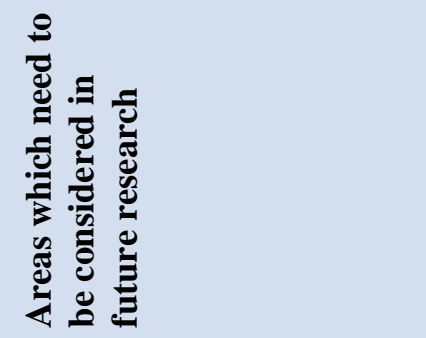 \\
\hline
\end{tabular}


Table 4.3: Current understandings of chronic illness and identity and areas in need of consideration in future research

As has been demonstrated, the understandings of self and identity in relation to CLBP have been limited to the impact of physical detriments on people's self-worth and identity. Moreover, the dominance of biomedical and Western notions of chronic illness in the available literature may have been accountable for overseeing integral aspects, including cultural discourses, social variation and gender, which can develop our understandings of the nuances and heterogeneity of people's experiences with chronic illness. Biomedical perspectives have been suggested to provide medicalised and homogenous explanations to account for social variation. For example, culture is viewed as being synonymous with ethnicity, language and nationality, and people who affiliate themselves to a certain cultural context or ethnic background are assumed to have a common set of beliefs about illness (Kleinman and Benson, 2006). Moreover, Western notions which assume people carry a set of individualised beliefs and values which transcend time and context (Gergen, 1991), may have been influential in overseeing the impact of cultural and social variation in the available literature. In terms of gender, variations in people's illness experiences have been accounted to medicalised, biological understandings of gender as merely a determinant of masculinity or femininity (Woodward, 2012). Finally, medical perspectives may explain the emphasis in the available literature on periods in individuals' illness trajectories where the 'patient' identity, or the sick role, was prominent.

It has been suggested that the concept of culture needs to be considered more holistically, such that culture is viewed as a fluid, unfinished and emergent process (Norma and Kleinman, 1992; Rasmussen, 1999) which is not merely transmitted across generations (Gone et al., 1999). This may be beneficial in developing understandings of illness experiences which incorporate gendered variations, when considering how women shape, alter and reproduce cultural ideologies defining femininity, and how their interpretations 
impact their manifestations and behaviours towards CLBP. Moreover, social constructionists and Mead's (1934) notion of self in particular, suggest that a person presents with multiple identities, and salience of identities depends on the social situation they are in. Since people are not always living as patients, future research needs to be oriented towards broader perspectives that consider the various identities that people present with and are actively constructing, and how living with a chronic illness may impact upon such identities.

This may provide a more holistic and deeper understanding, and shed light on aspects of individuals' lives that health professionals are not exposed to in practice but need to understand in order to offer effective care to patients. Moreover, it is timely to shift the focus to exploring chronic illness experiences in non-Western, collectivist societies, and how the concept of self and identity might be constructed differently in such social and cultural contexts. Existing literature has not focused on Arab societies, which may be considered collectivist societies, with social and cultural ideologies largely based on Islamic beliefs and practices.

\subsection{Research Question and Objectives}

The theories and research reviewed in this chapter indicate that people's subjective experiences of chronic illness are an essential dimension which is intertwined with their sense of self and identity construction. This has been implied in research studies exploring the subjective experiences of people with a variety of chronic conditions, including CLBP. While current literature has focused on Western, individualist notions of chronic pain and illness, there is a scarcity of research exploring Middle Eastern notions. Moreover, there is virtually no research exploring the subjective experiences of CLBP amongst women in Kuwait, an Arab collectivist society, and how this in turn may be associated with the construction of illness identities. The literature presented in Chapter 3 emphasised the 
need for formulating holistic, biopsychosocial understandings and management approaches to help people with CLBP in order broaden the essentialist, biomedical philosophies which dominate healthcare. Furthermore, the literature presented in this chapter has demonstrated the significance of people's subjectivities in constructing their manifestations of chronic illness, their sense of self, and their identities. Nevertheless, there has been emphasis on individual and physical influences, with less regard to issues, including social and cultural variation, and gender. In order to enhance the healthcare of people with CLBP, undertaking research which explores social variation and gendered understandings is crucial. Current literature, as demonstrated in this and the previous chapter highlights gaps in the existing knowledge, which this study aims to contribute to, and form the basis for the research question and objectives presented below.

\section{Research Question:}

How do women with CLBP construct illness identities in Kuwait?

\section{Research Objectives:}

- To explore the subjective experiences of CLBP and provide an in-depth understanding of women's construction of illness identities.

- To explore the influence of social and cultural factors on women's construction of illness identities.

- To develop a theoretical model which explains the process of illness identity construction, in order to provide a holistic understanding of women's experiences with CLBP.

\subsection{Conclusions}

The literature review presented in this chapter includes a conceptual framework for this thesis. The literature on chronic illness and the self and identity aided in developing the 
research question, and enhanced my theoretical sensitivity which guided the early data collection and analysis process. The literature reviewed during the later stages of the study is presented in Chapter 8. Utilising the literature as a 'conceptual lever' enabled me to develop various perspectives from which to view and interpret the data, and to develop the explanatory power of the substantive theory.

The following chapter details the methodological approach adopted in this study, and provides justifications for the methods employed to address the research question and objectives. It will be demonstrated how symbolic interactionist perspectives of the self and identity, and social constructionist notions presented in this chapter, helped to shape the epistemological assumptions and conceptual framework which guided this study. 


\section{CHAPTER 5 - METHODOLOGY}

\subsection{Introduction}

This chapter presents the philosophical and theoretical underpinnings, and the methodology adopted in this study. It discusses how the researcher's epistemological and ontological decisions influenced the perspectives used to analyse the data. The chapter moves on to discuss the rationale for adopting a constructivist approach to GT and the dimensional analysis (DA) approach to analysis. It then discusses the researcher's position as an insider-outsider researcher, and the ethical considerations relevant to this study. Finally, it discusses the measures taken to enhance the rigour of this research.

\subsection{Philosophical Assumptions}

In this section the ontological and epistemological positions adopted in this study are presented. Moreover, a conceptual framework developed in line with the epistemological assumptions guiding the study is provided.

\subsubsection{Ontological and Epistemological Positions}

This project is underpinned by a relativist ontology and social constructionist epistemology. Relativism assumes that an objective truth does not exist (Guba and Lincoln, 1994); rather, truth is provisional and knowledge is produced through the interpretation of an individual's or collective's language, interactions, and behaviours (Crotty, 1998). In this study, CLBP experience is assumed to be a construction that is influenced by a social process. As well as the various realities that may be constructed to explain an experience of a woman with CLBP, it is also assumed that women's social interactions with, but not limited to, family members and healthcare professionals, may have altered and influenced their experiences at different stages of their illness trajectories. Therefore, in order to investigate how women with CLBP construct their illness identities 
it was necessary to adopt an ontological stance, which acknowledges the provisional nature of such realities, and how social interactions can alter and redefine them. In this sense, relativism was chosen as an appropriate ontological position for this project.

A social constructionist epistemology acknowledges the historical and contextual influences on realities people construct (Crotty, 1998). Another assumption made by social constructionists is that knowledge is constructed through interactions between participants and the researcher, and reflects the interpretations of the researcher based on their experience, their engagement with the social world, and consequently their view of the world (Charmaz, 2006). As a physiotherapist who has managed patients with CLBP the influence of my experience and prior knowledge, as well as my beliefs and values pertaining to chronic illness, on the analysis and findings of my study cannot be neglected. Moreover, sharing a cultural background with my participants, and being a Kuwaiti woman myself, my own cultural interpretations may have had an impact on the interaction and subsequently the knowledge generated.

The social constructionist epistemology views reality to be a specific mental construction formulated by an individual and is dependent on the social situation context. Moreover, this paradigm assumes that multiple mental constructions exist to explain a phenomenon, and that a researcher is embedded in the realities constructed subjectively and interactively (Guba \& Lincoln, 1994). In this study, the theoretical assumption taken is that women with CLBP constructed various realities to explain their experiences. These realities portrayed multiple dimensions of women's lives, including their interpretations of cultural and societal expectations, their social relationships, and manifestations of their daily experiences with CLBP. 


\subsubsection{Conceptual Framework}

A productive conceptual framework is considered one that is constructed by the researcher, by borrowing and integrating different pieces of theories coherently (Maxwell, 2004). The conceptual framework developed in this study was guided by Mead's concept of the 'Me' and 'I', and Goffman's dramaturgical approach, and is based on a social constructionist perspective of the self.

Mead's (1934) theory on identity takes a pragmatic theoretical stance, focusing on the sociological concept which grounds identity into a specific context, and challenges the transcendental basis of the self (Woodward, 2002). It provides an understanding of how people view themselves and construct meanings of the self through language and social interactions. In Mead's (1934) symbolic interactionist approach, the self is constructed from the social to the individual. In other words, an individual designates different objects (with predetermined social meanings) to himself or herself, interprets them or gives them meanings, judges their suitability to her or his actions through an internal dialogue, and then acts upon them. In this sense people's behaviours are seen as social constructions rather than an arbitrary release (Blumer, 1969). The internal social dialogue, or the process of acting towards the self, is what Mead (1934) refers to as the 'me'. It is the thought process involved in the construction of self, which is based on interpreting prearranged relationships, cultural values and knowledge (Stevens, 1996). The 'I' is the part of the self that is reflected through individual actions or behaviours, and the part that a person imagines other people to perceive him or her to be (Woodward, 2002). Mead (1934) merges the concepts of instinct and social interaction in identity formation; the instinct refers to imagination and social interaction refers to constantly being aware or thinking who others perceive an individual to be. Moreover, in Mead's conceptualisation there exist multiple identities depending on the roles that individuals are required to adopt in different social situations. 
Mead's approach was used to distinguish particular aspects of women's narratives, social or cultural knowledge and values that influenced their thoughts and feelings about who they viewed themselves to be, and how living with CLBP has impacted on their identities. Interpreting the link between individual thoughts and contextual understandings was beneficial for developing theoretical constructs that explained why women with CLBP acted or behaved in certain ways, rather than merely reaching descriptions of how people with chronic illness behave. Moreover, taking into account the multiple identities that women presented with led to a theory which explained the impact of CLBP in women's everyday lives; importantly, it was not limited to the moments or periods when they adopted the sick role or when their identity as a 'patient' became salient.

It is clear that symbolic interactionism proposed a view of the construction of self through human interdependency. Mead (1934) suggests 'No hard-and-fast line can be drawn between our own selves and the selves of others, since our own selves exist and enter as such in our experience also' (p.164). It has been suggested that this approach may undermine the role of agency in identity construction by attributing our understandings of ourselves to be purely a consequence of how others views us (Gergen, 1991). Therefore, combining Goffman's (1959) dramaturgical approach to the conceptual framework in this study ensured that the role of individual agency in identity construction is not undermined. Goffman suggests that we are constantly giving off signals which define who we are to others. We choose our appearance, by the clothes we wear for example, with a specific purpose of creating a public identity. Moreover, the facial expressions, gestures, and terms or language we use, invite others to treat us as a specific kind of person. Goffman (1959) states, 'When an individual plays a part he implicitly requests his observer to take seriously the impression that is fostered before them' (p.17). Goffman (1959) further proposes that we simultaneously create a public self, and shield others from what he refers to as the 'back region', a region of action hidden from the observer. For example, a person 
with an invisible chronic illness may adopt the social role of a healthy individual, and shield disclosing the suffering they may live within their private space, as a way of avoiding stigma. The dramaturgical approach suggests that social life is a stage where people perform for each other, but also selectively choose their actions, rather than the actions being a by-product of others. Goffman's approach was utilised in this study to distinguish the active, individual role in women's construction of identities, including deliberate actions that were adopted to reflect specific images or identities during social interactions.

\subsection{Grounded Theory Approaches}

The constructivist approach to GT using DA was adopted in this study. This section will commence by discussing the development of the various approaches to GT, and some of the controversies and criticisms this variation has entailed. This will be followed by a rationale for adopting the constructivist GT approach in this study. An overview of the common characteristics of GT and the analytical methods characterising DA, and how they were applied in this study is then presented. The appropriateness of the constructivist approach to GT to this study will then be clarified, by focusing on the divergences between an objectivist and constructivist approach. Finally, the congruence of DA with the constructivist approach and the motivations for utilising this approach will be explained.

\subsubsection{The Development of Grounded Theory and the Rationale for Adopting a Constructivist Grounded Theory Approach}

GT is a systematic approach for data collection and analysis procedures to generate an inductively derived theory from the data (Strauss and Corbin, 1994; Charmaz, 2006; Birks and Mill, 2010). The GT approach was founded by the sociologists Glaser and Strauss (1967) who held contrasting philosophical positions, which were married in the GT approach. Glaser trained at Columbia University where his education was strongly 
influenced by a positivist stance (Annells 1996; Charmaz, 2006; Bryant and Charmaz, 2007), whilst Strauss trained at the University of Chicago where research methodologies related to a philosophical position of pragmatism were utilised (Annells, 1996; Charmaz, 2006; Bryant and Charmaz 2007).

Since the publication of their seminal text in the sixties (Glaser and Strauss, 1967), the GT approach has continuously evolved (Morse et al., 2009). Glaser later published 'Theoretical Sensitivity', which aimed to elaborate on key aspects of the approach that were not explained in sufficient detail in the original publication (Glaser, 1978). Strauss, in collaboration with Juliet Corbin, moved towards a verification approach and introduced new procedures and techniques which were not in the original or classic GT text (Strauss and Corbin, 1990; 1998). This led to two forms of GT: Glaserian or classic GT, and Straussian, which some refer to as evolved GT (Duchscher and Morgan, 2004; Mills et al., 2006b; Bryant and Charmaz, 2007).

A 'genealogy of grounded theory' (Morse et al., 2009, p.17), or what has been referred to as second-generation GT (Birks and Mill, 2010), is constituted of various GT approaches which have been developed in response to the 'methodological gaps in the seminal text' (Birks and Mill, 2000; p.5), or the lack of clarity with regards to the philosophical foundation or ontological and epistemological stance underpinning the approach (Annells, 1996; Morse, 2009; Birks and Mill, 2010). These approaches included Charmaz's constructivist GT (Charmaz, 2006; 2014), and Schatzman's DA (Schatzman, 1991), and are presented in the Figure 5.1. 


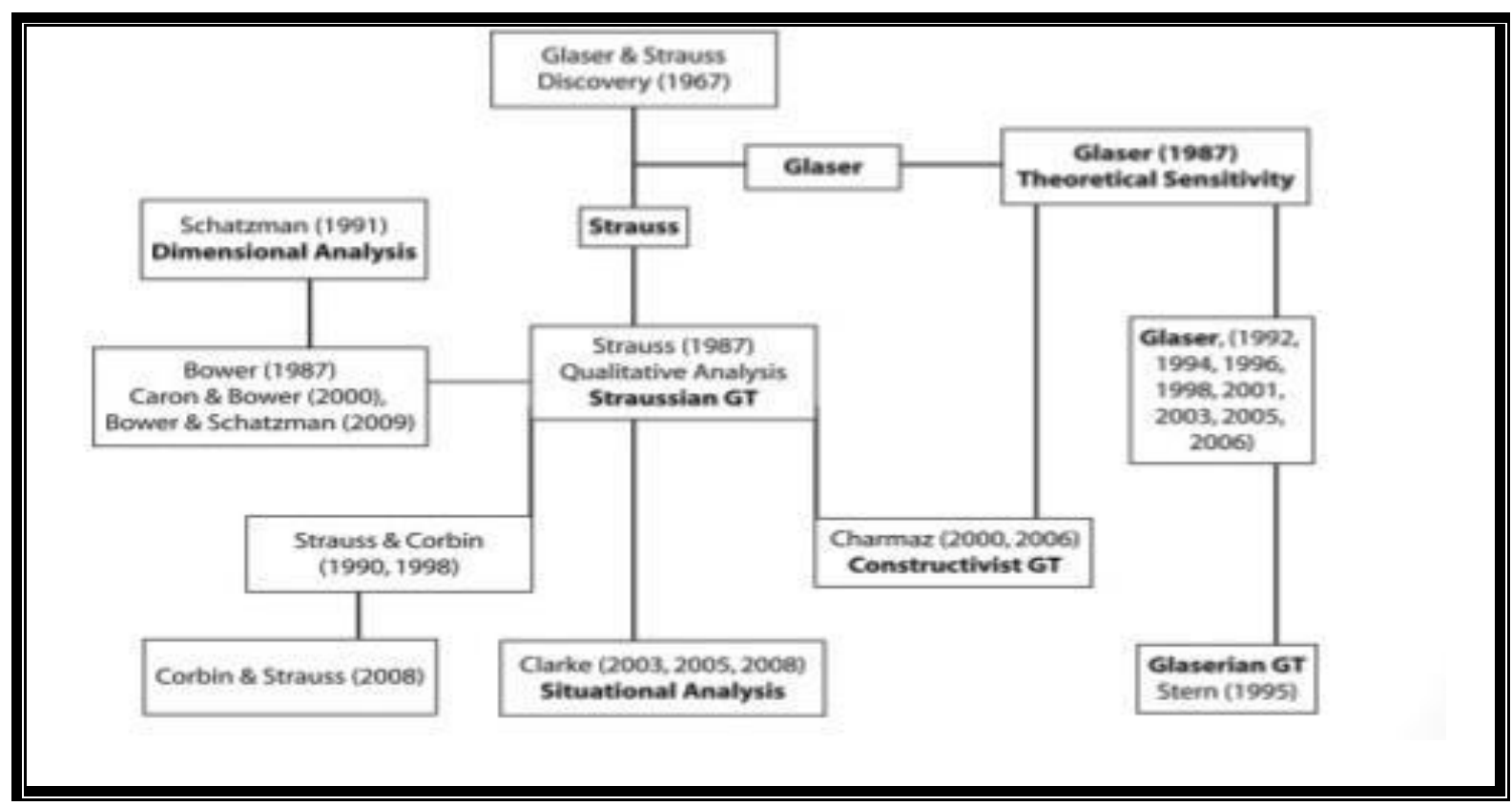

Figure 5.1: Development of the GT methodology

(source: Morse, 2009, p.17)

All the GT approaches share a common set of characteristics (refer to section 5.3.2), but vary in their underlying philosophical assumptions. This variation has led several authors to criticise the approach due to conflicting opinions, and there is some controversy regarding the nature and process of GT (Cutcliffe, 2000). Much of this controversy has been influenced by the epistemological assumptions which influenced their development (Annells, 1996; Bryant and Charmaz, 2007; Birks and Mills, 2010). Classic GT was developed in what Denzin and Lincoln (2005) have identified as the second moment of qualitative research, which was characterised by the dominance of the post-positivist mode of inquiry (Annells, 1996). The post-positivist stance assumes that while a 'real' reality exists and can be revealed through inquiry, it can never be perfectly understood or perceived (Guba and Lincoln, 1994). Under the influence of this stance, the theory which results from the classic GT approach is suggested to provide an objective reality. Classic GT emphasises the emergence of theory from the data, and suggests that if a researcher adheres to the constant comparative method of analysis (refer to section 5.3.2), then concepts will emerge without any influence from the researcher. In other words, this 
approach emphasises the researcher as a detached observer, and there is a distant, objectivist relationship between the researcher and the research participants.

Classic GT has been scrutinised for positioning the researcher as a detached expert and generating a theory which does not acknowledge the authors' voice (Charmaz, 2000). I would agree with this position, since my personal and professional background have influenced my motivation to pursue this research (refer to Sections 1.2 and 1.3) and the lenses through which the data were interpreted (refer to Section 6.5). Therefore, being transparent and reflexive about my influence on the formulated theory ensured the trustworthiness and credibility of the research findings (Charmaz 1990; Cutcliffe, 2000).

Straussian GT has been suggested to be influenced by the third moment identified by Denzin and Lincoln (2005), which 'demonstrated blurred genres as the social sciences moved from a golden age of autonomy towards the interpretative genre dispersion' (Annells, 1996, pp.121-122). These 'blurred genres' may have influenced what appears as contradicting epistemological positions evident in this approach. While it has been suggested that Straussian GT shifted the approach towards a social constructionist epistemological stance (Bryant and Charmaz, 2007), the analytical techniques provided in Straussian GT rely considerably on deductive reasoning, indicating a positivist slant to the approach. Strauss and Corbin's $(1990 ; 1998)$ approach acknowledges that the theory is constructed by the researcher and influenced by their perspectives. Nevertheless, particular notions in this approach, including the researcher claiming an objective position in relation to the participants and the data, suggest that the role of the participants in construction is neglected, and the researcher is considered to be an expert with authority to make claims about participants' experiences. This positivist slant to the approach does not fit in with the social constructionist epistemology taken in this study. In line with the epistemological stance taken in this study, a methodology which acknowledges both the role of the 
researcher in constructing the theory, and the participants' construction of meaning, needed to be utilised.

Charmaz's (2006) constructivist GT approach was developed and influenced by the third and fourth moments of qualitative research (Birks and Mill, 2010). These moments focused on the position of the researcher in the research process, and their relationship with the research participants (Charmaz 2000; 2006). Charmaz drove GT towards the interpretive tradition. The constructivist GT approach rejects the notions of objectivity or the researcher as a detached observer, and emergence of the theory from the data without influence from the researcher (Annells, 1997). Charmaz's (2006; 2014) constructivist approach focuses on the researcher's active role in influencing what concepts arise from the analysis and their position in the theory. It acknowledges the researcher's personal and professional backgrounds and interests, and emphasises being constantly reflexive and transparent about their influence of the formulated theory. Moreover, the constructivist approach assumes that the theory is formulated through a process of co-construction of knowledge through an interaction between the researcher, the participants, and the data.

Charmaz makes a broad distinction between a constructivist and objectivist approach to GT (Charmaz, 2006; 2014). Some of the variations between those two approaches are presented in Table $\mathbf{5 . 1}$ overleaf. 


\begin{tabular}{|l|l|l|}
\hline Theoretical assumptions & \multicolumn{1}{|c|}{ Constructivist GT } & \multicolumn{1}{|c|}{ Objectivist GT } \\
\hline $\begin{array}{l}\text { Assumes the existence of multiple, } \\
\text { provisional realities. }\end{array}$ & $\begin{array}{l}\text { Assumes the existence of an } \\
\text { objective reality. }\end{array}$ \\
\hline generating theory & $\begin{array}{l}\text { A co-construction of knowledge } \\
\text { developed through the interaction } \\
\text { between the researcher, research } \\
\text { participants and the data. } \\
\text { The theory is an interpretation and } \\
\text { is formulated depending on the } \\
\text { researcher's views and perspectives } \\
\text { through which the data is analysed. }\end{array}$ & $\begin{array}{l}\text { Emerges from the data, with no } \\
\text { influence from the researcher. } \\
\text { The theory represents an objective } \\
\text { truth which is discovered by an } \\
\text { unbiased researcher. }\end{array}$ \\
\hline Purposes of theory & $\begin{array}{l}\text { Provides an abstract, interpretive } \\
\text { and contextual understanding of the } \\
\text { studied phenomenon. } \\
\text { Aims to represent participants' } \\
\text { voices and views in the theory } \\
\text { generated. }\end{array}$ & $\begin{array}{l}\text { Provides explanations and predictions } \\
\text { of the studied phenomenon, and seeks } \\
\text { context-free, parsimonious theoretical } \\
\text { statements. } \\
\text { Prioritises the researcher's voice in } \\
\text { theory generated. }\end{array}$ \\
\hline
\end{tabular}

Table 5.1: Variations between the constructivist and objectivist GT approaches

The objective of the present study was to develop a deeper understanding of women's subjective experiences with CLBP, and how the construction of illness identities is influenced by a specific historical and social context, namely the Kuwaiti sociocultural context. Following a constructivist GT approach I was able to follow an analytical approach and formulate a theory which is 'contextually situated in time, place, culture and situation' (Charmaz, 2006, p.131). In other words, the constructivist approach enabled me to formulate a theory which provided an understanding of women's subjective experiences with CLBP, and the influence of historical and sociocultural factors on their manifestations and behaviours towards their illness. Moreover, this approach to GT corresponds with the social constructionist epistemology adopted in this study. It facilitated developing a theory which juxtaposed women's multiple realities (Allen, 2010), rather than focusing on an external, objective reality as might be suggested by an objectivist approach to GT (Charmaz, 2006). The constructivist approach is also congruent with the symbolic interactionist perspectives underpinning the conceptual framework adopted in this study (refer to Section 5.2.2). It facilitated interpreting women's illness identity construction as a process which incorporates their actions and ideologies, and how 
they are located in the larger social structures and discourses in the Kuwaiti context (Charmaz, 2009). Finally, a distinctive feature of the constructivist approach, which made it most suitable for this study's objectives, was the emphasis on the co-construction of knowledge, or the interaction between the researcher and the research participants. Constructivist GT emphasises modifying the power imbalance between the researcher and participants, treating the participants as the experts, and promotes building trust and a rapport with the participants (Charmaz, 2006; 2014). Adopting this stance in this study was necessary in order to gain a deep understanding of the construction of women's illness identities, a process which could be considered personal and emotional for people to discuss. Reducing power imbalances and establishing a rapport with the women in this study (refer to section 5.4 and 6.5.1) facilitated the generation of rich data, which enabled me to delve deep and gain intimate knowledge of women's personal and emotional experiences with CLBP, and in turn increased the depth and scope of the theory formulated.

\subsubsection{An Overview of Grounded Theory and Dimensional Analysis Methods}

Despite the existence of several approaches, the GT methodology constitutes a set of common characteristics or tools which consist of theoretical sensitivity, theoretical sampling, constant comparative method of analysis, coding, memoing, and theoretical saturation (Annells, 1996, 1997; McCann \& Clark, 2003). An overview of each tool and how it was utilised in this study will be presented in what follows.

It has been suggested that theoretical sensitivity involves the researcher's personal, professional and experiential history, which is enriched throughout the research process (Birks \& Mills, 2011). Glaser and Strauss (1967) refer to this concept by suggesting different methods of incorporating the researcher's insight into theory generation from the data. These include personal experiences prior to or outside the research, insight from other people's experiences, existing theory as a source of insight about the researcher's 
own data, and cultivation of new insights until the end of the study (pp.252-253). Subsequent publications by the two authors show some variation in the sources of theoretical sensitivity. Glaser (1978) suggests that theoretical sensitivity can be increased by researchers immersing themselves in the literature in order to become sensitised to constructing variables in multiple fields, rather than being restricted to a single field based on their professional background. Strauss and Corbin (1998) on the other hand, suggest that sensitivity could be increased by constant interaction between the researcher, immersion in the data, and the research act. They argue that this enables the researcher to become sensitive to the issues and problems of the people involved in their research.

Multiple strategies were utilised in this study to increase my theoretical sensitivity. Tapping into my personal experiences as a Kuwaiti woman, physiotherapist and postgraduate student, as well as the experiences of others, including my mother and my patients who suffer from CLBP (refer to Chapter 1), sensitised me to the issues and problems experienced by the participants. These experiences provided me with several perspectives through which I was able to interpret the participants' data. Moreover, the preliminary literature review I conducted (refer to Chapter 4), enabled me to explore various theoretical notions and assumptions from various fields of enquiry, through which the concepts of chronic illness and identity have been theorised. In line with Glaser's (1978) approach, I was able to broaden my awareness of sociological and feminist understandings, rather than limit myself to my professional understandings as a physiotherapist. Finally, theoretically sampling women and following up on changes and variations in their experiences over a period of one year (refer to Section 6.2.3) enabled me to constantly interact with them and gave me a better appreciation of their concerns.

The constant comparative method is the main principle of analysis in GT. In GT the purpose of making comparisons is to assist with the conceptualisation and categorisation in the course of data collection and analysis. It involves four stages: comparing incidents 
applicable to each category; integrating categories and their properties; delimiting the theory; and writing theory (Glaser and Strauss, 1967). By staying close to the data and constantly comparing incidents and generated concepts to the data, researchers are able to generate theory grounded in the data rather than from their preconceived ideas or existing theories.

In this study the constant comparative method was utilised to compare dimensions of experience across the data, and to explore similarities and differences across women's stories with CLBP. After an appreciation of each woman's individual story was gained in the early stages of the analysis (refer to Section 6.4.1), incidents and concepts generated from the data were constantly compared across participants' accounts. This was to ensure that the theoretical constructs being formulated were grounded in the data.

Memoing is an integral process that the researcher should engage in from the commencement of data collection to the very end stages of the research process and theory writing (Glaser, 1978; Charmaz, 2006). Memos capture the 'frontier of the analyst's thinking' (Glaser, 1978, p.83), and allow the researcher to increase the level of abstraction by writing ideas about relationships and comparisons between codes, and clarify directions they need to pursue (Glaser, 1978; Charmaz, 2006). According to Strauss and Corbin (1998), memos are specialised written records that can take several forms, such as code notes, theoretical memos and operational memos, and a single memo can contain one or more of these types.

In this study I used theoretical notes to document my hunches and hypotheses that I formulated from comparing incidents and concepts that were derived from the data. In my operational notes I included decisions about leads that I thought were necessary to follow in order to progress the study, such as making comparisons or conducting additional interviews (Strauss and Corbin, 1998). I also used reflexive memos, where I constantly 
challenged my preconceived ideas and tried to shift my perspectives as I became more immersed in the data and more sensitised to the women's main concerns.

Theoretical saturation is the point at which the researcher decides to terminate theoretical sampling and data collection. According to Glaser and Strauss (1967), theoretical saturation occurs when "no further data can be found whereby the sociologist can develop properties of the categories' (p.61). Charmaz suggests that theoretical saturation is 'the point at which gathering more data does not yield any further insight about the emerging grounded theory' (Bryant \& Charmaz, 2007, p.611). In this study, I decided that the theory generation process was completed at a point of theoretical sufficiency, where depth of conceptual linkage was reached (Kools et al., 1996). Data collection was terminated when women's interviews repetitively portrayed the same insights and no further dimensions and concepts were being generated from the data.

DA is a methodological approach for generating theory grounded in data (Schatzman, 1991). This approach was developed by Leonard Schatzman, a former student of Strauss and a colleague of Glaser and Strauss, to provide novice researchers with a theory which clarifies the nature and explains the steps involved in the process of analysis (Bowers and Schatzman, 2009). DA is informed by the core principal of the GT approaches in general, which is inductive generation of theory. Its philosophical foundation, which arises from symbolic interactionism, is most congruent with approaches that have shifted towards a constructionist epistemology in particular, and it has often been related to Strauss (1987) and Strauss and Corbin's $(1990,1998)$ approach to GT (Kools et al., 1996; Bowers and Strauss, 2009).

DA was developed in response to what Schatzman viewed as limitations of the analytical procedures of GT (Schatzman, 1991; Kools et al., 1996). Despite its congruence with GT, DA has its own epistemology and a distinctive set of operational procedures, which 
address the limitations outlined by Schatzman. Its epistemological assumptions fit closely with natural analysis, and in this sense DA is suggested to be an exaggerated form of natural analysis (Kools et al., 1996). According to Schatzman, natural analysis is a normal cognitive process, learned through socialisation and provides people with a schema to understand problematic experiences and phenomena (Kools et al., 1996). This epistemological position shows some congruence to the social constructionist assumptions adopted in this study, where women's manifestations of their realities are constructed in line with their social experiences and interactions (refer to Section 5.1); therefore, it was considered appropriate for this study. Schatzman believes that clarifying the similarities in the interpretive processes involved in natural analysis and research analysis, removes the mysteries of the analytical process involved in qualitative research, making its more accessible to novices (Bowers and Schatzman, 2009).

DA is designed around the principal of dimensionality, which refers to the ability of a researcher to interpret the attributes, context, processes and meanings of a complex phenomenon. In line with natural analysis, DA assumes that considerations researchers conjure are based on dimensions of experience (Schatzman, 1991). In this sense, this approach acknowledges that the dimensions which are generated from data reflect the researcher's personal interests, which in turn influences which dimensions are given salience, and how dimensions are organised in the theory constructed (Schatzman, 1991).

The three distinctive procedures which are involved in the DA analytical process are designation, differentiation and integration. Designation involves opening up the data in an attempt to find all the possibilities or label all the dimensions of participants' experiences. This allows the researcher to focus on 'what all is involved' in the data (Bower \& Schatzman, 2009, p.94), and to explore the density of the experience (phenomenon) that is under study (Kools et al., 1996). In this study, designation was utilised in the early stages 
of the analysis in order to gain an understanding of each woman's experiences and to identify the issues and concerns they deemed to be significant (see Section 6.4.1).

Differentiation involves integrating dimensions through the application of a framework called the explanatory matrix (Schatzman, 1991). The explanatory matrix allows the researcher to provide an understanding of the social processes involved in their data by assigning dimensions and properties to certain contexts, conditions, processes and consequences. Contexts elucidate the social conditions or environment in which the participants' dimensions of experience are embedded, while conditions are prominent dimensions which encourage, hinder or alter actions and interactions. Processes include actions or interactions that are driven by particular conditions, and consequences are the result of particular actions or interactions (Kools et al., 1996, p.318). The perspective through which the researcher chooses to view the data determines the salience of the dimensions, and the relationships between them. After several dimensions have been conceptually raised to the status of perspective, the central dimension is assigned. Identifying the central dimension provides the most fruitful explanation of the phenomenon under study and directs subsequent inquiry (Kools et al., 1996).

Integration allows the researcher to reconstitute the dimensions and their properties, and to clarify the relationships and patterns between them in order to formulate the substantive theory and make it comprehensible (Kools et al., 1996).

\subsubsection{Congruence of Dimensional Analysis with the Constructivist Approach to Grounded Theory}

GT approaches can be broadly classified as objectivist or constructivist, depending on the theoretical assumptions and the type of theory generated (Charmaz, 2006). This is not to say that a researcher necessarily adopts an objectivist or constructivist approach, since the two approaches share some assumptions and differ in others (Charmaz, 2009). Rather, it is 
the assumptions taken about how knowledge is generated and what purposes the theory formulated serves that determine which approach would be most suitable for a GT study. In this study the DA approach to generating GT (Schatzman, 1991; Kools et al., 1996; Bowers \& Schatzman, 2009) was adopted. DA is considered to share common assumptions with the constructivist approach to GT.

A constructivist approach to GT falls in the interpretive paradigm, and aims to provide an understanding of the studied phenomenon based on the researcher's interpretations. It assumes that multiple realities exist, facts and values are linked, truth is provisional, and social life is processual (Charmaz, 2006). An objective approach is suggested to be derived from positivism (Charmaz, 2009); it provides explanations and predictions of a phenomenon, assumes the existence of an objective truth that can be discovered, seeks context-free theoretical statements, and aims for parsimony and the applicability of the theory to a wide variety of empirical indicators (Glaser, 2004; Charmaz, 2006).

While an objectivist approach to GT would suggest that theoretical constructs are discovered with no influence from the researcher's presumptions (Glaser, 1992), a constructivist approach suggests a researcher constructs concepts based on their interpretation of the phenomenon under study, and clarifies the position of the researcher as an author, and the influence of his/her biography on the construction of theory (Strauss \& Corbin 1998; Charmaz, 2006; Mills et al., 2006a). In this sense, the researcher takes a reflexive stance to increase their awareness of their interpretations (Charmaz, 2009). A constructivist approach assumes that the researcher's decisions and interpretations are based on their perspectives, privileges, positions and interactions (Charmaz, 2009). In line with the assumptions of a constructivist approach to GT, DA assumes that researchers conjure dimensions, and assign a relative value to each dimension based on their personal and professional backgrounds (Bowers \& Schatzman, 2009). Moreover, DA assumes that 
the researchers make inferences about the dimensions, the relationships between them, and their relevance or irrelevance (Bowers \& Schatzman, 2009).

As explained in Chapter 1, my personal and professional background, and my prior experiences have influenced my desire to pursue this study. Moreover, my experience of living in the same cultural context as my participants sensitised me to issues, which were used as perspectives to guide the analytical process (refer to Chapter 2). Therefore, my biography has influenced several decisions and processes involved in this study, and a constructivist approach enabled me to be reflexive about the influence of my clinical and cultural perspectives on the theoretical concepts generated and the theory constructed.

Whereas a theory formulated by an objectivist approach to GT is detached from context and provides general concepts that can be applied to various empirical indicators (Glaser, 1978), a constructivist approach assumes that a theory is formulated from a coconstruction of meaning, which is grounded in the participants' and researcher's experiences (Charmaz, 2006; Mills et al., 2006a). A researcher adopting a constructivist approach assumes that knowledge is socially constructed and is influenced by perspectives and geographical locations (Charmaz, 2009); therefore, knowledge cannot be separated from its context. Moreover, constructivists locate participants' meanings and actions in larger social structures and discourses, thereby showing connections between micro and macro levels of analysis (Strauss and Corbin, 1998; Charmaz, 2009), and linking the subjective accounts of people to the social context in which they live (Charmaz, 2009). Similarly, DA suggests that context provides boundaries and controls the inclusiveness and relevance of the generated theory (Schatzman, 1991). Context is viewed as 'a repository of analytically useful dimensions, which are selectively assigned as conditions, processes and consequences', as the analytical process progresses (Schatzman, 1991, p.312). In this study, the theory was formulated through exploring connections between women's subjectivities and wider cultural structures and discourses. 
The theoretical constructs in this study provide an understanding of how women's emotional states, self-feelings and manifestations of CLBP where constructed in relation to their understandings of wider cultural ideologies and societal expectations.

Detaching the context from the generated theory contradicts the symbolic interactionist and social constructionist assumptions underpinning this study, as they focus on the meanings of people's behaviours within a social, cultural and historical context. Moreover, the literature exploring the perspectives of individuals on their CLBP experience has focused on Western cultures (see Chapter 4); one of the unique aspects of this study was to investigate how living in a country with an Arab culture influenced women's perspectives and behaviours. In this sense, as data analysis developed, women were theoretically sampled in order to understand how factors and conditions, including their age, educational levels, as well as familial and marital relationships, were influenced by various cultural ideologies and societal expectations, generating a theoretical outcome, which may be applicable to countries with similar cultural contexts, traditions and ideologies as Kuwait.

An objectivist GT is suggested to be 'simply a set of integrated conceptual hypotheses systematically generated to produce an inductive theory about a substantive area' (Glaser, 2004, p.2). A constructivist GT is constructed through the interaction between the researcher and participants. When generating a constructivist GT researchers continuously examine and reflect on their personal reactions towards the data, as well as exploring the dynamics of the relationship between the researcher and the researched, and how the resulting theory is a co-construction embedded in both the researcher and the participants' experiences (Charmaz, 2006). In the same sense, DA acknowledges that both the researcher and the participant's perspectives are influential on the dimensions acquired, where the researcher conjures dimensions based on their biography and interests, and the 
participants bring different perspectives depending on the context, which influences the dimensions of the conveyed experiences (Bowers \& Schatzman, 2009).

In this study the researcher's prior experience and the interaction between the researcher and participants has been influential on the knowledge generated during the interview process. Sharing the same cultural background and common understandings with the participants may have influenced the interaction with participants and what information participants chose to share or elaborate on. Constructivist GT enabled me to be reflexive about how my interaction with participants' influenced the data generation process.

The theory produced by classic GT is formulated around one basic social process that is considered to be the main problem for participants (Glaser, 1978). On the other hand, a theory produced by a constructivist approach aims to explain the complexities of the experiences of a collective sharing a commonality, such as a chronic illness, and therefore allows the inclusion of all the processes that may be necessary (Charmaz, 2006). It explores language used by participants, tacit meanings, beliefs and ideologies that may impact participants' constructions of their realities, actions and behaviours in relation to the social and cultural context. Similarly, DA does not aim to identify one basic social process; rather, it focuses on 'what all is involved' in order to generate a critical mass of dimensions that lead to a better understanding of the density of the experience or phenomenon being studied (Schatzman, 1991; Kools et al., 1996).

In line with the social constructionist epistemology the assumption taken in this study is that women construct multiple realities to explain the same phenomenon or their experiences with CLBP. Women's experiences were distinct and diverse, in the sense that each woman constructed a reality with distinct features. The group of women demonstrated various constructions, and this is attributed to the diverse factors which impact women's perspectives, actions and behaviours, including social and cultural 
ideologies, as well as social interactions. In this sense, adopting a broader perspective which enabled the researcher to explore all the processes involved in participants' experiences, or 'all what is involved' (Bowers \& Schatzman, 2009), enabled me to focus on all the dimensions of each woman's experience, and on the multiple processes involved This included how interactions with healthcare professionals influenced the meanings they constructed to explain their pain, and how interaction with family members and members of their social communities impacted on how women perceived themselves and behaved towards the difficulties they encountered as a result of CLBP.

\subsubsection{Motivations for Adopting Dimensional Analysis}

While several other approaches may suggest following a constructivist approach to GT (Charmaz 2006; Strauss \& Corbin, 1998), the motivation for adopting DA in particular was that the link made between natural analysis and research analysis, and the proposition that they are essentially the same (Schatzman, 1991; Bowers \& Schatzman, 2009). There is a distinctive set of operational procedures, which have been suggested to address the limitations of relying on the constant comparative analysis without focusing on other important analytical processes (Bower \& Schatzman, 2009).

The main aspect that links DA to natural analysis is that the researcher's considerations are perceived to be dimensions of experience (Bowers \& Schatzman, 2009). In other words, the perspectives that determine which dimensions are selected or generated from the data are based on the researcher's prior commitments, disciplines and biography. This notion was particularly beneficial in the process of designation and planning as the study developed. In the initial stages of data analysis I utilised my clinical and cultural perspectives, based on my background as a physiotherapist and a Kuwaiti woman, to start generating dimensions from participant's interviews. How those perspectives were utilised to generate dimensions will be discussed in Chapter 6 . 
While GT analysis commences with open coding (Glaser, 1978; Strauss \& Corbin, 1990, 1998; Charmaz, 2006), and the constant comparative analysis commences immediately after the first codes have been applied, DA commences with designation, in which the constant comparative analysis method is not employed (Bowers \& Schatzman, 2009). Designation entails the researcher to ask 'what all is involved', leading the researcher to a richer understanding of the phenomenon and a more complex range of dimensions before commencing the analytical process and engaging in comparative analysis (Bower \& Schatzman, 2009). During the initial stages of the study this process was beneficial with regards to exploring the distinctive components of women's experiences, as well as the various perspectives that women took to describe their experiences and the difficulties of living with CLBP. The following chapter (Chapter 6) will clarify how postponing the process of constant comparison aided in understanding and appreciating the complexity of women's experiences and elucidating variations in their behaviours.

\subsection{Insider-Outsider Research}

The insider/outsider binary can be restrictive in capturing the complexity and fluidity of the researcher's role throughout the research process (Breen, 2007). In this section I argue that I was an insider-researcher on some levels, and an outsider on others, and explain how these positions were managed as the research progressed.

As a physiotherapist with experience in treating women with CLBP, I may be seen as an insider with prior understandings and knowledge of the information with which I was handling (Brannick and Coghlan, 2007). Increasing my theoretical sensitivity through reviewing the literature on the subjectivities of CLBP experiences (refer to Section 4.6), and reflexive journaling were two strategies that enabled me to become introspective with regard to my underlying assumptions. An appreciation of the literature made me aware of the diversity of individuals' manifestations of CLBP. Through the process of reflexivity I 
was able to challenge my generic understanding of CLBP when listening to participants' accounts. As I assumed that women's experiences were distinct at some levels and similar at others, being reflexive ensured I was vigilant to the nuances in their accounts during the interview process.

As a Kuwaiti woman I was familiar with the cultural and gendered discourses espoused by the women in this study; this can position me as an insider and may be seen as advantage of being an insider-researcher (Bonner and Tolhurst, 2002). Nevertheless, being reflexive about my personal beliefs and values, and how women's interpretations of such discourses showed variations and similarities to my own understandings was crucial. I was aware that my personal experiences, such as living in a Western context for several years (refer to Section 1.2.2), impacted on the development of my personal morals and attitudes. While I may be seen as an insider to the sociocultural context of the women I interviewed, I considered myself an outsider to their truths and perceptions, their communities, and the expectations and relationships that influenced their identities. Moreover, sensitising myself to the various perspectives in the literature, which portrayed the development of women's roles in the Kuwaiti society (refer to Chapter 2), was beneficial in terms of considering the diversity and continuum of gendered ideologies and discourses in Kuwait, and how this impacted women's illness identity construal.

As a person who has not experienced CLBP I did not share an understanding of women's daily experiences with this condition, and in this sense I was an outsider-researcher (West et al., 2013). Moreover, I did not work in the hospitals from which I had recruited participants, and therefore had no prior relationship or future affiliation with the women interviewed. This enabled me to take a broader perspective during the interview process, since I did not have a shared understanding of the women's background or social circumstances (Drake, 2010). While it is generally believed that the recruitment of participants and establishing trust and rapport can be potentially challenging when the 
researcher is not an insider, I did not struggle in this regard. I believe this was because women were keen to 'voice' their experiences to someone who was willing to listen and had the ability to convey their voices to a larger audience. Moreover, being an outsider may have encouraged participants to share personal and sensitive information during the interview, since there was a minimal chance that I may use this information outside the context of the research study (Bonner and Tolhurst, 2002) or that it may jeopardise their future treatment or care. Nevertheless, following up with women over a course of one year eroded my outsider status, as I became more familiar with their experiences (Le Gallias, 2008) and empathised with their struggles. Being reflexive throughout the research journey enabled me to constantly document and manage my emotional reactions to the data, and to examine my own feelings and beliefs and their impact on the research process (Arber, 2006).

During the initial stages of the research, my very limited experience in qualitative research meant that I was inclined to take my assumptions of what was being said in interviews for granted. Moreover, I tended to be too agreeable with participants' accounts and failed to problematise the language, terms and phrases they used. Shifting from the role of clinician to researcher, I gained more confidence in distancing myself and adopting a relatively more neutral stance towards the interview, and my interpretations and understandings of women's experiences. For example, when an 'obvious' understanding of how women in Kuwait were expected to behave was mentioned, I became more accustomed to 'making the familiar strange' (Mannay, 2010). I followed up on such phrases to understand women's thoughts and feelings about societal expectations and how they influenced their actions, behaviours and self-feelings. 


\subsection{Ethical Considerations}

This section firstly describes the process of seeking and obtaining ethical approval. It then proceeds to discuss the major ethical considerations relevant to this research and how they were managed.

\subsubsection{Ethical Approval}

Ethical approval for this study was obtained from the University of Brighton's Faculty of Health and Social Science Research Ethics and Governance Committee (Appendix 2). Since the actual research project took place in Kuwait, ethical clearance was also obtained from the Joint Committee for the Protection of Human Subjects in Research at the Kuwait Institute for Medical Specialisation (Appendix 3). Approval was then obtained from the Administration of Physical Therapy Services at the Kuwait Ministry of Health (Appendix 2).

\subsubsection{Informed Consent}

Informed consent is a voluntary agreement made by participants after having been informed of the nature and objectives of a study (Holloway and Wheeler, 2002). In this research all participants gave written consent (Appendix 4) after reading the participant information sheet (Appendix 4). The participant information sheets detailed the nature and purpose of the study and provided contact details of the lead researcher, the supervisory team, and the local advisor. These documents were given to participants by the physiotherapy administration staff prior to the interview so that they had time to carefully consider their involvement in the study. In addition, consent was sought verbally prior to the commencement of each interview, and all participants were reminded that all details of the discussion would remain confidential to the researcher and the supervisory team. All participants were reminded of their right to cease participation in the study at any time, 
and that if at any point during the interview they felt uncomfortable or upset they could stop the interview without giving a reason; however, none requested to do so.

\subsubsection{Confidentiality and Anonymity}

To address any issues of confidentiality during the interview and transcription process, no names were used. Instead, transcriptions and participants were allocated pseudonyms, to which only the researcher had access to the 'key'. Other strategies to ensure confidentiality included placement of the consent forms in a private and locked location, and the storage of audio-taped recordings and hard-copy documents, which included participant identification, in a password protected laptop and locked file drawer, which was only accessible to me as the researcher. After the research has been completed, all audiotapes and back-up discs will be disposed of and transcripts of data will be destroyed. For the purpose of future publications, electronic data will be kept and will only be accessible through a password protected laptop device owned by the researcher.

\subsubsection{Participants' Well-being}

Qualitative interviews tend to encourage discussing deep and intimate details, which can elicit distressing memories and emotions (Holloway \& Wheeler 2002; Sim, 2010). Prior to each interview it was emphasised to all participants that they were the experts of their own experiences, and that the researcher role is to explore and understand their thoughts, feelings and perspectives about living with CLBP, not to evaluate or judge them (Unsworth 2008). Moreover, all participants were assured that if they felt upset, nervous or distressed during the interview for any reason at all, there was no obligation for them to continue. I remained vigilant to the interview questions which had the potential of causing some unease or emotional distress. I eased the participants into difficult questions and assured them that they could refrain from answering any questions which they did not feel comfortable about. To make sure that I prioritised participants' comfort levels over 
obtaining rich data, I had to make appropriate preparations in case a distressing situation arose. This meant being prepared to conduct a 'debriefing' telephone call to participants after the interview or directing them to support services available at the hospital where they were being treated. However, during the interviews none of the participants showed any signs of distress and no follow-up calls or referrals to support services were required.

\subsection{Methods for Enhancing Rigour}

Determining criteria that would be appropriate for evaluating the rigour or quality of qualitative research has been an issue of debate. The variation in philosophical assumptions, methodologies and methods that can be collectively adopted in any one study adopting a qualitative approach (Caelli et al., 2003; Rolfe, 2004) makes it unfeasible to implement one set of criteria to all studies. Therefore, it is suggested that a researcher should identify an approach that corresponds both philosophically and methodologically with their study (Caelli et al., 2003). The following sections discuss the criteria followed in this study to enhance the rigour of the research.

\subsubsection{Criteria for Evaluating Grounded Theory Research}

Glaser and Strauss (1967) propose that the criteria for assessing the rigour of a GT study are based on the actual strategies used for theory generation, including coding, analysing, how data are presented in the generated theory, and how readers understand the theory. Evaluating the rigour and quality of a GT study helps in terms of making decisions about the applicability of the findings to clinical settings (Elliot \& Laznebatt, 2004). In GT research, four criteria need to be adhered to in the process of theory generation in order to facilitate the practical application of the theory by the people involved in the substantive area that has been studied. First, the theory should fit the substantive field that it will be applied in. Second, it should be understandable to the people who are concerned with the area being studied. Third, it should be general so that it can be applied to diverse daily 
situations rather than to one specific situation. Finally, it should allow the users to control it in order to ensure it is meaningful and beneficial for application in everyday situations (Glaser \& Strauss, 1967, p.237). Therefore, the criteria for evaluating a GT study assesses the applicability of the substantive theory to the area investigated, and the closeness of the theoretical constructs to the data generated.

In this study, developing theoretical constructs that fit the data was facilitated by adhering to the constant comparative method of analysis. Data that has been analysed previously was constantly revisited when new concepts were generated from further analysis. Moreover, including participants' own words in the analytical memos enabled me to stay close to the data by always checking whether my interpretations were suitable. Being reflexive and constantly challenging my preconceived ideas during the analytical process ensured that the ideas generated were grounded in the data, rather than being arrived at by forcing my preconceived ideas.

Through follow-up interviews and the data collection process, it was possible to take interpretations and findings back to the participants. When I shared the theoretical constructs I generated with the women, they related to them and perceived that they did in fact represent their experiences with CLBP. This strategy was taken to make sure that the theory generated was understandable to the people who wish to apply it, to facilitate their readiness to use it, and to clarify the problems associated to the area and give them a sense of how to manage those problems (Glaser \& Strauss, 1967).

Generality involves the researcher attempting to generate a theory which is applicable to the whole picture, or to act as a 'general guide to the multi-conditional, ever-changing daily situations' (Glaser and Strauss, 1967, p.242). Through the process of differentiation, a 'critical mass of dimensions' (Schatzman, 1991) was generated, which clarified changes in the functional restrictions and pain intensity women experienced, their social conditions 
and emotional states, and how social interactions impacted on their experiences with CLBP. As the study progressed, theoretical sampling was aimed at investigating further the impact of social variation, including differences in educational attainment and financial situations, to determine plausible relationships between these concepts and to provide an understanding of women's everyday behaviours in relation to living with CLBP, thereby promoting generality (Glaser \& Strauss, 1967).

By ensuring that the generated theory closely fitted the data, and participants were able to relate to and understand the theory, participants were given some control in using the theory to gain insight into the controversies about their CLBP.

\subsubsection{Credibility}

Credibility is a consideration of the authenticity of the data, or determining how genuinely the data reflects participants' experience of the studied phenomenon (Beck, 1993; Barbour, 1998; Cresswell, 1998). Chiovitti and Piran (2003) provided several strategies to promote the credibility of a GT study, which were followed in this study.

First, the participants should be involved in guiding the inquiry process. In this study, in line with the constant comparative method, ideas or concepts generated from the data of one participant were considered when analysing the data from subsequent participants to determine its relevance. Moreover, the focus of the research was slightly broadened. Initially, I aimed to focus on how interaction with physiotherapists may influence women's constructions of illness identities in CLBP; however, analysis of the initial set of interviews revealed that women's identity constructions, actions and behaviours were influenced by interacting with a variety of people, including family members and other healthcare professionals, such as physicians. Therefore, interview questions were modified as the study progressed based on theoretical leads from the data (Cooney, 2001). 
Second, the theoretical constructions formulated needed to be taken back to the participants to ensure that they reflected their experiences of the studied phenomenon (Chiovitti \& Piran, 2003). Ensuring that women in this study found my theoretical constructs relatable to their experiences was necessary in line with the constructivist GT approach adopted in this study (Mills et al., 2006). I wanted to ensure that the women were involved during the different study stages by taking my interpretations of the data back to them to explore whether they represented women's experiences, or needed to be discarded (Cutcliffee, 2000). During the interviews the representativeness of concepts and dimensions which were generated from the data were explored in further interviews (Charmaz, 2014). As the study progressed, follow-up interviews gave me an opportunity to convey the theoretical constructs that were developed from the data to the women, enabling them to decide whether they reflected their experiences and they can relate to them, or whether some concepts did not explain their experiences and need to be altered or refuted.

Finally, credibility can be enhanced by using participant's actual words in the theory, and articulating the researcher's personal views and insights regarding the phenomenon explored. Quotes from the women's interview transcripts were included in the findings of this study in order to include participants' voices, support my interpretations, and to ensure that my interpretations reflected what was in the data (see Chapter 8). In Chapter 1 I explained how my professional background, and some prior conceptions and thoughts led me to pursue this study. Furthermore, my immediate and subsequent reflexive reactions to the data were documented separately from the interview data, through engaging in reflexive journaling and memoing (refer to Sections 6.3.1 and 6.5.1).

\subsubsection{Auditability}

Auditability indicates the possibility of other researchers and readers to follow the decisions made by the researcher during each stage of the research process (Beck, 1993). 
In GT research auditability entails being explicit about the criteria built into the researcher's thinking (Chiovitti \& Piran, 2003). In this study this can be demonstrated through an audit trail of the research decisions that was recorded in theoretical, operational, analytical and reflexive memos. In line with Strauss and Corbin's (1998) memoing techniques, theoretical notes contained questions and hunches that were formulated from concepts derived from the data; furthermore, operational notes included decisions about leads I thought were necessary to follow up in order to progress the processes of designation, differentiation and integration.

Analytical memos contained raw data, and my reflexive accounts about the data and my interpretations, which present an audit of the data, generated the dimensions and reflexive processes involved in the interpretation of the data. Reflexive memos further demonstrated how I challenged my professional presumptions and viewed the data through alternate perspectives. The use of memos has been demonstrated in Section 6.4.

\subsubsection{Transferability}

Transferability refers to the applicability of data to other settings or groups (Beck, 1993). This was addressed by attempting to provide a thorough description of the social, cultural and religious practices of people in Kuwait (refer to Chapter 1), thus enabling the readers to determine the applicability of the data to other contexts (Lincoln \& Guba, 1985). Furthermore, in Chapter 7 the findings are presented as rich, detailed and contextualised accounts of how women with CLBP constructed illness identities. Providing such rich descriptions enables readers to decide the transferability of the theoretical concepts of the research findings to other people in other settings, whilst also evaluating the quality of the research. In Chapter 8, literature related to each key finding generated was included to illustrate the possibility that the findings of this study have meaning to others in similar situations (Chiovitti \& Piran, 2003, p.433). For example, the extent to which the study findings are transferable to other Middle Eastern women. 


\subsubsection{Dependability and Confirmability}

Dependability evaluates the authenticity of the study findings and the consistency between the researcher's data analysis and the decision-making processes (Holloway \& Wheeler, 2010). Confirmability considers the degree to which the findings were founded in the data and offer a genuine interpretation of the view held by the participants, rather than reproduction of the researcher's' preconceived assumptions (Lincoln and Guba, 1985; Hamberg et al., 1994). In this study, a detailed account of the data collection strategies, the analytical process, and analytical decisions made throughout the various stages of the research process is provided in order to elucidate how the theory was constructed from the data (refer to Chapter 6). This detailed record serves as an audit trail to enhance the dependability and confirmability of this study. Memo writing, transcribing interview recordings, and formulating interview guides provided a trail of thoughts, ideas and decisions, so that readers can follow the inquiry process (Hamberg et al., 1994). Moreover, engaging in the process of reflexivity, recording reflexive insights in a journal, as well as ample insight from my supervisors, enabled me to develop my data collection and analytical skills, which contributed to promoting the quality of this study.

\subsection{Conclusions}

This chapter has discussed the methodological decisions made in this study. The aim of this chapter was to explain and justify the decision to locate this research in the interpretivist paradigm, and the adoption of a relativist ontology and social constructionist epistemology. Moreover, the rationale for adopting a constructivist approach to GT and the DA approach to analysis were presented. Considerations of the researcher being an insider at some levels and outsider at others have also been presented. The ethical considerations and measures taken to ensure that this study is trustworthy were also 
discussed. In the next chapter the data collection methods and how utilising the process of DA led to the research findings are detailed. 


\section{CHAPTER 6 - METHODS}

\subsection{Introduction}

In this chapter a discussion of the concurrent process of data collection and analysis, in line with iterative nature of GT research, is presented. By enclosing a detailed account of the methods utilised in this study to construct the substantive theory, the chapter provides an audit trail, and in so doing increases the dependability and confirmability of the study.

\subsection{Sampling}

\subsubsection{Access and Recruitment}

During the initial stages of the study participants were recruited from two physiotherapy musculoskeletal outpatient clinics in hospitals governed by the Ministry of Health in Kuwait (MOH), Al-Adan Hospital and the Physical Medicine and Rehabilitation Hospital (PMR). Al-Adan Hospital is one of the largest governmental hospitals in Kuwait, with a total bed capacity of 600 , and was established to provide medical health services to AlAhmadi and Mubarak Al-Kabeer governorates in the south of Kuwait (refer to Section 2.2). A high percentage of patients treated in this hospital are Bedouins from rural areas with varied educational backgrounds. The PMR hospital is the largest governmental rehabilitation centre in Kuwait, and receives patients mainly from the Hawali governorate (refer to Section 2.2). This hospital sees patients from a variety of social backgrounds. These two hospitals were chosen because their regional differences enabled the recruitment of women from various cultural, social and educational backgrounds. A total of three women were recruited from Al-Adan hospital and two from PMR hospital (refer to Section 6.2.2).

As the study progressed three women were theoretically sampled from the physiotherapy department in Dar Al-Shifa, a private hospital in Kuwait. This hospital is situated in a 
17,000 square metre building and is run by a team of American and European medical practitioners. It comprises a one-day surgery ward, five imperial suites, fifteen royal suites, 55 special suites, eight labour rooms, six operating theatres and 45 outpatient clinics. Some of the rehabilitative services it provides include musculoskeletal rehabilitation, neurological rehabilitation, and cardiac rehabilitation (http://www.daralshifa.com).

The study drew considerable interest amongst the women that were interviewed. As the study progressed snowball sampling was adopted, as participants directed me to other women they knew who had back pain and were interested in participating in the study. Three women were recruited through this sampling technique. Table 6.1 presents some background information of the eleven women that were recruited for this study, the sampling techniques, and the hospitals through which they were recruited. Sampling will be discussed further in the following sections (Section 6.2.2 and 6.2.3). Pseudonyms were used to identify each participant. 


\begin{tabular}{|c|c|c|c|c|c|c|c|c|}
\hline Participant & Age & $\begin{array}{l}\text { Duration } \\
\text { of CLBP }\end{array}$ & $\begin{array}{c}\text { Self-reported } \\
\text { diagnosis }\end{array}$ & $\begin{array}{l}\text { Educational } \\
\text { Attainment }\end{array}$ & $\begin{array}{l}\text { Occupation } \\
\text { Status }\end{array}$ & $\begin{array}{c}\text { Marital } \\
\text { Status }\end{array}$ & Sampling & Hospital \\
\hline Maha & 51 & $\begin{array}{l}>15 \\
\text { years }\end{array}$ & $\begin{array}{l}\text { L4/L5 disc } \\
\text { prolapse }\end{array}$ & $\begin{array}{l}\text { Secondary } \\
\text { school }\end{array}$ & Housewife & Married & Purposive & Al-Adan \\
\hline Elham & 50 & 4 years & $\begin{array}{l}\text { Disc prolapse } \\
\text { with sciatic } \\
\text { nerve } \\
\text { compression } \\
\text { (with } \\
\text { unilateral } \\
\text { radiating pain } \\
\text { to left lower } \\
\text { limb) }\end{array}$ & Certificate & $\begin{array}{l}\text { Retired } \\
\text { secretary }\end{array}$ & Divorced & Purposive & Al-Adan \\
\hline Fatimah & 22 & 2 years & Disc prolapse & $\begin{array}{l}\text { University } \\
\text { student }\end{array}$ & N/A & Married & Purposive & Al-Adan \\
\hline Noura & 26 & 1 year & $\begin{array}{l}\text { L4/L5 disc } \\
\text { prolapse with } \\
\text { sciatica (with } \\
\text { unilateral } \\
\text { radiating pain } \\
\text { and numbness } \\
\text { in left lower } \\
\text { limb) }\end{array}$ & $\begin{array}{l}\text { Bachelor's } \\
\text { degree }\end{array}$ & Teacher & Single & Purposive & PMR \\
\hline Tahani & 47 & 3 years & $\begin{array}{l}\text { Degenerative } \\
\text { changes, } \\
\text { L4/L5 disc } \\
\text { prolapse (with } \\
\text { unilateral } \\
\text { radiating pain } \\
\text { to left lower } \\
\text { limb) }\end{array}$ & Illiterate & Housewife & Married & Purposive & PMR \\
\hline Salwa & 28 & $>8$ years & $\begin{array}{l}\text { Disc prolapse } \\
\text { (with } \\
\text { unilateral } \\
\text { radiating pain } \\
\text { to left lower } \\
\text { limb) }\end{array}$ & $\begin{array}{l}\text { High school } \\
\text { degree }\end{array}$ & Housewife & Married & Theoretical & $\begin{array}{l}\text { Dar Al- } \\
\text { Shifa }\end{array}$ \\
\hline Najla & 32 & $\begin{array}{l}3 \text { or } 4 \\
\text { years }\end{array}$ & $\begin{array}{l}\text { Degenerative } \\
\text { changes, } \\
\text { L4/L5 disc } \\
\text { prolapse }\end{array}$ & $\begin{array}{l}\text { Master's } \\
\text { degree }\end{array}$ & Engineer & Single & Theoretical & $\begin{array}{l}\text { Dar Al- } \\
\text { Shifa }\end{array}$ \\
\hline Roqaya & 26 & 4 years & $\begin{array}{l}\text { X-ray } \\
\text { inconclusive }\end{array}$ & $\begin{array}{l}\text { Bachelor's } \\
\text { degree }\end{array}$ & Nurse & Single & Theoretical & $\begin{array}{l}\text { Dar Al- } \\
\text { Shifa }\end{array}$ \\
\hline Abrar & 49 & 22 years & Disc prolapse & Diploma & $\begin{array}{l}\text { Retired } \\
\text { assistant } \\
\text { accountant }\end{array}$ & Married & Snowball & N/A \\
\hline Asrar & 64 & 4 years & $\begin{array}{l}\text { L4/L5 disc } \\
\text { prolapse }\end{array}$ & $\begin{array}{l}\text { Bachelor's } \\
\text { degree }\end{array}$ & $\begin{array}{l}\text { Retired } \\
\text { social } \\
\text { worker }\end{array}$ & Widowed & Snowball & N/A \\
\hline Fadheela & 65 & 35 years & Disc prolapse & $\begin{array}{l}\text { Secondary } \\
\text { school }\end{array}$ & $\begin{array}{l}\text { Retired } \\
\text { clerical } \\
\text { worker }\end{array}$ & Married & Snowball & N/A \\
\hline
\end{tabular}

Table 6.1: Participant's background, sampling and recruitment 
Access to the clinical settings was gained by seeking approval from the $\mathrm{MOH}$ in Kuwait. After agreement was obtained from the $\mathrm{MOH}$, permission was sought from the directors of each of the two hospitals, followed by permission from the heads of physiotherapy outpatient clinics in each hospital. The head of the physiotherapy department in the Dar Al-Shifa hospital was also my local advisor, and therefore access to this setting was sought directly through him.

To ensure that participation in this study was voluntary and to prevent coercion, women were not approached directly by myself. In Kuwait, a patient needs to be referred to physiotherapy by a physician, and the referral would be handed to the patient, with the diagnosis written on it. The patient then comes into the physiotherapy out-patient department with their referral to set a physiotherapy appointment. Each department had one physiotherapist who was in charge of receiving referrals from patients and assigning them to their colleagues based on the availability of time slots. The two physiotherapists knew the condition of each patient (based on the diagnosis provided by the doctor on the referral), and were not involved in managing or treating these patients. Therefore, each patient with CLBP that set an appointment was given an information pack, containing the information sheet, a consent form and a participant contact form. The information sheet included contact information for the patients who were interested in participating in the study, so they could contact the researcher directly; this was to ensure confidentiality. It was clearly explained to all patients that their therapy or any other treatment or care would not be compromised if they choose not to participate in the study, both by the physiotherapists handing out the information packs, and by the researcher prior to obtaining consent. Many older patients in Kuwait are illiterate, and therefore the physiotherapists were asked to read the information sheet to such patients prior to obtaining consent. 


\subsubsection{Purposive Sampling}

There has been agreement that initial sampling in studies using the GT approach is purposive sampling (Coyne, 1997; McCann et al., 2003a; McCann et al., 2003b; Birks \& Mills, 2011). Strauss and Corbin (1990) refer to the initial phase as open sampling, which is 'sampling those persons, places, situations that will provide the greatest opportunity to gather the most relevant data about the phenomenon under investigation' (p.181). During the initial stages of the of the study, a total of five participants (Maha, Elham, Fatimah, Noura, Tahani) were recruited using purposive sampling (see Table 6.1), and following the criteria below:

\section{Inclusion criteria:}

Patients with LBP of more than 6 weeks' duration, either recurrent or newly referred to physiotherapy, who attended their initial session.

\section{Exclusion criteria:}

Patients who are too frail to an extent that they do not have the capacity to consent. Patients who do not speak either Arabic or English.

Initially, the study aimed to investigate the experiences of both males and females with CLBP. However, the study drew considerably more attention from female patients. By the end of the eight initial interviews, only one male participant had been recruited, and it was apparent that there was considerable variation between his experiences of CLBP to that of the women interviewed. Data generated from the male participant was used to actively frame an alternative analytical view of the research data, and to sensitise me to the gendered distinctions in the participants' accounts. When this participant was contacted for a follow-up interview, the call was not returned. As the study progressed it was apparent to me that in a society highly influenced by patriarchy, such as Kuwait (refer to Chapter 1), women may have perceived the research interview to be an opportunity to 
voice their views. In line with this need that was portrayed by the participants, and the richness of the data and concepts derived from analysing the women's interviews, an analytical decision was taken to focus the study on women's experiences.

\subsubsection{Theoretical Sampling}

Theoretical sampling is the process of data collection whereby the researcher collects pertinent data to develop the evolving theory, and is considered as a key component of GT research (Charmaz, 2006). In this study, theoretical sampling involved returning to four women (Maha, Elham Tahani, Salwa) one year after their first interview. In line with the longitudinal design of the study, the purpose was to follow up these women after they were discharged, and to explore any changes in their pain experiences. Moreover, the follow up interviews provided opportunities to share with the women and validate my developing interpretation of their experiences, and to explore specific areas that had been highlighted as significant during the interview discussions.

Theoretical sampling also involved the recruitment of women who were relatively younger in age, and women from relatively higher socioeconomic backgrounds. By recruiting three women (Salwa, Najla, Roqaya) who sought private healthcare, it was anticipated that the latter would be achieved. Three women were recruited through snowball sampling (Abrar, Asrar, Fadheela) towards the final stages of data collection in order to explore the variation in women's experiences at various stages in their illness trajectories. Moreover, recruiting women at this advanced stage of the study was useful for confirming and exploring the central dimension whilst broadening the scope of the developing theory (Cutcliffe, 2000).

\subsection{Data Collection}

Semi-structured interviews were adopted as the data collection method for this study, as this is considered to be an appropriate method for constructivist GT studies which aim to 
obtain detailed accounts of participant's experiences with chronic illness (Charmaz, 1990). Since the aim of this study was to explore how women's innate thoughts and feelings influenced their manifestation and behaviours towards CLBP, semi-structured interviewing, or what Charmaz (2006) considers 'intensive' interviewing (p.26), was appropriate to tap into the subjective dimensions of their experience. The objective of utilising semi-structured interviews was to gain an emic understanding of women's experiences with CLBP and how they constructed illness identities. I aimed to see this process as the women in this study did - 'from the inside' (Charmaz, 2014, p.24). The constructivist GT approach emphasises that the theory ought to be a co-construction of knowledge based on the experiences of the researcher and participants (Charmaz, 2006). Kvale (1996) suggests that the interview is ' $\ldots$ is a construction site of knowledge. An interview is literally an inter view, an inter change of views between two persons conversing about a theme of mutual interest' (p.2). In this sense, this study utilised interviews, and viewed the interview as a joint effort for generating data based on the researcher as well as the women's views. The 'shaped yet emergent' (Charmaz, 2006, p.28) nature of the interviewing process enabled me to pursue ideas that developed during the interview, which meant that some interview questions varied from one participant to the next. Moreover, not all the questions in the interview guides were necessarily asked in one particular interview. Examples of the interview guides are provided in Section 6.3.1.

Charmaz (2014) suggests that data collection methods are generated from the research question, the objectives of the research and the direction in which the study proceeds. In this sense, while other methods were considered, interviewing was determined to be the most suitable for addressing the research question and objectives.

Observation is a method which enables the researcher to witness both verbal and nonverbal interactions in participants' own environment (Cassey et al., 2004). The researcher usually engages in a variety of approaches, from participant observation where he/she 
interacts with participants and engages in their activities, to non-participant observation where the position of a complete observer is assumed (Casey et al., 2004). While observation has been suggested to be useful in understanding the association between the environmental and cultural context, and participants' behaviours (Mulhall, 2002), ethical considerations need to be acknowledged when considering this method. In particular, it should be ensured that participants' rights to privacy are not violated, which raises concerns regarding access to the research site (Stafford and Stafford, 1993; Mulhall, 2002). This study focused on the subjective experiences of women with CLBP outside healthcare settings, and how they dealt with and managed their CLBP in their day-to-day lives, and in the midst of their social existence. Therefore, it was not possible to carry out observations, since it would have not been feasible to observe women manage their pain in the realms of their private homes.

Focus groups are a method which collects qualitative data through group interaction, in which the researcher discusses a research topic with participants (Morgan, 1996). Focus groups have been suggested to be beneficial in aiding the researcher in their interpretations of previously collected data (Morgan, 1996; Doody et al., 2013). In this sense, focus groups were considered initially in this study, as a means of taking my interpretations of the data back to the women to check whether or not they found them relatable and that they truly reflected their experiences (refer to Section 6.5.2). However, it is advised to refrain from the use of focus groups when sensitive issues are being discussed and when confidentiality cannot be ensured (Doody et al., 2013; Connelly et al., 2015). Due to the intimate nature of women's accounts and the private details they shared throughout the data collection process, follow-up interviews, as well as informal talks, were utilised to check my interpretations of the data with participants, instead of focus groups (refer to Section 6.5 .2$)$. This decision was taken to protect women's anonymity and confidentiality, and to avoid situations where women may have been open to judgment from others, 
thereby prioritising participants' comfort and providing an environment where they could be open with their concerns. In this sense, interviews were deemed to be appropriate for capturing the subjectivities and emic understandings of women's experiences with CLBP, and observations and focus groups were not utilised for ethical reasons, and to avoid compromising the women's confidentiality and comfort when expressing their views, concerns and intimate details about their experiences.

\subsubsection{Interview Procedure}

Data were collected through both semi-structured, face-to-face and telephone interviews. Before commencing each interview the women were asked if they had read the information sheet and whether they required any further information. If they were happy to participate then they signed the consent form. At the beginning of each interview I explained to the women the topic under discussion and re-iterated the purpose of the interview and why they had been invited to participate. I reminded each woman that the interview would be audio-recorded, and that they were free to stop the interview at any time without providing a reason.

Approximately ten minutes was allocated at the end of each interview for debriefing (Kvale, 2007). The debriefing period involved asking the women if they had anything else they wished to add and they were asked how they had found the interview experience. They were reminded again that the recording would be fully transcribed, and that they would be contacted to ask if they had any further comments. Finally, the women were asked if they were happy to be contacted again at a later date for a follow-up interview, and it was explained to them that the decision was entirely theirs and there was no obligation.

It is suggested that listening to participants' recounting their stories is vital in the early stages of GT (Glaser \& Strauss, 1967; Duffy et al., 2004). The aim of the five initial 
interviews was to explore each woman's individual story in order to understand the variations and distinctive nature of each experience. Following a symbolic interactionist theoretical framework (Blumer, 1969), I wanted to explore the various perspectives women took to construct meanings to make sense of their CLBP, and the social conditions which influenced their thoughts, feelings, actions and behaviours.

The interview questions were aimed at understanding participants' words and meanings (Charmaz, 2014). Transitioning from clinician to researcher and exploring issues in this way during interviews was challenging. Engaging in reflexive writing was a constant reminder not to take anything the women said at face value. Moreover, adopting a position of ignorance during the interviews was necessary (refer to Section 5.5). For example, from my own clinical experience I had a generalised understanding about the nature of CLBP and some of the approaches women adopted to manage it at home. Nevertheless, paying attention to the subtleties in women's perceptions and manifestations of their various experiences with CLBP revealed to me the differences in their identity construction in relation to changes in their lives over time. Probing questions were used to delve into these issues more deeply. Below are excerpts from some reflexive journaling that I engaged in to challenge my prior understandings and broaden my perspectives (Figure 6.1). 
Bryant and Charmaz (2010) suggest that when a researcher has many commonalities with participants, it would be taken for granted that there are many shared understandings, and therefore participants may feel that they do not need to elaborate or provide too much detail. Therefore, I need to make myself a stranger to the culture, and ask questions as if I am an outsider... I think I need to think about societal or cultural expectations in Kuwait, do those influence women's ideologies about their roles? ...I believe that social and psychological issues influence patients' construction of their illness experiences, concerns and management approaches. This is from a purely clinician perspective. How can I use this and not let it impede my analysis or creativity? I can, as Schatzman suggests, use it as an initial perspective with which to view my data, but be open to changing this perspective and applying others to my data. More importantly, discarding it if I do not find evidence in my data to support this assumption. My first working idea can be: social and psychological dimensions influence how patients understand their illness, their concerns and their management approaches. Social and psychological issues are broad, but I think it gives me more room to view the data more broadly' it will help me to sensitise myself to what might be in the data, but not lock myself into very specific social/psychological conditions. This may be an opportunity to challenge my preconceived ideas, either verifying them or rejecting them depending on what I find in the data. It may also allow me to free myself from this perspective after I have experimented with this idea...I think another issue is my emphasis on the pain; I think that was not what the participants' stories were about, it was only one dimension, but not the focus... I think adopting an epistemological understanding of relativism, where truth is provisional, socially constructed, and that multiple realties exist, is something I have learned; it is a totally new perspective for me, but it strongly influences my ideology now. I am more open to accepting other people's constructions of knowledge and opinions even though they do not necessarily correspond to mine...this is helpful in exploring the nuances in women's experiences and viewing them as the experts in providing me with understandings of the subjectivities of CLBP.

Figure 6.1: Reflexive journaling

An interview guide with broad open-ended questions was used; however, the nature of the interviews allowed conversation to flow, as participants were encouraged to express their concerns. The interview guide was not adhered to, rather questions were altered during the interview to follow leads from participant's accounts rather than the study's preformulated questions (DiCicco-Bloom \& Crabtree, 2006). In line with the constructivist GT approach that was adopted, close attention was paid to women's definitions of the terms they used and the context in which the terms were expressed (Mills et al., 2006a). This involved prompting women to elaborate on the meaning of implicit statements or descriptions, which they may have taken for granted as part of their everyday experience with CLBP. It also involved asking questions to illuminate how women defined and viewed certain issues. This was achieved by repeating the language and terminology women used, and exploring this further through deeper questioning. Using an open-ended questioning approach helped prevent the forcing of data into predetermined categories, 
and ensured that the questions I asked were focused and significant, yet also enabled participants to freely express their views (Charmaz, 2006).

The study followed a longitudinal approach where four women were theoretically sampled (refer to Section 6.2.3) and interviewed again, in order to elaborate on issues that emerged from the initial set of interviews. This was beneficial as it allowed me to develop a relationship with the women. This made them to feel more relaxed and comfortable, thereby giving deeper insights into their experiences, sharing of more information, and allowing me to gain a better understanding of the complexities associated with their experiences.

All the initial interviews were carried out face-to-face. However, it was not always possible for women who were interested in participating to make time for an interview after their physiotherapy session. For example, some women had someone picking them up from the hospital, which in one instance led to the interview to being cut short. As the study progressed women were given a choice of whether they preferred to be interviewed face-to-face or by telephone. Some women chose telephone interviewing when they did not have the time to participate in a face-to-face interview, and preferred to be called at home than setting an interview time and making arrangements to be present.

While telephone interviewing has been criticised for leading to a loss of rapport, inability to probe and deception, there is no evidence that these problems arise (Novick, 2008). A study comparing face-to-face interviewing with telephone interviewing found that both modes of interviews generated the same quantity of data, and there was no difference noticed in the nature and depth of participant responses (Sturges \& Hanrahan, 2004). While telephone interviewing may jeopardise the rapport built with the participants, for the women in this study the telephone interview was their second interview and all first interviews were conducted face-to-face. This helped build rapport; also, in most instances, 
women were more comfortable sharing more intimate information during their telephone interview. This may have been because telephone interviewing allows participants to stay on 'their own turf' (McCoyd \& Kerson, 2006, p.399) and permits more privacy (Sturges \& Hanrahan, 2004). Moreover, the relationship, trust and rapport developed during the first interview may have facilitated the richness that was produced throughout the telephone interviews.

Before commencing an interview I attempted to make the women feel comfortable and relaxed by taking time to greet them, thanking them for their interest in my study, introducing myself, and informally conversing with them. Moreover, the focus of the interview was explained to them, and any questions regarding the interview or regarding the information sheet they received or any further questions were answered. When the women were happy with the information they received and expressed interested in taking part, they were invited to sign the consent form.

Charmaz $(2005,2006)$ emphasises prioritising the comfort of participant's over obtaining rich data, and suggests several principles to ensure participants' comfort. Therefore, as well attempting to create a comfortable and relaxing atmosphere, towards the end of the interview, women were asked if they felt that they gained anything from the interview experience. Moreover, participants were asked if there was any aspect of their experience they wanted to elaborate on, or that was not discussed and that they would like to talk about.

With the permission of the participants each interview was audio-recorded. Audiorecording captured the exact words participants used, the tone of their voice and pauses during speech, offering the researcher a more accurate account of the interview (Kvale, 1996; Opdenakker, 2006). Moreover, it allowed me to focus on the participants and on the dynamics of the interview in order to obtain richer data (Kvale, 1996; Charmaz, 2006). 
Listening to the audio-recordings also helped me to improve my interview skills, by listening to how effectively I used probes to aid women in elaborating on the concepts they were conveying, and whether or not I used leading or forced questions that may have shaped participants' responses (Dearnley, 2005; Charmaz, 2006).

The interviews' duration ranged from one to two hours. While women were initially informed that interviews would take approximately one hour, they were able to talk freely for as long as they liked. The data from all the interviews were transcribed verbatim. I transcribed the initial four interviews as it had the benefit of facilitating full data immersion as highlighted by Charmaz (2006). However, due to the number of interviews and my limited typing skills a professional transcriber was sought to transcribe the subsequent interviews. Once the transcripts were completed the interview tapes were retrieved from the transcriber and it was requested that he delete any electronic copies in his possession. I checked the transcripts for completeness and accuracy to ensure transcription accuracy, as well as to re-engage with the data. I reviewed each one by listening to the original audio-recording while simultaneously reading an electronic version of the transcript.

\subsection{Researcher-Participant Relationship}

Fostering a sense of trust, mutuality, rapport and empathy developed my relationship with the participants. I ensured the participants that confidentiality and anonymity would be maintained, and discussed the mechanisms built into the study to ensure this (refer to Section 5.5.3). My credibility was established by offering some details about myself, including my experience working as a physiotherapist and being a full-time $\mathrm{PhD}$ researcher. I also expressed to the women my genuine interest in understanding their perceptions, feelings, thoughts and concerns about their daily experiences with CLBP. 
During the early interviews my inexperience in the research process was apparent. I found it difficult to ask obvious questions in order to explore the meaning of what participants were saying. It may have been that women saw me as a physiotherapist rather than a researcher, which was of no surprise as during the early stages of the research I thought and felt more like a physiotherapist. This was evident when women ended their responses and sought affirmation on whether or not they were providing the right information. When occasions such as this occurred, I acknowledged a potential power imbalance and reassured participants that there was no right or wrong answer, since people's experiences with CLBP varied considerably. I also explained that I was interested in understanding their personal experiences with CLBP, which they were more knowledgeable about than I was. I planned how I could build mutuality into the relationship to facilitate the mutual construction of data (Mills et al., 2006a). While the first set of interviews were scheduled after a participant's first physiotherapy session and took place in a clinical setting, this strategy was changed as the research progressed. Women were given a choice of scheduling the interview at a time, date, and location of their choice (refer to Section 6.3.1). Other strategies to neutralise the relationship and promote mutuality included taking a flexible and honest approach to the interview questioning, sharing ideas and personal details so that there was an element of intimacy and reciprocity, and the chance to answer questions during and after the interview (Mills et al., 2006a).

As I shifted from the role of a physiotherapist to a researcher, I perceived that the researcher-participant relationship had developed and I became more confident in my researcher role and more assured in the women's role as participants. This was especially evident during the follow-up interviews, where participants appeared to display a greater degree of openness and trust and in addition, seemed more comfortable about expressing their feelings and conveying more intimate and private details about their lives and how 
they impacted on their sense of self and CLBP experiences. I considered this to be a positive which contributed to the credibility of the research generated.

For an interview to be effective, rapport needs to be established between the two parties. I took an empathetic approach to the interview, by being fully present to the situation, and fully attentive and responsive to the participants. Data collection consisted of open-ended, semi-structured interview questions, which were used as a reference and to initiate a discussion about the research objectives. During the interviews clarification was sought when I was unclear about the meanings of participants, and I would restate what I thought they had said in their own words. In all of the interviews I began by asking the first openended question, and subsequent questions were aimed at gaining an understanding of the participants' main concerns, thoughts and feelings that they felt were important to voice. Facilitating a rapport and empathy with participants helped build a relationship that enabled disclosure (Patton, 2002).

\subsection{Data Collection and Analysis}

In line with the iterative nature of GT, data collection and analysis occurred concurrently (Glaser and Strauss, 1967; Glaser, 1978; Strauss \& Corbin, 1990; 1998). The following sections detail how the process of data collection and analysis developed. They explain the dynamic and interactional relationship between the researcher and the data (Kools et al., 1996) by providing details about the development of the interview guides and questions, analytical insights and decisions, as the theory was being generated. While the analysis did not proceed via distinctive stages, it will be demonstrated how 'early analysis' commenced with the process of designation, and how 'later analysis' proceeded with differentiation. Finally, it will be explained how the central organising dimension was determined through the process of integration, in line with the DA approach adopted in this study (Schatzman, 1991; Kools et al., 1996). 


\subsubsection{Data Collection - Initial Interviews}

In the early stages of data collection the aim of the first interviews (Maha, Elham, Tahani, Salwa, Noura) was to explore key concepts, including CLBP and identity, in order to explore how they may have been associated with shaping women's experiences, actions and behaviours. Those concepts were used as 'points of departure' (Charmaz, 2014, p.31), or sensitising concepts to formulate the initial interview guide (Figure 6.2) and to start exploring the research question (refer to Section 4.9).

How did you come to experiencing LBP?

What were your thoughts and feeling when you learned you had LBP?

How would you describe living with CLBP?

How would you describe the person you are now?

Is this different to how you would have described yourself before experiencing LBP?

Figure 6.2: Interview guide used for the initial interviews

\subsubsection{Early Analysis of Initial Interviews}

The analytical process commenced directly after the interview with each participant. Schatzman (1991) refers broadly to two stages of analysis: 'early analysis' and 'later analysis'. Early analysis involves the process of designation, which focuses on answering the methodological question 'what all is involved here', and aims to generate a critical mass of dimensions that constitute the 'all' or 'whole of considerations involved in the phenomenon under study' (Schatzman, 1991, p.312). In this sense, I commenced with the process of designation, in order to generate multiple components or considerations that seemed to be related to the experiences of women with CLBP. The initial analysis was aimed at exploring and gaining an understanding of how women construed themselves and their illness.

In line with the constructivist approach adopted in this study, the process of designation was guided by reflexivity, which helped me challenge my professional assumptions and 
view the data through alternative perspectives. I used reflexive memos in order to document my initial impression of each interview. Analytical memos were also written in order to aid in linking data gathering with data analysis. These memos included interpretations of women's manifestations of their CLBP experience, and elucidated similarities and differences in their experiences.

Throughout the process of designation I used analytical tables to aid me in staying close to the data, and to ensure that interpretations were grounded in the data. Designation involves naming data bits and expanding them into their various properties and dimensions (Kools et al., 1996). Initially, I read through each interview transcript, extracted bits of data and placed them into one column of a table; subsequently, I applied labels to each element of the data in an adjoining column. These labels reflected my initial impressions of the data, and therefore were more descriptive than conceptual. I re-read the interview transcripts several times, and went through the initial impressions or labels I had documented, and grouped the labels that were related to a similar aspect, reflected on them, and collapsed the descriptive labels into one conceptual label.

The DA approach commences with the researcher using dimensions of experience as perspectives to generate dimensions from the data (Schatzman 1991; Bowers \& Schatzman, 2009). In this sense, the main perspective that impacted on which dimensions were generated at the initial stage of the study was my professional or clinical perspective. However, in line with the constructivist approach to GT adopted in this study, I utilised reflexive memos to challenge my presumptions to determine their relevance or discard them, and to eventually apply a relevant conceptual label. Through the process of designation I was able to start uncovering various dimensions and properties that were apparent in women's stories. 
In contrast to classic GT, which requires the researcher to initiate constant comparative analysis directly after the first code is applied (Glaser, 1978; Strauss \& Corbin, 1998), DA suggests the researcher should delay the constant comparison until a critical mass of dimensions has been generated. This is suggested to enable the researcher to generate a wide range of dimensions in order to gain a richer understanding of the phenomenon and to prevent early theoretical closure (Bowers and Schatzman, 2009). I found that every woman's story was very complex, as they each had their own distinctive features, and it was difficult to compare the stories during the analytical process. Therefore, this approach enabled me to commence my analysis by focusing on the distinctive aspects of each woman's account separately, in order to unravel the complexities and to discover the aspects or dimensions through which each experience can be understood. Reflexivity was helpful during this stage, as I constantly reflected on my experience and my prior knowledge to challenge my presumptions in an attempt to open my mind and interpret the participants' meanings, rather than forcing my preconceived ideas onto the data.

While the constant comparative method was not applied during the initial stage of the study, after using the process of designation with the first four interviews I started to see similarities and variances between the different conceptual labels elicited from each woman's story. It was not a linear process, where each conceptual label generated was compared across each interview transcript, rather it stemmed from my familiarity with the data, so that when one conceptual label was applied in one interview, I would recall how an aspect of another interview corresponded, differed or contrasted, and therefore I would go back to it to further develop my conceptualisations, dimensions and properties. Figure 6.3 is an excerpt from an analytical table, demonstrating how conceptual labels distinctive to Elham's interview were applied, and how reflexivity was incorporated. Figure 6.4 illustrates how similarities and variances between Elham's experience and the experiences of Maha and Noura were recalled and considered. 


\begin{tabular}{|c|c|c|}
\hline Analytical Comments & Reflexive Notes & Preliminary Labels \\
\hline $\begin{array}{l}\text { Associating pain to } \\
\text { physical deficit. } \\
\text { Significance of pain in } \\
\text { terms of disability. } \\
\text { Duration of pain. } \\
\text { Associating pain to } \\
\text { functional limitations. } \\
\text { Significance of pain in } \\
\text { terms of intensity. }\end{array}$ & $\begin{array}{l}\text { The central concept in the labels, which I } \\
\text { appointed to the first bulk of data, was pain. } \\
\text { When explaining the problem, Elham seemed } \\
\text { to explain the different dimensions, which are } \\
\text { associated to the pain, rather than describing } \\
\text { the pain itself. As a clinician, I think I used to } \\
\text { lead the patient into describing the type of pain } \\
\text { e.g., throbbing, deep/aching, sharp pain etc. to } \\
\text { try and determine whether it was muscular } \\
\text { pain, radiating pain due to nerve impingement } \\
\text { etc. But it seems here that this is not the } \\
\text { patient's perspective on pain. She is more } \\
\text { concerned with how the pain is associated to } \\
\text { changes that are occurring in her body } \\
\text { (physical deficit in the spine), and the changes } \\
\text { in her life that have occurred (the } \\
\text { consequences of disability and functional } \\
\text { limitations) as a result of her pain. I would } \\
\text { need to explore how other participants } \\
\text { constructed the meaning of their pain and what } \\
\text { other perspectives they used, and the } \\
\text { dimensions of their lives they associated to } \\
\text { their pain, but for now I think I can apply one } \\
\text { conceptual label: pain dimensions. Physical } \\
\text { deficits, disability, duration, functional } \\
\text { limitations, and intensity may be properties of } \\
\text { this concept. }\end{array}$ & Pain dimensions. \\
\hline
\end{tabular}

Figure 6.3: Labelling distinctive dimensions of Elham's interview and reflexively challenging presumptions 


\begin{tabular}{|l|l|l|}
\hline Analytical Comments & Reflexive Notes & Preliminary Label \\
\hline phildren support in managing & $\begin{array}{l}\text { This label makes me think of } \\
\text { recurrence of the significance of } \\
\text { other's support in the participants' } \\
\text { illness experiences. Elham } \\
\text { explained the importance of her } \\
\text { daughter's care and support in } \\
\text { managing her pain. Maha } \\
\text { explained the impact that a lack of } \\
\text { empathy shown from her family } \\
\text { had on her experience. Also, } \\
\text { Noura talked about being } \\
\text { motivated to take control of her } \\
\text { illness by her parents reminding } \\
\text { her of her best friends' experience } \\
\text { with CLBP, and how she } \\
\text { managed it. I will need to go back } \\
\text { to the other transcripts to } \\
\text { understand this label further, but } \\
\text { for now I will call it: social } \\
\text { support. }\end{array}$ & \\
\hline
\end{tabular}

Figure 6.4: Recalling similarities and variations across the data

Due to the influence of my clinical perspective in the early stages of the analysis, the first aspects of women's experiences that I started applying labels to were the physical restrictions women encountered. Some of the initial labels applied to this aspect of women's experiences are displayed in Figure 6.5.

\begin{tabular}{|l|l|}
\hline Excerpt & Analytical Label \\
\hline $\begin{array}{l}\text { When the pain was at its worse, my left leg was } \\
\text { almost paralyzed. (Elham, 1) }\end{array}$ & Total restriction of movement. \\
\hline $\begin{array}{l}\text { I couldn't move my leg; it got so bad that my } \\
\text { brothers had to support me while I was walking. } \\
\text { (Noura) }\end{array}$ & Needing help to walk. \\
\hline $\begin{array}{l}\text { I use to enjoy cooking and sewing dresses for my } \\
\text { daughters...now these things have been taken from } \\
\text { me. (Tahani, 1) }\end{array}$ & Interference with social activities. \\
\hline
\end{tabular}

Figure 6.5: Labels applied to physical restrictions as described by the women

After some valuable insight from supervision meetings, I could see how the majority of the labels were focused on the physical and functional aspect of women's experience with CLBP, and while this was one dimension of their experience, it was not the only aspect as is apparent from the above excerpts. I decided to write a reflexive memo about my 
preconceived ideas in order to make decisions about how I would manage them. This is described in Figure 6.6.

I think the main challenge for me is letting go of my clinical perspective.

I think I lack confidence in my sociological knowledge, and therefore I feel I need to read and grasp as much detail from the sociological literature as possible, to have sufficient sociological concepts to think about when looking at my data. But when I was reading the literature, every time I read an article, I felt my data fit into the whole paper, and tried using all the ideas and details, and find aspects of my data that fit into their concepts. That impedes creativity and originality of my work, because all those concepts have been well established in the literature, I am not showing my ability to think conceptually or my ability to create a theory based on some of my own derived concepts, rather than relying completely on other people's concepts and patterns.

I think I need to become more creative... I can use visual aids such as diagrams... as well as read things very briefly on Wikipedia...I need to step out of my comfort zone and take risks.

I also need to use grids and start finding quotes that relate to any ideas or perspectives I use to view my data. This is to make sure I am not imposing ideas on my data and that the data does in fact support my line of thinking.

The way my supervisor put it, the process of assessing/re-assessing is very helpful; it corresponds with having a grid for your data to fall back on, as it enables you to check whether or not your interpretations fit the data

\section{Figure 6.6: Excerpt from a reflexive memo concerning the challenges faced and decisions}

\section{made to manage them}

Following the first five interviews it was felt that a substantial amount of data had been collected, and data collection was halted in order to obtain a handle on the analysis, and to compare and explore with more depth the variations and similarities, and overarching patterns across the women's accounts. This pause was very useful, and entailed considerable reflexive memoing, I increased my theoretical sensitivity by resorting to the sociological literature and continuously challenging my clinical and professional perspective and assumptions.

Through reflexive journaling, challenging my clinical perspective enabled me to actively frame alternative perspectives to view the research data. I attempted to explore issues beyond the physical dimension of women's experiences. I re-read my transcripts, this time focusing on the role of others in women's stories. It quickly became apparent that while women described similar functional limitations, their manifestation of these limitations 
varied depending on the social conditions, social roles and responsibilities they construed.

I became aware that women's accounts included significant others, as well as people they interacted with regularly, such as healthcare professionals. The influence of family members on women's manifestations of CLBP started to become clearer. It became apparent that some women perceived their family members to be supportive and empathetic, whereas others were inconsiderate towards women's suffering. Moreover, some healthcare professionals were seen to be paternal and dismissive, and others were perceived to be collaborative and empathetic. How this variation started surfacing through the process of designation is illustrated in Figure 6.7 and Figure 6.8.

I think there are three main aspects to Tahani's interview. First, contextualising her illness and elucidating how it impacted her daily activities. While that is usually what I would be interested in as a physiotherapist, there is something deeper that I would have missed in clinical practice: the emotional aspect of her description. I read something interesting in Morse et al.'s (2009) book, where she depicted a dialogue between Charmaz and Corbin. What struck me as interesting was how each person's ontological and epistemological positions came in to their analytical perspectives. Charmaz suggested listening to the interviews while analysing, because that would allow the researcher to capture the emotional aspect by listening to the tone, pauses etc. Listening to the patient's tone, it was very painful for her to describe how she felt dependent on others, how she could not carry out her duties and how she was concerned that she could not be there for her children. This brings me to the second aspect of her interview: impact on family. Many of the literature investigate the impact of family from the family's perspective. However, they have not focused on the patient's perspective. Tahani discussed at length how her daughters would cry when they saw the state she was in, how they had to miss their final exams to be there for her, how her husband had to quit his job for a while when she could not walk because of the pain. It sounded like much of her manifestation of CLBP was associated with her concern for her family, and how her illness has impacted them...

Figure 6.7: Excerpt from an analytical memo illustrating ideas about emotional and family aspects of CLBP experience from Tahani's interview 


\begin{tabular}{|c|c|}
\hline Excerpt & Analytical Label \\
\hline $\begin{array}{l}\text { I felt comfortable with doctor X because of his kind } \\
\text { approach and words...he talked to me with a soothing tone, } \\
\text { and at a pace where I can understand exactly what he was } \\
\text { saying. He explained thoroughly what was happening in my } \\
\text { back, he used a spine prototype to show me...what was most } \\
\text { comforting was when I explained what I was going through, } \\
\text { it was almost as if he was completing my sentences, it was } \\
\text { like he was living with me and knew exactly how much I } \\
\text { was suffering... (Salwa, 1) }\end{array}$ & Empathetic approach \\
\hline $\begin{array}{l}\text { One time I experienced pain at night and I came to hospital } \\
X . \text { I was in continuous pain for three to four hours, and for } \\
\text { three days before that I did not sleep because of the pain. All } \\
\text { they did was give me a pill, they did not even explain what it } \\
\text { was for or what was happening in my back. I didn't even } \\
\text { know what the pain was from, it came suddenly; I didn't } \\
\text { even know what caused it. (Maha, 1) }\end{array}$ & Dismissive approach \\
\hline
\end{tabular}

Figure 6.8: Variations in women's perspectives regarding the approaches of healthcare professionals

Broadening my perspectives and acknowledging the social and relational aspects of women's experiences enabled me to start deriving the variations in the illness behaviours women portrayed to manage CLBP. I became aware that some women took a dominant approach and were in control, whereas others took a more passive approach and were considerably restricted by their pain. Figure 6.9 provides two excerpts that exemplify this variation.

\begin{tabular}{|l|l|}
\hline Excerpt & Analytical Label \\
\hline $\begin{array}{l}\text { I have tried everything. I bought medications and ointments, I used } \\
\text { the ones the doctor prescribed, I bought ointments for the muscles, I } \\
\text { bought painkillers, I tried them all...but it's pointless...there is no } \\
\text { comfort...no comfort at all... (Maha, 1) }\end{array}$ & $\begin{array}{l}\text { Reliance on medication, constant } \\
\text { pain. }\end{array}$ \\
\hline $\begin{array}{l}\text { I am working on a project that I aspired to complete... I used to work } \\
\text { on it daily...now I can only work on it every other day. It /back pain] } \\
\text { restricts my ability, but I don't let it take over and I don't stop } \\
\text { pursuing my goals because of it. (Noura) }\end{array}$ & $\begin{array}{l}\text { Active approach, in control of } \\
\text { pain. }\end{array}$ \\
\hline
\end{tabular}

Figure 6.9: Variations in women's illness behaviours

After unravelling the components of women's accounts that were related to their illness, I decided to turn to the second aim of the initial analysis - exploring how women construed 
themselves. Repeatedly re-visiting my transcripts enabled me to look more closely at the language women used to describe themselves. Women talked about how they perceived themselves, and described themselves in terms of their social conditions and feelings. Some women described themselves as strong, resilient and self-governing, while others described themselves as held-down, confined and controlled. Moreover, women's descriptions of themselves varied in relation to their educational attainment, financial situation, and marital status. I also started to interpret the different ways women expressed their feelings. Some women described themselves as happy, hopeful, comfortable and secure, while others described themselves as depressed, stressed, exhausted, hopeless and insecure.

Looking closely at how women described themselves illuminated the temporality of women's accounts; women's accounts were not static. They referred to various stages of their lives that were characterised by social conditions, feelings and manifestations of CLBP. Some periods were characterised by an exacerbation of CLBP, while others were characterised by a reduction of CLBP.

Through the process of designation I came up with six initial dimensions, which I thought were most prominent in women's accounts of their experience with CLBP. Schatzman (1991) suggests that during the 'early analysis', dimensions that are generated are simply a list, while 'later analysis' is geared at experimenting with explanatory scenarios, and determining the position of dimensions in the explanatory matrix. The list of the conceptual labels given to the six dimensions is provided in Figure 6.10. 


\begin{tabular}{|l|l|}
\hline Dimension & Properties \\
\hline Functional & $\begin{array}{l}\text { Limitations in performing functional activities } \\
\text { Difficulty maintaining social roles and responsibilities } \\
\text { Fluctuations and changes in functional restriction }\end{array}$ \\
\hline Behavioural & $\begin{array}{l}\text { Dominant approach, in control } \\
\text { Passive approach, considerable restriction }\end{array}$ \\
\hline Healthcare & Uncertainty \\
& Seeking meaning \\
& Dissatisfaction with healthcare \\
Effective healthcare \\
Approach to healthcare
\end{tabular}

Figure 6.10: Dimensions and properties generated in the early analysis

As illustrated in Figure 6.10, I identified corporeal, behavioural, healthcare, emotional, social and temporal dimensions to women's self-construals and illness experiences. An integral dimension that unravelled at this stage was the temporal aspect of women's 
experiences, and how changes across time seemed to be associated with variations in women's pain experiences.

As is reflected in the dimensions generated, this stage of analysis was more descriptive than conceptual or abstract. Further analysis was aimed at delving deeper into the dimensions generated at this stage by investigating under what conditions did women's self-construals vary, and what consequences this entailed for their experiences with CLBP. Some of the questions that were formulated included:

- Why did women's emotional expression vary? What were the associated conditions and what were the consequences of this variation?

- What did educational attainment, financial situation and marital status mean to women?

- How did variations in the support women perceived from others influence their self-construals and illness experiences?

- What conditions led to the changes noted in different stages of women's accounts? Why and how did those changes impact their experiences with CLBP?

\subsubsection{Data Collection - Follow-up Interviews}

The concepts of CLBP and identity were used as 'tentative tools' rather than 'definitive concepts' (Charmaz, 2014, p.31) to initiate the interview process in its aims of exploring the research question and objectives. Nevertheless, the iterative nature of GT, as well as constantly being reflective in line with the constructivist approach adopted, enabled me to remain open and vigilant to other ideas and concepts which emerged during the interviews.

As the process of data collection continued, I aimed to gather focused data which would answer analytical questions generated through the early analysis of the five initial interviews (refer to Section 6.5.1). Follow-up interviews were carried out with four 
women who were theoretically sampled (Elham, Maha, Tahani, Salwa, refer to Section 6.2.3) one year after their initial interviews. There was particular emphasis on gaining a deeper understanding of the temporality and intangible dimensions of women's experiences during these interviews. Moreover, the follow-up interviews were taken as an opportunity to take back my interpretations of the data to the women and to explore whether or not the theoretical constructs generated from the data resonated with their experiences. Charmaz (2014) suggests that when interviews are conducted using theoretical sampling, the researcher may take a more forefront stance and focus the interview. In this sense, the objectives of the follow-up interview were broadly clarified to women in the following manner; at the beginning of each interview, women were given a summary of my interpretations of the main issues discussed in the initial interview and asked whether or not they found them relatable to their experiences. It was then explained to them that there were issues they had talked about in our last interview that I found interesting and would like to understand with more depth, but emphasised that if there was anything else they wanted to talk about, I would be interested to hear it. Moreover, if they felt there were any changes in the past year, or anything they wanted to add, women were encouraged discuss those changes or additions.

The interview guide questions were developed to encourage elaboration on concepts which emerged in the initial five interviews, in order to develop the dimensions generated in the early analysis. Questions were developed to focus on the dimensions of experience which needed to be explored further, and also kept sufficiently broad to allow pursuing new ideas and concepts which may have not emerged in my interpretations of the initial data (Charmaz, 2014). Not all of the questions included in the interview guide (Figure 6.11) were asked in every interview. The flow of the interview varied, and probing questions were utilised to pursue issues women discussed and emphasised during their interviews. 
Temporal dimension

Can you tell me about your LBP and any changes that may have occurred since we last spoke? Can you tell me your thoughts and feelings about any changes in your experience with LBP?

Can you tell me about any significant changes, if any, which have occurred in your life since we last spoke? Can you talk to me about your thoughts and feelings about this/those change/s in your life?

Social dimension

Can you tell me more about the role of your family members in periods where you were in pain?

Did their role have an impact on your experience with LBP, if so how?

Can you tell me how the role that your family members/friends play in your life makes you feel?

Did this have an impact on your experience with LBP, if so can you explain how?

What did this change/s mean to you? Why was it significant? Was anyone else involved in this change? Did their involvement make a difference to your experience?

Emotional dimension

Can you explain in more detail what things make you (sad/happy/afraid)? Can you provide some examples of incidents that made you feel this way? Can you explain why it made you feel this way? How did those feelings affect you?

Did those feelings make a difference to your experience with LBP, if so how?

Healthcare dimension

Can you talk more about your experience with healthcare?

How did your encounter with the physician/physiotherapist affect you? How was this different from your encounter with other healthcare professionals?

\section{Figure 6.11: Focused interview guide used during follow-up interviews}

As well as questions from the interview guide (Figure 6.11), several probing questions were developed throughout the follow-up interviews. I used probing questions such as 'You mentioned your children recurrently when we last spoke, can you give me some more details about their role in your life?' and 'You talked a lot about feelings of fear during our last talk, can you explain in your own words how would you define those feelings and how they affect you?'.

All of the follow-up interviews were carried out via telephone. Utilising telephone interviews was particularly useful to eradicate any power-imbalance that may have arisen in clinical settings (Holton 2010) during the initial face-to-face interviews. Eliminating the professional-patient status that may have been encouraged in clinical settings, and carrying out the interviews at a time and place that was chosen by the women, gave them more control over the interview process, and over the privacy of the conversation (Holton, 2010; 
Ward et al., 2015). For example, one participant needed to attend to one of her daughters after an hour of the interview, but still felt she had more to discuss. Therefore, she asked if the interview could be continued a couple of hours later when she would be alone. Rather than cutting the interview short, this flexibility and carrying out the interviews with consideration of women's circumstances and convenience facilitated the generation of richer and more intimate data. Women were also able to move around their homes during the interviews. For example, one participant decided to move to a different part of her home when her husband came into her space. This control over privacy facilitated very intimate conversations, where women were open about their thoughts and feelings with regards to sensitive issues, including marital troubles and familial struggles.

As I became more sensitive to the women's concerns and vulnerabilities, I felt more confident to go deeper and to explore innate details about their experiences. Some sensitive topics that arose during telephone interviews included hardships, such as financial difficulties and the loss of loved ones, and women made implicit associations between such hardships and periods of pain exacerbation. Ensuring women's comfort was maintained by being vigilant to their tone and pace was my main concern while they described such difficulties (Charmaz, 2014). I maintained a balance between encouraging women to elaborate on their concerns, whilst assuring them that we would only pursue such topics if they felt comfortable talking about them and if they felt they were important to discuss. I pursued these associations with questions such as 'Could you talk to me more about that? How did this affect your experience with CLBP?' Several questions were developed by reusing women's words to gain a better understanding. An example of this strategy is provided below:

Tahani: What really affected me is that I feel I am not normal like the other women...

Probing Questions: Can you tell me what you mean by 'I feel I am not normal like the other women? How did those feelings affect you? 
Tahani: I mean I am not normal like the women that can work in their homes, even when I work I have to wear the lumbar belt, its fear, fear of pain...some women tell me you don't buy pretty dresses and nice things to decorate your home anymore, our financial situation is difficult, that makes things hard...

In line with the constructivist approach adopted, such questions were used to delve deeper into the words and language that women used to understand their thoughts, feelings and experiences in their own terms.

\subsubsection{Data Analysis of Follow-up Interviews}

As I developed the properties of the six dimensions generated through the follow-up interviews, it became apparent that they were 'resistant' to combination, and therefore a decision was made to experiment with explanatory scenarios, and to elucidate the relative value of each dimension and their location in the explanatory matrix (Schatzman, 1991). The process of differentiation was utilised at this stage and the data analysis became more focus directed (Kools et al., 1996). Differentiation involves auditioning several dimensions as the central perspective, until the most fruitful one from which to explain the social phenomenon under study is determined (Schatzman, 1991). In this sense, I auditioned each of the six dimensions I generated as a perspective from which to view my data and interpret how the other dimensions and properties were associated to it. I commenced with the temporal and emotional dimensions and began by scrutinising the properties of this dimension. For example, it quickly became apparent that feelings of helplessness and hopelessness contradicted with feelings of happiness and hopefulness. I realised that some women conveyed positive feelings and others negative feelings. I also realised that women's emotional accounts varied as they discussed different periods of their lives. Throughout my theoretical and operational memos, I formulated conceptual questions to ask as I re-visited my data: 
- What conditions were associated to the positive/negative emotions women portrayed?

- What conditions were associated to changes in women's feelings across time?

- How were women's emotions related to their self-construals and illness experiences?

Consulting the literature on the sociology of emotions was particularly useful and helped me to increase my theoretical sensitivity. Challenging my clinical perspective enabled me to see that I was initially viewing women's emotions from an individualist perspective, and re-visiting the data made me aware of how their emotions were contextualised in the midst of their social conditions and relationships. The interactionist perspective portrayed through the work of Hochschild (1983) and Freund (1990) was particularly useful in enabling me to see the patterns and connections in the data and the dimensions I had generated, and reflexivity was also particularly useful here. This perspective enabled me to understand the social and relational construction of women's emotional experiences, and how they manifest as embodied expressions. I was able to understand the profoundness of the emotional expression within the women's accounts and its relevance to their experiences with CLBP. The interactionist perspective illuminated the association between emotional pain, and the bodily or physical expression of pain (Freund, 1990). Moreover, I was able to interpret how women's different social positions, which were influenced by their communities, resources and the support available to them, were conditions that influenced their self-perceptions, feelings and behaviours towards CLBP (Hochschild, 1983; Freund, 1990).

The follow-up interviews were particularly useful in reinforcing the significance of time, or the temporal dimension, and the variation in women's emotions, manifestations and behaviours towards CLBP over time, as changes in their social conditions and circumstances occurred. Figure 6.12 provides an excerpt from an analytical memo where 
the significance of the temporal dimension and its relevance to the other dimensions generated during the early analysis started to unravel.

The first year [during the divorce process] was difficult, I was exhausted and stressed out, going to court, facing the judge, I was always anxious, that year I fell hard because of my back, when I sat with you last year at the hospital, I had come in because my back pain was bad...the second year [after the divorce] I feel comfortable, secure and relaxed...I was able to rid myself of all that load and being overworked, pushing heavy furniture to clean behind it, I'm not obliged to do those things anymore, during this year I have not once suffered from my back pain...I feel relaxed and comfortable, no more worries, no more pressure which forces me to overwork and exhaust myself (Elham, 2).

Elham talked about changes in her life over the course of two years; a change in her social conditions and relationships. Her divorce was a critical incident which was associated to considerable emotional distress and severe back pain. The year after her divorce showed a variation in Elham's experience. She described feelings of emotional content in, a change in her social circumstances where she is not obliged to overexert herself and an elimination of her back pain. It seems like there is an overlap between the dimensions formulated so far. In this case there seems to be a connection between the temporal, emotional, social and physical dimensions. These connections need to be further investigated in subsequent interviews.

Last June, my nephew past away...in a car accident...two months before that we lost his brother in a car accident too...when you lose people dear to you, nothing can fill that place in your heart...my mother and son before that...my brother...those were the most difficult things I went through in my life...the pain in my heart affects my body...my back...my legs...if I carry a box that weighs only two kilograms, I feel burning in my back (Maha, 2).

Maha talked about losing two people who are dear to her since her last interview and associated tragic events of losing several loved ones with emotional pain. She makes an interesting association between emotional pain and physical pain. The interviews carried out so far have revealed a 'critical mass' of dimensions. But I need to collect more data to start elucidating more clearly the variations and similarities across women's accounts, and get a clearer understanding of the social conditions under which changes occur in women's lives, and develop the storyline of how those changes and conditions may affect their experiences with CLBP and their illness identity construction.

Figure 6.12: Analytical memo on the significance of the temporal dimension and its relevance to the other dimensions

\subsubsection{Data collection - Final interviews}

Increasing my theoretical sensitivity was beneficial in further focusing the interview question in subsequent interviews with five women (Fadhela, Abrar, Asrar, Najla, Roqaya) who were theoretically sampled. The objective of those interviews was to focus on the relational nature of women's experiences. In other words, the aim was to explore further how the six dimensions developed interrelated to explain the complexity of CLBP and how women's illness identities were constructed. Moreover, I aimed to contextualise my interpretations of the data, by delving deeper into women's cultural values and ideologies, and how they may have related to their manifestations, thoughts, feelings and behaviours. 
A combination of interview questions developed in the initial and second interview guide (Figure 6.2and Figure 6.11), as well as more integrative questions were used during the interviews aimed at developing the patterns which explain the connections between the dimensions of women's experiences. Examples of some integrative questions are provided in Figure 6.13 below.

Can you tell me about your LBP in the midst of your social roles, your interaction with your friends and family, and your social circumstances? How or where does it fit?

How do your friends and family members make your experience with LBP better or worse?

How do your social roles and responsibilities make a difference to your experience with LBP and how you manage it?

How do you manage your LBP throughout your day-to-day life? How do you integrate this with your social roles and responsibilities? Do your family members and/or friends have an influence?

Why did you decide to change your behaviour at this stage in your life? How did this affect you as a person? Did it make a difference to your behaviour towards your LBP, if so how?

Can you talk about yourself and your LBP before this change occurred? Why did you decide to make this change? How did it impact you?

What does marriage/employment/financial situation mean to you? What is the significance of this to who you are as a person? How does this relate to your experience with CLBP?

Figure 6.13: Integrative interview guide used during final interviews

\subsubsection{Data Analysis of Final Interviews}

I began to decipher the social and relational nature of women's emotional experiences. As deeper analysis of the emotional dimension progressed, the ways women's emotional expressions were construed in relation to others' expectations and behaviours towards them became apparent, and were associated with their illness. The unravelling of these associations is demonstrated in an excerpt from an analytical memo in Figure 6.14. 
Even if I go [to the hospital]... as long as I am uncomfortable, there's no point in having treatment...treatment is treatment of the self more than anything else...I know all the pain and tiredness I feel is because of our man [husband]...when he travels I feel like a different woman, I feel fresh and pain free, I feel like my self is comfortable.

Fadhela talks about her self-discomfort in relation to her marital relationship and periods when she is in pain. She endorses this association by referring to periods in her life where she is distant from her husband to herself being comfortable and happy, and to a reduction of her pain.

My daughters are more than my daughters...they are my friends...they are my dear friends...they are a blessing and they make me love my life, they are my source of happiness, they motivate me to hang in and never give up...I love living with them...I hang in for them and for their children...because they are happy to have me in their lives...this is the secret behind me holding onto this life and not allowing illness to win...I won't give up...I don't grow weak for anything...because I love my life...I want it.

It is apparent from Asrar and Fadhela's comments that how women felt about themselves was associated with how others behaved towards them and perceived them. Fadhela's quote suggests that others are unsupportive and unempathetic; this is associated to self-discomfort and pain. Another interesting aspect of Asrar's comment is how she associated her strength and her incentive to take an assertive approach to manage her pain to the love she receives from her children. I need to explore further how others' impacted women's illness behaviours, but it seems to me that women described themselves in terms of their 'selffeelings'. I need to investigate further what other components were included in women's manifestations of self or identity construal.

Figure 6.14: Analytical memo raising emotional dimension to perspective

At this stage, the constant comparative method of analysis was particularly useful. I compared and contrasted sets of data with each other, looking for similarities and differences in women's actions, interactions, feelings and experiences within the data generated from the same participant and between data generated from different participants (Charmaz, 2006). Raw data was included in the process of memoing to keep the participants' voice in the theory (Charmaz, 2006).

Following the leads from the previous analytical memo in Figure 6.14, I revisited the transcripts from the initial and follow-up interviews to compare these with the final interviews and to explore if there were variations or similarities in how significant others and people they interacted with influenced their self-feelings or behaviours. An excerpt from an analytical memo with interpretations from Salwa's account follows to demonstrate this in Figure 6.15. 
I was not comfortable at all during that period of my life when I was living with my husband's family while he was abroad...I was forced to do a lot of housework... and I was pregnant...in the year and a half I lived with them...I got the pain...my husband wasn't with me... and three of his brothers interfered with my life...they would dictate when I am allowed to leave the house...no one would say you should rest you are pregnant...I don't like talking about that period of my life...but I feel in that year and a half my back pain was at its worst...I wasn't comfortable...I was under pressure.

Similar to Fadhela, Salwa associated her self-discomfort to her CLBP. It seems that the discomfort she felt was associated to a lack of self-agency during that particular period of her life.

I became pregnant with my second daughter... and had caesarean...and a week after I gave birth I threw a dinner...because I was comfortable during that pregnancy...I ate what I like...I rested when I needed to...you may not believe it...but in my second pregnancy I did not feel any back pain.

Salwa refers to another period of her life here. She associated her self-comfort to the choices she was able to make while she was pregnant - in other words, Salwa had relatively more agency during this period of her life. This period of her life was associated to remission of CLBP. It seems that the temporality of Salwa's experience was associated to changes in levels of agency she perceived at various stages of her life. What factors influenced the temporal dimension of other women's experiences?

I'm blessed with caring daughters and a husband...sometimes I forget and just as I am about to carry something heavy my eldest daughter reminds me not to and helps me...if it wasn't for their care...I wouldn't have taken care of myself... I would have neglected my health and back...I would have done something to aggravate my disk again...it is thanks to them that I have improved.

Again, similar to Asrar, Salwa associated her initiative to take care of her back to the care she perceived from her family members. She suggests that if she did not have this care in her life she would have neglected her health. This brings me to the social dimension I formulated.

Some women perceived others in their lives to be supportive and empathetic, and others unsupportive and inconsiderate. What happened if women perceived a lack of support and care from others? How did that impact their behaviours?

Figure 6.15: Analytical memo demonstrating the constant comparative method of analysis

Following the leads in the previous memo, I compared other women's accounts to investigate if they had varying perspectives on the support they perceived from others in their lives, and how this may have influenced their self-construals and illness experiences. Moreover, Salwa's account portrayed a pattern explaining the temporal dimension of her experience. Changes in her self-feelings and manifestation of CLBP were associated with the levels of self-agency she perceived at various periods of her life. These patterns were compared and contrasted with the accounts of other women, to explore their resonance in the data. An excerpt from an analytical memo interpreting Elham's accounts demonstrates this process in Figure 6.16. 
The pressure I was under before [divorce] is what led to all the catastrophes...it was what affected my body...it effected my legs...it effected my bones... what happened to me was the consequence of the challenges and tiredness I faced in my life.

Similar to Salwa, Elham associated a time when she was under pressure to the physicality of her pain. Her association was so explicit that she suggested that the social hardship she experienced caused her pain.

I was under more strain than my body can handle...I was an employee...helped my daughters with their homework... attended to their needs...bought everything they needed...took care of my house...it wasn't easy...I was under pressure and I was tired...it was exhausting...I felt my knee meniscus were completely worn out... and the same for my back...there was so much heavy work to be done...cleaning behind sofas...under rugs.

Elham associated the pressure and exhaustion from her social responsibilities to her CLBP. Throughout her interview, she suggested that her spouse imposed the domestic and child caring roles on her, without providing any support. Why did she feel obliged to adhere to his impositions despite the exhaustion, pressure and pain she was under? How was this different for women that perceived reciprocity in their marital or social relationships?

At this point [after settling the divorce in court] I felt steadiness in my life and in my self...my blood pressure is steady now... I comforted my body from the heavy work I used to do... after my last physiotherapy session a year ago...I have not experienced back pain again...even my knee stopped hurting even though I have a meniscal tear...I only do the work my body can tolerate...I run the errands that I can tolerate...my daughters are free...they can go out and buy what they need...they weren't allowed to so before...I calm and content.

Elham talks about a period in her life when an integral change in her social conditions occurred. She associated self-steadiness to remission of her CLBP. In contrast to the period of her life prior to the divorce, this period is characterised by self-agency and freedom. I think this pattern is an integral one and has been recurrent in women's accounts. Perceiving self-agency is associated to positive self-feelings and to remission of CLBP. Perceiving a lack of self-agency is associated to negative self-feelings and an exacerbation of CLBP. The temporal dimension of women's experiences seems to be portraying transitions that are characterised by a change in the levels of agency women perceive at various periods of their lives. Those transitions seem to be intermeshed with the fluctuations in women's pain throughout their illness trajectories.

Figure 6.16: Analytical memo elucidating patterns in the data through the constant comparative method of analysis

As the associations and patterns between the dimensions started to become apparent, I realised that it was necessary to start making sense of these associations, similarities and variances in the data in line with my research question. The literature theorising the concepts of self and identity was helpful to increase my theoretical sensitivity and to enable me to integrate the components of women's identity construals. Wetherall's (2009) notion, which suggests that identity is how people locate themselves and make sense of their biographies and trajectories and tell their stories, was particularly useful to help make the patterns and associations I was unravelling more concrete. I realised that women's stories were made up of several dimensions that defined their identity. Woodward's (2004) suggestion that identity construction is a process which involves how we perceive 
ourselves and how other's perceive us, was useful for me to understand why women in this study constantly referred to others' in their lives, and how social interactions and the expectations of others influenced their identity construction. Woodward (2004) also suggests that the extent to which we shape our identities varies, and this led me to scrutinise the concept of agency that was apparent in women's accounts. Increasing my theoretical sensitivity was helpful in enabling me to see the theoretical possibilities in my data in relation to the impact of the social structure on women's identity construals.

Revisiting the data I was able to more clearly see the distinctions and commonalities in the identity construals that women portrayed. I formulated a grid where one excerpt represented the different identity construals that seemed apparent in the data, and started rearranging the dimensions and properties I generated to distinguish the characteristics of each identity, and this is illustrated in Figure 6.17 below. 


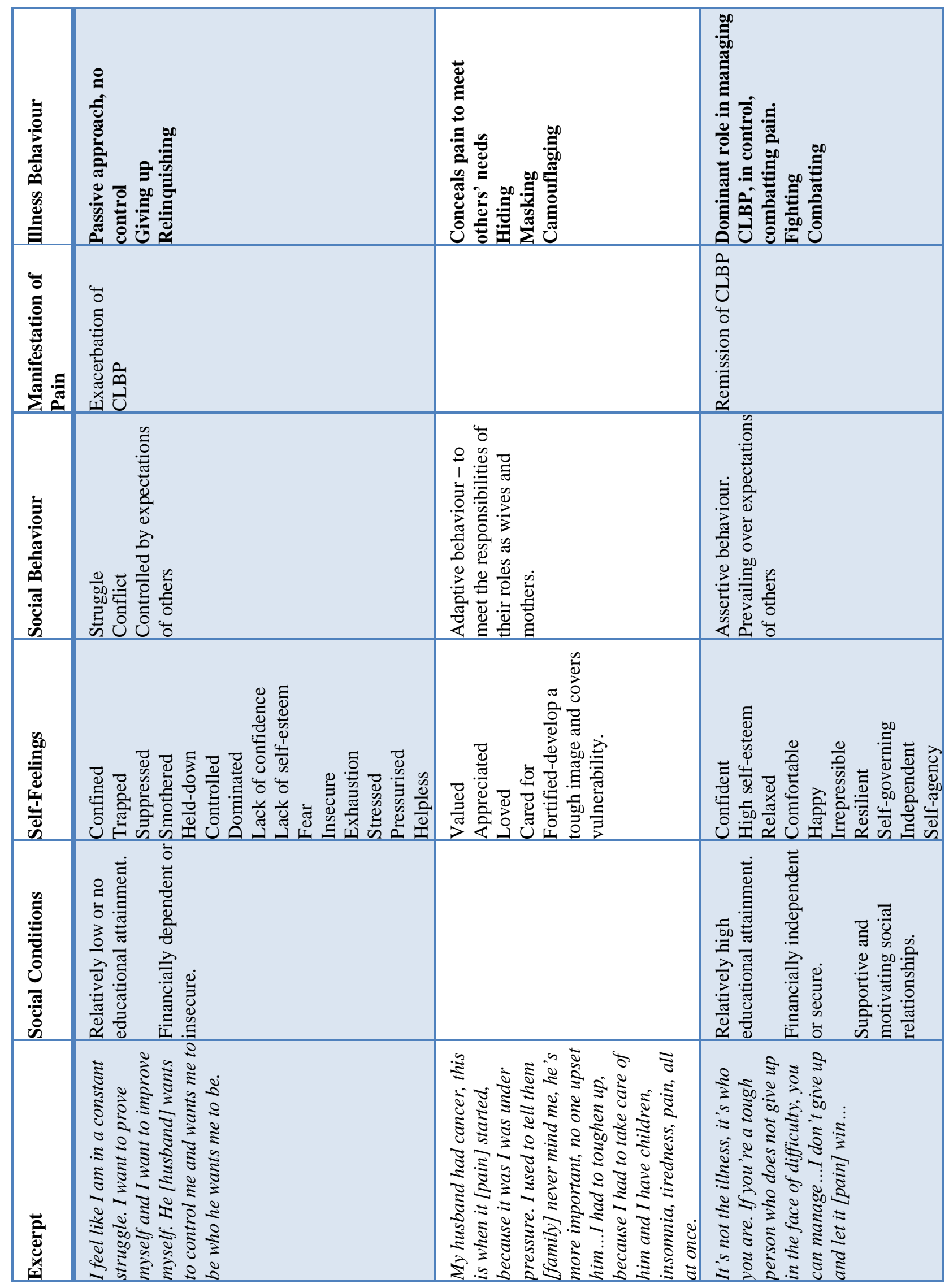

Figure 6.17: Defining the characteristics of women's identity construal 
Formulating this grid highlighted that there was a pattern associating women's social conditions, self-feelings and social roles and behaviours to their manifestations of pain and their illness behaviours. The majority of women that had participated were relatively older and had relatively lower levels of educational achievement. Therefore, three younger women, and women with relatively higher levels of formal education (Fatimah, Roqaya, Najla) were theoretically sampled to more deeply explore how these conditions influenced women's identity construals and illness experiences. Moreover, these women were theoretically sampled from a private hospital to further explore how variations in financial situations may influence women's experiences (refer to Table 6.1). Finally, three women were also recruited through snowball sampling (refer to Table 6.1). The majority of women were recruited at a time when they were receiving treatment for their pain. Therefore, snowball sampling was beneficial in recruiting women at various stages of their illness trajectories who were not receiving treatment at the time of their interview, to explore how their accounts may vary and why.

The data analysis from women who were theoretically sampled further developed the three social and illness identities generated in this study. Recruiting relatively younger women, and women with a higher educational attainment, illuminated how variations in social communities, cultural understandings, and societal expectations impacted on the resources and levels of support available to women. Theoretically sampling relatively affluent women from a private hospital enabled me to compare how variations in human and material resources available to women impacted on their feelings and thoughts about their identity and behaviour. Sampling four women one year after their initial interview (Eman, Manal, Tahani, Salwa) and women at different stages of their illness trajectories (Asrar, Abrar, Fadhela), clarified the temporal dimension of women's experiences and how their feelings, thoughts, manifestations of pain and behaviours varied across time. 
As the theory developed through a cycle of immersing myself in the data, constant comparative analysis, and engaging with the literature, I frequently checked my ideas and hunches by informally talking to the women I interviewed. Diagramming was useful to help me visualise the relationships and connections between the dimensions, and to give different dimensions 'a conceptual opportunity to be elevated to the status of perspective' (Kools et al., 1996, p.319) in order to determine the central dimension.

\subsubsection{Finding the Central Organising Dimension and Integration}

After testing each dimension as perspective and explicating their properties, the central organising dimension needed to be determined. The aim at this stage of analysis was to produce an integrated theoretical story (Kools et al., 1996), which explained how women's identity construals developed and changed over time. My hunch was that the temporal dimension, which showed the fluidity in women's experiences, was central to explaining the processual nature of women's identity constructions.

While I had an idea about what my theory was about, it was challenging to articulate what it was trying to explain coherently, and to avoid the risk of formulating a descriptive account rather than a conceptual GT (Cutcliffe, 2005). Unravelling the central organising dimension was crucial to enable me to organise the data and form a conceptual theory, and to ensure it had explanatory power rather than merely being descriptive.

Several re-writes of the storyline enabled me to apply the theoretical sensitivity I had gained from engaging with the literature during the data analysis process. This helped to develop the explanatory power of the developing theory (Birks \& Mills, 2011). The storyline and explanatory matrix were continuously revised, and this involved grouping the dimensions generated in the analysis with their analytical memos and raw interview data in which to ground the theoretical constructs developed. During this prolonged process when I was moving between establishing the storyline and engaging with the data 
and the literature, the concept of 'biographical transition' was developed (refer to Section 8.2), which was selected as a grounded perspective from which to explain the theory (Schatzman, 1991). By engaging with the literature around biographical disruption and transitions in chronic illness (Bury, 1982; Williams, 2000; Kralik, 2002; Kralik et al., 2006), I began to view the data and theory through these theoretical perspectives. These perspectives enabled the theory to be brought together, and provided an order to all the dimensions, which was helpful in explaining the variations in the salience of the women's social identities and illness identities across time.

I explored the social conditions under which women's identities developed and investigated the impact of the social structure in which women lived on the variations in their conditions. This in turn generated new dimensions and properties which explained the impact of cultural variations and understandings in Kuwaiti society pertaining to women's social conditions, behaviours, identity construal, and illness experiences. This process helped move the central organising dimension to theoretical sufficiency, meaning that all aspects of the theory could be effectively explained and variations in the data were accounted for.

Figure 6.18 portrays an early representation of the process of biographical transition in an explanatory matrix. The explanatory matrix was further developed and populated with data, and this shaped the early storyline drafts of the findings which are presented in Chapter 7. Writing moved from integrating abstract concepts from theoretical memos; they were supplemented with evidence from the data, which is presented in the following chapter. 


\section{Biographical transitions}

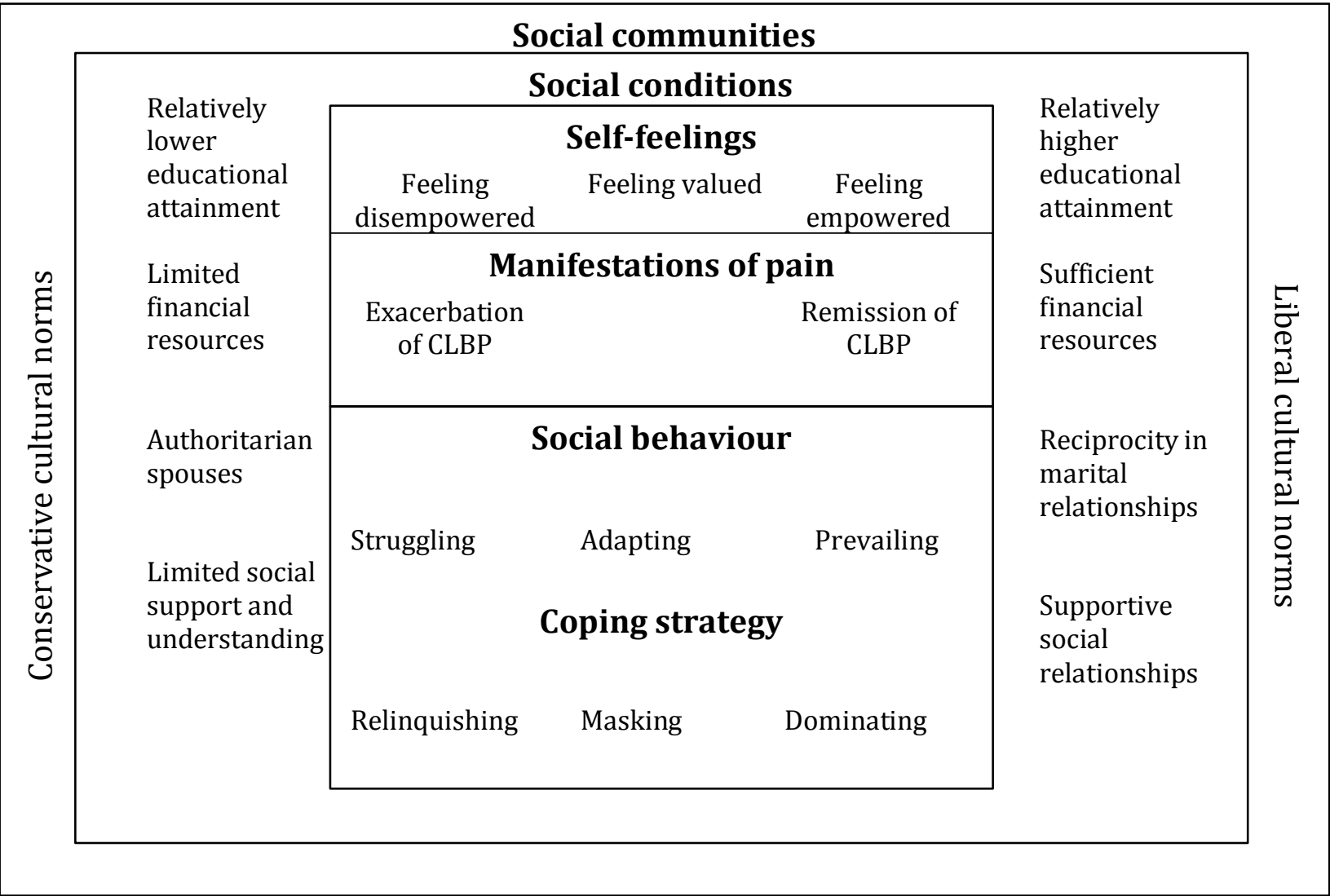

Figure 6.18: Early experimentation with the explanatory matrix to portray the process of

\section{biographical transition}

\subsection{Conclusions}

This chapter has presented the rationale behind the methods utilised for the data collection and analysis processes in this study. The characteristics of the women who participated and the process of their sampling and recruitment have been clarified. Furthermore, the chapter has detailed the development of the interview guides, and the interview techniques adopted during the data collection process. The data was analysed using the DA approach, which utilises a constant comparative method of analysis and memo writing throughout 
the process of analysis, and theoretical sorting, as well as theoretical sampling in order to explicate the dimensions and their properties.

This chapter and the previous one provide an audit trail, demonstrating how a theory which provides an understanding of the construction of illness identities in women with CLBP has been constructed. The next chapter uses the explanatory matrix introduced in this chapter to propose a substantive theory grounded in evidence from the interview data. 


\section{CHAPTER 7 - FINDINGS}

\subsection{Introduction}

This chapter presents the findings of this study. The constructed theory is process-based, and each aspect is supported by excerpts from participants' interview data and serves as supportive evidence for the theoretical claims made. Excerpts were selected to ensure there was variation across study participants. At times, an excerpt was selected as representative of a particular theoretical claim. In other instances, several excerpts were provided to display major variations or minor nuances in women's experiences in relation to a specific theoretical construct. The chapter commences by introducing participant's backgrounds to provide context to the findings of this research. Subsequently, the substantive theory of 'biographical transitions' will be presented in the following way. The theory commences by explaining variations in women's social conditions, and goes on to

present three distinct social identities, which characterised women in this study. It continues to clarify women's history with CLBP, and the associations between their illness experiences and the salience of various social identities over the course of their lives. Then, three distinct illness identities are presented, and the association between women's social identities and illness identities is explained. The chapter presents the central dimension of 'biographical transitions', to clarify the variations in and associations between women's life and illness trajectories.

\subsection{Participants' Background}

There was considerable variation in the age, levels of education, working situations and marital status of women in this study. Amongst the older women who participated in this study, the highest degree attained was a bachelor's degree by Asrar. Educational levels were as low as secondary school in the case of Maha, and Tahani was illiterate. Amongst 
the younger women who participated in this study, the lowest degree was a high school diploma in the case of Salwa. Noura and Roqaya had both obtained a bachelor's degree, and Najla had obtained a master's degree. Fatimah was still pursuing her university education. In regards to employment, three women were employed (Noura, Roqaya, Najla), four were retired from paid work (Fadhela, Asrar, Abrar, Elham), three identified themselves as housewives (Tahani, Maha, Salwa) and one was a student (Fatimah). Since the majority of older women (Fadhela, Maha, Abrar, Tahani) had relatively lower levels of educational attainment or no formal education, they worked in relatively lower status occupations, including secretarial and clerical work. On the other hand, the majority of younger women (Najla, Noura Roqaya) had relatively higher educational qualifications, enabling them to pursue relatively higher status occupations including engineering and nursing. Women's marital status varied. The majority were married (Fadhela, Maha, Abrar, Tahani, Salwa, Fatimah), one was divorced (Elham), one was widowed (Asrar) and three were single (Najla, Noura, Roqaya). Women in this study lived in various regions in Kuwait. The majority of women lived in the Hawali governorate (Tahani, Najla, Salwa, Noura, Roqaya), three lived in Al-Farwaniya (Fadhela, Elham, Abrar), one in Al-Asimah (Asrar), one in Mubarak Al-Kabeer (Maha) and one in Al-Jahra (Fatimah). Table 7.1 summarises participants' age, educational level, occupation, marital status and the region in which they live. 


\begin{tabular}{|c|c|c|c|c|c|}
\hline Participant & Age & $\begin{array}{l}\text { Educational } \\
\text { Attainment }\end{array}$ & Occupation Status & $\begin{array}{l}\text { Marital } \\
\text { Status }\end{array}$ & Region \\
\hline Fadhela & 65 & $\begin{array}{l}\text { Secondary } \\
\text { school }\end{array}$ & $\begin{array}{l}\text { Retired clerical } \\
\text { worker }\end{array}$ & Married & Al-Farwaniya \\
\hline Asrar & 64 & $\begin{array}{l}\text { Bachelor's } \\
\text { degree }\end{array}$ & $\begin{array}{l}\text { Retired social } \\
\text { worker }\end{array}$ & Widowed & Al-Asimah \\
\hline Maha & 51 & $\begin{array}{l}\text { Secondary } \\
\text { school }\end{array}$ & Housewife & Married & $\begin{array}{l}\text { Mubarak Al- } \\
\text { Kabeer }\end{array}$ \\
\hline Elham & 50 & Certificate & Retired secretary & Divorced & Al-Farwaniya \\
\hline Abrar & 49 & Diploma & $\begin{array}{l}\text { Retired assistant } \\
\text { accountant }\end{array}$ & Married & Al-Farwaniya \\
\hline Tahani & 47 & Illiterate & Housewife & Married & Hawali \\
\hline Najla & 32 & Master's degree & Engineer & Single & Hawali \\
\hline Salwa & 28 & $\begin{array}{l}\text { High school } \\
\text { degree }\end{array}$ & Housewife & Married & Hawali \\
\hline Noura & 26 & $\begin{array}{l}\text { Bachelor's } \\
\text { degree }\end{array}$ & Teacher & Single & Hawali \\
\hline Roqaya & 26 & $\begin{array}{l}\text { Bachelor's } \\
\text { degree }\end{array}$ & Nurse & Single & Hawali \\
\hline Fatimah & 22 & $\begin{array}{l}\text { University } \\
\text { student }\end{array}$ & N/A & Married & Al-Jahra \\
\hline
\end{tabular}

Table 7.1: Summarising women's social conditions

This chapter refers to women's educational attainment, occupational status, marital status and region in which they live as their 'social conditions' (Table 7.1).

\subsection{Self-Feelings}

Variations in women's social conditions impacted how they viewed and felt about themselves, or their self-feelings.

Those perspectives and feelings will be explained in relation to:

- Educational attainment and occupational status

- Marital and family support

- Social communities and norms

\subsubsection{Educational Attainment and Occupational Status}

Four women had little or no formal education (Maha, Elham, Tahani, Fadhela). Those women were all among the older generation of women in this study. The comment below illustrates women's perceptions regarding a lack of access to higher education: 
I would have studied, gotten a degree...I wouldn't have thought of getting married until my degree was in my hands and I have developed myself well... a degree gives you valuable knowledge... it helps you manage your life and deal with people...you don't always feel like people are ruthless like wolves like I feel now. (Fadhela)

Fadhela reflected on the ways a degree would have enabled her to develop her status and confidence. Referring to people as ruthless and wolves emphasised the vulnerable, or disempowered position she felt she was in relation to others.

The feeling of disempowerment was also tied to financial income. The following comments illustrate the various ways in which limitations in income influenced women's self-feelings:

My job didn't pay very well ... and after I retired I only received a small retirement pension... and he [husband] insisted I give him a part of my salary each month...I used to think of investing in a property...but I feared that he [husband] would find out...it's his house [the one she lives in]...I feared that he would have made me quit my job [if he found out] ...how would I have managed the loans? (Fadhela)

Due to the lower levels of educational attainment and occupational status, or limited human resources, Fadhela's income was relatively low. The fact that her husband took a part of her salary suggests she had a lack of access to the household income. Both factors caused significant limitations in material resources available to her. Moreover, she was dependent on her spouse for shelter. Low human and material resources as well as dependence were associated with feelings of fear and insecurity. Feelings of fear and insecurity stood in the way of Fadhela's aspirations to develop her social status through investment. In the following, Tahani explains how a limited income made her feel:

Their [her children's] father is a driver and transports water to farm areas for a living. He does not have a proper job with a fixed income, and you know, rent, living expenses, schooling expenses...fear...fear. I am afraid of everything, thunder, lightning, everything frightens me...my blood pressure goes up and my body shakes and trembles...I am not sure how to explain how I feel...even slight dust and wind scares me. I always fear the house will collapse, I feel my room is going away. I wake up from my sleep, my heart pounds; I put my fingers in my ears so I don't hear the thunder. My daughters read Qur'an over my head, my 
husband tries to comfort me, my younger children tell me it will be OK, even the little kids are not afraid, but I am...fear...fear... (Tahani, 2)

Tahani had no formal education and therefore no source of personal income. While she had access to household income, it was limited. Limitation in household income was related to insecurity, where she feared losing familiar spaces and objects that she identified with. Fadhela and Tahani's comments illustrate that limitations in both personal and household income were associated to feelings of fear and insecurity, and limited opportunities for women to develop themselves. Moreover, those feelings were associated with corporeal ailments described as 'body shakes', 'trembles' and high blood pressure.

In contrast, five other women were well educated and financially secure, and with the exception of one (Asrar), were all from a younger generation (Najla, Noura, Fatimah, Roqaya,). The following comments illustrate the benefits women perceived from their education:

One of the most important goals in my life is to graduate with my engineering degree, things are not the same today as they used to be for our grandmothers. I have to depend on myself not on my husband or anyone else, and a university degree is an asset which will allow me to do that. (Fatimah)

I chose this profession [nursing] because I was very interested in it...I liked the idea of working in the medical field, plus you get to build a relationship and have a connection with your patients, and you get to do something good for people, so if you make people feel good, you will feel good about yourself, that's how I feel... It is extremely boring to sit at home and do nothing. It is good to feel that you are an active member of society and contributing to it. (Roqaya)

Fatimah suggested that a university degree is an empowering asset, which enabled her to depend on herself. Roqaya associated her professional degree to being an active member of society. The comments above suggest that women regarded education to be an asset which ensured independence; also, being an educated professional is associated with a positive self-image. The following comment demonstrates how education was associated to being financially secure: 
I don't need a husband to cover my expenses, as I have my own salary. I don't need him to provide me with shelter, I have a whole level in our house built specially for me to live in. I travel whenever I feel like it, alone sometimes. I can support myself, as I am an engineer. (Najla)

Najla perceived herself to be independent on account of her high levels of education and income. The comments above suggest that sufficient human and material resources were related to feelings of security and independence.

For two women (Salwa, Abrar), limitations in their personal income did not elicit negative feelings. The following comment illustrates an alternative perspective:

He [husband] is very generous. He does not leave me ever needing anything, the allowance he provides is always enough, he covers all the household needs, he is very compassionate and always tender and kind with his words and ways...I used to be shy to tell him whenever I liked a dress or something, so he would say, I will always leave money in your wallet so you can buy whatever you like whenever you feel like it. (Salwa, 2)

Salwa had relatively low level of educational attainment, and identified herself as a housewife. While she had no source of personal income, her husband provided her with financial support which made her feel valued and cared for.

In summary, variations in women's social conditions; namely their educational attainment, occupational status and financial situations, influenced their self-feelings in different ways. The majority of older women had limited educational attainment and income. A lower level of academic achievement was associated to a lack of self-confidence and a perception of being in a disempowered social position. Moreover, lacking access or having limited household income impeded women's attempts to improve their social status and led to feelings of insecurity. The majority of younger women were well educated and financially secure, which reinforced positive feelings and self-image, including independence, security and being active members of society. Finally, when personal income was limited, sufficient amounts of household income made available to women by their spouses made them feel valued. 


\subsubsection{Marital and Family Support}

Women's self-feelings were also impacted by their position in social relationships, and how significant others perceived them and behaved towards them. Of the four women who had limited education and income, and were dependent on their spouses, three were married (Maha, Tahani, Fadhela). One woman was divorced (Elham); however, she emphasised the impact her marriage had on her life. The following comments demonstrate the impact of a lack of marital and family support:

House duties can be more difficult than office work. I spent three months without any help in the house, I wash, I clean, I cook, all the children are in school [she has 13 children]. Girls these days don't help their mothers...I needed to ask at least 10 times if I wanted a glass of water, my husband too. Men in Kuwait show no cooperation, no way would a man help his wife in house duties, but this is not right. He [husband], suffered from a stroke in his eye, and he has diabetes, and I organised his medications in a box, each slot had the pills he needed to take for the day. All he has to do is get the box but he insists I bring it to him, I don't understand why, I don't know if it is lack of appreciation or lack of respect. (Maha, 1)

There was tissue on the floor, he [husband] said something painful that left a mark in my heart. He said get up and pick the tissue off the floor, being sick [she was recovering from a miscarriagel is not an excuse to leave our house dirty...Couldn't he wait and say something supportive to help me get well? Our man [head of the family] is not the type that makes you feel he is by your side when you need him, no no no... (Fadhela)

I was an employee, I would come back from work, cook lunch, clean the house, provide what we needed at home, buy groceries, attend to what the girls needed, all the responsibility was loaded on me, and that really exhausted me... We have reached a stage, me and my daughters, where we do not have a husband or father, because he decided not to be a part of our lives. (Elham, 1)

Women were expected to fulfil the domestic role in their marital relationship, irrespective of their state of health. Role strain and overload were experienced when familial responsibilities were combined with occupation-related stress. The comments illustrated that a lack of social and emotional support from family members, and spouses taking an authoritarian approach in marital relationships, were associated to women feeling 
unappreciated, disrespected and hurt. Being obliged to carry out household duties, despite feeling ill, tired and exhausted, made them feel disempowered.

Women who were well educated and financially secure demonstrated a contrasting perspective about the support they perceived in familial relationships. Moreover, the majority were among the younger generation of women in this study: one was married (Fatimah) and three were single (Najla, Noura, Roqaya). One of the women was relatively older (Asrar), and while she was a widow, she emphasised the support her late husband provided. The following three comments represent those women's perspectives on the support they received from social relationships:

My family has been very sympathetic...they spoil me so much now... more than they used to...So although I have a problem, I get to enjoy the extra attention and compassion now. This has motivated me to move beyond the depression I felt and to move forward in my life and career. (Noura)

My husband left the house and never came back [passed away in hospital after a car accident]...till when should I cry...? Should I give up or raise my children? Should I feel sorry for myself and cry and give up? I had children who needed me...they needed someone to be there for them...to help them with their homework...to make sure they make it to university...they needed someone who is tough...We have a strong bond, we love each other, the father loved his daughters, loved me, we are a family who is understanding towards one another's needs...That helped me stay strong, and to continue the path me and their father started...I stayed strong because they love having me in their lives, and I love being a part of theirs. (Asrar)

The support provided in familial relationships led to feelings of motivation and enabled Noura to surpass a negative emotional state and continue to progress in her life and career. Asrar related her ability to be tough on account of the love she felt from her children and from her late husband. In other words, women owed their ability to move past a negative emotional state to the emotional support they perceived from family members and the reciprocity and affection in marital relationships. The comments above suggested that emotional support perceived in familial relationships enabled women to replace negative feelings such as depression and grief, which put the self in a state of disempowerment, 
with positive emotional states including motivation, and positive self-views of being empowered. Moreover, family support helped women utilise the human resources available to them, such as their careers, to develop themselves and progress in their lives.

While the four women (Maha, Tahani, Elham, Fadhela), who perceived a lack of support from their husbands, associated their emotional burden to their domestic role, two women (Salwa, Abrar) offered a contrasting perspective to this role:

My husband respects me...he relies on me... without me he would be lost... and my children respect me too, In 2007 my husband had colon cancer, in this period I started feeling very tired, because I had to take care of him, but every time someone asked me about how I was doing, I would say: don't worry about me it doesn't matter how I feel, his feelings are the most important thing. I was very protective of him, making sure no one said anything to upset him...it was a turning point, I had to make my heart tough, because I had to take care of him, and I have children. I have to take care of everybody...exhaustion, insomnia, everything together...This is my life now, so I have to change from the inside, I used to be very sensitive, I used to like listening to poems...that's all gone now...I have changed...toughened up...I don't talk much anymore... always quiet... as the days and years pass by, you have to change... (Abrar)

I started reconsidering and thinking...why be stubborn? Why should I ruin my life?...When I started to do the things his way...he started to respect me more.... and that is what let me go along with his ways happily...and I feel what has made my life a success is listening to my husband and doing things his way. (Salwa, 1)

Feeling valued and needed by family members led women to put the needs of family members over their own. Abrar hid or put her own feelings aside, and altered her personal habits and emotional needs to adapt to and cope with her social situation and relationships. Salwa altered her behaviours to ensure that they matched her husband's desires and expectations. The comments above suggest that emotional support in familial and marital relationships made women feel valued and in turn reinforced their acceptance of prioritising their domestic and child caring duties over their personal needs and desires.

Overall, being surrounded by social and emotional support endorsed women's self-worth and made them feel empowered and valued. Those conditions encouraged women to 
increase their human and material resources and utilise them to build their independence, self-esteem and other aspects of self-development. On the other hand, a lack of social and emotional support lowered women's self-esteem and led to feelings of disempowerment, which impeded their aspirations for improving their educational attainment and material resources for self-development. This illustrates how women's self-feelings and views were constructed in relation to the resources they possessed or had access to, as well as how significant others perceived them and behaved towards them.

\subsubsection{Social Communities, Networks and Social Norms}

Women in this study lived in various regions in Kuwait (refer to Section 6.2). They lived and worked in different social communities, where people conformed to various social norms and cultural attitudes. Social norms and the expectations of people in their immediate communities influenced women's sense of self or self-feelings. Moreover, women's social conditions - their educational attainment, occupational status, financial situations, and the ways their family members perceived them and behaved towards them may have been influenced by their communities and social norms people surrounding them conformed to. In the following, Najla explains how judgments from people in her social community made her feel about herself:

It is a good thing [how she was raised], but it is making me very independent. I can do everything myself. One time a guy proposed to me and said you are too strong I can't live with a lady like you, I want to marry a girl who needs me, I don't feel like you are in need of a man...My younger sister does not know how to take care of herself and she got married...is the flaw in me? (Najla)

Najla perceived herself to be independent. However, she viewed her independence as a disadvantage due to the expectations of a man who proposed to her. Viewing her strength as detrimental to being an eligible wife compromised Najla's self-esteem, where she questioned her self-worth and considered the possibility of being flawed. In other words, people in Najla's community conformed to conservative norms, which associated 
femininity to dependency and docility, leading her to question the value of being independent. In the following comments, Najla explains how she felt about being single:

I have experience with children, I helped raised my younger siblings, and my brother and his children live with us, my sister too, but when I talk they [married women] tell me, what would you know, get married and have children first, then you can talk...These words hurt me from the inside, so I don't like socialising...My close friends make me feel like I am inferior because I am not married. I hate that, that's why I stay away from people. (Najla)

Women surrounding Najla viewed being single as a detriment. In Najla's community, a woman was given relatively less credibility if she was not married. Their views endorsed feelings of inferiority and emotional pain. This illustrates that for women in the conservative community Najla was living in, social acceptance was associated to their marital and childbearing roles. Najla was excluded from participation in social activities because she was different. The stigmatisation that others imposed on Najla for being single and independent aggravated negative feelings about who she was:

I am thirty two [years old] now, I am not married, I don't have anything to do. OK, I set up my own little business to keep me occupied, but still there is a lot of emptiness in my life. I become tired because I think a lot about the future, that I have to get married, I have to have children so that they can take care of me when I am older, my parents will not be there for me forever, all those things are on my mind 24/7, and I know that is not healthy... I feel my life is on hold, like it has stopped. I graduated, I worked, I got my master's degree, OK, now what? My life is not moving forward, it's not evolving... I feel lonely, it is not the life I wanted for myself... When a woman has a husband and children she has everything she needs in this world, her motherly instincts are satisfied, and her intimacy desires are satisfied. (Najla)

While Najla stated her personal attributes, namely her business, her job, and her postgraduate degree, she did not portray those attributes and events as achievements or positive self-attributes. On the contrary, she felt tired, lonely, and empty and felt a lack of progression in her life, because she was not married and was not a mother. Being denied social acceptance by married women and being rejected as an eligible wife led to feelings of inferiority and lack of self-worth. This illustrates that women's negative and 
disempowering feelings were shaped by a consideration of social norms and the judgment of others who conformed to those norms.

In contrast, Fatima demonstrated how the social ideologies her brothers conformed to were associated with a positive and empowering emotional state and self-view:

I was raised differently [to her sisters], I had choices they did not have. I did not see my husband [before marriage], but my brothers took my opinion in the matter...my sisters were married off by my father immediately after high school and they had no say in them matter...I am different, I went to university, I got to state that I want to continue my studies even after marriage. I was entitled to a lot of choices my sisters weren't, that gave me self-confidence that they don't have. (Fatimah)

While Fatimah lived in a conservative community, which restricted women's choices and autonomy, her brothers did not conform strictly to such values. She did not meet her husband before marriage; however, she still perceived that she had a choice in the matter. Her brother's consideration of her opinion on whether or not she was ready to marry, her stating conditions regarding her marital arrangement and comparing her situation to that of her sisters made Fatimah perceive that she had some control over her life decisions. In addition, her brothers' support helped her pursue her education. Fatimah related those factors to feeling confident. In the following comment, Roqaya demonstrates how her family raised her and her siblings:

There wasn't much responsibility on my eldest brother because my sister had a stronger personality, so most of the responsibility was put on her [by her parents]; we would go to her whenever we needed anything. (Roqaya)

Roqaya stated that her parents delegated more responsibilities to her elder sister on account of her strong personality. Roqaya was raised in a household, which reinforced the characteristics of strength that young women possessed. Fatimah and Roqaya's comments demonstrate that women's perspective of choice or self-agency was relative and was constructed in relation to the social understandings of people surrounding them. Moreover, living in a community with liberal norms, which encouraged women to be strong and self- 
governing, elicited positive and empowering emotional states, reflecting how they felt about themselves.

As well as living in communities in the Kuwaiti context, being exposed to other social contexts was influential on women's sense of self. Asrar lived with her husband in the UK, while he was studying for his master's degree; she explained the impact this experience had on her:

Living abroad, distant from your family, toughens you up...I was a spoilt child...my mother spoilt me...I depended on myself when I was abroad...I had my first daughter...I didn't have anyone with me...how was I going to take care of this child? Wash her? Feed her? I learnt...I raised my child...I depended on myself...I went out...took care of formalities and procedures such as rent and bills...I took care of responsibilities I never took care of here [in Kuwait]...I learnt how to deal with formal organisations ...things I never learnt...Those skills helped me a lot when my husband passed away. (Asrar)

Asrar suggested that living abroad toughened her up because she took sole responsibility for matters, which may have been shared with her family in Kuwait. This implies the interconnected nature of family life in Kuwait, and explains the significant impact of family relationships on women's self-feelings. Moreover, Asrar related her experience to attaining skills, which enabled her to deal with the loss of her husband. Embracing alternative cultural norms was associated with gaining independence, which she described by her ability to raise her child on her own, and to deal with responsibilities pertaining to the public sphere.

Overall, the social community women lived in and the social norms people surrounding them abided by impacted their self-development and self-feelings. A community with conservative norms, which associated femininity to submissiveness and domestic roles, created boundaries that women who affirmed themselves with strength and independence did not fit into. This aggravated negative and disempowering feelings about who they perceived themselves to be, impeding their desire to develop themselves through high levels of educational attainment, occupational status and personal income. Living in a 
community with liberal social norms, which encouraged feminine strength and independence, supported women who identified themselves through such attributes, and reinforced positive and empowering feelings about who they were. Moreover, being surrounded by people who conformed to liberal norms provided women with the support to develop themselves through higher education.

Women's feelings lay on a continuum between feelings of disempowerment and feelings of empowerment. Their self-feelings were shaped by the human and material resources had access to, support they perceived from social relationships, and the social norms they were accustomed to which impacted the manner in which they were judged by others. Living in social conservative communities, which endorsed female dependence and docility, impeded women's attempts to develop themselves educationally and financially, and encouraged spouses' authoritarian approach in marital relationships, leading to negative and disempowering self-perceptions and feelings. Living in liberal social communities, which endorsed female strength and independence, fostered mutuality and reciprocity in familial and marital relationships. This encouraged women to develop themselves by pursuing their education and careers, leading to positive and empowering self-feelings. Three distinct types of emotional states were constructed to explain the feelings women expressed in relation to their social conditions: feeling disempowered, feeling valued and feeling empowered. These are summarised in Figure 7.1 below. 


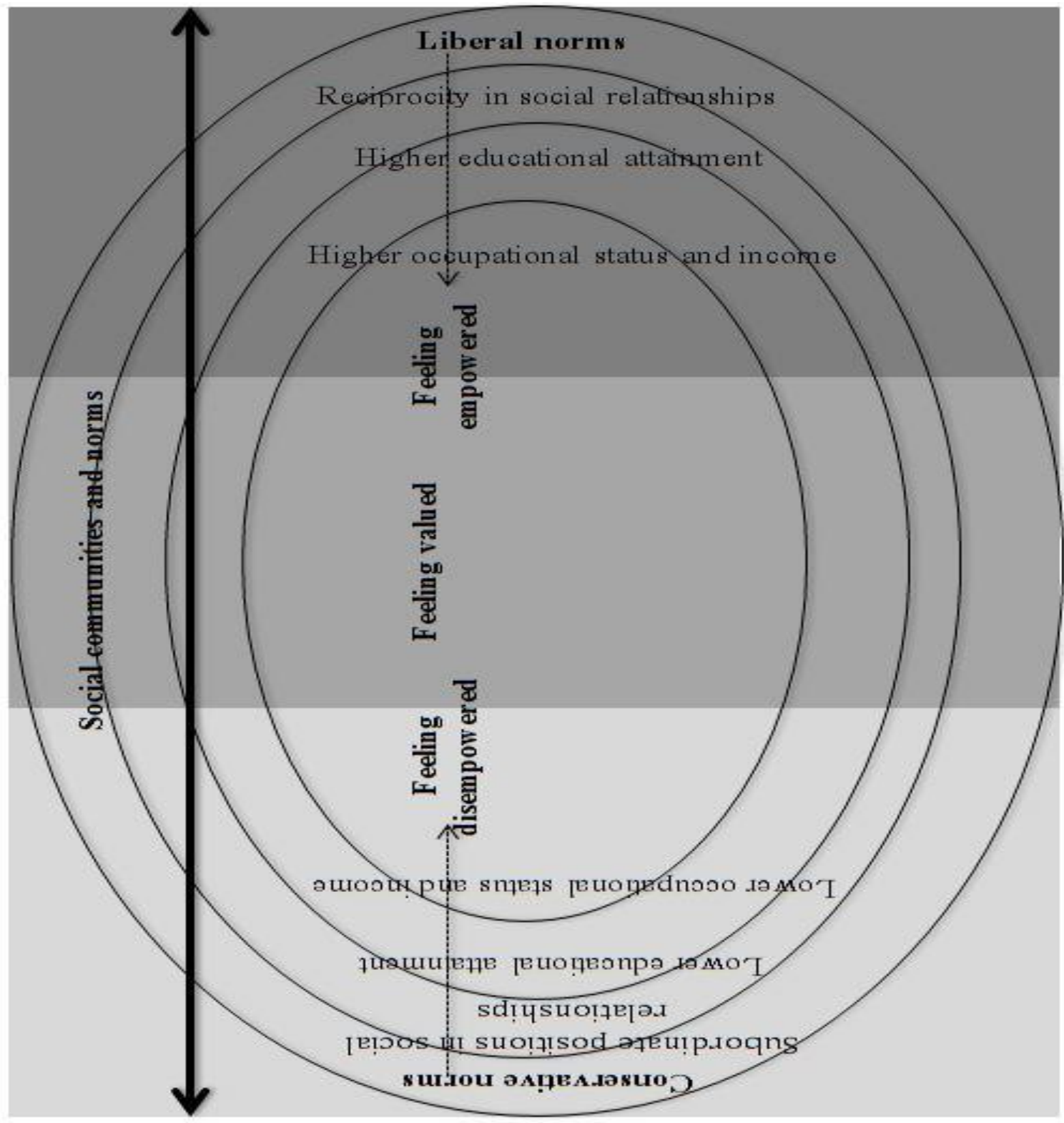

Figure 7.1: Illustrating the relation between women's social conditions and emotional states

\subsection{Social Behaviour}

Feeling disempowered, feeling valued, and feeling empowered were associated with variations in women's behaviours in social situations and interactions. Those behaviours will be explained in the context of:

- Marital and familial relationships

- Social communities and networks 


\subsubsection{Marital and Familial Relationships}

Women who were married, or previously married and had children (Maha, Tahani, Fadhela, Salwa, Abrar, Asrar) emphasised the influence of their marital and familial relationships on their social behaviour. The following comment demonstrates how feeling disempowered impacted women's behaviours in the context of their marital relationships:

... [Stayed in marriage for 20 years] because I had a sick daughter [with congenital deformities] and I needed sufficient funds for her treatment...I needed my husband's financial aid...my salary alone could not cover her operations...so I was patient for her... (Elham, 1)

Elham was patient in her marriage because of her ill daughter's financial requirements, rather than her own desire to stay in it. This suggests that financial dependency was a relational construct, where women regarded the requirement of their spouse's financial support not just for their personal needs, but the needs of their children. Feelings of fear and insecurity in relation to financial limitations (refer to Section 5.3.1) were constructed relationally, in response to their own and their children's situation. This relational emotional response as mothers took precedence over women's personal feelings and needs and diminished their choices.

Financial dependency led women to feel dominated in marital relationships. In the following, Fadhela explains how this influenced her behaviours towards her marriage:

I don't want to cause disruption for my children, but if it were up to me, I would kick him out [husband]... What is breaking my back is my daughter who is at the ideal age for marriage... and my son who graduates from university this year, he wants to work and get married...It wouldn't be right to cause chaos...my other son graduates from high school next year...I always think I have sailed the ship this far...I can't tell them I am stopping in the middle of the ocean. (Fadhela)

Fadhela suggested that if the decision only had an impact on her, she would end her marriage. Her use of an expressive metaphor of kicking her husband out implies that the marriage makes her feel angry or frustrated. Nevertheless, she goes on to suggest that she 
maintained her marital relationship in order to avoid causing disruption, as the decision would be detrimental to her children's needs. Fadhela, uses another metaphor, 'what is breaking my back', suggesting that maintaining her marriage because of her motherly obligations, felt painful. Another interesting aspect of that metaphor is that Fadhela related emotional pain to severe bodily pain. Moreover, she related separating from her spouse to causing 'chaos' for her daughter who is at the 'ideal' age for marriage. In other words, Fadhela stayed in her marriage to avoid harming her daughter's chances of being viewed as eligible for marriage. This suggests that feeling disempowered resulted in women suppressing their feelings about social relationships. Societal understandings of divorce or separation also impact Maha's behaviour and perspective:

If I were a troublemaker, I would not spend one minute with him [husband] ... but I stay out of respect and care for my children. I don't want to talk about his flaws in front of them, although he is full of them. I have in-laws, if one of my-sons-inlaw finds out where my husband hangs out, you think my daughter will remain his wife? No man would accept seeing a flaw in the mother or father of his wife or even her brother and not take action towards her, and I don't want to distort my daughters' reputation ... they are not one or two...they are nine... (Maha, 2)

Maha referred to leaving her husband as the behaviour of a troublemaker. Similar to Fadhela, there was a contradiction between the negative feelings she had about staying in her marriage and maintaining her marriage to avoid what was perceived as inappropriate behaviour. Eman, Fadhela and Maha's situations highlight the struggle women faced, when their personal feelings towards their marital relationships contradicted with how they felt obliged to behave towards them - societal judgments are influential in shaping their behaviours. In other words, when the women felt disempowered, they perceived they had no choice but to shape their behaviours to correspond to how others expected them to behave. 
Feeling valued on the other hand was associated with women taking a different approach to their marital relationships. The following comment demonstrates how Salwa's behaviours were influenced by her spouse:

When my husband tells me I am the only women that fills his world, sure I would do everything to please him, he treats me right, so I do the same happily, because I know the gains are worth it. He doesn't do anything to upset me... he is caring and affectionate.... and that is why I go along with his ways happily. (Salwa, 2)

The care and affection Salwa felt from her spouse's approach was associated with her wilful acceptance of following his directions. His dominance in their marriage was associated to feelings of happiness and success. This suggests that feeling valued enabled women to find acceptance and comfort in abiding to a submissive role, which for women who felt disempowered was perceived to be detrimental. The following comments illustrate how Abrar's behaviours were influenced by the needs of her husband and children:

I had to be the official speaker on his [husband] behalf, he became weak from his illness, so I had to act strong. He did not help himself so I had to support him. I was terrified, I would cry, but I would never show my tears in front of him or his family... (Abrar)

Abrar made changes to herself in relation to the care she felt obliged to provide to her ill husband. The changes entailed prioritising the comfort of her husband over her own feelings and needs. This suggests that women who felt valued, moulded their behaviours to meet the requirements of caring for their family members. In other words, feeling valued encouraged women to wilfully change their selves and behaviours in relation to the needs of others. Nevertheless, the change in self extended only as far as the self that women portrayed to others. Abrar built a fortified outer-shell in response to the needs of others, and covered her inner vulnerability and personal needs. 
Feeling valued gave women an incentive to engage in adaptive behaviour which helped them to accept social conditions that women who felt disempowered struggled with. In the following quote, Abrar demonstrates how she dealt with financial restrictions:

I feel I am comfortable from the inside, I feel inner peace. I only receive a small percentage of my salary after I retired, and I have loans to pay back, but I adapted. At first my self was at unease, but I asked around and learned how to adapt to my situation. (Abrar)

Abrar felt comfortable and at peace despite her financial situation. Asking others for advice and developing alternative strategies to help her deal with restrictions in her income, enabled her to find self-comfort. This suggests that women who felt valued had an incentive to develop a perspective of self that enabled them to reclaim a sense of control. Women appraised their situation, assessed the conditions imposed on them, and identified relevant adaptive behaviours which helped them cope with self-impositions. Actively making choices to reshape their behaviour is a distinctive characteristic of this approach.

Feeling empowered was driven by confidence and self-security. Those feelings were reinforced by supportive familial and marital relationships, endorsed by living communities with liberal social norms (refer to Section 7.3.3). In the following quote, Asrar illustrated how her marital relationship impacted her behaviours:

Because I lived with him [husband] abroad, he toughened me up...he disciplined me. I admit that and I am proud of it...that made me love him even more, because he did not want to show me that he was disciplining me by controlling me, not at all. He did it with love and affection, when there is love and affection, it covers for a lot of things. I loved him, he loved me, and we lived a wonderful life... we raised them [daughters] with respect, we taught them how to be independent, we helped them build their self-confidence. (Asrar)

Asrar's husband showed her how to behave in a manner that gave her self-control and made her stronger. Moreover, she stated that his loving and affectionate ways, made her feel proud about his influence on shaping her behaviour. In addition, they raised their daughters to be independent and confident. This suggests that for married women, feeling 
empowered enabled them to adopt assertive behaviours. This behavioural approach was formed through a supportive marital relationship, where the husband believed in and encouraged the empowerment of women.

The comments above suggest that women's behavioural approach to their marital relationships was influenced by their emotional states. The insecurity and fear associated with feeling disempowered and the social conditions leading to this emotional state forced women to restrict their behaviours in accordance with the expectations of people around them. Their subordinate position in marital relationships obligated them to prioritise their domestic role over their own needs. This put women who felt disempowered in conflictual situations, where they struggled to maintain their marriages despite their desire to terminate them. In contrast, feeling valued was associated with feelings of love and care from marital and familial relationships. This emotional state encouraged women to wilfully accept prioritising their domestic role. In other words, feeling valued enabled women to deliberately adapt their behaviours to the needs of their husbands and children, rather than forcefully. Feeling empowered was driven by feelings of strength, confidence and independence. Those feelings, which were reinforced by high levels of education and financial independence, enabled women to undertake assertive behaviours to develop themselves and grow through their marriage. This behavioural approach was relationally formed, influenced by having a spouse who encouraged female empowerment.

\subsubsection{Social Communities and Networks}

While the older married women emphasised their marital and familial relationships, the single women (Najla, Noura, Roqaya) and the youngest married woman (Fatimah) emphasised the impact of their social communities and networks on their behaviours. Variations in how young women utilised their human and material attributes for selfdevelopment was influenced by their emotional state and the views of their community. 
Feeling disempowered was associated to living in a community where women who did not conform to traditional, conservative societal expectations were made to feel inferior. This resulted in women questioning positive self-attributes and their self-worth. The following comment illustrates how this impacted Najla's behaviours:

Sometimes I feel I am different from other girls, so I think let me try being like them...but I can't, unfortunately...I am different...I don't like girls that spend their time talking about what this girl is wearing or what colour that girl's lenses are, or what eyeliner she's wearing, or what brand her bag is...I am not interested in those things and that's why they make me feel like I am less of a girl. My father and others tell me you are equivalent to ten men because of my actions and because I am not like other girls. I am not all girlie, OK I don't act it, but I am a female from the inside. I don't have to walk a certain way, as if I am on a cat walk, and laugh in a certain way...I don't enjoy talking to them or going to their gatherings, I much rather talk to the guys at work. I like the things they talk about, for example projects...I am an engineer. I like wearing jeans and shirts. Why should I wear heels? I don't like wearing make-up. Wear make-up to a construction site? That doesn't make sense to me...Men look at me as one of their guy friends, not as a girl they can marry... (Najla)

Najla viewed herself to possess qualities that made her different from other women; however, she did not believe it made her 'less of a girl' or less feminine. While Najla had different views to define femininity than people surrounding her, she still attempted to shape her behaviours in accordance with their expectations. This suggests that a lack of self-esteem and confidence, which characterises feeling disempowered, influenced Najla's behaviours. She struggled to shape her behaviours in accordance with how people in her social community expected women to behave, rather than her personal views about acceptable behaviour.

In contrast, women who felt empowered lived in social communities with liberal norms, where they felt accepted. Roqaya explains how conditions associated with feeling empowered influenced her behaviour in social situations:

Money is important. I won't tell you I am doing this [working] only for the selfsatisfaction...If a man proposes to me and says to me I am prepared to give you an income if you quit your job and become a house wife, I will refuse...I am 
against traditional marriage, where a man's mother would see me, and decide I am an eligible wife for her son. I refuse to accept this principle...so every time a person would propose to me following the traditional ways I would shut them all out and refuse to see them...I am confident enough to take a stand and say I am not ready to get married, that this is not the right time for me. I am very happy with my life...More than half of my friends are married with children, but that does not affect how I feel about the matter, because I know what I want, I know this is not the life I want. I want to focus first on how to grow as a person, from several aspects, in my career and in my life, and after that when I feel I am ready to settle I will settle... (Roqaya)

The self-confidence, security and financial independence associated with feeling empowered gave Roqaya the reassurance to prevail over traditional customs that women who felt disempowered struggled to conform to. The self-confidence she felt encouraged her to act upon what she believed in, rather than allowing others to influence her actions. This suggests that feeling empowered enabled women to have a say in their life decisions. Being surrounded by people who supported female empowerment encouraged Roqaya to challenge, and become purposively selective in the cultural ideologies she valued, and acted upon.

Feeling empowered was also associated with confidence and independence, and these were related to high levels of education (refer to Section 7.3.1). The following comments illustrate how those feelings impacted the ways women utilised their educational achievements:

I am a science teacher and it requires a lot of effort...I love to work, I love to participate in projects, I love to achieve my goals and ambitions...Everyone at work knows me [as a hard worker], I received several prestigious awards and I am always involved in extracurricular activities. (Noura)

I am married, but that does not mean that I will stop focusing on myself. At the end of the day, the only person I can count on is me, so one of my conditions before getting married was that I will pursue my university education. (Fatimah)

Noura expressed the passion she felt towards her profession. This passion is associated with achieving her goals and ambitions. Moreover, she took pride in the 'hard worker' status that her colleagues recognised her by, and the prestigious awards she earned. For 
Fatimah, pursuing an education was viewed as an asset that will foster self-development so she can become independent. This suggests that feeling empowered enabled women to utilise their education to fulfil their personal objectives and grow. This behaviour was further motivated by the self-satisfaction gained from how others in their social network viewed them.

Overall, women's social behaviours were influenced by their emotional state. Feeling disempowered resulted in a submissive approach, where women struggled to shape their behaviours in conformance with the expectations of spouses and other people, rather than their own needs and desires. Feeling valued resulted in an acquiescent approach, where women willingly adapted their behaviours in response to the needs of their family members. Feeling empowered resulted in an assertive approach, where women had relatively more choices in terms of how to behave. They were purposefully selective in the value they gave to certain societal expectations, and the extent to which they permitted such expectations to impact their behaviours. This variation in women's behaviours resulted in three distinct types of behavioural approaches: struggling, adapting and prevailing. These are discussed below.

Feeling disempowered resulted in women struggling to conform to societal expectations at the expense of their personal needs and desires. For several women, the struggle was a result of living in communities with conservative values that endorsed female docility. This was associated with limitations in women's human and material resources, a subordinate position in marital relationships and their spouses taking an authoritarian approach. The struggle was a result of trying to conform to societal expectations of female dependence and docility to gain social acceptance, impeding women's desires to pursue or utilise higher educational levels and financial independence. Women were engaged in a constant struggle: they desired to purse activities aimed at their self-development, but felt restricted by how others expected them to behave. 
Feeling valued resulted in women happily adapting their behaviours to meet the requirements of their spouses and children. This behavioural approach was most prominent amongst married women. The emotional encouragement from family members enabled women to mould their behaviours to suit other's needs, and find acceptance in this approach.

Feeling empowered facilitated prevailing over cultural customs that put restraints on women's independence. A social community with liberal norms which promoted female empowerment and reciprocity in marital relationships, encouraged women to utilise their human and material resources for self-development, and to engage in this assertive behavioural approach.

\subsection{Social Identities}

Self-feelings and social behaviours presented in the previous sections (Section 7.3 and 7.4), contributed to the development of three social identities which characterised the women in this study: the confined identity, the fortified identity and the irrepressible identity. This is not to suggest that all women fitted distinctly into each identity; rather, it offers a broad differentiation of women's social identities for theoretical comparison. The development of each social identity will be discussed below.

\subsubsection{The Confined Identity}

Living in conservative communities, where people conformed to ideologies supporting female docility and dependence, had a detrimental effect on some women's access to education, employment opportunities, and financial situation, or social conditions. Women with low levels of educational attainment, low occupational status and low personal income perceived themselves to be in a subordinate social position in relation to others, especially in relation to their spouses. Conservative social norms and ideologies were 
associated with their spouses' authoritarian approach in their marital relationships, reinforcing the subordinate position women perceived themselves to be in.

When women possessed human and material resources and were independent, living in communities which abided to conservative social ideologies impeded their aspirations to develop themselves. Possessing high levels of educational attainment, high occupational status and personal income did not grant women in such communities a higher social status. Women were judged by their marital and childbearing roles, and women who refracted from those roles were made to feel socially inferior; women were socially excluded and stigmatised for challenging social norms and being different.

The social conditions discussed above were associated with the development of the confined identity. The confined identity was an ascribed identity, imposed by conservative and oppressive social norms, which defined the role of women. Restrictions of human resources, material resources, as well as social and emotional support imposed on women by such communities gave rise to a lack of confidence, self-esteem and negative selfperceptions associated with feeling disempowered. Living in such communities also explains struggling, or why women perceived a lack of agency in the ways they acted and behaved. Women struggled to shape their behaviours in line with the expectations of their spouses and children, and with how people in their communities defined femininity, in the hope of attaining social acceptance and status. They struggled because they felt obliged to act in accordance with prescriptive norms, which facilitated particular behaviours associated to female docility and fragility, and constrained other behaviours associated to female strength and independence.

\subsubsection{The Fortified Identity}

Being surrounded by care and affection was a factor that was instrumental in women's identity construal. Mutuality, reciprocity and respect women perceived from spouses and 
family members impacted their emotional states and behaviours. While some women had limited or no personal income, their spouses providing them with access to household income, as well as emotional support and care from their spouses and children made, them feel valued. Feeling valued encouraged them to adopt an identity that accommodated family member's needs, which where prioritised over their own desires in some instances. Those conditions contributed to the development of the fortified identity. Women adopting this identity moulded their behaviours in accordance with the expectations of significant others, which explains adapting, the adaptive social behaviour characterising this identity. While both the confined identity and the fortified identity entailed women to shape their behaviours in accordance with other's expectations, the difference in social and emotional support available to them influenced their acceptance of this approach. Struggling was characterised by forceful acceptance, which opposed women's desires. Adapting, on the other hand, was characterised by wilful acceptance, where women intermeshed their own desires, with the desires of their family members.

\subsubsection{The Irrepressible Identity}

Living in social communities or being surrounded by social networks, which conformed to liberal social norms supporting female strength and independence, enhanced women's educational and occupational opportunities. Having spouses, family members and peers who conformed to these ideologies motivated and supported women to develop themselves by utilising their educational achievements and progressing in their careers. This endorsed high self-esteem, confidence, security and positive self-feelings associated with feeling empowered. The independence and security women in such communities felt, gave them a sense of control over their lives, in other words, self-agency. Those factors enabled them to acquire prevailing, the assertive social behaviour which permitted them to prevail over conservative social norms which they perceived to be detrimental to their selfdevelopment. Those social conditions contributed to the development of the irrepressible 
identity, characterised by an empowering emotional state, an assertive behavioural approach, and a sense of control or agency.

Women presented with multiple social identities, and the variations in their social conditions during different periods of their lives influenced the salience of a particular identity. This fluidity will be illuminated as the theory progresses (refer to Sections 7.6, 7.7 and 7.8). For the purpose of theoretical comparison, in this section, each woman was identified through the social identity that was most prominent in her account. Table 7.2 shows the distribution of women amongst the three identities, and Figure 7.2 overleaf illustrates the process through which women's social identities were constructed.

\begin{tabular}{|l|l|l|l|}
\hline Social Identity & The Confined & The Fortified & The Irrepressible \\
\hline Participants & $\begin{array}{l}\text { Maha, Tahani, Fadhela, } \\
\text { Elham, Najla }\end{array}$ & Abrar, Salwa & $\begin{array}{l}\text { Roqaya, Noura, } \\
\text { Fatimah, Asrar }\end{array}$ \\
\hline
\end{tabular}

Table 7.2: Summarising the distribution of women amongst the three social identities 


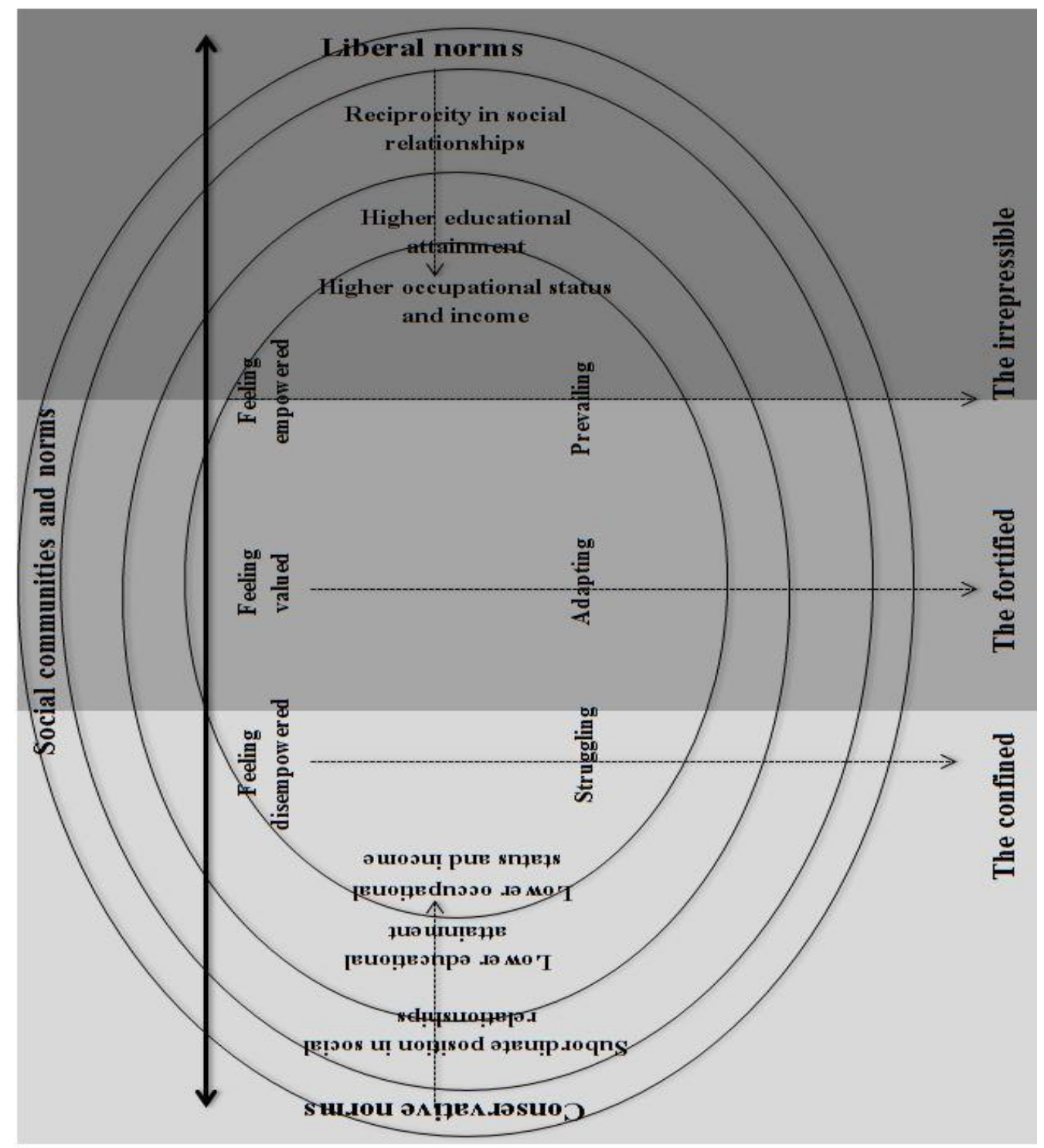

Figure 7.2: Illustrating the construction of women's social identities

In summary, the construction of women's social identities occurred through a multifaceted process, which developed in relation to their perspectives and feelings about their social conditions. The human resources they possessed - namely levels of educational attainment, occupational status, access to material resources, personal income, and access to household income - influenced the development of their social identities. Moreover, their identities were developed through social interactions and by the manner in which family members and peers expected women to behave. The perspectives and behaviours of family members and other's towards women were influenced by the cultural 
understandings and social norms embedded in the various social communities in which the women lived.

The perspectives and feelings women developed in relation to their various social conditions, influenced the choices they perceived, or levels of agency they had in terms of determining and shaping their behaviours in social interactions and constructing preferred or desired identities. Their social identities were developed around the levels of agency their personal attributes and social communities entitled them to, as well as through a process of socialisation with others - an interplay between agency and social construction (Goffman, 1959; Woodward, 2002).

The following sections (Sections 7.6, 7.7, 7.8) illuminate the embedment of women's social conditions, relationships and identities in their daily realities of CLBP. The development of a temporal process, built on an intertwined relationship between selffeelings, manifestations of pain, actions and behaviours, and coping with CLBP is revealed.

\subsection{Illness History}

The duration of time women suffered from CLBP varied. It ranged from as long as 35 years in the case of Fadhela to one year in the case of Noura. The majority of women (Maha, Elham, Noura, Salwa, Fadhela, Asrar, Abrar, Fatimah) reported that magnetic resonance imaging (MRI) revealed a lumbar disc prolapse, most commonly between the fourth and fifth lumbar vertebrae (L4 and L5 respectively). In addition to a disc prolapse, Najla and Tahani stated that their X-rays showed degenerative changes in the lumbar spine. Roqaya's X-ray did not show any anomalies. Table 7.3 summarises the duration of pain and diagnoses of the women in this study. 


\begin{tabular}{|l|l|l|}
\hline Participant & Duration of CLBP & Self-Reported Diagnosis \\
\hline Fadhela & 35 years & Disc prolapse \\
\hline Asrar & 4 years & L4/L5 disc prolapse \\
\hline Maha & $>15$ years & L4/L5 disc prolapse (with bilateral radiating pain) \\
\hline Elham & years & $\begin{array}{l}\text { Disc prolapse with sciatic nerve compression (with unilateral } \\
\text { radiating pain to left lower limb) }\end{array}$ \\
\hline Abrar & 22 years & Disc prolapse \\
\hline Tahani & 3 years & $\begin{array}{l}\text { Degenerative changes, L4/L5 disc prolapse (with unilateral } \\
\text { radiating pain to left lower limb) }\end{array}$ \\
\hline Najla & 3 or 4 years & Degenerative changes, L4/L5 disc prolapse \\
\hline Salwa & $>8$ years & $\begin{array}{l}\text { Disc prolapse (with unilateral radiating pain to left lower } \\
\text { limb) }\end{array}$ \\
\hline Noura & 1 year & $\begin{array}{l}\text { L4/L5 disc prolapse with sciatica (with unilateral radiating } \\
\text { pain and numbness in left lower limb) }\end{array}$ \\
\hline Roqaya & 4 years & X-ray inconclusive \\
\hline Fatimah & 2 years & Disc prolapse \\
\hline
\end{tabular}

Table 7.3: Duration of CLBP and diagnosis

In the following section, more details about women's history with CLBP will be revealed as the following issues are discussed:

- Onset and exacerbation of CLBP

- History with healthcare

- Illness disruption

- Remission of CLBP

\subsubsection{Onset and Exacerbation of CLBP}

While the majority of women were diagnosed with a disc prolapse, there was considerable uncertainty displayed when they explained their illness experiences in their own terms. Some women initiated their accounts by attempting to recall mechanical strains or injuries that may have been associated with the onset of their pain:

I don't know, maybe because we travelled by car, my body was heavy [she was overweight]...I didn't over exert myself or walk for a long distance or anything of that sort. When I got out of the car, my legs were swollen and my back was aching, I don't know if the reason was prolonged sitting or because I carried something heavy, but I did not carry anything heavy when it [pain] started. (Tahani, 1) 
The only thing I recall is falling off the stairs five or six years ago...but the pain only started a couple of years after that, and it was only mild pain. It started to increase gradually, so I don't think it's possible that the two things are related...I don't know what caused the pain. (Najla)

Tahani and Najla could not identify a straightforward corporeal explanation for the onset of their pain. While they started to explain their pain in terms of physical detriments, they could not come up with a plausible association. Tahani began by saying, 'I don't know', and Najla ended by stating 'I don't know what caused the pain'. This suggests that a lack of such explanations led to uncertainty about the cause of CLBP.

Other women described the progression of their CLBP, as the following comment demonstrates:

The pain started one year ago. I suffered from pain in my lower back. I used to think it was just normal episodes...until it started to gradually increase in severity. Of course I thought I needed to get it checked by a doctor... it started getting worse and impacted my leg and I feel numbness in my big toe... After that the pain became so bad that I could not even move my leg; it was so bad that my brothers would have to support me so that I could walk. The pain would radiate. (Noura)

Noura talked about the onset and gradual increase in severity of her pain. She perceived the initial phases to be 'normal episodes', suggesting that the pain was not associated to a strain or injury. The gradual increase in severity of pain caused concern and prompted Noura to seek medical attention. Nevertheless, the cause of gradual increase in pain was not evident in her account.

Some women described the abrupt nature of their CLBP, as illustrated by the following comment:

[The pain started] suddenly...for a little while you would see me, and I would be absolutely fine and [then] it will only take a few seconds until I felt like someone put electricity into me and my bones [would] start to ache. I [could] feel the pain in my big toe. (Maha, 1) 
Maha did not perceive a definitive cause for the onset of her back pain. Moreover, she described the frequent fluctuations in pain intensity, which she portrayed as a haphazard experience, where the pain was not necessarily provoked by particular movements or activities.

As the comments above illustrated, there was uncertainty when women could not recall a physical detriment or reason for the onset of their pain. Some women attempted to recall physical strains or injuries, but could not associate them to the onset of their pain. Others explained the gradual worsening of their pain, however, there was no evidence of particular physical strains that aggravated the pain in their accounts. Others talked about the sudden fluctuations in their pain intensity and could not seem to relate such fluctuations to particular movements or activities.

As women's accounts developed, additional facets of their illness stories emerged. Connections were made between their social conditions (refer to Section 7.2) and their manifestations of CLBP. Difficult social conditions, characterising the confined identity, were associated to the onset of their pain, as the following comments demonstrate:

He was our only hope, he is my eldest son, our financial situation is not that great... We sent him abroad in order for him to study. When he calls saying, 'mum I have exams', the whole family fasts and prays for him. He told me he had a couple of weeks left to graduation then suddenly I get news that he dropped out of school...I was shocked, for three months my tears did not dry out...This is what destroyed me...I felt this was related [to her pain]. Even the colour of my body changed, it was dark, although I was indoors all the time. I feel my body was suffocated, blue, I don't know if it [pain] is related to this, but I feel that it is related to the tiredness and discomfort I feel in myself. (Tahani, 1)

Tahani associated a period of her life filled with emotional anguish to the onset of her back pain; she used strong words to describe the incidence such as it 'destroyed me'. Her emotional burden was associated to the limitations in household income available to her and her family, which her son failed to improve due to a lack of progress in his educational achievement. She linked drastic bodily changes to this harsh period of her life, 
suggesting her body turned blue as she felt 'suffocated', and emphasised that this change in colour was not related to sun exposure, but rather to the emotional burden she carried. This suggests that the onset of back pain was associated to agonising bodily changes, which occurred in a period where Tahani experienced considerable disappointment in relation to a failed attempt to improve limitations in household income - these are characteristics of feeling disempowered. While she felt strongly about this association, there was some uncertainty displayed in her comment. Roqaya also associated a period of her life, when she was having what she described as social problems, to the worsening of her pain:

One time I started feeling severe pain and tenderness that was not even localised in my low back, it was in my whole spine. I was stressed, because after I graduated I worked with a doctor who treated me very badly...He put a lot of pressure on me. While I was working there I started feeling there was something wrong with my back. I realised that after I left his practice, I was still angry. I was constantly fighting with him...I believe when you are not comfortable or when you have social problems, it has an impact, because when you're under stress, you're constantly thinking and your whole body feels tense. So if you have a problem in one area [of your body] it will become worse... He was rude, he didn't talk to his staff with respect, and he was neither willing to accept my resignation, nor was he willing to pay me what I deserved...All of this caused me a lot of stress... One month after I left his practice, I realised that I was in severe pain, because I was constantly thinking about why did he did that to me, and why I allowed it. (Roqaya)

Roqaya associated a period of her life where she was in a negative emotional state due to a lack of mutuality and reciprocity in her relationship with her employer and limitations in her personal income to the exacerbation of her back pain.

The comments above demonstrate how difficult social conditions and emotional experiences characterising the confined identity were associated to the exacerbation of CLBP. Limitations in personal and/or household income as well as lack of social and emotional support led to negative self-feelings or feeling disempowered, and were factors associated to the onset and periods of exacerbation of CLBP. 
Several women associated the onset of their back pain to periods of pregnancy, as the following comments demonstrate:

I was not comfortable for a year and a half when I was living with my in-laws...I felt I was overworked, I felt exhausted ...I was pregnant during that period. A pregnant lady needs rest, she needs someone to take care of her...I felt all the pain came during that year and a half which I spent living with my in-laws. I wasn't comfortable because my husband was not with me. I have three brothers-in-law and they all interfered with my life. They did not allow me to go out when I pleased...I worked [in the house] while I was pregnant. None of them said I should rest. I cooked what I was told and was forced to eat with everyone even if it made me sick, because if I didn't there was no alternative...I don't like to talk about this period of my life, it is in the past now, but I feel that my pain started and was at its worst during this year and a half... (Salwa, 2)

Salwa associated feelings of exhaustion and discomfort in a period of her life, where she was forced by her in-laws to take care of household chores without regard to her state of health and needs as a pregnant woman, to the exacerbation of her pain. Her in-laws' authoritarian approach limited her self-agency; this meant that she lacked social and emotional support from the people she lived with. Those conditions obliged her to overexert herself physically, which put her in a state of feeling discomfort and unease. During Fadhela's pregnancy, similar social conditions were associated to the onset of her pain:

I only started feeling it [pain] after I became pregnant and went through a miscarriage. Four years after I gave birth to my eldest daughter, I got pregnant twice, and I had a miscarriage both times...I worked too hard at home, cleaning, pulling furniture to clean behind it, and till this day he [husband] looks at me and expects me to keep working around the house...[After the miscarriages] I was so upset, I don't know how to explain to you the pain I felt. I kept thinking how can I make my children live, and during that period our man wasn't supportive...He didn't even want me to stay at the hospital to recover, he wanted to bring me straight home [to work at the house], although my sister-in-law is very thorough when it comes to the house's cleanliness... (Fadhela)

While Fadhela associated the onset of her back pain to her miscarriages, her account portrayed several breadths intertwined to those events. The association between her miscarriages and the onset of her back pain was interweaved with painful events, an 
unsupportive, dictatorial spouse and physical overexertion by domestic chores she was obliged to fulfil - conditions leading her to feel considerable emotional anguish and despair, or feeling disempowered. Finally, Abrar explained the multifaceted nature of her first experience with pregnancy and its association with her back pain:

I was pregnant with my son $M$, this was in $1992 . . . I$ was fat of course after I gave birth, I was over, overweight, People used to mock me, so I decided to start doing exercise. I exercised for a month, I pushed very hard and played with a lot of dedication...the trainers always told me you're pushing yourself way too hard, it's not healthy...After one month I felt heaviness in my right leg, and my back turned to one side. I did not believe it till I saw it in the mirror, my back was tilted to one side. This is when the pain started. (Abrar)

Abrar suggested the onset of her back pain was associated to vigorous exercising after her pregnancy. Saying 'I pushed myself' and the fact that the trainers advised her that the way she trained was unhealthy may suggest that Abrar exerted her body over its physical limits, which may have led to a back injury. The incentive for overexertion was the stigmatising views of others, who portrayed natural changes her body went through as a flaw. This pressurised Abrar to ensure her appearance fits their standards at the expense of her wellbeing. A lack of social acceptance and stigmatisation, which were conditions associated to salience of the confined identity, influenced women's perspective and behaviours towards their physical being.

The comments above portray the particularity of social pressures and difficulties that women faced in relation to their childbearing role. The tangible experience of pregnancy was intertwined with societal expectations about how women were expected to behave and appear, limiting their self-agency and impacting their emotional state, behaviours and physical wellbeing.

In summary, all of the women had radiographic imaging, and with the exception of one, where given a diagnosis. Despite their conditions being medically diagnosed, women portrayed some uncertainty about the causes of their CLBP. They commenced their 
accounts by trying to devise tangible explanations for the onset of their pain. When women could not associate their pain to a physical strain or injury, this led to uncertainty about the cause of their pain. As their accounts progressed, they associated periods of their lives, through which they experienced considerable emotional burden in relation to difficult social conditions, to periods of back pain exacerbation. Limitations in personal and/or household income, a lack of social and emotional support, a dictatorial approach by spouses and others, and stigmatising experiences where all factors which limited women's self-agency. Limited agency was associated with weakening and disempowering selffeelings, which women linked to their pain. In other words, periods where women's social conditions ascribed the confined identity, leading them to feeling disempowered, were associated with the onset and periods of exacerbation of CLBP.

\subsubsection{History with Healthcare}

The uncertainty women displayed about the causes of their pain may have been impacted by their encounters with healthcare professionals. When women sought medical attention, they were not always provided with an explanation that clarified the cause of their CLBP, as the following comments demonstrate:

One time I felt pain at night and I went to hospital X. I was in continuous pain for three to four hours, and for three days before that, I did not sleep because of the pain. All they did was give me a pill, they did not even explain what it was for or what's happening in my back. I did not know what the pain was from, it came suddenly. I did not even know what caused it (Manal, 1).

$I$ requested an $X$-ray from the emergency room in the hospital I worked in, and I showed it to the doctor I worked with. He said its normal, there is no problem... nothing wrong with the vertebrae... When I showed him the X-ray, I explained what I was going through. I had tenderness across my vertebrae, I couldn't bare anything touching my back, and I couldn't do any extension movements. One extension movement would cause me pain for days. I felt he wasn't that interested, he made me feel like he was thinking come on, there's nothing wrong with you, 
you're going to live. He made me feel like I was exaggerating. It's a bit of muscle tightness and that's it. I felt bothered because I have pain! I have pain and that's why I'm here, I wanted an explanation based on his experience, why was I feeling this pain? OK, the X-ray was inconclusive but why did I have this pain? He didn't seem like he really cared. (Roqaya)

Maha suggested that healthcare professionals did not explain the benefits of the medication she was given or why she was in pain. Not being provided with a medical explanation did not help her deal with the uncertainty about the cause of her pain. The absence of a spinal anomaly led Roqaya's doctor to conclude that everything was 'normal' and that there was nothing 'wrong' with her back. Roqaya's comment suggests incongruence between the doctor's perspective of back pain and her personal experience. The doctor portrayed a biomedical perspective, where he sought a biological or physiological cause for her complaint, and dismissed her pain because it could not be correlated to a physical deficit. Conversely, Roqaya associated her experience of CLBP to a period of her life occupied with stress, negative thoughts and financial limitations (refer to Section 6.7.1). The following comments show a similar variance between medical explanations and women's interpretation of their back pain:

What caused my back pain was my pregnancy. I heard this from the doctor, but sometimes I think maybe that is not the reason. (Salwa, 2)

I went to the doctors, they did an MRI and told me I have a disc prolapse... But you know, there's no point in going to the doctors while the problems persist at home, I won't benefit. (Fadhela)

While the doctor suggested Salwa's back pain was caused by her pregnancy, she was hesitant about the soundness of this association. Fadhela's doctor explained to her that she has a disc prolapse. Nevertheless, she focused on the association between the social problems she had within her household and her pain. The comments above suggest that the uncertainty displayed in women's accounts was aggravated by the fact that their subjective experiences did not match the biomedical explanations offered by healthcare professionals 
and the dismissive attitude of doctors towards their pain that could not be correlated to a physical deficit.

Living with CLBP for several years meant that women had recurrent hospital visits and were managed by several healthcare professionals. Therefore, women also referred to more positive experiences with healthcare professionals, and in some cases made comparisons between different encounters. This is demonstrated in the following three quotes:

I felt comfortable with her [physiotherapist] and felt her treatment was good, because she talks to us, she is empathetic, she talks to us about our problems, she encourages and motivates us, she gives us advices to help us deal with our specific concerns. (Tahani, 1)

I felt comfortable with doctor $X$ because of his kind approach and words...He talked to me with a soothing tone, and at a pace where I could understand exactly what he was saying. He explained thoroughly what was happening in my back. He used a spine prototype to show me... What was most comforting was when I explained what I was going through, it was almost as if he was completing my sentences, it was like he was living with me and knew exactly how much I was suffering... [Before meeting this doctor] I saw a lot of doctors and all they did was prescribe some Profen and Muscadol [medication for pain relief and for relieving muscle spasms]...they didn't explain, and their treatment wasn't beneficial. (Salwa)

Doctor $Y$ is very caring. He came to the hospital after my operation [to remove a benign tumour] to see how I was doing... since my back pain started I went to see several doctors... but I really like doctor Y because he is kind...he is a doctor with morals... and he does not escalate things like a lot other doctors just because they want to perform a surgical procedure and make money...He cares, and he advises, and he's very patient, and he listens to my opinion on which approach I would prefer...He advised me to start aqua therapy, my daughter told him I am afraid of the water, but I said I could go, because I want to help myself, I want to take action. He told my daughter that I am not the type of person that has lost hope and wants to rely on the doctor to fix her with surgery...The other doctor told my daughter that we had to resort to surgery or I would not be able to walk anymore. I said to him that was not for him to decide. I refuse to resort to surgery. (Asrar)

All women favoured healthcare professionals who were empathetic, kind and caring. When a professional showed interest in women's concerns, provided sufficient 
explanation, and advice catered to their individual needs, and involved them in their care, women were able to better understand their condition; this was perceived to be related to effective treatment. Moreover, it motivated women to take an active role in managing their CLBP. On the contrary, healthcare approaches, which were geared towards prescription and surgical intervention, were not favoured and were seen to be ineffective. This demonstrates how mutuality and reciprocity in relationships with healthcare professionals influenced the gains and benefits women perceived from healthcare intervention.

In summary, the uncertainty women displayed may have been influenced by the mismatch between their subjective experiences with CLBP and health professionals' emphasis on biomedical reasoning. Biomedical approaches which focussed on the prescription and surgical intervention, and lacked sufficient explanation about the causes of pain where seen to be ineffective in alleviating and managing the pain. When women perceived reciprocity and mutuality in their relationships with healthcare professionals, were provided with sufficient explanation and advice, and were involved in their care, they were motivated to take an active role in managing their pain.

\subsubsection{Illness Disruption}

The illness disruption experienced during periods of exacerbation was associated with the difficult social conditions and emotional state pertaining to the confined identity. Salience of the confined identity was associated with social norms, which endorsed women's domestic role, a lack of social and emotional support, a subordinate social position and a lack of agency - conditions leading to feeling disempowered (refer to Section 7.5). The following comments illustrate how those conditions and feelings influenced women's daily struggles with CLBP:

Working at home is so tiring, more than working at an office...I do all the washing and cooking... Girls these days don't help their mothers...and the man [husband] is the same way, there is no cooperation...My 13-year-old son tells me 
to prepare him food or iron his shirt, and my other son says 'that's why you are a mother'. Even my husband., their demands don't end, and I have to attend to their needs, going up and down the stairs, although I am in pain. (Maha, 1)

All the exhaustion and anguish I felt over all those years affected my back and legs...I would tell my husband I feel like my back is being electrocuted and I am in pain. He wouldn't give me any financial support to get the medical attention I needed...There wasn't any appreciation for the woman who took care of his needs and his house's needs... It started gradually, the disc in my back, [pain in] my legs...These things don't just happen in one day...It happened over years of feeling tired and neglecting my self and my health...I didn't take care of my health or my self... (Elham, 1)

Maha's comment suggested that the tiredness she felt was associated with her children and husband expecting her to fulfil household duties, regardless of the pain she felt in her back. The exhaustion and anguish experienced by Elham were related a lack of emotional and financial support from her spouse, which gave her no choice but to neglect herself and health. The comments above suggest that a lack of access to household income, and a lack of social and emotional support, impeded women from attending to their health and obliged them to overexert themselves. Those conditions led to feelings of tiredness, exhaustion and anguish, or feeling disempowered, and exacerbated the illness disruption experienced during these periods.

Periods of exacerbation of CLBP were associated with considerable limitations which women experienced in their daily lives. While they did not always relate their CLBP to an incident with a physical strain or injury (refer to Section 7.6.1), all the women referred to physical restrictions they lived with as a result of their CLBP, as the following comments illustrate:

For a month and a half...I was just sitting on the sofa...sleeping on the sofa...I couldn't move...I needed to sit in a wheelchair. One of my daughters had to push me to the toilet...I couldn't climb the stairs...I didn't enter my room for a whole month and a half...just sitting on that sofa because I couldn't walk. (Tahani, 1)

For a period of time, I used to walk using a walker... and when I went out, my daughters would push me in a wheelchair. I couldn't walk, I used to go to aqua therapy using a walker, my tears would rush down, I used to cry like a little 
child...I wanted to walk down the stairs in the swimming pool and I couldn't. My daughter held me from one hand and the physiotherapist held me from the other hand and they assisted me down. She [physiotherapist] used to hold my hand and assist me to walk and my tears would rush down. (Asrar)

Women referred to durations of time where their pain was exacerbated and led to considerable functional limitations. Tahani and Asrar refer to a period where they found extreme difficulties in walking and needed to use wheelchairs, walking aids or rely on physical support from others. Moreover, Asrar conveyed the sadness she felt during this period. This suggests that the functional limitations women experienced from CLBP where associated with emotional pain and discomfort.

When women referred to periods of exacerbation of CLBP, they used the most profound descriptions to explain the severity of their pain:

For four months, the pain was continuous and so severe it stopped me from moving completely...The pain was so bad it felt like I was out of breath...It felt like fire was burning my back... (Elham, 1)

When I wake up in the morning I think, I have to get out of bed in this way [demonstrates], so my disc doesn't bulge out more...I'm up...I go to the toilet, again, I think, I have to sit this way because I fear my disc will bulge out... Every movement I make, every little thing I do...I fear my disc will bulge out further... The disc is always on my mind...I fear the pain will get worse than it already is...I can't forget [the back pain], not even for five minutes a day. (Salwa, 1)

Elham portrayed feeling intense, continuous pain that led to considerable restriction of movement. Salwa illustrated the dominance of her back pain over her functional activities, thoughts and emotions. The severity of the pain and its impact on Salwa's emotional state caused the back pain to dominate her thoughts.

Women talked about particular activities they could no longer engage in due to their CLBP, as demonstrated by the following comments:

I have to sit and work on the computer, to put together presentations for the students...I can only tolerate sitting for the first ten minutes...Before, I used to always walk amongst the students, now my movement is so restricted I have to sit on a chair. Even if I sit for prolonged periods, I feel pain. Also as a teacher I have 
to explain things while I am standing and science in particular because there are experiments that need to be demonstrated and carried out. When you have 30 students in a classroom they need attention...I feel that I am unable to control the situation like I did before...I was used to going for a walk with my sister...now I can't even cover 500 metres and if I try to, I spend the whole night in pain. (Noura)

I have been deprived from so many things. Every mother likes to carry her daughter, hug her tight while she is carrying her, these things have been taken away from me. Sometimes my daughter comes up to me and asks me to carry her. I cry, I can't handle the fact that I am not able to do that anymore. (Salwa, 1)

The activities women referred were not simply explained in a functional sense. Women's manifestation of the disruption caused by CLBP was relational and emotional. It was explained in relation to duties and responsibilities they perceived towards others, and could no longer fulfil as a consequence of their CLBP. Inability to comply with those responsibilities was associated with negative emotional states.

The comments above portray the association between women's emotional pain and their manifestation of CLBP. Feeling disempowered, which was endorsed by the oppressive social conditions ascribing the confined identity on women, was associated to the illness disruption women portrayed during periods of exacerbation. The profoundness of pain and functional restrictions experienced when CLBP was exacerbated generated further emotional pain and anguish.

In summary, a lack of social and emotional support from spouses and family members, financial dependency and a lack of access to household income, and the feelings of disempowerment those conditions entailed, led to the salience of the confined identity; this impacted the disruption women experienced when their pain was exacerbated. During periods of exacerbation of CLBP, women conveyed profound pain and referred to restrictions they lived with on a daily basis. Those restrictions where not only described in a functional sense, but also in terms of difficulties in maintaining social roles, responsibilities and obligations they perceived towards others. This portrays the relational 
nature of women's manifestation of their experiences with CLBP, and how their social identities and the behaviours of others towards them influenced those experiences.

\subsubsection{Remission of CLBP}

Women's accounts covered the course of their CLBP over the years. For some women, their illness trajectories included periods of remission of CLBP. The social conditions and emotional states leading to salience of the fortified identity and the irrepressible identity were associated with periods of remission of CLBP. Salience of those identities was associated to women's access to material resources, social and emotional support, and self-agency - conditions leading to feeling valued and feeling empowered (refer to Section 7.5). The following comments illustrate how those social conditions and feelings were associated to remission of CLBP:

After I started my new job, I was so happy with it, and the pain started to subside until it was gone. (Roqaya)

When I moved out [of my husband's house after the divorce] I did not have enough funds to furnish my flat, but my family and friends supported me and helped me...Things are better now... One of my daughters graduated and works now. The eldest graduated a while back but was forbidden to work [by her husband]...I am feeling steady and secure... When I am secure and comfortable, I feel comfort from everything else, even from illnesses. Illnesses do not come to me anymore...The [back] pain that I used to feel is gone...Since I came in for my back pain one year ago, I had not felt the pain again...my retirement pension alone covers most of the rent but my daughters chip in and help... We are free from the constraints we were living under... (Elham, 2)

I became pregnant with my second daughter and had caesarean. A week after I gave birth, I threw a dinner party as I was comfortable during that pregnancy. I ate what I like, I rested when I needed to...my husband is very caring. Once he looked everywhere and bought me strawberries even though they weren't in season because I was craving them. What I didn't like eating, I stayed away from, and when I needed to sleep, he made sure I got as much rest as I needed...You may not believe it, but during my second pregnancy, I did not feel any back pain. (Salwa, 2)

Roqaya referred to the period of her life after she quit her first job. While her first job was associated to a lack of mutuality and reciprocity, financial limitations, emotional unrest 
and an exacerbation of pain (refer to Section 7.6.1), moving to a new job led to an improvement in the prior conditions, happiness and remission of CLBP. The social support provided by family and friends as well as the financial support facilitated Elham's transition after her divorce. Surpassing the constraining social conditions she was living under while she was married, improved her opportunities to promote the material resources available to her. Her personal income was limited; nevertheless, she was able to increase her access to household income through her daughter's employment. While she associated feelings of tiredness and anguish and exacerbation of pain to the period she was married (refer to Section 7.6.1), she related the period after her divorce to feelings of security, comfort and remission of pain. Salwa referred to the period of her life after she moved out from her in-laws' house. She focused on the comfort she felt because of the social and emotional support provided by her husband during the period of her second pregnancy. Unlike the period of her first pregnancy, which was associated with a lack of self-agency, feelings of self-discomfort and severe pain (refer to Section 7.6.1), her second pregnancy was associated with freedom of choice, feeling comfortable and a lack of back pain. The comments above suggest that positive transitions in women's life trajectories, including improvements in their financial state, self-agency, and being emotionally supported by others led to positive self-feelings. Such transitions endorsed women's agency and led to feelings of happiness, security, comfort, and being cared for, or feeling valued and feeling empowered, and were associated with periods of remission of CLBP.

Supportive relationships encouraged salience of the fortified identity and the irrepressible identity, and were influential in helping women reach periods of remission of CLBP. The following comments illustrate how social and emotional support from familial relationships influenced women's CLBP experience:

Men these days get tired so fast, not like women who they are caring. But not my husband, he will always be by my side when I am not feeling well, when my back hurts...Its only been a year [since the last interview] but I feel my daughters have 
matured, they know what I am going through and are very caring and empathetic. My eldest is only nine years old and she helps me by bathing her little sister, they eat and clean their plates, I am blessed thanks to God...God put this illness [CLBP] in me, but he gave me much more, he gave me a loving husband and affectionate daughters... and this makes me feel very happy and comfortable...The things I see from my husband and daughters is what makes my back pain improve day by day. (Salwa, 2).

My family made me feel normal...like I did not have a problem...like I am not ill...They were very caring, but at the same time, they did not make me feel ill, or that I was helpless and could not do anything... They would give me smaller tasks, tasks that they knew I can handle, like instead of letting me carry four grocery bags, they would let me carry one or two...My family had a huge role...their constant care and talks...constant negotiations... all this had a huge impact on allowing me to challenge the depression I felt because of the pain and move past it. (Noura)

Salwa felt care and empathy from her husband and daughters, which she was lacking when she lived with her in-laws. Her daughters supported her by undertaking the household chores, and she felt considerable love and affection from her family. She associated feeling valued by her family members with the gradual improvement in her back pain. Noura's family made her feel strong and able. Feeling empowered enabled her to challenge her pain and surpass the depression she felt. The comments above illustrate how the availability of social and emotional support, or transitions leading to improvements in the levels of support over time, led to positive self-feelings, which was associated to diminishing their pain.

When women talked about periods of remission of CLBP, there was a considerable reduction in the extent of illness disruption they portrayed, as illustrated by the following comments:

The low back pain is not severe, to an extent where it interfered with my life, it didn't interfere, it was something annoying I was experiencing but I did not stop my life because of it. It wasn't severe at all. (Roqaya)

I am much much better...my body...my self...everything in my life is better... I don't feel the fear I used to feel, because the pain is not as bad as it was before. I don't feel the fear I used to because I don't have pain in my left leg anymore. The fear is gone because I can sit comfortably now, sometimes, I like to sit on the floor 
and enjoy my afternoon tea. Before I used to fear doing this, worrying the pain will get worse, but after a few months I felt normal again. (Salwa, 2)

Roqaya's comment referred to a period in her life where the pain was tolerable. The pain was of low intensity, and therefore did not profoundly interfere with her daily life. Salwa's comment suggested a link between improvements in her bodily function, herself and her life circumstances. Moreover, remission of CLBP is associated to an improvement in her emotional state, where she was able to overcome the fear she felt.

The comments above suggest that transitions in women's life trajectories, which were associated with improvements in the social and emotional support they perceived in social relationships, as well as access to material resources, facilitated a positive change in their emotional states from feeling disempowered which was associated with exacerbation of their pain (refer to Section 7.6.1) to feeling valued and feeling empowered. Positive changes in their social conditions improved their emotional states, and this was associated with periods of remission of CLBP. Remission of CLBP was associated with further improvements in women's emotional state, when they were able to overcome negative feelings associated with their pain.

While some women were fortunate to experience positive changes in their social conditions and acquire valued and empowered social identities, other women faced greater social difficulties that they could not overcome:

I was not comfortable, I have siblings, only one of them was caring and was always there for me. Since he passed away, none of my siblings have picked up the phone to ask [about her] over the last five years... Even my mum came and visited me, she passed away in my house. My heart has withstood more than it can handle...You might see me chatting and laughing but from the inside I feel a black cloud. When a person is occupied with negative thoughts, they become ill...My son passed away, his father accidentally ran him over with the car...My tears did not stop falling and neither did his [father]...So the [back] pain has been with me for a long time now, it's not a matter that started today or the day before. (Maha, 1) 
I feel hopeless. I don't know how to explain, I've lost all hope in feeling better... after what happened in Syria, I lost a lot of my family members... First my sister was gone and then her son, and then my cousins and my mother's cousins...Too many people, too many people are gone...I am so tired...I feel something gloomy over my chest...I can't stand myself and I can't stand anyone talking to me. When people ask me why I don't go out for a change, I feel agitated. (Tahani, 2)

Maha expressed great sorrow and discomfort in response to the loss of several loved ones. She conveyed the emotional pain she felt and described the negative feelings as a black cloud' that was trapped inside of her. She associated those events and the negative thoughts and feelings that occupied her mind with illness and her back pain. Similar to Maha's account, Tahani expressed feeling tired and emotional anguish; she described this as something 'gloomy' covering her chest. She linked the state she was in to feeling burdened by her own self, suggesting she was not satisfied by who she had become as a result of the hardships she has experienced. The comments above suggest that losing loved ones who offered them care or emotional support, made it challenging to overcome feelings of discomfort, tiredness, anguish and hopelessness, or feeling disempowered.

Feeling disempowered was construed during difficult social conditions. Married women who felt disempowered were financially dependent, lacked social and emotional support from their spouses, and perceived themselves to be in a subordinate position in their marital relationships (refer to Sections 7.3.1 and 7.3.2). Those factors may have been influential on the distinct marital struggles that were evident in the accounts of women, which were characterised by the confined identity (refer to Section 7.5):

He is kind sometimes, but there is one thing I hate about him, the constant and unnecessary trips. He just decides and suddenly packs his bags and leaves...I followed him...I tell myself he is the father of my children I shouldn't give up on him no matter how bad he is to me...He torments me...He doesn't show me respect and appreciation...He is rude to me and talks to me with disrespect, and I just let it go and walk away...These things torment me...He lies, he's a liar...I arrived at the hotel he was in... he was drunk, not to mention the ladies that call his phone...If any other women was in my place she wouldn't do what I did, she would just go out and enjoy her life just like he is doing, but I am holding this 
house and family together... Every bit of money he saves he uses for travel. At one point I took his passport, and tore it into pieces. (Maha, 2)

Everything I see from him [husband] reflects back on my self, I tell them [children], if he would improve his ways maybe I won't be in pain anymore...I'm fed up...it agitates me so much! The head of my office came to me one day and said Fadhela, your husband called me asking about this lady...Every time I go to work she makes comments implying he [husband] calls her, and I feel agonised and frustrated, and when I ask him why he called her, he denies it and starts yelling, and for six months she kept dropping those hints and I feel like I'm burning from the inside...I know he's the type that plays around so I have no reason not to believe her...For the past 13 years, every year in December his bag is packed and ready next to the door...Imagine, one time before his trip he asked me to come with him saying he wants to buy some make-up. I asked, 'who's it for?' And he said, 'there's an old woman there'...so I told him, 'old woman or young lady, she's a lady and I'm a lady, I don't care how old she is, I won't go with you to buy anything for her. You go and buy it yourself. I know what's going on, and no matter how much you swear otherwise I'll say you're a liar'. (Fadhela)

Maha explained how she felt tormented by her husband's reckless behaviour. She referred to his lack of respect and appreciation and the fact that he lies. Despite the agony that she expressed, she believed that she should not give up on the father of her children no matter how badly he treats her, as she wants to hold her family together. Fadhela referred to feeling similar distress in her marital relationship. Fadhela associated her spouse's spiteful behaviour in their marriage to the back pain she experienced along with negative emotions. The disempowered and dependent nature of the confined identity led women to maintain their marriages despite their desire to end them (refer to Section 7.4.1). In this sense, women's dependent status in an unequal and unhappy marriage, resulted in considerable emotional burden which they perceived no choice but to put up with, and which was associated with their experience of CLBP.

Unlike women who related periods of remission of CLBP with transitions leading to positive changes in their social conditions over time, some women's circumstances became worse over time, as the following comment demonstrates:

I cannot be fixed, because mostly I think about the past, they say people forget with time, I am not forgetting. Sometimes while I'm eating it keeps replaying in 
my head as if it were a recorded tape, I feel everything is happening right in front of me over and over again, even while we are celebrating a happy occasion the thoughts don't stop...Maybe because it was my only dream that my son becomes somebody, my hopes and dreams did not come true...my mind is not resting, my circumstances are not becoming serene. (Tahani, 2)

The pain is the same no difference, I am tired. The passing away of my nephews just added to my burden, may God give us and their mother patience. (Maha, 2)

Tahani conveyed a lack of serenity in her circumstances, as she was unable to transcend painful events that happened in the past, and the burdening emotions and thoughts those events were tied to. It can be inferred that feeling stuck in this negative emotional state led Tahani to feel hopeless about 'fixing' herself. This suggests that she was maintaining an identity, which was undesirable to her, and the negative emotional state that she was in impeded her ability to reconstruct a preferred identity. Maha suggested that she has not experienced a change in the intensity or nature of her pain. She explained that she felt tired and referred to further losses that she experienced, and how that added to the emotional burden she was carrying. The comments above suggest that when transitions in women's lives entailed their social conditions becoming worse over time, this added to the emotional burden associated with feeling disempowered. Lacking the resources to transcend this emotional state, the confined identity was imposed on them, and this was associated with continuous pain.

The comments above portray how transitions, or changes in women's social conditions and emotional states, impacted the salience of each of the social identities over time and their experiences with CLBP. Women who had friends and family members who provided them with emotional and social support were able to surpass negative social conditions, which ascribed the confined identity, and develop feelings of care and empathy from family members, as well as happiness, security and control, associated with salience of the fortified and irrepressible identities. Transitions that entailed positive changes in women's social conditions and emotional states were associated with periods of remission 
of CLBP. Women who lacked social and emotional support due to circumstances, such as losing loved ones or emotionally abusive marriages, could not transcend the lack of serenity they felt in their lives associated with the confined identity. Transitions in those women's lives entailed further emotional turmoil and hardship, and they did not portray any difference or improvement in their suffering over time. In other words, the disempowering emotional state, which characterised the salience of the oppressed confined identity, was associated with periods of exacerbation of CLBP. Feeling valued and feeling empowered, which characterised the salience of the desirable fortified identity and liberated irrepressible identity, were associated with periods of remission of CLBP. This association is demonstrated in Figure 7.3. 


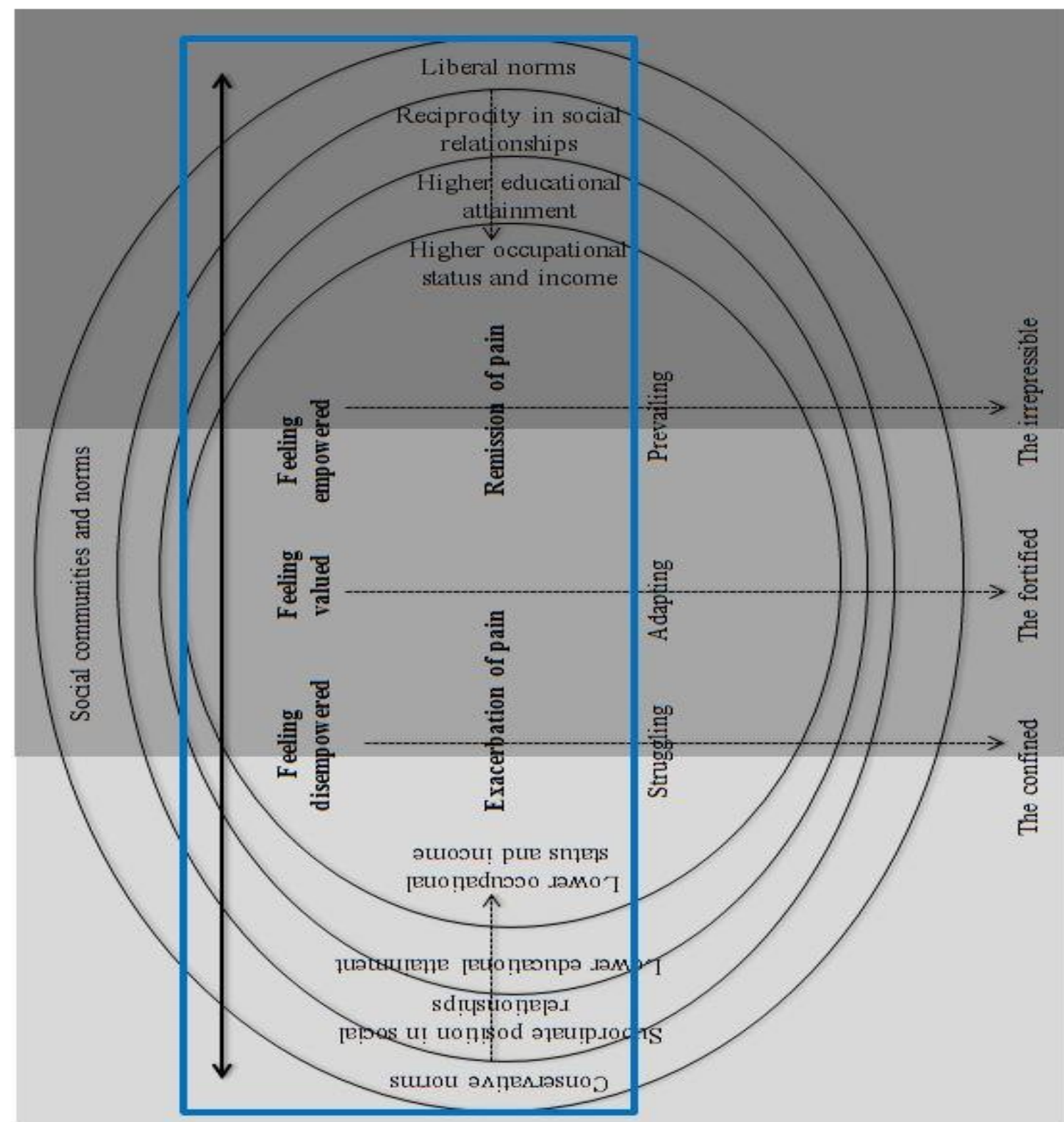

Figure 7.3: Emphasising the association between women's emotional state and perceived pain intensity

\subsection{Illness Behaviours}

Transitions in women's lives led to the salience of different social identities over various periods of their lives, and this was associated with variations in their illness behaviours. Illness behaviours refer to the ways women managed and coped with their pain at different stages of their illness trajectory. This will be explained by clarifying the following:

- The confined identity and coping with CLBP

- The fortified identity and coping with CLBP 
- The irrepressible identity and coping with CLBP

\subsubsection{The Confined Identity and Coping with CLBP}

When the confined identity was salient, women perceived themselves to be in a subordinate social position due to financial dependency, their spouses' authoritarian approach, a lack of social and emotional support and social stigma (refer to Section 7.5). The following comments illustrate how those social conditions impacted the ways women behaved to cope with their pain:

During the time when I was living with my husband, I just neglected my health...I don't think any women would have accepted living the way I was living...Some days I could not even afford to buy myself a dress for one and a half Kuwaiti Dinars [approximately 3 pounds]... I just ignored it [pain]...I forgot that I am human and I need to take care of my body...because I never had a chance to remember...I did not have time to feel that I had pain in my back and look after it...I didn't have mercy on myself...my job...working at home...my husband...my daughters...I exhausted myself in all those things... My circumstances forced me to live this way...If I had someone to help me with the housework this wouldn't have happened as they could've carried part of the burden. (Elham, 1)

I told my daughter for my next appointment I will just tell him [the doctor] to give me pain killers and that's it, your father doesn't let me leave the house...that's why I hate going to the hospital now...if I could only join a gym and start swimming it would be good... (Fadhela)

My back still hurts ...I don't do any exercise, I am not active, I spend most of my days just sitting on the couch, so that may be the reason [back pain is not improving]...I am always sitting because I have nothing better to do...I am not married, there is a lot of emptiness in my life, I don't like going out because I don't like seeing other people who have what I can't have. So I sit at home...I don't like socialising...they throw words at me that hurt me...when I gained weight they would say things like 'you're such a sweet girl. If you were not fat, you could be married'...those things hurt me a lot so I stay away from people. (Najla)

Elham associated neglecting her health to the oppressive social conditions she experienced during her marriage. Her dependency on her spouse and a lack of social support obliged her to overexert herself and prioritise her domestic responsibilities over her wellbeing conditions which she associated with her pain. Fadhela suggested that she was unable to 
join a gym and engage in an active approach to manage her pain, due to her husband's impositions. In other words, she owed her inability to engage in a self-management approach to constraints her husband imposed on her. Najla associated her sedentary lifestyle and lack of initiative to the stigma she experienced from her social community. The prior comments suggest that when the confined identity was salient, conservative and restrictive social norms, conditions and relationships associated to this identity obstructed women's ability and initiative to take an active role in managing their illness; this led to passive, relinquishing illness behaviours.

The following comments demonstrate how women utilised medical management when the confined identity was salient:

I tried everything, I bought medications and ointments, I used the ones the doctor prescribed, I bought ointments for the muscles, I bought painkillers, I tried them all...but it's pointless ...there is no comfort...no comfort at all... (Maha, 1)

I started with Panadol and then I started on Cataflam. It's like an addiction, whenever I am afraid of the pain, I take painkillers. (Tahani, 1)

Maha and Tahani displayed a heavy reliance on medications. When one medication proved to be ineffective, they resorted to another. Their behaviours demonstrate a passive approach to managing CLBP, where women depended on medications to alleviate their pain.

Adopting relinquishing illness behaviours, where women lacked the initiative to engage in self-management approaches, was associated with women perceiving a lack of control over their pain, as the following comments demonstrate:

My whole back was aching, I could not fall asleep...I have been in pain for years, and I'm tired [of it]...pain killers...injections...it is impossible to find anything that will work for me. I feel like electric vibes are being passed through my body, I can't do anything about it. (Maha, 1)

I started thinking that I will never be able to walk again, because of what I went through...I thought it was impossible... because nothing worked, ointments and 
medications...I used to enjoy cooking and sewing dresses for my daughters...now these things have been taken away from me. (Tahani, 1)

The women portrayed a sense of hopelessness; they felt defeated by their pain and believed that alleviating it was out of their control. They perceived that CLBP took over their daily activities and deprived them from activities they once engaged in. In other words, relinquishing illness behaviours were ineffective in alleviating women's pain, and were associated with persistent exacerbation of pain and disruption.

Transitions including positive changes in the social circumstances of women who were characterised by the confined identity (refer to Section 7.7.4) were associated with changes in the illness behaviours they portrayed along their illness trajectories. This is illustrated by the following two quotes:

I know that all the pain I feel is because of my husband. When he travels I feel fresh, I become a different woman, comfortable. As soon as he walks out the door, I join a gym...my weight drops automatically and I am not in pain anymore. (Fadhela)

I should not exhaust myself anymore by pushing or lifting heavy objects, or bending...I want to look after myself and my body, because now no one can force me. The judge was considerate and ruled that my husband cover expenses for me to hire help...although I prefer to do the work myself, but there are some things I don't want to do, I can but I don't want to, because I don't want my back to ache again. I feel happy and secure...so now I feel I have to take care of myself and my health...I don't complain about the disc or anything else...I don't need physiotherapy sessions...I don't even take any medication...The pain killers I used to take before...I don't need them anymore. (Elham, 2)

Liberating themselves from oppressive social conditions gave women choices about how they wanted to behave and manage their pain. This led to positive changes in their emotional state and motivated them to take an active approach to managing their pain. While a relinquishing approach was associated to exacerbation of CLBP, changing their behaviours to an active approach was associated to remission of pain. In other words, transitions which improved women's access to material resources and the social and emotional support they felt surrounded by, had a positive impact on their emotional state. 
Those conditions enabled women to liberate themselves from the confinements of the confined identity, enhancing their levels of perceived self-agency and improving the approach they utilised to manage their CLBP.

In summary, the salience of the confined identity obliged women to take a relinquishing, passive approach to manage their pain. Women's subordinate position in marital relationships obliged them to behave in accordance with their spouses' expectations rather than their own health needs. Moreover, a lack of social acceptance and stigmatising experiences led women to restrict their activities by isolating themselves from their surrounding community. In other words, women felt obliged to refrain from social activities to avoid the emotional burden that socialising entailed, leading to a lack of initiative and a sedentary, passive lifestyle and an ineffective approach to managing CLBP. The passive nature of relinquishing was further demonstrated in women's heavy reliance on medication to alleviate their pain. The relinquishing coping strategy associated with salience of the confined identity, shows resemblance to struggling, the social behaviour approach characterising this identity. Struggling entailed women to shape their behaviours in line with societal expectations, at the expense of their personal needs and desires (refer to Section 7.4.2). Similarly, the relinquishing coping strategy was a passive approach where women shaped their illness behaviours in relation to others' expectations and judgements, rather than their own health needs and perspectives about how to manage their pain. This approach was ineffective in alleviating women's pain and led to a sense of hopelessness and defeat, adding to the emotional burden associated with the confined identity.

\subsubsection{The Fortified Identity and Coping with CLBP}

The salience of the fortified identity was encouraged by abundant social and emotional support from spouses and family members, which made women feel valued (refer to 
Section 7.3.2). The following comments demonstrate how salience of this identity influenced women's illness behaviours:

I always tell them [family] I am fine, I don't tell them I am in pain...Even when I am in pain, I make sure lunch is ready. I greet my husband with a smile on my face, because he appreciates it and tells me everything I ever wished for in my wife is in you... and he treats me with respect and love...So I want to do the same...I do this because he is empathetic and compassionate. (Salwa, 2)

I adapted to my situation because I have to take care of everybody...one leg in his [husband] pitch one leg in theirs [children]...one time I got so tired from the pain, I decided to go to my mother's house...but they [children] insisted on coming with me, and so I had to tell my mother I am feeling better now even though I needed to rest. (Abrar)

Salwa explained how her husband's compassion and empathy encouraged her to conceal her pain in the presence of her family, and carryout the domestic responsibilities she felt obliged to fulfil. Similarly, Abrar explained how she needed to hide her pain from her mother because of her responsibilities towards her husband and children. In other words, the marital and childcare duties Abrar and Salwa perceived, led them to mask their pain in the presence of their family members. This behaviour was encouraged by the emotional content they felt from their familial relationships.

The following comments further demonstrate women's illness behaviours when the fortified identity was salient:

Change is fun, this is my situation and it won't change, but I can incorporate fun in my life, all I need are minor adjustments. I watch the episode I like, then I do a bit of ironing, when I am in pain I attach my TENS machine [to her back], and make sure the wires are secured, and I do my work...I make sure dinner preparations are ready early so that I have time to listen to my favourite music channel at night... (Abrar)

I can finally sit on the floor now...I like to sit on the floor when I am a having tea with my husband or helping my daughters study. I wasn't able to before. I felt something hot, hot, hot burning my back if I tried, but now I can. How do I manage? I just put a pillow under me and sit on it. (Salwa, 2)

Abrar and Salwa explained how they developed adaptive behaviours to help them function around their pain. Abrar explained how she made adjustments to prevent the pain from 
restricting her from fulfilling household chores. She also suggested those changes were fun, demonstrating her acceptance of this approach. Salwa described the change she made in order to prevent the pain from interfering with activities she enjoyed undertaking with her husband, and with her duties towards her daughters. In other words, women developed strategies to help them function around their pain, to prevent it from interfering with their responsibilities as wives and mothers.

The masking nature of women's illness behaviours resonated in their approach to healthcare, as the following comments demonstrate:

I only go to the doctor when the pain has reached its highest level, when I can't bare it anymore; when it's so bad I need to walk sideways because I can't walk forward, when it's so bad that I can't sleep. (Abrar)

I didn't go to the doctor. I used to say this pain is from the epidural injection they gave me so there's nothing to worry about, its normal...For eight years I just lived with it, until the last three months, my pain got so bad that I could not sit comfortably. My pelvis felt so stiff...the doctor told me I had a disc [prolapse]...I used to carry heavy things...because I have to do my housework...I wish I had gone [to the doctors] back when the pain started. He would have told me there was something wrong with my back and corrected my false thoughts...I could've done something about it then and maybe it wouldn't have reached this stage. (Salwa, 1)

Women put up with their pain and did not seek medical attention until the pain was unbearable. Prioritising their family member's needs led them to put their domestic responsibilities in the forefront and their health needs in the background. They regretted postponing seeking medical attention, as addressing the issue earlier may have diminished the levels of pain and disruption experienced.

In summary, the salience of the fortified identity was associated with women masking their pain. The social and emotional support they perceived from family members encouraged them to conceal their pain and work around it, in order to prevent it from interfering with their domestic and childbearing responsibilities. Women showed acceptance to this approach by suggesting the changes and adjustments they made to accommodate their 
family's needs were enjoyable. The masking nature of this coping strategy was further demonstrated in women's approach to seeking medical intervention, where it was postponed until levels of pain and disruption reached unbearable levels. The stoic, adaptive and acquiescent nature of the masking coping strategy shows resemblance to adapting - the social behaviour approach characterising the fortified identity. Masking the extent of their pain from their family members mirrored how adapting entailed women to construct a reinforced exterior to hide their inner vulnerabilities (refer to Section 7.4.1). Moreover, wilfully changing their behaviours, in relation to the needs of others was a characteristic of both adapting and masking.

\subsubsection{The Irrepressible Identity and Coping with CLBP}

High educational attainment and high levels of social and emotional support were conditions which enabled women to acquire the irrepressible identity (refer to Section 7.5). The following comments illustrate how the salience of the irrepressible identity influenced women's illness behaviours:

Education means the world to me. I can't imagine what my life would have been like had I not gone to university. Even if a woman chooses not to work, she has to have an education, because you grow as a person with education, you feed your brain and you grow...You learn how to build different perspectives to tackle anything that comes your way. This helped me deal with my pain. (Roqaya)

My family always helped me...like my mother helped me with computer work, and my brothers helped me put the student's grades into charts... so my responsibilities were delegated amongst my whole family...They helped me with things I was supposed to carry out myself...This gave me a push and motivated me to continue my path forward...I thank God [for the support of her family and being able to move forward]. (Noura)

My daughters are more than my daughters...they are my dear friends...they are a blessing and they make me love my life and motivate me to hang in and never give up...I hang in for them and for their children...This is the secret behind me holding onto this life and not allowing illness to win...I won't give up...I don't grow weak for anything...because I love my life...I want it. (Asrar) 
Roqaya emphasised how education helped her take an active role in relieving her pain. Noura associated the support she perceived from her family to the motivation she felt to push forward and not give in to the pain. Similarly, Asrar related the emotional support she perceived from her family to her initiative to challenge her pain. In other words, the social and emotional support perceived from family members gave women an incentive to stay strong and not give in to the pain.

The following comments show further behaviours women engaged in to manage their CLBP when the irrepressible identity was salient:

I focused on carrying out the exercises, as if I improved my back muscles' strength I would feel better. (Roqaya)

I shouldn't let it [back pain] win or take over...I don't rely on medications...no, no, there are things inside me that are capable of expelling it [back pain] from my body. If I surround myself with positivity, I will overcome it [back pain]. (Asrar)

Roqaya showed an active approach; she engaged in physical activity, which was effective in reducing her pain. Asrar illustrated the control she perceived to have over her pain. Rather than resorting to medications, she took a coercive approach, where she challenged the pain and resorted to surrounding herself with positivity to expel it from her body.

Taking a dominating, coercive approach to manage CLBP influenced women's approach to healthcare, as the following comments demonstrate:

I woke up one day, and I was in pain. I told my daughter to take me to the hospital, I explained to the doctor that I am a disc patient, but there is something new happening in my back. He told me, 'I will give you the strongest pain killer injection and it should do the trick'. I said, 'no doctor, I am telling you this won't work, can I please ask you to refer me to get an ultrasound'...So he took me to get an ultrasound...After he was done, he spoke to my daughter outside, I told her that I had an MRI appointment today, so I want to be taken to get that done now...because sometimes there are problems in a patient's body that the doctor can miss...they found a tumour which was compressing the spine. (Asrar)

When I went to the doctor, he said there was nothing wrong with my back and my $X$-rays look fine. I did not just give up, I tried to think of an alternative way to 
manage my pain. I tried several methods until I reached the most effective way and relieved it. (Roqaya)

Asrar demonstrated a directive approach, where she took a firm stance to ensure she received the management she perceived was necessary. She relied on her own understanding of her condition and body to direct the health management she received. Moreover, she resorted to her own expertise about the ability of her body, rather than the doctors' instructions. Roqaya decided to take control and trust her own expertise to manage her pain, rather than relying on healthcare professionals, who did not seem to have the answers to explain or alleviate the pain she felt.

The illness behaviours demonstrated when the irrepressible identity was salient were associated with remission of pain and diminished illness disruption, as the following comments show:

In aqua therapy, I jump on the trampoline and I feel like a little child. Have you seen little children when they are happy? That's how I feel. I do the movements and I enjoy and I play...the rest [ladies] don't play like me... The water has helped me defeat the pain, defeat the walker. The water has helped me to remove a lot of bad things from my body. (Asrar)

I really did feel better...I didn't have inner peace. Exercise helped me a lot in becoming a calm person. (Roqaya)

Taking an active approach enabled Asrar to eliminate the use of a walking aid, diminishing the illness disruption she experienced. She expressed great happiness because she was able to 'defeat' her back pain by engaging in physical activity while in the water. Similarly, Roqaya's comment demonstrates that exercise helped her 'feel better' by diminishing the pain she experienced, which was associated with feeling inner peace. The comments above suggest that active and dominating illness behaviours were effective in alleviating women's pain and preventing it from interfering with their daily functioning, leading to positive feelings of happiness, triumph and inner peace. 
While the salience of the confined identity led to a sense of hopelessness and defeat, where women perceived their pain to have taken over (refer to Section 7.7.1), the salience of the irrepressible identity was associated with assertiveness, as the following comments demonstrate:

I will never give in to the pain...I won't let it...I won't let it settle in me. (Asrar)

The pain was there...but I didn't let it interfere with my life...I did not let it stop me from doing the things I wanted to do. (Roqaya)

I am working on a project that I aspired to complete... and I am still working on it...I used to work on it daily...now I can only work on it every other day, it [back pain] restricts my ability, but I don't let it take over and I don't stop pursuing my goals because of it. (Noura)

Women fought their pain to ensure they were dominating it, and did not allow it to obstruct their ability to pursue their life goals.

In summary, the salience of the irrepressible identity enabled women to take an active and dominating approach to cope with their pain. Dominating was associated with the social conditions characterising the salience of the irrepressible identity. Having high levels of educational attainment and being surrounded by supportive and caring family members gave women the strength or feelings of empowerment to challenge their pain and prevent it from taking over. Dominating mirrored prevailing, the social behaviour approach characterising the irrepressible identity, where women took a directive approach in the way they behaved in social situations (refer to Section 7.4).

Overall, the salience of each social identity was associated with different illness behaviours that women demonstrated to cope with their CLBP. The social conditions characterising each identity determined the social, material and human resources available to women to utilise in management of their CLBP. Three distinct coping strategies were developed to explain the illness behaviours women portrayed and how they were related to 
their social identities: relinquishing, masking and dominating. This association is illustrated in Figure 7.4.

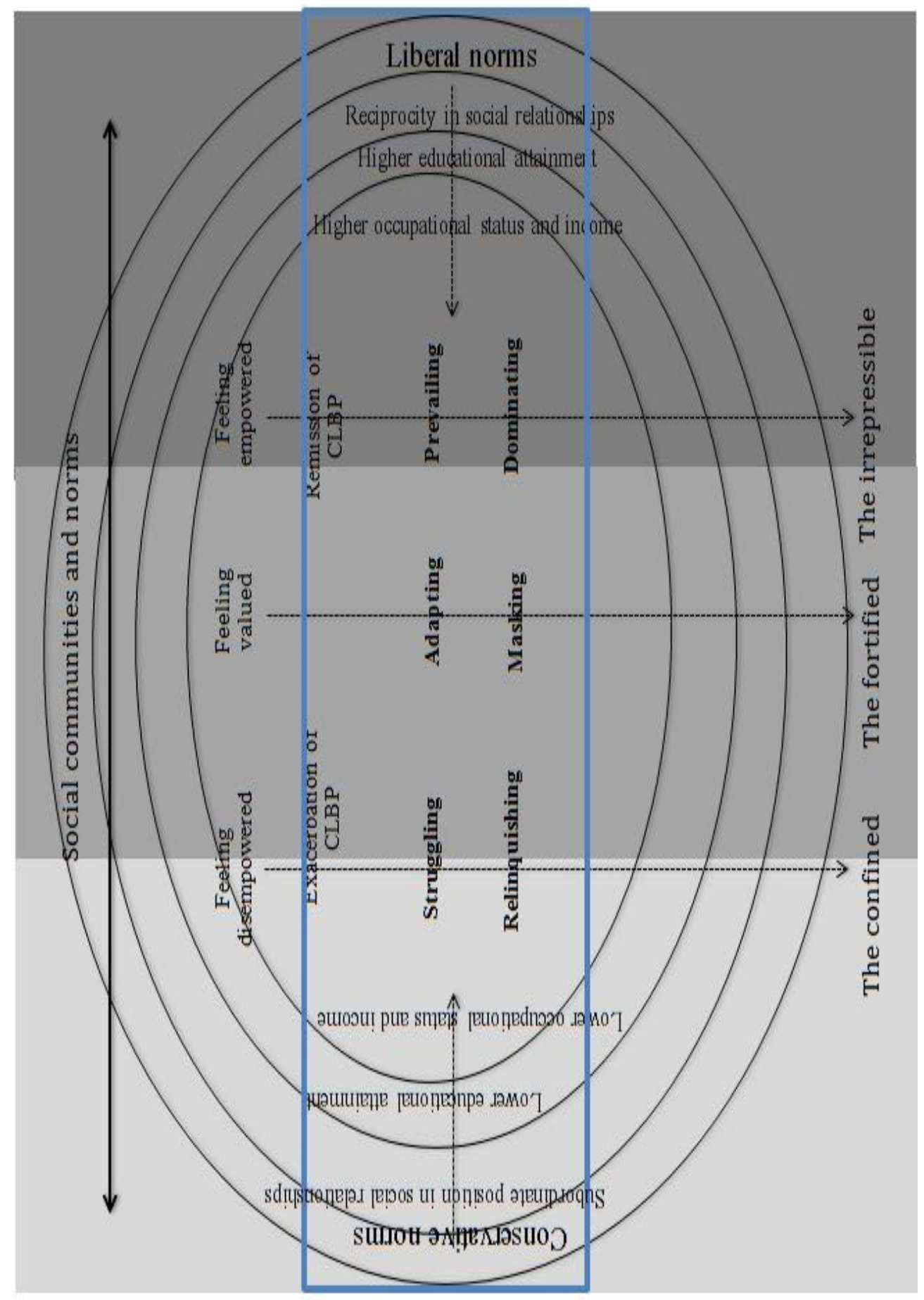

Figure 7.4: Emphasising the association between women's social and illness behaviours 


\subsection{Illness Identities}

The illness disruption experienced and coping strategy utilised, which were presented in the previous sections (Section 7.6 and 7.7), contributed to the development of three illness identities, which characterised the women in this study: the submitter identity, the camouflager identity, and the combater identity. This is not to suggest that women's illness identities were distinct from their social identities; rather, they have been presented separately to provide a conceptual presentation in order to help illuminate the association between women's social and illness experiences.

\subsubsection{The Submitter Identity}

The submitter identity is a submissive, dependent identity. Women who were characterised by this identity experienced persistent exacerbation of CLBP and illness disruption, and perceived no control over their CLBP. Emergence of the submitter identity was associated with the salience of the confined identity. Feeling disempowered was related to the persistent exacerbation of CLBP associated with the submitter identity. Moreover, the relinquishing coping strategy characterising the submitter identity, was associated with struggling, where oppressive social conditions and relationships governed the social behaviours of women when the confined identity was salient, giving them no choice but to follow a passive coping strategy. It can be inferred that the lack of control over CLBP and periods of exacerbation of CLBP characterising the submitter identity, were associated with the lack of self-agency and feelings of disempowerment women experienced during periods where the confined identity was salient.

\subsubsection{The Camouflager Identity}

The camouflager identity is an adaptive illness identity. Women who were characterised by this identity followed the masking coping strategy. They concealed the extent of pain they were experiencing from family members, as they prioritised their families' wellbeing 
over their own. Moreover, they developed strategies to ensure that CLBP did not interfere with their responsibilities towards their family. The salience of the camouflager identity was associated to the salience of the fortified identity. Feeling valued by family members, which led to the salience of the fortified identity, was the driver that inspired women to prioritise their roles as wives and mothers over their personal desires, health and wellbeing. Masking entailed women willingly engaging in adaptive behaviours to work around their pain and prevent it from interfering with their domestic roles and responsibilities. Similarly, adapting was characterised by women altering their selves and behaviours to accommodate their family member's needs and prioritising them over their own.

\subsubsection{The Combater Identity}

The combater identity is an empowered illness identity. This illness identity was associated with remission of CLBP and with women perceiving control over their CLBP. Appearance of the combater identity was associated with the salience of the irrepressible identity. Feeling empowered, which characterised the irrepressible identity, was associated with periods of remission of pain. Moreover, dominating, where women took a coercive approach to manage their CLBP, showed resemblance to prevailing, where women behaved assertively in social interactions. Put in another way, empowerment and selfagency, and the positive emotional state characterising the irrepressible identity, were associated with having control over the pain and remission of CLBP, which characterised the combater identity.

Table 7.4 shows the distribution of women amongst the three identities. While the salience of illness identities varied throughout some women's illness trajectories (refer to Section 7.6), the table characterises them in terms of the identity that was most prominent in each of their accounts. 


\begin{tabular}{|l|l|l|l|}
\hline Illness Identity & The Submitter & The Camouflager & The Combater \\
\hline Participants & $\begin{array}{l}\text { Maha, Tahani, Fadhela, } \\
\text { Elham, Najla }\end{array}$ & Abrar, Salwa & $\begin{array}{l}\text { Roqaya, Noura, } \\
\text { Fatimah, Asrar }\end{array}$ \\
\hline
\end{tabular}

Table 7.4: Summarising the distribution of women amongst the three illness identities

The previous sections presented women's social and illness identities. The association between women's emotional states and the severity of pain and illness disruption experienced, as well as their social behaviours and the coping strategy they adopted to manage CLBP, were demonstrated. Moreover, it was illustrated how transitions in women's life trajectories impacted transitions throughout their illness trajectories. Women's biographies (life and illness accounts) included cyclical transitions, which impacted the continuous development and variations in their identities over time. Transitions in women's life trajectories, which were associated with negative emotional states and ascribed to an oppressed social identity, endorsed the salience of an illness identity characterised by a passive coping strategy and an exacerbation of CLBP. Transitions in women's life trajectories, which were associated with positive emotional states and enhanced the salience of desirable, liberated social identities, endorsed the salience of illness identities characterised by active coping strategies and remission of CLBP. This process of 'biographical transitions' is illustrated in Figure 7.5. 


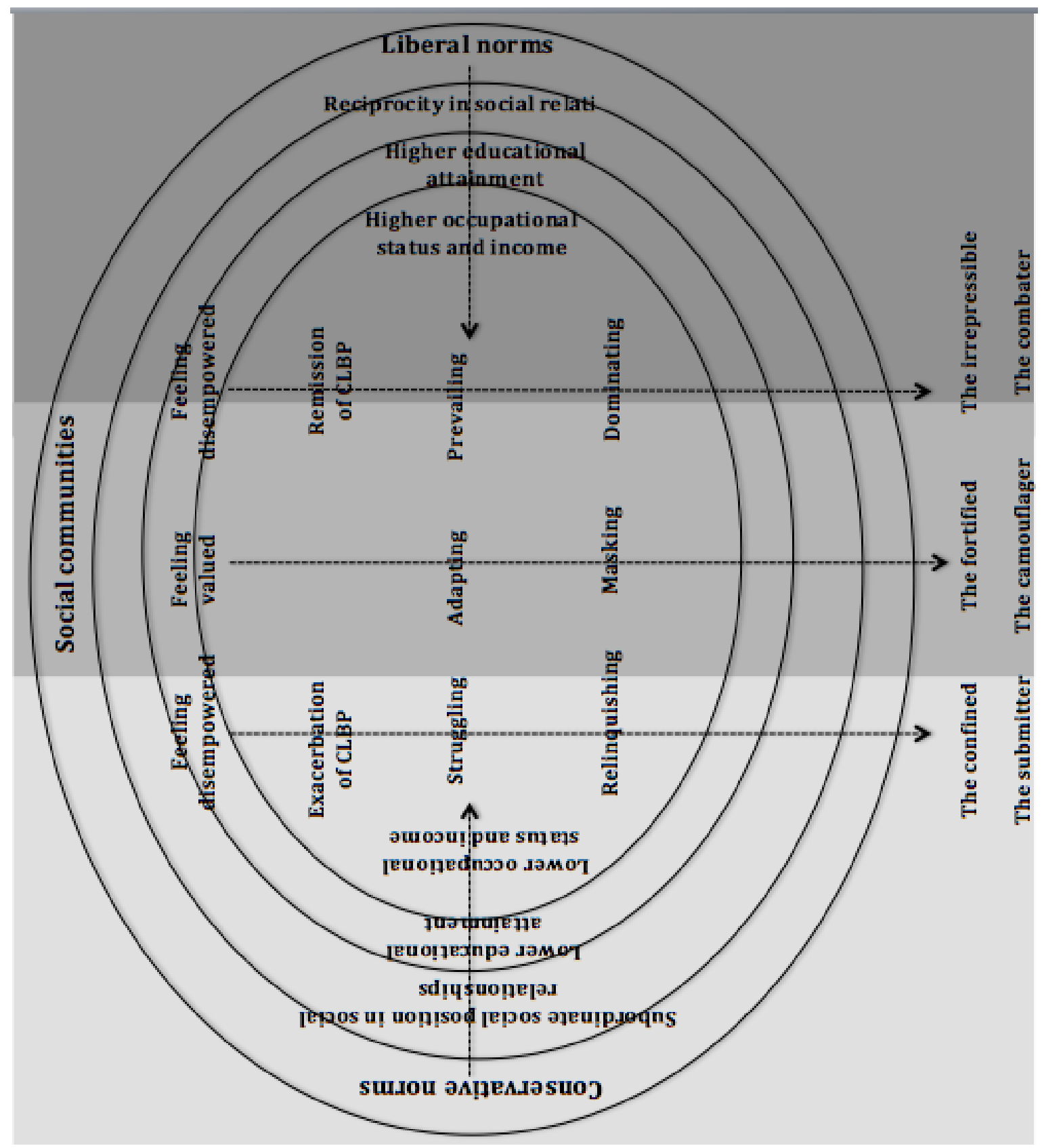

Figure 7.5: Illustrating the process of biographical transitions

\subsection{Conclusions}

The findings have led to the development of a substantive theory of 'biographical transitions' in the lives of women experiencing CLBP in Kuwait. Biographical transitions led to the salience of various social and illness identities over time. Variations in the emergence of identities entailed differences in women's self-feelings, manifestations of CLBP, social conditions and relationships and coping strategies over time. Positive 
changes in women's lives led to improvements in their social conditions, endorsed positive self-feelings, and were associated with periods of exacerbation of CLBP. Positive changes also entailed improvements in resources and levels of support available to women, which enabled them to engage in active and effective coping strategies to alleviate their pain. In other words, positive biographical transitions fostered the salience of empowered and liberated social identities, and active and dominant illness identities. Negative changes on the other hand, worsened women's perspectives and feelings over time and exacerbated the CLBP. Negative changes also restricted the levels of social and emotional support and resources available to women, obliging them to undertake a passive, ineffective approach to coping with CLBP. In this sense, negative biographical transitions ascribed a disempowered and oppressed social identity on women, as well as a passive and submissive illness identity. The theory demonstrates the multifaceted, processual nature of the construction of illness identities in women with CLBP, and portrays the intertwining of women's social and illness experiences throughout their biographical trajectories.

The following chapter discusses the findings of this study in relation to the existing literature. Moreover, it presents the theory's implications for practice, education and future research, and cites the study's contributions. 


\section{CHAPTER 8 - DISCUSSION}

\subsection{Introduction}

This chapter discusses the study findings in the context of the existing literature. The chapter theoretically compares and contrasts the substantive theory with the existing literature. Engaging aspects of the emergent theory with the theoretical and empirical literature was considered important to counteract the criticism that GT studies often produce substantive theories that are superficial in their theoretical roots (McCann \& Clark, 2003). The chapter commences by explaining how the concept of 'biographical transitions' emerged and was subsequently developed. It moves on to highlight the key findings of this study and discusses them in light of the existing literature. The chapter proceeds by explaining how the process of reflexivity was incorporated into the study and provides some reflexive insights gained from the study findings. Implications of the theory for physiotherapy and clinical education and practice, suggestions for further research, as well as the limitations of the study and its contribution to knowledge are then presented.

\subsection{Biographical Transitions}

In this study, the construction of illness identities amongst women with CLBP has been portrayed as a theory of 'biographical transitions'. In order to elucidate how this theoretical concept developed throughout the process of data analysis, the resonance of both its components to the study findings related to 'biographical' and 'transitions' will be identified.

The term 'biographical' has been utilised to portray a reflexive, inter-relationship between women's illness experiences and identity construction (Gergen, 1991; Wilson et al., 2007). Women's biographical trajectories have been interpreted as an amalgamation of their social, emotional and physical experiences. 
'Transition' was developed as a multifaceted concept, which signified a temporal process of changing perspectives, feelings, social conditions, relationships and environments, as women with CLBP passed from one life period to another (Chick \& Meleis, 1986; Schumacher \& Meleis, 1994; Meleis et al., 2000). While previous perspectives have portrayed living with chronic illness as a process which follows a predictable trajectory, the position taken in this study was that it as an on-going, continually shifting process (Patterson, 2001; Kralik, 2002).

In line with the social constructionist epistemology adopted in this study, the concept of 'biographical transitions' was utilised to explain the multiple identities that women with CLBP portrayed at different phases of their lives in response to changes in factors, including social conditions, relationships and environments (Mead, 1934). It has been suggested that people with chronic illness climb up or down identity levels depending on their social contexts and circumstances (Charmaz, 1987). Therefore, it was necessary to develop a theoretical construct which portrayed the fluidity of women's identity constructions in relation to CLBP.

The concept of biographical transitions was inspired by Bury's (1982) seminal work on 'biographical disruptions' faced by people with chronic illness. Bury's conceptualisation portrayed biographical disruption as individually experienced difficulties caused by the onset of chronic illness. In this study the concept of biographical transitions is seen to be an extension of Bury's notion, which emphasised the temporal, contextual and gendered aspects and conditions under which women's identities and experiences with CLBP developed across their biographical trajectories (Williams, 2000; Ciambrone, 2001; Wilson, 2007). The concept of biographical transitions has been used to portray sociobiographical changes in the life course and life situations of women, in the context of social communities and relationships, and their impact on the manifestations of CLBP and illness behaviours. 
This concept was developed by analysing the data, which were rich with cultural understandings, gendered ideologies and innate feelings. The significance of women's subjectivities to their illness experiences could not be overlooked by interpreting their accounts through biomedical and individualist perspectives, which form the basis of current understandings of chronic illness experiences (see Chapter 4). Indeed, Bury (1982) suggested that consequences of illness and searching for meanings of illness are an intertwined process in lay thought. While Bury focused on the consequences of illness, 'biographical transitions' focuses on the changes in subjective realities symbolising CLBP experiences throughout various periods of women's lives. 'Biographical transitions' signifies both the physical and social entities of women's experiences with CLBP. It focuses on the emotionally expressive body, which provides a crucial mediatory role between the realm of personal troubles and broader public issues of social structure (Hochschild, 1983; Freund, 1990; Williams, 2000).

Biographical transitions was a process through which women's illness identities were constructed, and this process entailed social, interdependent attributes (Mead, 1934), as well as personal, agentic attributes (Goffman, 1959). Women developed their illness identities in relation to cultural norms, social interactions and significant other's expectations. Nevertheless, this internalisation of social factors was an active process, in which women were actively engaged in interpreting the expectations and behaviours of others towards them, and incorporating them into their innate experiences and extrinsic behaviours, or their self construals and identities they portrayed. Women's identities were constructed through a process of internalising social and cultural influences (Mead, 1934), and actively determining the influence of these factors on their sense of self identity construction (Goffman, 1959).

An integral component of this process, which has seldom received attention in the symbolic interactionist notions of self and identity incorporated in this study's conceptual 
framework, is the significance of women's feelings or emotional states on their illness identity construals. The process of biographical transitions considered the impact of societal expectations embedded in various social communities, which either facilitated or impeded women's education, career opportunities, and levels of social support. Women's emotional states, levels of self-esteem, and levels of self-agency were relational to these social conditions. How women felt about themselves and the levels of agency they perceived over their lives influenced either acquiring liberated resilient identities, or oppressed, confined identities. In other words, women's social positions influenced their feelings and their control over their lives, which was manifested as an embodied expression (Hochschild, 1983; Freund, 1990), revealed as the complex, fluid and nuanced experience of CLBP, and the construction of illness identities.

In the following sections key findings of the theory of 'biographical transitions' will be discussed in the context of the existing literature.

\subsection{Social Identities, Social Support and Women with Chronic Illness}

Women in this study portrayed three social identities: the confined identity, the fortified identity, and the irrepressible identity. The emergence of the confined identity was associated with a lack of social and emotional support in women's lives. This endorsed the lack of confidence, self-esteem and negative self-feelings associated with feeling disempowered. This disempowerment and lack of support was associated with women feeling obliged to behave in line with the expectations of others in the hope of attaining social acceptance; furthermore, these behaviours often contradicted their personal and health needs.

Several studies portrayed the negative impact of a lack of social support on women's experiences with chronic illness. This included partners disbelieving the legitimacy of women's pain and suffering (Warwick et al., 2004), an exacerbation of pain triggered by 
the stress associated with a lack of understanding and support from workmates and supervisors (Liedberg \& Henriksson, 2002), a sense of powerlessness, feelings of loneliness and a lack of control over continuous pain (Raheim \& Haland 2006), and questioning of self-worth and feelings of dependence (Kralik, 2003). Similarly, women in this study associated a lack of consideration from their partners to the exacerbation of their pain; they felt pressurised into carrying out domestic chores and responsibilities despite their state of health and their need for rest and support. Feelings of loneliness, dependence, powerlessness and questioning of self-worth are similar to the feelings women in this study portrayed when the confined identity was salient and they were feeling disempowered.

The appearance of fortified and irrepressible identities was influenced by the existence of supportive relationships. Having social and emotional support from others enhanced women's self-esteem and feelings of empowerment. This support and positive emotional state motivated women to engage in an active coping strategy and to take control over their pain.

The need for women with chronic illness to receive social and emotional support, and its positive impact on their emotional state, identities and illness experiences, has been portrayed in the literature. Women appreciated tangible support, such as sharing practical duties and financial help (Warwick et al., 2004; Skuladottir and Halldorsdottir 2011). Moreover, they valued emotional support, including empathy, love, consideration, reassurance and comfort (Raheim \& Haland, 2006; Evans and de Souza, 2008). Receiving such support improved their experience of chronic pain (Warwick et al., 2004; Skuladottir \& Halldorsdottir 2011), and helped them to avoid and overcome feelings of depression, despair and isolation (Evans \& de Souza, 2008; Sharpe, 2013). Women perceived that supportive relationships filled their lives with feelings of strength, joy and resilience. Those positive feelings gave them a motive to focus on other areas of their lives, and the 
strength to develop successful coping strategies that enabled them to conquer or take control of their pain (Raheim, 2006; Evans and de Souza, 2008). Sharpe et al. (2013) found that having support increased women's levels of confidence, and this encouraged them to engage in self-advocacy, a technique which was associated with women developing a positive identity. This included women standing up for their needs, such as taking extra time to complete work projects, the implementation of assistive devices in public areas, and advocating for services and treatment provided through the medical system (Sharpe et al., 2013).

Similarly, the findings of this study suggested that support from others, including financial and emotional support, facilitated positive transitions in women's lives, such as transcending the difficulties of going through a divorce, and surpassing the grief experienced after the loss of a spouse. Surpassing financial constraints and disempowering feelings was associated with the salience of liberated identities, fostering self-agency and control over CLBP. The control over pain that women in other studies described resembled the control women in this study portrayed when the combater identity was salient, which was characterised by the dominating coping strategy, where women were in control of their pain, continuously challenged it, and did not allow it to disrupt them from maintaining their preferred social activities and desired identity. Self-advocacy, the technique women in Sharpe's (2013) study used to develop a positive identity, is similar to prevailing, the behaviour characterising the salience of the irrepressible identity. Being surrounded by people who supported women's empowerment, enabled women to stand up for their beliefs and act in accordance with their personal views, or to prevail over societal expectations which opposed maintaining their desired, liberated identity. 


\subsection{Illness Identities and Coping with Chronic Illness}

Women in this study portrayed three illness identities: the submitter identity, the camouflager identity and the combater identity. The emergence of each illness identity was characterised by various coping strategies women adopted to manage CLBP: relinquishing, masking and dominating. Moreover, there was congruence between the social identities and illness identities women in this study portrayed during various periods of their lives. The social conditions, emotions and behaviours characterising these identities were interrelated.

Variations in the coping strategies adopted by people with chronic illness have been well addressed in the current literature; some approaches resemble the characteristics of the coping strategies in this study. The relinquishing coping strategy was a passive approach to dealing with CLBP. Women led a sedentary lifestyle and limited their social activities, relied heavily on medication, and shaped their illness behaviours in relation to the expectations of others. Benjaminsson et al. (2007) explored and described how patients with recurrent LBP perceive and respond to the recurrence of pain. Some patients in this study undertook a passive approach, where movement was avoided, and where they constantly looked for medical solutions to diminish their pain. Crowe et al. (2010) explored the self-management strategies of people with CLBP. Many participants felt powerless and frustrated; they perceived there was nothing they could do to alleviate their pain. Participants who took this approach gave in to the pain and let it take over their lives. Busch (2005) examined the development of pain-related appraisals, coping, and well behaviours among CLBP patients. Some participants took a non-disregarding approach to managing CLBP. Non-disregarding was characterised by having a fear of the pain, as well as withdrawing from social activities. Participants who took this approach expressed additional emotional anguish because of their pain and conveyed more catastrophic thoughts. While the literature draws light on the ways people manage chronic illness, the 
association between people's social conditions and coping strategies has been under theorised. One aspect of women's experiences that this study highlighted was the manner in which their coping strategy was driven by their access to human, material and social resources. Moreover, it portrayed an overlap between women's social behaviours and coping strategies. When the confined identity was salient, the lack of agency characterising this identity impacted on women's behaviours and the coping strategy they portrayed. Conservative and restrictive social norms, financial dependency, and spouses adopting an authoritarian approach are conditions which were related to isolation (particularly to avoid social stigma), limited funds to seek medical care, and limited access to healthcare. These conditions led women to feel a lack of initiative and to neglect their pain. Moreover, as explained above, such social conditions imposed the struggling social behaviour on women; in addition, the relinquishing coping strategy showed considerable resemblance to women's behaviour in social situations and interactions.

In this study, dominating was a coping strategy where women took an active, assertive approach; they were in control of their pain and did not allow it to interfere with maintaining their desired social identities and activities. One technique adopted by women included avoiding the use of medication, and relying on the 'positivity' they felt to cultivate the strength to challenge the pain and 'expel it from their bodies.' Similarly, Skuladottir and Halldorsdottir (2011) found that some women stopped taking medication and expressed that as a turning point, where they perceived themselves to be in a stronger position and felt that they were in control of the pain. Nevertheless, the factors that may have facilitated such a turning point and what differentiated these women from others who did not stop taking medication, was not clarified. While some studies have proposed that social support helped women cope with chronic illness (Warwick et al., 2004; White et al., 2007), how this support impacted on women's management of their conditions was not reported. In this study it was found that living in an environment that supported female 
strength and independence, and having social and emotional support from others, gave women the strength to take an assertive and active approach in managing their pain. These social conditions fostered the emergence of liberated and assertive identities (the irrepressible and the combater identities), which gave women a sense of agency over their lives, a sense of control over their pain, and an incentive to fight it.

\subsection{Chronic Illness as a Subjective Experience, and Experiences with Healthcare}

Women's experiences and manifestations of CLBP were intertwined with their social conditions and self-feelings. Women preferred healthcare professionals who were empathetic, kind and caring, as it made them feel they were interested in their concerns and in developing treatments tailored to their individual needs.

There was agreement in the literature that women sought care and support from healthcare professionals. Women favoured professionals who were empathetic, willing to listen and provide information, and allowed emotional expression (Skuladottir \& Halldorsdottir, 2011). The findings of this study also suggest that women were motivated to take an active role in managing their pain when they perceived reciprocity and mutuality in their relationships with healthcare professionals, and when they were provided with sufficient explanation and advice about their condition. Werner et al. (2003) found that when women were met with recognition and felt respected and appreciated in treatment groups, their sense of confidence, self-esteem and strength was enhanced. Enhanced self-esteem helped women to deal with the judgments of others, as they were less sensitive and less preoccupied with trying to gain acceptance and understanding from others. Moreover, it helped them surpass feelings of depression, frustration and resignation, and these feelings were replaced by energetic and happy feelings. Such changes enabled women to perceive their pain differently and this changed their experience and made it less disabling. They 
were able to alter their focus from pain and disablement to resources and enhancement (Werner et al., 2003).

Women in this study did not favour healthcare professionals who followed biomedical approaches to their care. Approaches focusing on prescriptions and surgical interventions, and which lacked sufficient explanation about the causes of pain were seen to be ineffective in alleviating or managing their pain. An emphasis on the physical aspects of CLBP was associated with a mismatch between women's subjective experiences and healthcare professionals' emphasis on biomedical reasoning. Similarly, the literature suggests that women often experience a lack of support and caring (Skuladottir \& Halldorsdottir, 2011), a lack of validation and recognition, and perceive that their credibility was questioned when doctors tried to objectify the symptoms of their medically unexplained pain, which they viewed from a biomedical perspective (Werner \& Malterud, 2003; McGowan et al., 2007).

The findings of this study suggested that the approach and behaviours women portrayed in healthcare settings varied. This variation was associated with the identities they portrayed and the coping strategies they adopted during various periods of their lives. For example, the salience of the irrepressible and combater identities was associated with assertive and dominant behaviours. This included women taking a firm stance to ensure they received the management they perceived was necessary, relying on their own expertise about the ability of their bodies rather than on the instructions of doctors, and taking control of alleviating their pain when healthcare providers did not seem to have the answers and disregarded their suffering. This assertive approach was similar to the power strategies women with CFS and fibromyalgia in Asbring and Naravanen's (2004) study used in their interaction with healthcare professionals. Noncompliance refers to a power strategy women adopted; they refused to follow medical advice that did not make sense as they had their own ideas about treatment. Making demands was another strategy where women 
pressed health professionals to carry out various interventions, such as conducting tests or writing referrals to specialists. Women with CFS seemed to be in more control than the women with fibromyalgia, and the authors suggested this might be because women with CSF had relatively higher levels of education (Asbring and Naravanen, 2004). This study's findings suggested that relatively higher educational attainment fostered the salience of the irrepressible and combater identities, and was associated with the assertive behaviours women who portrayed those identities demonstrated. For example, women perceived that being educated taught them to view their CLBP from different perspectives, which helped them cope with and manage their pain.

\subsection{Living as Wives and Mothers, and Suffering from Chronic Illness}

This study's findings revealed that women perceived their roles as wives and mothers to be important; women valued caring for their family members. When this was reciprocated through emotional support from familial and marital relationships, feeling valued reinforced their acceptance of prioritising their child caring duties over their personal needs and desires, as well as their health needs. Moreover, it gave them an incentive to develop adaptive coping behaviours, which enabled them to work around their pain and prevent it from interfering with their responsibilities towards their family members.

The emphasis that women in this study placed on their roles as wives and mothers was also portrayed in Reynolds' (2004) study. It was found that women prioritised their family roles and relationships, and they bought their roles as wives, mothers, sisters and daughters to the forefront. Balancing between their family roles and their illness, such as maintaining their pride for being good wives or mothers and at times feeling inadequate as wives and mothers, and between prioritising their own well-being or their family's wellbeing, and receiving or providing care, were challenges women faced when trying to manage their illness (Reynolds, 2004). The findings in Neil's (2002) study suggested that 
despite feeling fatigue as a result of experiencing rheumatoid arthritis, women still found ways to care for others. Some women lived through periods of 'giving without receiving', where they tried to balance their time and energy between caring responsibilities, as sisters and wives, and their jobs; however, they found no reciprocity or sympathy from family members and spouses. These conditions were associated with the onset of chronic illness periods in their lives they felt were chaotic, and where they perceived themselves to be out of control and constrained. On the other hand, a pattern of 'giving-receiving', where women carried out caring roles and their efforts were reciprocated, gave them an incentive to learn how to build order and stability when faced with illness (Neil, 2002). Despite the difficulties of living with rheumatoid arthritis, having supportive relationships restored women's confidence and enabled them to recognise their inner strength and develop a philosophy of positive living (Neil, 2002). These findings suggest that women with chronic conditions do not simply manage illness according to their own values and preferred coping strategies.

In this study, having reciprocity and empathy from family members fostered the salience of the fortified and camouflager identities. Feeling valued by family members, which led to the salience of the fortified identity, inspired women to prioritise their roles as wives and mothers, which influenced the coping strategy which characterises the camouflager identity. Adapting was characterised by women altering their selves and behaviours to accommodate their family member's needs and prioritising them over their health needs. Similarly, in Skuladottir and Halldorsdottir's (2011) study, women stated that the increase in pain due to childbirth and taking care of their children was not burdensome. They did not see these responsibilities as an obligation; rather, they perceived them to be satisfying and fulfilling, and something that was their choice. They valued feeling needed by their family members. The women in this study prioritised the needs of others over their own 
needs; their need for belonging and to be good mothers, wives and housewives jeopardised their own health and increased their pain.

\subsection{Exacerbation and Remission of Chronic Illness}

The findings of this study suggested that women's biographical trajectories included fluctuations between periods of exacerbation and remission of CLBP. These transitions were associated with changes in their social conditions, and whether these conditions fostered the salience of oppressed social and illness identities characterised by feelings of disempowerment, a lack of self-agency and control over pain, or liberated identities characterised by feelings of empowerment, self-agency and being in control of pain, respectively.

The confined identity was associated with constraining social conditions, including being in a subordinate position in marital relationships and receiving limited social and emotional support from others. The lack of self-agency and feelings of disempowerment characterising the confined identity were associated with an exacerbation of CLBP, the lack of control women perceived over their pain, and the passive illness behaviours they portrayed, conditions characterising the salience of the submitter identity. For example, a lack of confidence and self-esteem which characterises feeling disempowered, made women feel subordinate to their spouses and obliged to overwork themselves on account of their family members' expectations despite their health needs. This association between women's social conditions, emotional states and experiences with chronic illness showed some resonance in the literature. Women conveyed that stressful life events and periods of considerable despair triggered severe medically unexplained pain (Sharpe, 2013). Periods where women perceived themselves to be overworked and suffering from emotional strain related to demands and pressures from family members, a death in the family and work 
conflicts, were all associated with the onset and exacerbation of the symptoms of CFS (Soderlun \& Malterud, 2005).

In this study, women's emotional states were further anguished by the considerable illness disruption and functional limitations that were associated with an exacerbation of CLBP. The association between physical limitations experienced from chronic illness and emotional distress has been well addressed in the literature. This includes feelings of fear and anxiety in relation to over-exertion, recurrence and hyper-vigilance for symptoms, as well as sadness and grief in relation to a perceived loss of independence and physical activity (White et al., 2007). Moreover, women experienced feelings of vulnerability due to the unpredictability of outbursts and remission of their illness, and feelings of distress because of changes to their appearance (Mendelson, 2006). Women also expressed feeling a lack of energy and strength due to their illness, which interfered with their work life, social life, and family life (Soderburg \& Lundman, 2001). Feelings of fear, sadness and grief, and a lack of strength or powerlessness portrayed in the literature, mirror the emotions characterising feeling disempowered, which women in this study associated with an exacerbation of CLBP.

In contrast to the existing literature, one aspect of this study's findings concentrated on the experiences of women during periods of remission from chronic pain and the social conditions and emotional states associated with these periods. Several studies have explored the strategies that women have adopted to live positively with chronic illness. These include humour and laughter to ease their daily stresses and tensions, and courageous behaviours, including challenging themselves and choosing to maintain a positive attitude rather than falling into despair and depression (Sullivan et al., 2003; Adili, 2013; Sharpe et al., 2013). Viewing chronic pain as one part of the whole self rather than as a defining feature of the self, turning inwards to create a space for bodily sensations and emotions to be explored at a deeper level in order to develop pain 
management techniques (Sharpe et al., 2013), and focusing on blessings, such as having caring children and family members (Evans and de Souza, 2008), were other factors that gave women resilience and helped them cope more effectively with their pain. Nevertheless, how women developed these strategies and why some women were not able to see the positive side of living with pain was not clarified.

This study's findings suggested that a remission of CLBP was associated with the salience of liberated identities. The irrepressible identity was characterised by relatively high human and material resources, which was associated with high confidence and selfesteem, and a sense of security. It was also characterised by receiving an abundant amount of social and emotional support, which made women feel happy and gave them an incentive to stay strong, or gave women resilience, as suggested in the studies by Evan and Souza (2008) and Sharpe (2013). In other words, using humour and laughter to ease the stresses of illness (Suvillan et al., 2003) or feelings of happiness were developed in the context of having abundant human, material and social resources that fostered the salience of desirable, liberated identities. The availability of human, material and social resources, and the positive emotional state associated with these factors, enabled women to focus on the positive aspects of their lives, and this finding is supported by Suvillan et al. (2003), Adili (2013) and Sharpe et al. (2013). The incentive to stay strong was associated with dominating, the assertive coping strategy characterising the combater identity, where women challenged the pain and resorted to the 'positivity' they were surrounded by to expel it from their bodies. Adopting an active and dominant coping strategy enabled women to gain control over their pain and was associated with periods of remission. In other words, social conditions which fostered the salience of liberated identities provided women in this study with resources and enhanced their emotional state. These factors enabled them to develop resilience and to cope more effectively with chronic pain, a 
finding supported by Evans and de Souza (2008) and Sharpe (2013), or tailored the salience of the combater identity.

\subsection{Biographical Transitions and Women's Experiences with Chronic}

\section{Illness}

The findings of this study focused on the fluidity and non-linear nature of women's experiences with CLBP. They portrayed how changes, including relationship changes and environmental changes impacted on the salience of various social and illness identities over time. For example, women with friends and family members who provided them with emotional and social support were able to surpass negative social conditions, which ascribed the confined identity on them. They developed feelings of care and empathy from family members, as well as happiness, security and control, associated with the salience of the fortified and irrepressible identities. Transitions which entailed positive changes in women's social conditions and emotional states gave them an incentive to engage in active coping strategies and were associated with a remission of CLBP. In other words, conditions leading to salience of the fortified and irrepressible social identities fostered the salience of the camouflager and combater illness identities, respectively.

The fluidity in women's illness experiences was demonstrated in the literature. Studies have demonstrated that transitions in women's lives do not follow a chronological illness trajectory, rather, they are convoluted and dynamic, and incorporate episodes of uncertainty and exacerbation of illness, as well as times of illness stability (Kralik, 2002). Having emotionally supportive relationships gave women an incentive to take an active role in managing their conditions, and enabled them to transition from a period where illness was considerably disruptive and where women felt a lack of control, to periods where women were in a state of balance, empowerment and control (Kralik et al., 2003; Adili et al., 2013). Neil (2002) found that some transitions in women's lives, which 
included reciprocal connections, were associated with receiving and conserving energy in a self-protective way. For example, remarrying a loving spouse or moving to live closer to children, were associated with support and an increase in self-confidence. Perceiving more care and support from others gave women different perspectives on their lives, which liberated them from old constraints, helped them to find different ways to live with their illness, enabled them to recognise their inner strength, and assisted them to develop a philosophy of positive living and experience periods of remission of illness symptoms.

The women in Sharpe et al.'s (2013) study suggested that the construction of a desirable identity characterised by empowerment and strength entailed a sense of empathy, understanding and validation from others, which fostered the development of confidence, strength and courage to challenge the pain and have a positive outlook on life. The conditions that fostered the development of a positive identity in Sharpe et al.'s (2013) study are similar to the conditions that influenced the construction of the fortified and irrepressible identities in this study. Social acceptance and feelings of care and empathy from others increased women's confidence and self-esteem. This was associated with the salience of the camouflager and combater illness identities, where women sought to develop adaptive and assertive strategies to avoid the pain from interfering with their social roles and activities.

Findings from this study also suggested that women who lacked social and emotional support, due to circumstances such as financial dependency, losing loved ones or emotionally abusive marriages, could not transcend the lack of serenity they felt in their lives associated with the confined identity. Transitions in these women's lives entailed further emotional turmoil and hardship, and they did not portray any difference or improvement in their suffering over time. Changes in their social conditions continued to ascribe the confined social identity on them. This fostered the salience of the submitter illness identity, which was characterised by a lack of incentive and a passive approach to 
managing CLBP, and associated with continuous exacerbation of pain and illness disruption. Similarly, the literature suggested that conditions including poverty, poor social support, being in an abusive marriage or with an unsupportive and unsympathetic spouse, feelings of insecurity and low self-esteem, were associated with periods of an exacerbation of symptoms (Neil, 2002). Such conditions acted as constraints and did not enable women to transition to a state of 'ordinariness', namely a state of balance, empowerment and control (Kralik, 2002). Rather, women were caught in a state of 'extraordinariness', where they perceived a lack of control over their lives and their bodies, perceived their bodies were a burden, and felt dependent on others, such as healthcare professionals, to take care of their bodily functions (Kralik, 2002).

In this study it was demonstrated how transitions in women's lives were associated with changes in the illness behaviours or coping strategies they portrayed over time. Transitions, which improved women's access to material resources and the social and emotional support they received, had a positive impact on their emotional state. These conditions enabled women to liberate themselves from the confinements of the confined identity, enhancing the degree of their self-agency they perceived, and the approach they utilised to manage their CLBP. A similar association was portrayed in Raheim and Haland's (2006) study, where their findings showed how changes in social conditions across time impacted on women's illness experiences and coping abilities. There was ambivalence in some women's experiences. One period was characterised by feelings of control, where they engaged in physical activity daily as a way of controlling the pain and not allowing it to dominate their lives. In other periods, which involved the birth of a new baby for example, women felt overwhelming pain and exhaustion, as they could no longer maintain their coping strategies because of increased responsibilities (Raheim and Haland, 2006). 


\subsection{Culture, Gender and Chronic illness}

The findings of this study suggested that the construction of women's social and illness identities were influenced by the Kuwaiti cultural context. There appeared to be a continuum of ideologies pertaining to the female gender, some laying on the more conservative and traditional end of the spectrum, defining femininity through docility and dependence, and others laying on the more liberal and modern end of the spectrum, constructing the meanings of the female gender through ideologies of strength and independence.

The association between cultural constructions of the female gender, and their behaviours and identity construal resonated in the literature. It was found that women internalised cultural constructions of gender; they were expected to place the needs of others before their own, and to maintain the cleanliness and tidiness of their households. Women made every effort to meet these expectations to avoid being undervalued, which caused conflict, led women to question their self-worth, and was associated with periods where women perceived a lack of control over their lives, their bodies and their pain, and where they experienced overwhelming fatigue (Kralik, 2002; Kralik et al., 2005). In Richardson's (2005) study, women presented themselves as 'good housewives' despite their pain, in order to maintain a positive identity by continuing to undertake traditional female tasks.

The cultural understandings and behaviours portrayed in the findings of Kralik (2002), Kralik et al. (2005) and Richardson (2005) resemble the cultural ideologies and behaviours characterising salience of the confined and submitter identities, as well as the fortified and camouflager identity in this study. The lack of confidence and self-esteem associated with the confined and submitter identities led women to shape their behaviours in line with other's expectations. Feeling obliged to maintain their domestic and child caring roles despite their pain led them to experience considerable exhaustion and an inability to 
control and actively manage CLBP. In terms of the fortified and camouflager identities, family members who showed consideration and appreciation for women's efforts in their households encouraged women to prioritise their roles as wives and mothers over their personal needs. They maintained desirable and culturally accepted identities, which was reinforced by the acceptance of others. Prioritising their responsibilities as wives and mothers meant developing an adaptive coping strategy, which enabled them to work around their pain and stop it from interfering with their responsibilities towards their spouses and children.

The literature exploring women's experiences of chronic illness discussed thus far has paid particular attention to Western traditional understandings of women, and how such understandings may have influenced their behaviours and experiences with healthcare. Historical understandings of women as prone to sickness, vulnerable and fragile, were believed to make them more likely to report health problems, and experience prolonged mental symptoms, as well as medically unexplainable symptoms (Malterud, 2000). Moreover, historical notions of hysteria owed their medical complaints to the fact that women were 'crazy, lazy and illness-fixated' (Werner \& Malterud, 2005, p.43). In a review by Hoffmann and Tarzian (2001), it was found that the literature suggested that women's subjective experiences of illness and treatment are frequently ignored, and their pain complaints were taken less seriously than men due to cultural understandings of women's ability to reason being compromised, and their opinions being thoughtless, emotional and naive (Milles and August, 1990; Parks, 2012, as cited in Hoffmann and Tarzian, 2001).

The Western ideologies portrayed in the literature, which related the female gender to weakness and delicacy, show a resemblance to the traditional and conservative ideologies in this study, which associated femininity to docility and dependence. The findings of this study portrayed how such understandings impacted on women's day-to-day experiences 
with CLBP outside the medical context. Associating the female gender with docility may explain why spouses and family members in conservative social communities were inconsiderate and disregarded women's pain. Frequent pain may have been perceived as part of females' weak nature, rather than as an anomaly that they needed support in order to overcome.

It has been acknowledged that biomedical theory and practice has historically been developed by men, and continues to reflect gendered understandings of health disorders, making medical encounters difficult for women (Hoffmann \& Tarzian, 2001; Werner \& Malterud; 2003, 2005). This emphasis, which did not incorporate women's experiences, made their encounters with doctors degrading and demeaning, led them to adopt stoic behaviours (Sharpe, 2013), and to conceal their illness and suffering in a quest for normalcy (Skuladottir \& Halldorsdottir, 2011). The work that women needed to do to confront misunderstandings and disbelief detracted energy from challenging the pain in order to maintain a desirable life (Werner \& Malterud, 2005). This biomedical emphasis on male experiences may explain the mismatch portrayed in this study between women's subjective experiences, and doctors attempts to objectify their pain.

One aspect of this study that did not show much resonance in the literature was the impact of empowering cultural ideologies on women's experiences with chronic illness. This study's findings suggested that communities affirming female strength and independence encouraged educational and career development, enhanced women's independence, selfagency, confidence, and in turn gave them the strength to behave in line with their personal beliefs and understandings. Living in communities with liberal understandings fostered the salience of liberated identities characterised by emotional content, active illness behaviours, and a remission of CLBP. Nevertheless, several authors have advocated for the importance of empowering women in the healthcare context by recognising their suffering as well as their strength, providing them with helpful 
information and knowledge, increasing their self-confidence and involving them more in decision-making regarding their own care and treatment (Werner et al., 2003; Werner \& Malterud, 2005; Skuladottir \& Halldorsdottir; 2008, 2011). Since the healthcare consultation constitutes only a minor proportion of the life of women, this study's findings sheds some light on the importance of gathering a wider understanding of women's cultural and social contexts, and how the expectations of others surrounding them may influence their manifestations of chronic illness and their illness behaviours.

Overall, the theoretical model presented in this study emphasises the fluidity and subjectivity of the multifaceted CLBP phenomenon. It emphasises the embedding of women's social and emotional experiences in the construction of their illness identities, which in turn shape their manifestations of CLBP and their behaviours for coping and managing their pain. The literature has shed light on the significance of these 'intangible', and often overseen aspects of experience, in shaping women's experiences of chronic illness. Like the present study, there is an acknowledgment in the recent literature for the need to develop more holistic perspectives from which to explore and analyse people's experiences with chronic pain and illness.

The theory in this study postulates that the process of biographical transitions develops through the internalisation of an amalgamation of emotional experiences, social interactions, societal expectations, and cultural ideologies. These include the impact of social and familial support and interactions with significant others, the significance of gendered motherly and childbearing roles, and conservative and liberal norms cultural ideologies, on shaping women's illness identities. While associations between women's social conditions and illness experiences have been proposed in the current literature, this study's findings puts forward a novel theorisation of such associations, and shed light on the interconnected and relational nature of women's sociobiological existence. This study focuses on the development of women's social identities, and how the social conditions, 
interactions, thoughts and feelings embedded in this process are intertwined in shaping their illness identities and experiences of pain. Whereas the available literature emphasises the impact of chronic illness on reshaping people's lives and identities, this study suggests that women's social experiences and being are equally significant in shaping and reordering their illness experiences. This was portrayed by explaining how periods of social difficulties and emotional turmoil were associated with an exacerbation of CLBP and passive coping behaviours. On the other hand, periods of favourable social conditions and emotional content were associated with a remission of CLBP and assertive coping strategies.

There has been emphasis in the current literature on portraying the onset of chronic illness as a disruption which compromises people's preferred identities. The theory presented in this study emphasises that people's experience with chronic pain does not necessarily follow a tragic, regressive trajectory which subjugates them to desert former selves and identities. The onset or exacerbation of CLBP was intertwined with multiple emotional and social events and experiences, which were influential on the social and illness identities women portrayed at various periods in their lives. For example, the theory demonstrated how women who felt valued and had social and emotional support prioritised, and maintained their gendered roles despite their pain. This was achieved by developing adaptive coping strategies to enable them to maintain their preferred identities. In other words, the availability of social and emotional resources enabled women to maintain their preferred identities and develop effective coping strategies to control their pain.

Finally, an aspect of the current theory which needs further investigation is the impact of empowering cultural ideologies on improving women's experiences with CLBP. It emphasises how liberating norms fostered the development of confident, empowered women, who are able to control and be dominant over their pain. While the literature 
focuses on the impact of oppressive ideologies on shaping the struggles women with chronic illness experience, this study illuminates how liberating ideologies have the potential to empower women with CLBP, and in turn enhance their coping behaviours and improve the quality of their lives despite their illness. This requires further exploration in other social contexts in order to develop more holistic management approaches which incorporate empowering and liberating advancements. Table 8.1 overleaf summarises the findings of this study which have been supported and refuted in the available literature, and findings which are considered novel understandings of the experiences of women with CLBP and the process of illness identity construction.

\begin{tabular}{|l|l|l|}
\hline $\begin{array}{l}\text { Findings supported by the } \\
\text { literature }\end{array}$ & $\begin{array}{l}\text { Novel understandings provided } \\
\text { by this study }\end{array}$ & $\begin{array}{l}\text { Ideas in the literature which } \\
\text { refute the study findings }\end{array}$ \\
\hline $\begin{array}{l}\text { The significance of women's } \\
\text { social and emotional experiences } \\
\text { and the necessity of } \\
\text { acknowledging such experiences } \\
\text { in the conceptualisation of chronic } \\
\text { pain. }\end{array}$ & $\begin{array}{l}\text { The development of women's } \\
\text { social identities, and how social } \\
\text { conditions and innate experiences } \\
\text { are embedded in this process and } \\
\text { intertwined in shaping women's } \\
\text { illness identities and their } \\
\text { experiences of pain. }\end{array}$ & \\
\hline $\begin{array}{l}\text { The association between women's } \\
\text { social conditions, including social } \\
\text { and familial support, interaction } \\
\text { with others, gendered roles and } \\
\text { cultural ideologies on their } \\
\text { experiences with chronic pain and } \\
\text { illness. }\end{array}$ & $\begin{array}{l}\text { Emphasis on social and emotional } \\
\text { resources which improve } \\
\text { time and enable them to take } \\
\text { control of their pain and maintain } \\
\text { preferred identities. }\end{array}$ & $\begin{array}{l}\text { Emphasis on a regressive illness } \\
\text { trajectory leading to loss of self } \\
\text { and preferred identities. }\end{array}$ \\
\hline \multicolumn{1}{|c|}{$\begin{array}{l}\text { Emphasis on the impact of } \\
\text { liberating cultural ideologies on } \\
\text { constructing empowered social } \\
\text { and illness identities and } \\
\text { improving the quality of women's } \\
\text { lives despite their pain. }\end{array}$} & $\begin{array}{l}\text { Emphasis on oppressive gendered } \\
\text { ideologies which have detrimental } \\
\text { consequences on the lives of } \\
\text { women with chronic pain and } \\
\text { illness. }\end{array}$ \\
\hline
\end{tabular}

Table 8.1: Support and rebuttal of the theoretical model by the literature and the novel contributions resulting from this study

The next section presents a reflection on the research journey and acknowledges and discusses how I influenced the research process, and the ways in which I may have impacted upon the findings. 


\subsection{Reflexivity}

\subsubsection{During the Research Process}

The constructivist GT theory in this study was developed through a process of coconstruction of knowledge between the researcher and participants, and reflects an interpretation of the data. In this sense, I assumed a reflexive stance and needed to be aware of my presumptions and values, and how they may have influenced the perspectives through which I viewed data, the questions asked during the interviews, and the theory formulated (Charmaz, 2006; Bryant \& Charmaz, 2010). While generating the theory I continuously examined and reflected on my personal reactions towards the data, as well as exploring the dynamics of the relationship between the researcher and the researched, and how the resulting theory is a co-construction imbedded in both the researcher and the participants' experiences. The following discussion will address how reflexivity was incorporated in this study. Moreover, it discusses some reflexive insights that I have gained from the research journey.

My background as a physiotherapist was influential in my decision to pursue this study (refer to Section 1.1). I started this research study with my own pre-understandings and assumptions, which were mainly clinical understandings based on my professional biography. However, my sociological knowledge and awareness of the theoretical concepts available was very limited. Therefore, my initial analysis of the data was naive and discomforting. For several months I found myself lost in the vast amount of data that my participants and I had constructed. It felt more comfortable to seek answers within my data to questions, such as those posed by other researchers. It was appealing to respond simply to questions asked within other researcher's studies, rather than utilise perspectives which may lead to novel knowledge about how women with CLBP construct identities in Kuwait. 
Being too cautious about delving deep into the literature limited my understanding of the position of 'perspectives' in DA. One of the main reasons that drew me to DA was Schatzmans' proposition that natural analysis and research analysis are essentially the same (Schatzman, 1991; Bowers \& Schatzman, 2009). My understanding of natural analysis was limited to what I already knew, or my personal and professional biography. The dimensions that were generated from applying my professional perspective were focused on pain and physical limitations. I could also see how my prior conceptions and knowledge were the main perspectives taken to generate dimensions; in addition, reflecting on my prior assumptions and perspectives enabled me to actively frame alternative analytical views of the research data.

I realised the importance of continuously reflecting on my underlying assumptions and their influence on my analysis and interpretations. My assumptions based on my professional background were constantly challenged through reflexive memos and reflexive notes while I was conceptualising and labelling pieces of data. I reflected on my prior knowledge and experience from managing patients with CLBP and tried to challenge them if the data were opposing them to avoid forcing presumptions on my data, and ensure my interpretations can be supported and are grounded in the data.

Having reviewed the literature I saw that the emphasis on clinical aspects of illness experiences was one reason for producing reductionist or limited understandings of the construction of identity in people living with chronic illness. In order to extend existing knowledge and understandings, I needed to utilise broader and alternative perspectives that may contribute to understanding the social dimensions of identity construction. I understood that experiential knowledge, or personal biography, was only one source from which a qualitative researcher draws upon. Strauss and Corbin (1990) supported reviewing the literature early in the study as a way of increasing theoretical sensitivity. In line with their recommendation and with guidance from my supervisors, I realised that in 
order to formulate a theory explaining the social processes involved in women's CLBP experiences, I needed to broaden my understanding of the sociological literature exploring people' experiences with chronic conditions. Constantly being reflexive and challenging my prior knowledge and assumptions enabled me to acknowledge the emotional and social dimensions of women's experiences, and how their biographies influenced their manifestation of CLBP and the behaviours they adopted to manage their pain.

It is suggested that when the researcher has many commonalities with participants, participants may make assumptions of a shared understanding and therefore fail to explain or elaborate on aspects of their individual experiences (Charmaz \& Bryant, 2010). Being a Kuwaiti female who grew up and lived in the same cultural context as the women in my study, I was aware of the societal expectations on women in Kuwait. Being reflexive allowed me to appreciate that the meaning of the female gender in Kuwait was not constructed based on a fixed set of beliefs and assumptions. It allowed me to think broadly and compare values and beliefs that I was exposed to, and how such values and beliefs may have evolved and modernised over time; it also enabled to me examine how families with different social backgrounds may still hold on to more conservative and traditional ideas about women's roles. Consequently, this reflective process led me to pursue this issue in later stages of this study through theoretical sampling in order to understand how factors, including age and the social environment women lived in, influenced the cultural understandings they were exposed to, and how such ideologies shaped their identities. Understanding this issue in more depth enabled me to embed my analysis into the cultural context of my study, thereby increasing its relevance.

\subsubsection{Insights Gained from the Research Process}

This thesis represents a journey of personal and professional development and growth. As I formulated my theory I realised how the lens through which I interpreted the data was directly shaped by the research experience and the data. My interpretive lens was 
constructed of knowledge and assumptions which I acquired from multiple sources, including relevant literature and my personal and professional experiences. The resonance of my clinical experience and knowledge, and my personal life in the research process is irrefutable. Adopting a constructivist GT approach enabled me to be entirely transparent and reflexive about my position in the theory, and about my active role as the primary researcher (Charmaz, 2006; 2014).

Reflecting on my clinical practice, the sociological literature I have been immersed in for four years, and my study findings, which I have been developing over the course of two years, I was able to build several fruitful insights about the experiences of women with chronic illness. I now view women's experiences with CLBP as a process that follows a cyclical rather than a linear trajectory. As a clinician I have changed my view about the number of years a woman has suffered from the pain being a priority. A more important question to ask would be why she is experiencing a period of exacerbation at the point that she has been referred to me. Moreover, the influence of women's self-feelings on their manifestations of illness has alerted me to the importance of investing in the relationship with my patients, in order to be empathetic and accommodating to their needs as part of my treatment approach.

Reflecting on my prior understanding of CLBP, made me acknowledge that viewing women's pain through a biomedical lens may lead to an essentialist, limited understanding of the issue. A widened scope of reading and interpretation of sociological, psychological and anthropological literature enabled me to develop a holistic and integrated understanding of women's experiences with chronic pain. One of the most important realisations I made is that women live most of their lives outside the hospital, and their encounter with healthcare professionals, including myself, is only a minor proportion of their lives with illness. 


\subsection{Implications for Education}

Considerable attention has been bought to the gendered nature of biomedical explanations of medical conditions (where the description of symptoms and the course of illness are predominantly based on male experiences), and the impact this has on women with medically unexplained pain (Hoffmann \& Tarzian, 2001; Malterud et al., 2004). The interconnectedness between women's social biographies and illness trajectories demonstrated in this study calls for educational programmes which encourage future clinicians to pay attention to a patient's illness perspectives, even when they diverge from biomedical templates. This can be achieved by incorporating several reflexive strategies related to personal experience, empathy and self-knowledge into clinical education.

Baarts et al. (2000) proposed how the general practitioner (GP) can consciously use reflexivity as a strategy to gain access to additional knowledge about patients' understanding of their health. Personal experience can be resorted to when a GP cannot observe a patient's complaints or symptoms. Reflecting on and relating personal experience of similar symptoms may enhance understanding and enable a GP to get closer to their patient's perspective. Identifying oneself with the patient's situation by reliance on personal experience leads to an empathetic understanding and bridges the gap between lay and professional perceptions of illness. Self-knowledge involves practitioners being reflective about their backgrounds and personalities, position in the social world, attitudes and personal experiences, and how these aspects may influence their understanding of and interaction with each patient. As this study's findings demonstrated, women's subjective experiences, sociocultural contexts and the expectations and interactions with others, including healthcare professionals, are aspects that are interrelated with their manifestations of CLBP. Therefore, adopting a strategy similar to Bart et al.'s (2000) into clinical education programmes of physiotherapy may provide students with a platform that enables them to be reflexive about aspects including their cultural understandings and 
expectations, their positions in the sociocultural context and how these aspects may influence their interaction with and management of women with CLBP.

Another strategy which may enable physiotherapists to delve into the subjectivity of women's experiences with CLBP is narrative analysis. Bleakley (2001) suggested that narrative approaches in clinical education claim specific practice benefits, such as increased empathy. He suggested that narrative analysis brings practitioners closer to the patient's world through the medium of story. Such an approach requires educators to provide students with skills that may enhance their understandings of affective, relational, and ethical dimensions of patient's illness experiences. This may be achieved by including Edwards et al.'s (2000; 2005) clinical reasoning strategies, with a particular emphasis on narrative reasoning into education curricula. These clinical reasoning strategies are presented in Figure 8.1 below.

Diagnostic reasoning: The formation of a diagnosis related to physical disability and impairment with consideration of associated pain mechanisms, tissue pathology and the broad scope of potential contributing factors.

Narrative reasoning: The apprehension and understanding of patients' illness experiences, 'stories', contexts, beliefs and cultures.

Reasoning about procedure: The determination and implementation of treatment procedures.

Interactive reasoning: The purposeful establishment and on-going management of therapist-patient rapport.

Collaborative reasoning: The nurturing of a consensual approach towards the interpretation of examination findings, the setting of goals and priorities, and the implementation and progression of treatment.

Reasoning about teaching: The activity of individualised and context sensitive teaching.

Predictive reasoning: The active envisioning of future scenarios with patients including the exploration of their choices and the implications of those choices.

Ethical reasoning: The apprehension of ethical and practical dilemmas that impinge on both the conduct of treatment and its desired goals, and the resultant action towards their resolution.

(Edwards et al., 2000)

Figure 8.1: Clinical reasoning strategies

Edwards et al. (2000) suggested that narrative reasoning is a strategy that can be applied by physiotherapists to understand patients' stories in order to gain insight into their experiences with pain and how their manifestations impact their beliefs, feelings and health behaviours. It includes communicative interaction, which is characterised by open- 
ended questions with the aim of gaining an understanding about a person's values, beliefs or assumptions regarding their illness or treatment. As has been illuminated in this study's findings, women's manifestation of CLBP was considerably impacted by their perceptions of their social contexts, positions and relationships. Therefore, incorporating narrative reasoning in the education of future physiotherapists may give them the skills required to explore women's individual experiences of CLBP and how their particular sociocultural conditions may influence their pain and behaviours.

\subsection{Implications for Practice}

The findings of this study offer an understanding of the multiple roles and identities women portray, and how biographical transitions entailed changes in these roles and identities over time. CLBP was portrayed as one aspect or part of their biographies which was intermeshed with social, emotional and temporal dimensions of women's lives.

The 'shifting perspectives model of chronic illness', formulated by Patterson (2001), demonstrates a dialectical, continuously shifting process in which 'an illness-in-theforeground or wellness-in the foreground perspective has specific functions in the person's world' (p.21). In this study, illness was brought to the foreground during periods of emotional turmoil and constraining social conditions. These feelings and conditions were associated with the exacerbation of CLBP, where it was a dominant aspect of women's lives. Wellness was brought to the foreground during periods of emotional content and liberating social conditions, which were associated with the remission of CLBP; it was a more marginal aspect of their lives during this time. Therefore, the study findings illuminate the need for clinicians to extend their views of chronic illness experience from a focus on how it affects people's health and well-being, to acknowledging how larger sociocultural contexts may impact on women's manifestations of pain. Acknowledgement 
of the social and family context, and how women's gendered identities may interplay with their CLBP experiences, may be more effective when managing CLBP.

The transitional nature of women's biographies and the associated changes in their manifestation of CLBP is an indication that clinicians should not be inclined to treat and manage chronic pain as a static entity. Rather, there is a need to be aware of the changes in women's behaviours and perspectives over time, in line with transitions and changes in their identities, and continuously adapt management and treatment plans accordingly.

Women in this study emphasised their need for healthcare professionals who listened to their concerns, were empathetic, and gave them sufficient information to help them understand their pain. In other words, women appreciated clinicians who validated their subjective experiences. Several communicative techniques have been proposed to gain a better understanding and incorporate women's subjective experiences in their care. These include the use of open-ended questions, reinforcing the role of patients in the healthcare encounter as an important source of information and knowledge, legitimising patient's language as expressed in their own words, and using humour to prevent embarrassing patients when they deliver their own version of the situation (Malterud, 2000).

In this study, a sense of support and acceptance from others was associated with building self-confidence and self-esteem, and empowering women to engage in active coping strategies in order to take control of their CLBP. This sense of support and acceptance may be promoted in healthcare settings by providing group treatment for women suffering from CLBP. The benefits of group treatment include giving women a sense of appreciation for being part of a treatment group, as they encounter people who listen to them, understand them and acknowledge their pain and suffering (Steihaug et al., 2002). In this study, some women lived in social communities with constraining cultural ideologies, where they felt a lack of support and acceptance, perceived themselves as subordinate to 
others, and perceived a lack of control over their pain. Therefore, the reciprocity and mutuality that may be found in group treatment may contrast with the power imbalances in social interactions with individuals who did not acknowledge women's emotional state and suffering. This may lead to positive impacts on women's perceptions of self, emotional well-being and the management of pain.

While group treatment has been perceived to be beneficial, Werner et al. (2003) suggested that women faced difficulties with the application of their enhanced bodily, emotional, and social competence outside a treatment programme due to negative reactions from husbands or other people who were inconsiderate towards their needs. To help women overcome such obstacles formulating support groups may be beneficial. Having the support of others who share similar experiences can validate women's feelings, provide them with coping resources, and allow them to seek out positive role models (Sharpe et al., 2013).

In this study, women valued education and perceived it to be an asset, which promoted self-confidence, security and independence. One way clinicians may enhance women's education is by providing them with helpful information and knowledge about their conditions. Providing women with knowledge has been suggested to be empowering, and has encouraged them to be more involved in decision-making regarding their own care and treatment (Skuladottir \& Halldorsdottir, 2011).

The findings of this study portrayed the integral role family members and significant others played in women's lives, and how social interactions and the expectations of others influenced their manifestations and experiences of CLBP. Therefore, it may also be necessary to provide more awareness and education to family members about CLBP and the impacts it may have on women's lives. This can be achieved through distributing leaflets, directing them to relevant webpages, providing televisions with informative 
programmes in the physiotherapy waiting area, and engaging in face-to-face discussions with family members.

This study's findings suggested that the role women took in managing their CLBP was influenced by the identities their social conditions and emotional states fostered the salience of. Some periods of women's lives were associated with a passive, dependent approach, other periods were associated with bringing the needs of others to the forefront while their illness needs were swept to the background, and others still were associated with a dominant and assertive approach to managing CLBP. While patient-centred care has been continuously advocated in the literature, this study's findings indicated that it may be necessary to negotiate with women and consider the role they prefer to play regarding their care. For example, salience of the confined and submitter identities may be associated with the need of women to be more dependent on health professionals and may oppose clinician's goals to delegate authority to women to make decisions regarding their care.

\subsection{Suggestions for Future Research}

This study has provided theoretical insight into the construction of gendered identities amongst women with CLBP, which was strongly influenced by sociocultural understandings of the female gender in Kuwaiti society, and changes in their social conditions, relationships and environments over time. This is the first study which investigates the construction of illness identities in the CLBP literature, and the extensive findings generated indicate that there are a number of key areas of women's experiences with CLBP which warrant further exploration.

This study investigated the construction of women's social and illness identities, and how they impacted on their day-to-day experiences with CLBP in their family and social contexts. Further research needs to be carried out to investigate how variations in women's 
identities may influence their interactions with physiotherapists and their behaviours in healthcare settings. Signs of emotional distress or content, levels of activeness or passivity, and a willingness or lack of initiative to be involved in care and decision-making are aspects that may be worth exploring.

In this study, insight into the impact of prevalent social and cultural understandings defining female gendered identities in Kuwait has been explored. Women internalised these understandings and other people's expectations, and how these ideologies manifested into the construction of their identities and social roles as mothers, wives, employees, and women suffering from CLBP was explored. Further research is needed to explore the transferability of these findings by investigating the associations illuminated in this study in various other cultural and social contexts. The complexity of women's lives and the multiple and intersecting aspects of identity and chronic illness may need to be addressed in future research.

This study placed a particular emphasis on the benefits of empowering social communities, which fostered the salience of liberated and desired identities and was associated with positive periods of effective coping, remission of pain and minimal disruption. Living positively with chronic illness has been an area that has received noticeable attention in more recent studies investigating the experiences of women with chronic illness (Neil, 2002; Kralik, 2002; Sharpe et al., 2013). Nevertheless, it has been suggested that resilience (of people living with chronic illness) is contextual, rather than a quality that people either possess or do not possess. Moreover, people may be more or less resilient at different points in their lives depending on a range of factors (Kralik et al., 2006). In this sense, how the understandings and ideologies constructing female gendered identities in other social and cultural contexts, and what factors may promote effective coping, remission of illness symptoms, and living more positively with chronic pain are aspects that may need to be further explored in various contexts. 


\subsection{Thesis Limitations}

Whilst this research has produced knowledge of the construction of illness identities in women from Kuwait, a number of limitations need to be highlighted. These are discussed below.

While considerable amounts of data pertained to the ways women perceived their social interactions and the expectations of others influenced their identity construal, the data in this study was based on individual narratives. This may have possibly led to some form of bias as the participants may have misreported or under-reported their relationship perceptions. However, this study aimed to understand the construction of illness identities from the perspective of women in the Kuwaiti context, and the iterative nature of the GT methodology adopted was useful in constantly comparing the interpretations generated across participant's data, and going back to participants to verify theoretical constructions.

Another limitation is concerned with the data collection methods utilised in this study. Interviewing was selected as it was fitting with the social constructionist epistemological stance underpinning this study, and enabled me and the participants to reflect on the multiple realities of living with CLBP. However, participants may have shaped their responses to the interview questions to please me or leave a positive impression (Holloway \& Wheeler, 2002). Being aware of this possibility prompted me to ask probing questions during the interviews in order to gain further insight into women's responses. One way of diminishing the possibility of women altering their responses is for the interviewer to gain participants' trust by developing the participant-research relationship (Holloway and Wheeler, 2002). I adopted this approach by using the first ten minutes of the interview to have a general discussion with the women, such as asking women about their social background and talking a little about their children if they were mentioned. These opening interview questions were necessary to ensure that the women felt comfort during the 
interview process. The opening questions were also important for developing trust and a rapport with the women, so that they would feel comfortable in sharing personal details of their experience with CLBP.

Another limitation of this study was my skills and expertise as a qualitative researcher and a grounded theorist. While I extensively engaged with the GT literature and attended workshops to help me feel more confident about my understanding of GT and qualitative methods; however, the implementation of these processes in the field was more challenging. The lengthy data collection period and extended analysis, in combination with consulting the literature, resulted in analytical insights which enabled the data to be viewed from a variety of perspectives.

\subsection{Contribution to Knowledge}

This study is the first constructivist grounded-theory-based study exploring the construction of illness identities in women with CLBP from Kuwait. The findings of this research provide a substantive theory that will help to develop knowledge of, and feed into, current debates on the impact and influence of culture, social norms, and values on women's perspectives, feelings and behaviours, which have a direct effect on their pain experiences and they ways they cope with it.

This study's findings emphasised the fluctuations between periods of exacerbation and remission, which were associated with the salience of oppressed and liberated identities, respectively. There has been agreement in the available literature that chronic illness trajectories are fluid; nevertheless, the emphasis has been on a linear, regressive trajectory. This study discussed how women's access to human, financial and social resources was associated with improvements in their experiences. Utilising these resources was beneficial in enabling them to engage in active and effective coping strategies, thereby reducing and eliminating the impact of CLBP on their lives. The literature has shed some 
light on the experiences of women living positively with chronic illness. Nevertheless, variations in women's experiences and why some women are able to live positively with illness while others are not, an area which has been emphasised in this study, has scarcely been addressed.

The substantive theory presented in this study emphasises the fluid, inconsistent, and multifaceted nature of women's experiences with CLBP. It encourages healthcare practitioners to disengage from dichotomous biomedical conceptualisations of pain, which reduce people's experiences to a one-dimensional physiological anomaly (Bendelow 1993; Bendelow and Williams, 1995). Rather, it advocates more empathetic and person-centred understandings of people's experiences, which endorse changes in their social conditions and circumstances, and the impact on their pain experiences and behaviours.

This study provided an understanding of how women's emotional states and the behaviours and expectations of others towards them impacted on the variations in the coping strategies they portrayed. While there has been an abundance of literature published on the variations in people's coping styles, there has been less emphasis on the impact of women's feelings and social differences. Associations similar to the ones in this study have been proposed, but seldom theorised.

The theory constructed in this study emphasises the significance of women's subjectivities, or their social and emotional experiences, in constructing their illness identities, and in shaping their experiences of physical pain. It urges clinicians to adjust biomedical discourses which privilege physical and 'visible' dimensions of pain experience, over emotional and intangible dimensions (Freund, 1990; Chandler, 2013). This is particularly important with CLBP, which has been classified as 'idiopathic pain,' in which there is no tissue damage, and no consensus on a physiological cause (Melzack and Wall, 1988). 
The theoretical model in this study emphasises the consideration of sociocultural influences in order to develop biopsychosocial approaches to the management of CLBP, which are sensitive to the experiences of people in various social and cultural contexts. While the study focused on the experiences of women in Kuwait, the ramifications of the substantive theory may have a wider resonance, and warrants further development, refinement and enhancement with other gender constructions and in other social settings. The findings of this research may be transferable to other women in similar situations to those of the participants, and testing this may be a good means of evaluating the quality of this research. This is particularly necessary since it has been argued that gendered struggles faced by women in this study, such as being confined to domestic, childbearing roles and being financially dependent, can be considered to be 'universal' struggles or bound to commonalities in the social construction of the female gender (Sheldon, 1999; Bradley, 2013). Moreover, the interactive, relational character of illness identities construction proposed in this study calls for exploring this process in the experiences of males with CLBP, in order to explore the impact of social constructions of masculinity on this process.

In terms of the research methodology, this study was amongst the first in CLBP literature to adopt a constructivist GT approach. In providing an audit trail of how the major processes and procedures of GT (Charmaz, 2006) were employed, and detailing how these practices resulted in the development of the substantive theory (Chapter 6), this thesis makes an original methodological contribution to the research base in identity construction amongst women with CLBP.

Finally, there is a scarcity of literature theorising the distinct aspects of women's experiences with CLBP, as most studies include mixed gender samples. This study significantly addressed this gap by focusing only on women. Therefore, a further strength of this study is the fact that women's voices have been heard here whereas previously they 
were overlooked in gender related research.

\subsection{Conclusions}

The process through which women in Arab countries construct illness identities is unknown. There has been scarcely any research investigating the construction of illness identities amongst women with CLBP and none has been conducted in Kuwait. This thesis provides the first substantive theory of this process amongst women suffering from CLBP in Kuwait. It illuminates the influence of a continuum of social and cultural ideologies and structures on the development of oppressed and liberated gendered identities, and how such identities are intermeshed with the manifestation of CLBP amongst women in Kuwait. Suggestions have been made for physiotherapist educators to consider, and reflective practices in relation to the subjective experiences of women with CLBP should be encouraged in the professional development of physiotherapists. Reflective practice, aided by professional supervision, enhances the self-awareness of healthcare professionals regarding their influence over women and their involvement in care decisions.

\subsection{Epilogue}

CLBP is a complex phenomenon, which needs to be understood and managed through more holistic perspectives and approaches. The future development of management approaches for people with CLBP in particular, and chronic pain in general, need to acknowledge the mind-body connection which constitutes people's experiences. It is timely to shift from essentialist notions of chronic illness, to eradicate mind-body binaries, and to address people's suffering through holistic notions which address their thoughts, feelings, social conditions, and cultural contexts, and how these factors intertwine in shaping physical manifestations and existential experiences of chronic pain and illness. 


\section{References}

Aceves-Avila, F. J., Ferrari, R., \& Ramus-Remus, C. (2004) 'New insights into culture driven disorders.' Best Practice and Research Clinical Rheumatology 18(2): 155-171.

Adili, F., Higgins, I., \& Koch, T. (2013) 'Older women and chronic illness: transitioning and learning to live with diabetes.' Action Research 0(0): 1-15.

Airaksinen, O., \& J. Hilderbrandt (2004) 'European guidelines for the management of chronic non-specific low back pain.' Working Group on Guidelines for Chronic Low Back Pain.

Al-Diwan Al-Amiri, Kuwait (2012) Historical Background. Available online at: http://www.da.gov.kw/eng/diwnamiri/about-diwan-amiri.php

Al-Hamli, S. A. K. (2013) 'The impact of the level of women's participation in the workforce on economic growth in Kuwait.' PhD Thesis. Department of Middle East and Mediterranean Studies, School of Arts and Humanities. King's College London.

Al-Kazi, L. (2011) 'Women in non-governmental organisations in Kuwait: a platform for human resource development and social change.' Human Resource Development International 14(2): 167178.

Allen, L. M. (2010) 'A critique of four grounded theory texts.' The Qualitative Report 15(6): 1606-1620.

Al-Mughni, H. (2001) 'Women in Kuwait: The politics of gender.' London: Saqi Books.

Al-Sabah, Y. S. F. (1980) 'The Oil Economy of Kuwait.' Kegan Paul International: London. Al-Suwaihel, O. (2009) 'Kuwaiti female leader's perspectives: The influence of culture on leadership.' Journal of Public Administration and Policy Research 1(3): 55-62.

Alvesson, M., \& Skoldberg, K. (2000) 'Reflexive methodology: New vistas for qualitative research.' London: Sage

Anderson, K. O., Green, C. R., \& Payne, R. (2009) 'Racial and ethnic disparities in pain: Causes and consequences of unequal care.' The Journal of Pain 10(12): 1187-1204.

Annells, M. (1996) 'Grounded theory method: philosophical perspectives, paradigm of inquiry, and postmodernism.' Qualitative Health Research 6(3): 379-393.

Annells, M. (1997) 'Grounded theory method, part II: options for users of the method.' Nurse Inquiry 4:176-180. 
Arber, A. (2006) 'Reflexivity. A challenge for the researcher as practitioner?' Journal of Research in Nursing 11(2): 147-157.

Asbring, P., \& Naravanen, P. (2004) 'Patient power and control: A study women with uncertain illness trajectories.' Qualitative Health Research 14: 226-240.

Askew, R., Kibelstis, C., Overbaugh, S., Walker, S., Nixon-Cave, K., \& Shepher, K. F. (1998) 'Physical therapists' perception of patients' pain and its affect on management.' Physiotherapy Research International 3(1): 37-57.

Ayubi, N. N. (1992) 'State Islam and communal plurality.' Annals of America Academy of Political and Social Science 524: 79-91.

Baarts, C., Tulinius C., \& Reventlow, S. (2000) 'Reflexivity - a strategy for a patient-centred approach in general practice.' Family Practice 17: 430-434.

Badran, M. (1998) 'Gender, Islam, and the state: Kuwaiti women in struggle, pre-Invasion to post Liberation.' In Yvonne Yazbeck Haddad and John L. Esposito (Eds.) Islam, Gender, and Social Change New York: Oxford University Press.

Bair, M. J., Matthias, M. S., Nyland, K. A., Huffman, M. A., Stubbs, D. L., Kroenke, K., \& Damush, T. M. (2009) 'Barriers and facilitators to chronic pain self-management: a qualitative study of primary care patients with comorbid musculoskeletal pain and depression.' Pain Medicine 10(7): 1280-1290.

Balague, F., Mannion, A. F., Pellise, F., \& Cedraschi, C. (2007) 'Clinical update: low back pain.' The Lancet 369: 726-728.

Barbour, R. S. (1998) 'Mixing qualitative methods: quality assurance or qualitative quagmire?' Qualitative Health Research 8(3): 352-361.

Bates, M. S., Rank-Hill, L., \& Sanchez-Ayendez, M. (1997) 'The effects of the cultural context of health care on treatment of and responses to chronic pain and illness.' Social Science and Medicine 45(9): 1433-1447

Bauermeister, R. F. (1986) 'Identity: cultural change and the struggle for self.' New York: Oxford University.

Baumgartner, L. M. (2007) 'The incorporation of the HIV/AIDS identity into the self over time.' Qualitative Health Research 17(7): 919-931

Beck, C. T. (1993) 'Qualitative research: the evaluation of its credibility, fittingness and auditability.' Western Journal of Nursing Research 15: 263-266. 
Bendelow, G. (1993) 'Pain perceptions, emotions and gender.' Sociology of Health and Illness 15(3): 273-294.

Bendelow, G., \& Williams, S. J. (1995) 'Transcending the dualisms: towards a sociology of pain.' Sociology of Health and Illness 17(2): 139-165.

Benjaminsson, O., Gabriele, B., Arvidsson, I., \& Nilsson-Wilkmar, L. (2007) 'Recurrent low back pain: relapse from a patient perspective.’ Journal of Rehabilitation Medicine 39-640-645.

Benton, D. C. (1996). 'Grounded Theory.' In D.F.S. Cormack (Ed.), The research process in nursing (3rd ed., pp. 30-39). Oxford, UK: Blackwell Science Ltd.

Birks, M., \& Mills, J. (2011). ‘Grounded theory: A practical guide.’ London: Sage.

Beurskens, A.J., Henrica, C., Koke, A. J., van der Heijden, G. J., \& Knipschild, P. G. (1995)

'Measuring the functional status of patients with low back pain. Assessment of the quality of four disease-specific questionnaires.' Spine 20(9): 1017-10128.

Bishop, A., \& Foster, N. E. (2005) 'Do physical therapists in the United Kingdom recognize psychosocial factors in patients with acute low back pain?' Spine 30(11): 1316-1322.

Bleakley, A. (2001) 'Stories as data, data as stories: making sense of narrative inquiry in clinical education.' Medical Education 39: 534-540.

Blumer, H. (1969) 'Symbolic Interactionism - perspective and method.' Berkley, California: University of California.

Boos, N., Rieder, R., Schade, V., Spratt, K. F., Semmer, N., \& Aebi, M. (1995) '1995 Volvo award in clinical sciences: The diagnostic accuracy of magnetic resonance imaging, work perception and psychosocial factors in identifying symptomatic disc herniation.' Spine 20(24): 2613-2652.

Bonner, A., \& Tolhurst, G. (2002) 'Insider-outsider perspectives on participant observation.' Nurse Researcher 9(4): 7-19.

Bourdieu, P. (1990) 'The logic of practice.' Cambridge: Polity

Bowers, B., \& Schatzman, L. (2009) 'Dimensional Analysis' in J. M. Morse (Ed.), Developing grounded theory: the second generation (pp. 86-106). Creek: Left Cost.

Boychuk Duchscher, J. E., \& Morgan, D. (1994) 'Grounded theory: reflections on the emergence vs. forcing debate.' Journal of Advanced Nursing 48(6): 605-612.

Bradley, H. (2013) ‘Gender: key concepts.' Cambridge: Polity Press. 
Brannick, T., \& Coghlan, D. (2007) 'In defense of being "native": The case for insider academic research.' Organisational Research Methods 10(1): 59-74.

Breen, L. J. (2007) 'The researcher 'in the middle: negotiating the insider/outsider dichotomy.' The Australian Community Psychologist 19(1): 163-174.

Brodsky, J., \& Habib, J. (2003) 'Key policy issues in long-term care.' World Health Organisation. Bryant, A., \& Charmaz, K. (2007) 'The Sage handbook of grounded theory.' London: Sage.

Busch, H. (2005) 'Appraisal and coping processes among chronic low back pain patients.' Scandinavian Journal of Caring Sciences 19: 396-402.

Butler, J. (1996) 'Gender as performance.' In P. Osborne, (Ed.), A critical sense: Interviews with intellectuals. London: Routledge.

Burton, A. K., Balague, F., Cardon, G., Eriksen, H. R., Henrotin, Y., Lahad, A., Leclerc, A., Muller, G., \& Van Der Beel, A. J. (20060 'Chapter 2 European guidelines from prevention in low back pain.' European Spine Journal 15: s136-s168.

Bury, M. (1982) 'Chronic illness as a biographical disruption.' Sociology of Health and Illness 4(2): 167-182.

Bury, M. (1997) 'Health and illness in a changing society.' London: Routledge

Byrne K., Doody, C., \& Hurley, D. A. (2006) 'Exercise therapy for low back pain: A small-scale explanatory survey of current physiotherapy practice in the Republic of Ireland acute hospital setting.' Manual Therapy 11: 272-278.

Caelli, K., Ray, L., \& Mill, J. (2003) 'Clear as mud: Toward greater clarity in generic qualitative research.' International Journal of Qualitative Methods 2(2): 1-13.

Callaghan, M. (1994) 'Evaluation of back rehabilitation group for chronic low back pain in an outpatient setting.' Physiotherapy 80: 677-680.

Campbell, C., \& Guy, A. (2007) 'Why can't they do anything for a simple back problem? A qualitative examination of expectations for low back pain treatment and outcome.' Journal of Health Psychology 12(4): 641-652.

Carragee, E. J., AlAmin, T. F., Miller, J. L., \& Carragee, J. M. (2005) 'Discographic, MRI and psychosocial determinants of low back pain disability and remission: A prospective study in subjects with benign persistent back pain.' The Spine Journal 5: 24-35.

Casey, D. (2004) 'Challenges of collection data in clinical settings.' Nursing Times Research 9(2): 131-141. 
Cedraschi, C., Robert, J., Goerg, D., Perrin, E., Foscher, W., \& Vischer, T. L. (1999) 'Is chronic non-specific low back pain chronic? Definitions of a problem and problems of a definition.' British Journal of General Practice 49: 358-362.

Chandler, A. (2013) 'Inviting pain? Pain, dualism and emdominet in narratives of self-injury.' Sociology of Health and Illness 35(5): 716-730.

Charmaz, K. (1983) 'Loss of self: A fundamental form of suffering in the chronically ill.' Sociology of Health and Illness 5(2): 168-195.

Charmaz, K. (1987) 'Struggling for a self: Identity levels of the chronically ill.' Research in the Sociology of Health Care 6: 283-321.

Charmaz, K. (1990) 'Discovering chronic illness: Using grounded theory.' Sociology and Science Medical 30(11): 1161-1172.

Charmaz, K. (1999) 'Stories of suffering: Subjective tales and research narratives.' Qualitative Health Research 9(3): 362-382.

Charmaz, K. (2000) 'Constructivist and objectivist grounded theory.' In N. K. Denzin, \& Y.S. Lincoln (Eds.) Handbook of qualitative research $\left(2^{\text {nd }}\right.$ Ed.) Thousand Oaks: Sage (pp. 509-535).

Charmaz, K. (2005) 'Qualitative interviewing and grounded theory analysis.' In J. A Holstein, \& J. F. Gubrium (Eds.) Inside interviewing: new lenses, new concerns. London: Sage (pp. 3-20).

Charmaz, K. (2006) 'Constructing grounded theory: A practical guide through qualitative analysis.' London: Sage.

Charmaz (2009) 'Shifting the grounds.' In Morse, J.M., Stern, P. N. et al. (Ed.) Developing grounded theory the second generation. California: Left Coast Press (pp. 127-154).

Charmaz, K. (2014) 'Constructing grounded theory.' Chicago: Sage.

Chick, N., \& Meleis, A. (1986) 'Transitions: A nursing concern.' In Chinn, P.L. (Ed.) Nursing Research Methodology: Issues and Implementation. Rockville: Aspen (pp. 237-257).

Chiovitti, R. F., \& Piran, N. (2003) 'Rigour and grounded theory research.' Journal of Advanced Nursing, 44(4): 427-435.

Ciambrone, D. (2001) 'Illness and other assaults on self: The relative impact of HIV/AIDS on women's lives.' Sociology of Health and Illness 23(4): 517-540.

Cooney, A. (2011). 'Rigour and grounded theory.' Nurse Researcher 18(4): 17-22.

Cook, F. M., \& Hassenkamp, A. M. (2000) 'Active Rehabilitation for chronic low back pain: The patients' perspective.' Physiotherapy 86(2): 61-68. 
Connelly, L. M. (2015) 'Focus groups.' Medsurg Nursing 24(5): 369-370.

Conrad, P., \& Barker, K. K. (2001) 'The social construction of illness: Key insights and policy implications.' Journal of Health and Social Behaviour 51(5): S67-S79.

Coyne, I. T. (1997). 'Sampling in qualitative research. Purposeful and theoretical sampling; merging or clear boundaries?' Journal of Advanced Nursing 26: 623-630.

Cresswell, J. W. (1998). 'Qualitative inquiry and research design: Choosing among five traditions.' London: Sage.

Creswell, J. M. (2003) 'Research design: qualitative, quantitative, and mixed method approaches.' London: Thousand Oaks.

Croft, P. R., Macfarlane, G. J., Papageorgiou, A. C., Thomas, E., \& Silman, A. J. (1998) 'Outcome of low back pain in general practice: A prospective study.' British Medical Journal 316: 13561359 .

Crombez, G., Vlaeyen, J. W., Heuts, P. H., \& Lysens, R. (1999) 'Pain-related fear is more disabling than pain itself: Evidence on the role of pain-related fear in chronic back pain disability.' Pain 80(1): 329-339.

Crotty, M. (1998). 'The foundations of social research: Meaning and perspective in the research process.' London: Sage.

Crowe, M., Whitehead, L., Jo Gagan, M., Baxter, D., \& Panckhurst, A. (2010) 'Self-management and chronic low back pain: A qualitative study.' Journal of Advanced Nursing 66(7): 1478-1486.

Cutcliffe, J. R. (2000). 'Methodological issues in grounded theory.' Journal of Advanced Nursing 31(6): 1476-1484.

Cutcliffe, J. R. (2003) 'Reconsidering reflexivity: Introducing the case for intellectual entrepreneurship.' Qualitative Health Research 13(1): 136-148.

Cutcliffe, J. R. (2005). 'Adapt or adopt: developing and transgressing the methodological boundaries of grounded theory.' Journal of Advanced Nursing 51(4): 421-428.

Cuthill J.A., \& Cuthill, G. S. (2006) 'Partial-thickness bum to the leg following application of cold pack: Case report and results of a questionnaire survey of Scottish physiotherapists in private practice.' Physiotherapy 92: 61-65.

Daftary, A. (2012) 'HIV and tuberculosis: the construction and management of double stigma.' Social Science and Medicine 74: 1512-1519.

Dar Al-Shifa Hospital. Available online at: http://www.daralshifa.com 
Dashti, A. (1997) Language in the State of Kuwait: A sociolinguistic investigation. PhD thesis. Department of language and Linguistics, University of Essex.

Dearnley, C. (2005) 'A reflection on the use of semi-structured interviews.' Nurse Researcher 13: 19-28.

Dellito, A., George, S. Z., Whitman, J. M., Sowa, G., Shekelle, P., Denninger, T. R., \& Godges, J. J. (2012) 'Low back pain: Clinical practice guidelines linked to the international classification of functioning, disability, and health from the orthopaedic section.' Journal of Orthopaedic and Sports Physical Therapy 42(2): A1-A57.

DeSouza, L. H., \& Frank, A. O. (2007) 'Experiences of living with chronic back pain: The physical disabilities.' Disability and Rehabilitation 29(7): 587-596.

DiCicco-Bloom, B., \& Crabtree, F. (2006) 'The qualitative research interview.' Medican Education 40: 314-321.

Dick, B. (2007). 'What can grounded theorists and action researchers learn from each other.' In A. Bryant \& K. Charmaz (Eds.), The Sage handbook of grounded theory (pp. 398-416). London, UK: Sage.

Doody, O., Eamonn, S., \& Taggart, L. (2013) 'Focus group interviews: part 1' Journal of British Nursing 22(1): 16-19.

Drake, P. (2010) 'Grasping at methodological understanding: a cautionary tale from insider research.' International Journal of Research and Method in Education 33(1): 85-99.

Duffy, K., Ferguson, C., \& Watson, H. (2004) 'Data collecting in grounded theory-- some practical issues.' Nurse Researcher 1: 67-78.

Dune, C. (2011) 'The place of the literature review in grounded theory research.' International Journal of Social Research Methodology 14(2): 111-124.

Duchscher, J. E. B., \& Morgan, D. (2004) 'Grounded theory: reflections on emergence vs. Forcing debate.' Methodological Issues in Nursing Research 48(6): 605-612.

Edwards, I., Jones, M., Carr, J., Braunack-Mayer, A., \& Jensen, G. M. (2000) 'Clinical reasoning strategies in physical therapy.' Physical Therapy 84: 312-355.

Edwards, I, Braunnack-Mayer, A., \& Jones, M. (2005) 'Ethical reasoning as a clinical-reasoning strategy in physiotherapy.' Physiotherapy 91: 229-236.

Egwu, M. O., \& Nwuga, V. C. B. (2008) 'Relationship between low back pain and life-stressing events among Nigerian and Caucasian patients.' Physiotherapy 94: 133-140. 
Ehrlich, G. E. (2003) 'Low back pain.’ Bulletin of the World Health Organisation 81(9): 671-676.

Ellegaard, H., \& Pedersen, B. D. (2012) 'Stress is dominant in patients with depression and chronic low back pain. A qualitative study of psychotherapeutic interventions for patients with non-specific low back pain of 3-12 months' duration.' BMC Musculoskeletal Disorders 13: 166175.

Elliot, N., \& Laznebatt, A. (2004) 'How to recognize a "quality" grounded theory research study.' Australian Journal of Advanced Nursing 22(3): 48-52.

Emerson, M. O. (1996) 'Through tinted glasses: Religion, worldviews and abortion attitudes.' Journal for the Scientific Study of Religion 35(1): 41-55.

Engel, G. L. (1989) 'The need for a new medical model: A challenge for biomedicine.' Holistic Medicine 4: 37-53.

Evans, S., \& de Souza, L. (2008) 'Dealing with chronic pain: Giving voice to the experiences of mothers with chronic pain and their children.' Qualitative Health Research 18(4): 489-500.

Fava, G. N., \& Sonino, N. (2008) 'The biopsychosocial model thirty years later.' Psychotherapy and Psychomatics 77: 1-2.

Finlay, L. (2002) 'Outing the researcher: the provenance, process and practice of reflexivity.' Qualitative Health Research 12: 531-545.

Flor, H., Turk, D. C., \& Birbaumer, N. (1985) 'Assessment of stress-related psychophysiological reactions in chronic back pain patients.' Journal of Consulting and Clinical Psychology 53(3): 354364.

Foster, N. E., Thomas, E., Bishop, A., Dunn, K. M., \& Main, C. J. (2010) 'Distinctiveness of psychological obstacles to recovery in low back pain patients in primary care.' Pain148: 398-406.

Foster, N. E. (2011) 'Barriers and progress in the treatment of low back pain.' Biomed Central Medicine 9: 108-112.

Freidson, E. (1970) 'Professional dominance. The social structure of medical care.' New Jersey: Transaction.

French S. D., M., Cameron, M., Walker, B. F., Reggars, J. W., \& Esterman, A. J. (2006) 'A Cochrane review of superficial heat or cold for low back pain.' Spine 31(9): 998-1006.

Freund, P. E. S. (1990) 'The expressive body: A common ground for the sociology of emotions and health and illness.' Sociology of Health and Illness 12(4): 452-477. 
Furlan, A.D., Brosseau, L., Imamura, M., \& Irvin, E. (2002) 'Massage for low-back pain: A systematic review within the framework of the Cochrane Collaboration Back Review Group.' Spine 27(17): 1896-18910.

Gergen, K. J. (1991) 'The saturated self: Dilemmas of identity in contemporary life.' New York: Basic Books.

Ghaffari, M., Alipour, A., Jensen, I., Farshad, A. A., \& Vingard, E. (2006) 'Low back pain among Iranian industrial workers.' Occupational Medicine 56: 455-460.

Giddens, A. (1991) 'Modernity and self-identity: Self and society in the late modern age.' Cambridge: Polity.

Glaser, B. G. (1978) 'Theoretical sensitivity.' California: Sociology Press.

Glaser, B. G. (1992) 'Basics of grounded theory analysis: Emergence versus forcing.' California: Sociology Press.

Glaser, B. (2001) 'The grounded theory perspective: Conceptualization and contrasted with description.' California: Sociology Press.

Glaser, B. (2004) 'Remodelling Grounded Theory.' Forum: Qualitative Social Research 5(2), Art. 4.

Glaser, B. G., \& Strauss, A. L. (1967) 'The discovery of grounded theory: Strategies for qualitative research.' New York: Aldine de Gruyter.

Goffman, E. (1959) 'The presentation of self in everyday life.' London: Penguin.

Goffman, E. (1963) 'Stigma: notes on the management of spoiled identity.' Harmondsworth: Penguin.

Gone, J. P., Miller, P. J., \& Rappaport, J. (1999) 'Conceptual self as normatively oriented: the suitability of past personal narrative for the study of cultural identity.' Culture \& Psychology 5(4): 371-398.

Guba, E. G., \& Lincoln, Y. S. (1994) 'Competing Paradigms in qualitative research.’ In N.K.Denzin \& Y. S. Lincoln (Eds.), Handbook of Qualitative Research (pp. 105-117). Thousand Oaks: Sage.

Guise, J., McKinlay, A., \& Widdicombe, S. (2010) 'The impact of early stroke on identity: A discourse analytic study.' Health 14(1): 75-90. 
Guzman, J., Esmail, R., Karjalainen, K., Malmivaara, A., Irvin, E., \& Bombardier, C. (2001) 'Multidisciplinary rehabilitation for chronic low back pain: Systematic review.' BMJ 322: 15111516.

Hall, W. A., \& Callery, P. (2001) 'Enhancing the rigor of grounded theory: Incorporating reflexivity and relationality.' Qualitative Health Research 11(2): 257-272.

Hamberg, K., Johansson, E., Lindgren, G., \& Westman, G. (1994) 'Scientific rigour in qualitative research - examples from a study of women's health in family practice.' Family Practice 11(2): 176-181.

Harland, N., \& Lavallee, D. (2003) 'Biopsychosocial management of chronic low back pain patients with psychological assessment and management tools.' Physiotherapy 89 (5): 305-312.

Harman, K., Fenety, A., Hoens, A., Crouse, J., \& Padfield, B. (2009) 'Physiotherapy and low back pain in the injured worker: An examination of current practice during the subacute phase of healing.' Physiotherapy 61(2): 88-106.

Heath, H., \& Cowley, S. (2004) 'Developing a grounded theory approach: A comparison of Glaser and Strauss.' International Journal of Nursing Studies 41: 141-150.

Heath, H. (2006) 'Exploring the influences and use of the literature during a grounded theory study.' Journal of Research in Nursing 11(6): 519-528.

Henwood, K., \& Pidgeon, N. (2006) 'Grounded theory.' Research Methods in Psychology 3: 342 365.

Hickey, G. (1997) 'The use of literature in grounded theory.' Nursing Times Research 2(3): 371 378.

Hochschild, A. R. (1983) 'The managed heart. Commercialization of human feelings.' Berkley: University of California.

Hoffman, D. E., \& Tarzian, A. (2001) 'The girl who cried pain: A bias against women in the treatment of pain.' The Journal of Law, Medicine \& Ethics 28(s4): 13-27.

Holloway, I. \& Fulbrook, P. (2001) 'Revisiting qualitative inquiry: Interviewing in nursing and midwifery research.' Nursing Times Research, 6: 539-550.

Holloway, I., \& Wheeler, S. (2002). 'Qualitative research in nursing.' Oxford, Blackwell Science. 
Holloway, I., Sofaer-Bennette, B., \& Walker, J. (2007) 'The stigmatisation of people with chronic back pain.' Disability and Rehabilitation 29(18): 1456-1464.

Holloway, I., and Wheeler, S. (2010). 'Qualitative research in nursing.' Oxford, Wiley- Blackwell. Holton, A. (2010) 'Using the telephone for narrative interviewing: a research note.' Qualitative Research 10(1): 113-121.

Hoy, D., \& Bain, C. (2012) 'A systematic review of the global prevalence of low back pain.' Arthritis and Rheumatism 64(6): 2028-2037.

Hickey, G. (1997) 'The use of literature in grounded theory.' Nursing Times Research 2(3): 371378.

Hunt, M. (2007) 'Taking culture seriously: Considerations for physiotherapists.' Physiotherapy 93: 229-232.

Hunter, G. (1998) 'Specific soft tissue mobilization in the management of soft tissue dysfunction.' Manual Therapy 3: 2-11.

Jensen, M. C., Brant-Zawadzki, M. N., Obuchowski, N., Modic, M. T., Malkasian, D., \& Ross, J. S. (1994) 'Magnetic resonance imaging in people without back pain.' The New England Journal of Medicine 331(2) 69-73.

Jerant, A. F, von Friederichs-Fitzwater, M. M., \& Moore, M. (2005) 'Patient' perceived barriers to active self-management of chronic conditions.' Patient Education and Counselling 57: 300-307.

Johnson, E.K., \& Chiarello, C.M. (1997) 'The slump test: The effects of head and lower extremity position on knee extension.' Journal of Orthopaedic and Sports Physical Therapy 26(6): 310-317.

Jorgensen, C. K., Fink, P., \& Olesen, F. (2000) 'Psychological distress and somatisation as prognostic factors in patients with musculoskeletal illness in general practice.' British Journal of General Practice 50: 537-541.

Julia, M., \& Ridha, H. (2001) 'Women and war: The role Kuwaiti women played during the Iraqi occupation.' Journal of International Development 13: 583-598.

Kamper, S. J., Apeldoorn, A. T., Chiarotto, A., Smeets, R. J. E. M., Ostelo, R. W. J. G., Guzman, J., \& van Tulder, M. W. (2015) 'Multidisciplinary biopsychosocial rehabilitation for chronic low back pain: Cochrane systematic review of meta-analysis.' British Medical Journal 350: 444-455.

Kelle, U. (2005) “"Emerging” vs. "forcing” of empirical data? A crucial problem of "grounded theory” reconsidered.' Forum: Qualitative Social Research 6(2), Art. 27. 
Kendall, N. A. (1999) 'Psychosocial approaches to the prevention of chronic pain: The low back paradigm.' Baillieres Best Practice Research in Clinical Rheumatology 13: 545-554.

Key, S. (2000) 'You can treat your own back.' In Back Suferrers' Bible (pp. 27-47). London: Vermilion.

Kleinman, A., \& Benson, P. (2006) 'Anthropology in the clinic: the problem of cultural competency and how to fix it.' PLos Medicine 3(10): 1673-1676.

Koenig, A. L., Kupper, A. E., Skidmore, J. R., \& Murphy, K. M. (2014) 'Biopsychosocial functioning and pain self-efficacy in chronic low back pain patients.' Journal of Rehabilitation Research and Development 51(8): 1277-1286.

Koes, B. W., van Tulder, M. W., \& Thomas, S. (2006) 'Diagnosis and treatment of low back pain.' British Medical Journal 332: 1430-1434.

Kools, S., McCarthy, M., Durham, R., \& Robrecht, L. (1996). 'Dimensional analysis: Broadening the conception of grounded theory.' Qualitative Health Research 6: 312-330.

Kuwait Government Online (2011) Available online at:

http://www.e.gov.kw/sites/KGoEnglish/Portal/Pages/PortalMain.aspx (Arabic website)

Kralik, D. (2002) 'The quest for ordinariness: Transition experienced by midlife women with chronic illness.' Journal of Advanced Nursing 39(2): 146-154.

Kralik, D., Koch, T., \& Eastwood, S. (2003) 'The salience of the body: Transition in sexual selfidentity for women living with multiple scelorosis.' Journal of Advanced Nursing 42(1): 11-20.

Kralik, D., Telford, K., Price, K., \& Koch, T. (2005) 'Women's experiences of fatigue in chronic illness.' Journal of Advanced Nursing 52(4): 372-380.

Kralik, D., K. Visentin et al. (2006) 'Transition: A literature review.' Journal of Advanced Nursing 55(3): 320-329.

Krismer, M., \& van Tulder, M. (2007) 'Low back pain (non-specific).' Best Practice and Research Clinical Rheumatology 21(1): 77-91.

Kvale, S. (1996) 'InterViews: An introduction to qualitative research interviewing.' London: Sage.

Kvale, S. (2007). 'Doing interviews.' Thousand Oaks, CA: Sage Publications.

Lalljee, M., \& Lamb, R. (1996) 'Lay prototypes of illness: Their content use.' Psychology and Health 8: 33-49.

Lawler, S. (2014) 'Identity: Sociological perspectives.' Cambridge: Polity. 
Le Gallias, T. (2008) 'Wherever I go there I am: Reflections on reflexivity and the research stance.' Reflective Practice 9(2): 145-155.

Liedberg, G. M., \& Henriksson, C. M. (2002) 'Factors of importance for work disability in women with fibromyalgia: An interview study.' Arthritis and Rheumatism 47(3): 266-274.

Liddle, S. D., Baxter, D., \& Gracey, J. H. (2007) 'Chronic low back pain: Patients' experiences, opinions and expectations for clinical management.' Disability and Rehabilitation 29(24): 18991909.

Lillrank, A. (2003) 'Back pain and the resolution of diagnostic uncertainty in illness narratives.' Social Science \& Medicine 57: 1045-1054

Lincoln, Y.S., \& Guba, E. G. (1985). 'Establishing trustworthiness.' In Y. S. Lincoln \& E. G. Guba, eds. Naturalistic Inquiry. London: Sage Publications Ltd, pp. 289-331.

Linton, S. J. (2000) 'A review of psychological risk factors in back and neck pain.' Spine 25(9): $1148-1156$.

Lonardi, C. (2007) 'The passing dilemma in socially invisible diseases: Narratives on chronic headaches.' Social Science and Medicine 65: 1619-1629.

Malterud, K. (2000) 'Symptoms as a source of medical knowledge: Understanding medically unexplained disorders in women.' Family Medicine 32(9): 603-611).

Malterud, K., Candib, L. \& Code, L. (2004) 'Responsible and responsive knowing in medical diagnosis: The medical gaze.' Nordic Journal of Feminist and Gender Research 12(1): 8-9.

Mannay, D. (2010) 'Making the familiar strange: Can visual research methods render the familiar setting more perceptible?’ 10(1): 91-111.

Mannion, A. F., Junge, A., Taimela, S., Müntener, M., Lorenzo, K., \& Dvorak, J. (2001) 'Active therapy for chronic low back pain.' Spine 26(8): 920-929.

Maxwell, J. A. (2004) 'Qualitative research design: An interactive approach.' California: Sage.

May, S. (2007) 'Patients' attitudes and beliefs about back pain and its management after physiotherapy for low back pain.' Physiotherapy Research International 12(3): 126-135.

McCann, T., \& Clark, E. (2003) 'Grounded theory in nursing research: Part 1: methodology.' Nurse Researcher 11: 7-18.

McCann, T. V. \& Clark, E. (2003a). 'Grounded theory in nursing research: Part 2:

Critique.' Nurse Researcher 11: 19-28. 
McCann, T. V. \& Clark, E. (2003b). 'Grounded theory in nursing research: Part 3:

Application.' Nurse Researcher 11: 29-39.

McCoyd, J. L. M., \& Kerson, T. S. (2006) 'Conducting intensive interviews using email. A seredendipitou comparative opportunity.' Qualitative Social Work 5(3): 389-406.

McGhee, G., Marland, G. R., \& Atkinson, J. (2007) 'Grounded theory research: Literature reviewing and reflexivity.' Journal of Advanced Nursing 60(3): 334-342.

McGowan, L., Luker, K., Creed, F., \& Chew-Graham, C. A. (2007) 'How do you explain a pain that can't be seen?: The narratives of women with chronic pelvic pain and their disengagement with diagnostic cycle.' British Journal of Health Psychology 12: 261-274.

McCormick, J. B., Hammer, R. R., Farrell, R. M., Geller, G., James, K. M., Loftus Jr., E. V., Mercer, M. B., Tilburt, J. C., Sharp, R. R. (2012) 'Experiences of patients with chronic gastrointestinal conditions: in their own words.' Health and Quality of Life Outcomes 10:25-36.

Mead, H. (1934) 'Mind, self and society.' Chicago: The University of Chicago.

Meleis, A. I. (1979) 'The health care system of Kuwait: The social paradoxes.' Social Science and Medicne 13A: 74-79.

Meleis, A. I., Sawyer, L. M., Im, E. O., Messias, D. K. H., \& Schumacher, K. (2000)

'Experiencing transitions: An emerging middle-range theory.' Advances in Nursing Science 23(1): $12-28$.

Mendelson, C. (2006) 'Managing a medically and socially complex life: Women living with lupus.' Qualitative Health Research 16: 982-997.

Melzack, R., \& Wall, P. D. (1988) 'The challenge of pain.' Harmondsworth: Penguin.

Metcalfe, B.D., \& Rees, C.J. (2010) 'Gender, globalization and organisation: Exploring power, relations and intersections.' Equality, Diversity and Inclusion 29(1): 5-22.

Meyer, K., Rizzo, H. \& Ali, Y. (1998) 'Islam and the extension of citizenship rights to Women in Kuwait.' Journal for the Scientific Study of Religion 37(1): 131-144.

Middleton, A. (2004) 'Chronic low back pain: Patient compliance with physiotherapy advice and exercise, perceived barriers and motivation.' Physical Therapy Reviews 9: 153-160.

Mills, J., Bonner, A., \& Francis, K. (2006a) 'Adopting a constructivist approach to grounded theory: Implications for research design.' International Journal of Nursing Practice 12: 8-13.

Mills, J., Bonner, A., \& Francis, K. (2006b) 'The development of constructivist grounded theory.' International Journal of Qualitative Methods 5(1): 1-10. 
Morris, D. (1991) 'The Culture of Pain.’ University of California, Berkeley.

Morris, D. (2000) 'Illness and culture in the postmodern age.' Berkeley, California: University of California.

Morse, J. M. (2007). 'Sampling in grounded theory.' In A. Bryant \& K. Charmaz (Eds.), The Sage handbook of grounded theory (pp. 229-244). London, UK: Sage.

Mulhall, A. (2002) 'In the field: on observation in qualitative research.' Methdological Issues in Nursing Research 41(3): 306-313.

Morse, J. M. 'Tussles, Tensions and Resolutions.' In J. M. Morse, P. N. Stern, J. Corbin, B. Bowers, K. Charmaz, \& A. E. Clarke (Eds.) Developing grounded theory (pp. 13-19). Walnut Creek, CA: Left Coast Press.

Nachemson, A. L., Waddell, G., \& Norlund, A. (2000). 'Epidemiology of neck and low back pain.' In Nachemson, A.L., \& Jonsson, E. (Eds.), Neck and back pain: The scientific evidence of causes, diagnosis, and treatment (pp. 165-188). Philadelphia: Lippencott Wlliams \& Wilkins.

Neill, J. (2002) 'Transcendence and transformation in the life patterns of women living with Rheuamtoid Arthritis.' Advanced Nursing Science 24(4): 27-47.

Neill, S. J. (2006) 'Grounded theory sampling: The contribution of reflexivity.' Journal of Research in Nursing 11(3): 253-260.

Nordin, M., Balague, F., \& Cedraschi, C. (2006) 'Nonspecific lower-back pain: Surgical versus nonsurgical treatment.' Clinical Orthopaedics and Related Research 443: 156-167.

Norma, C., \& Kleinman, A. (1992) 'Culture and somatic experience: the social course of illness in neurasthenia and chronic fatigue syndrome.' Psychomatic Medicine 54: 546-560.

Novick, G. (2008) 'Is there a bias against telephone interviews in qualitative research?' Research in Nursing and Health 31: 391-398.

Oliver, M. (2009) 'Understanding disability: From theory to practice.' Basingstoke: Palgrave Macmillan

Opdenakker, R. (2006) 'Advantages and disadvantages of four interview techniques in qualitative research.' Forum of Qualitative Social Research 7(4): Art. 11.

Padiyar, A., Pandipati, S., Kim, T., \& Haig, A. J. (2001) 'An objective review of consumer books about back pain.' Journal of Neuroscience Nursing 33(6): 326-337.

Paterson, B. L. (2001) 'The shifting perspectives model of chronic illness.' Journal of Nursing Scholarship 33(1): 21-25. 
Pinnigton, M. A. (2001) 'Why are we finding it so hard to change our approach to low back pain?' Physiotherapy 87(2): 58-59.

Price, B. (1996) 'Illness careers: The chronic illness experience.' Journal of Advanced Nursing 24: 275-279.

Public Authority of Civil Information (2011) Available online at: http://www.paci.gov.kw/index.php/2011-03-06-18-21-09/2011-03-07-19-29-35

Raheim, M., \& Haland, W. (2006) 'Lived experience of chronic pain and fibromyalgia: Women's stories from daily life.' Qualitative Health Research 16: 741-761.

Randolph, J. J. (2009) 'A guide to writing dissertation literature review.' Practical Assessment, Research and Evaluation 14(13): 2-13.

Rasmussen, S. (1999) 'Culture, personhood and narrative: the problem of norms and agency.' Culture and Psychology 5(4): 399-412.

Reynolds, F. (2004) 'Women's narratives of living with MS in the family context: Reconciling complex experiences, integrating complex identities.' University of Hudersfield Repository.

Rhodes, L., McPhillips-Tangum, C. A., Markham, C., \& Klenk, R. (2009) 'The power of the visible: The meaning of diagnostic tests in chronic low back pain.' Social Science and Medicine 48(9): 1189-1203.

Richardon, J. C. (2005) 'Establishing the (extra)ordinary in chronic widespread pain.' An International Journal for the Social Study of Health, Illness and Medicine 9(1): 31-48.

Rizzo, H., Meyer, K., \& Ali, Y. (2002) 'Women's political rights: Islam, status and networks in Kuwait.' Sociology 36(3): 639-662.

Rolfe, G. (2004) 'Validity, trustworthiness and rigour: Quality and the idea of qualitative research.' Journal of Advanced Nursing 53(3): 304-310.

Rose, M. J., Reilly, J. P., Slade, P. D., \& Dewey, M. (1995) 'A comparative analysis of psychological and physical models of low back pain experience.' Physiotherapy 81(12): 710-716.

Savigny, P., S. Kuntze, Watson, P., Underwood, M., Ritchie, G., Cotterell, M., \& Walsh, D. (2009) 'Low back pain: Early management of persistent non- specific low back pain.' London, National Collaborating Centre for Primary Care and Royal College of General Practitioners.

Scambler, G., \& Scambler, S. J. (2010) 'New directions in the sociology of chronic and disabling conditions: assaults on the lifeworld.' Basingstoke: Palgrave Macmillan 
Schatzman, L. \& Strauss, A. (1973). 'Field research: Strategies for a natural sociology.'

Englewood Cliffs: Prentice-Hall

Schatzman, L. (1991). 'Dimensional analysis: notes on an alternative approach to the grounding of theory in qualitative research.' In D.R.Maines (Ed.), Social organisation and social process (pp. 303-314). New York: Aldine De Gruyter.

Schumacher K., A. Meleis (1994) 'Transitions: a central concept in nursing.' Image, Journal of Nursing Scholarship 26: 119-127.

Semrau, J., Christian, H., Buchmann, J., Meng, K., Vogel, H., Faller, H., Bork, H., Pfeifer, K. (2015) 'Long-term effects of interprofessional biopsychosocial rehabilitation for adults with chronic non-specific low back pain: A multicenter, quasi-experimental study.' Public Library of Science One 10(3):1371-1399.

Shah, N. M. (2004) 'Women's socioeconomic characteristics and marital patterns in a rapidly developing Muslim society, Kuwait.' Journal of Comparitive Family Studies 35(2): 163-183.

Shakespeare, T. (2006) 'Disability rights and wrongs.' New York: Routledge.

Sharpe, H., Alderson, K., \& Collins, S. (2013) 'An exploration of a positive identity development in women living with chronic pain.' The Qualitative report 18(29): 1-22.

Sheldon, A. (1999) 'Personal and perplexing: feminist disability politics evaluated.' Disability and Society 14(5): 643-657.

Sim, J. (2010) 'Addressing conflicts in research ethics: Consent and risk of harm.' Physiotherapy Research International 15: 80-87.

Sim, J., \& Madden, S. (2008) 'Illness experiences in fibromyalgia syndrome: A metasynthesis of qualitative studies.' Social Sciences and Medicine 67: 57-67.

Skuladottir, H., \& Halldorsdottir, S. (2008) 'Women in chronic pain: sense of control and encounters with health professionals.' Qualitative Health Research 18: 891-901.

Skuladottir, H., \& Halldorsdottir, S. (2011) 'The quest for well-being: Self-identified needs of women in chronic pain.' Scandanavian Journal of Caring Sciences. 25: 81-91.

Slade, C. S., Molloy, E., \& Keating, J. L. (2009) 'Stigma experienced by people with nonspecific chronic low back pain: A qualitative study.' Pain Medicine 10(1): 143-154.

Slade, C. S., Molloy, E., \& Keating, J. L (2009) 'People with non-specific chronic low back pain who have participated in exercise programs have preferences about exercise: A qualitative study.' Australian Journal of Physiotherapy 55: 115-121. 
Snelgrove, S., \& Liossi, C. (2009) 'An interpretative phenomenological analysis of living with chronic low back pain.’ British Journal of Health Psychology 14: 735-749.

Soderberg, S., \& Lundman, B. (2001) 'Transitions experienced by women with fibromyalgia.' Health Care for Women International 22: 617-631.

Soderlund, A., \& Malterud, K. (2005) 'Why did I get chronic fatigue syndrome: A qualitative interview study of causal attributions in women patients.' Scandinavian Journal of Primary Health Care 23: 242-247.

Sparkes, V. (2005) 'Treatment of low back pain: Monitoring clinical practice through audit.' Physiotherapy 91: 171-177.

Spitzer, W. O., \& Leblanc, F. E. (1987) 'Scientific approach to the assessment and management of activity-related spinal disorders. A monograph for clinicians. Report of the Quebec Task Force on spinal disorders.' Spine 12 (7 Suppl), S1-59.

Steihaug, S., Ahlsen, B., \& Malterud, K. (2002) 'I am allowed to be myself: Women with chronic muscular pain being recognized.' Scandinavian Journal of Public Health 30: 281-287.

Stevens, R. (1996) 'Understanding the self.' London: Thousand Oaks.

Stafford, M. R., \& Strafford, T. F. 'Participant observation and the pursuit of truth: methodological and ethical considerations.' Journal of the Market Research Society 35(1): 63-77.

Strauss, A. (1987) 'Qualitative analysis for social scientists.' United States of America: Cambridge University Press.

Strauss, A. L., \& Corbin, J. (1990) 'Basics of qualitative research: Grounded theory procedures and techniques.' London: Sage.

Strauss, A. L., \& Corbin, J. (1998) 'Basics of qualitative research: grounded theory procedures and techniques.' London: Sage.

Sturges, J. E., \& Hanrahan, K. J. (2004) 'Comparing telephone and face-to-face qualitative interviewing: A research note.' Qualitative Research 4: 107-118.

Strunin, L., \& Boden, L. I. (2004) 'Family consequences of chronic back pain.' Social Science and Medicine 58: 1385-1393.

Sullivan, T., \& Weinert, C. (2003) 'Management of chronic illness: Voices of rural women.' Journal of Advanced Nursing 44(6): 566-574.

Taimela, S., Negrini, S., \& \& Paroli, C. (2004) 'Functional rehabilitation of low back disorders.' Europa Medicophysica 40: 29-36. 
Taqi, H. (2010) 'Two ethnicities, three generations: Phonological variation and change in Kuwait.' $\mathrm{PhD}$ Thesis. The School of Education, Communication, and Language Sciences. Newcastle University.

Thomas, C. (1999) 'Female forms. Experiencing and understanding disability.' Buckingham: Open University.

Thomas, S. P., \& Johnson, M. (2000) 'A phenomologic study of chronic pain.' Western Journal of Nursing Research. 22(6), 683-705.

Thomas, C. (2007) 'Sociologies of disability and illness: Contested ideas in disability studies and medical sociology.' New York: Palgrave.

Tetreault, M. A. (1993) 'Civil society in Kuwait: Protected spaces and women's rights.' The Middle East Journal 47(2): 275-291.

Tetreault, M. A., \& Al-Mughni, H. (1995) 'Modernization and its discontents: State and gender in Kuwait.' Middle East Journal 49(3): 403-417.

Tetreault, M. A., Meyer, K., \& Rizzo, H. (2009) 'Women's rights in the Middle East. A longitudinal study of Kuwait.' International Political Sociology 3: 218-237.

Thomas, C. (1999) 'Female forms: Experiencing and understanding disability.' Buckingham: Open University.

Thomas, C. (2006) 'Disability and gender: Some reflections on theory and research.' Scandinavian Journal of Disability Research 8(3): 177-185.

Thomas, C. (2007) 'Sociologies of disability and illness.' Basingstoke : Palgrave Macmillan Thorne, S., \& Patterson, B. (1998) 'Shifting images of chronic illness.' Journal of Nursing Scholarship 30(2): 173-178.

Thorne, S. E. and Paterson, B. L. (2000) 'Two decades of insider research: what we know and don't know about chronic illness experience.' Annual Review of Nursing Research 18(1): 3-25

Townsend, A., Wyke, S., \& Hunt, K. (2006) 'Self-managing and managing self: practical and moral dilemmas in accounts of living with chronic illness.' Chronic Illness 2: 185-194.

Travers, M. K., \& Lawler, J. (2008) 'Self within a climate of contention: Experiences of chronic fatigue syndrome.' Social Science and Medicine 66: 315-326.

Turner, B. A. (1981) 'Some practical aspects of qualitative data analysis: one way of organizing the cognitive processes associated with the generation of grounded theory.' Quality and Quantity 15: 225:247. 
Turner, J.A. (1996) 'Educational and behavioural interventions for back pain in primary care.' Spine 21(24): 2851-2859.

Twigg, J. (2006) 'The body in health and social care.' Basingstoke: Palgrave Macmillan Unsworth, C. A. (2008). 'Review of methodologies for researching clinical reasoning.' In B.A. Boyt Schell \& J. W. Schell (Eds.), Clinical and professional reasoning in occupational therapy (pp. 371-400). Baltimore: Lippincott.

U.S. Department of State (2012) 'Background note: Kuwait.' Available online at: http://www.state.gov/r/pa/ei/bgn/35876.htm

Vlaeyen, J. W., Kole-Snijders, A. M., Boeren, R. G., \& Van Eek, H. (1995) 'Fear of movement/(re)injury in chronic low back pain and its relation to behavioural performance.' Pain 62: 363-372.

Vlaeyen, J. W., \& Crombez, G. (1999) 'Fear of movement/(re)injury, avoidance and pain disability in chronic low back pain patients.' Manual Therapy 4(4): 187-195.

Vlaeyen, J. W., \& Linton, S. J. (2000) 'Fear-avoidance and its consequences in chronic musculoskeletal pain: A state of the art.' Pain 85(3): 17-32.

Waddell, G. (1987) 'A new clinical model for the treatment of low back pain.'

Spine 12, 632-644.

Waddell, G. (1996) 'Low back pain: A twentieth century health care enigma.' Spine 21(24): 28202825

Waddell, G. (2004) 'The back pain revolution.’ Edinburgh: Churchill Livingstone.

Ward, K., Gott, M., \& Hoare, K. (2015) 'Participants' views on telephone interviews within a grounded theory study.' Journal of Advanced Nursing 71(12): 2775-2785.

Warwick, R., Joseph, S., Cordle, C., \& Ashworth, P. (2004) 'Social support for women with chronic pelvic pain: What is helpful from whom?' Psychology and Health 19(1): 117-134.

Werner, A., Steihaug, S., \& Malterud, K. (2003) 'Encountering the continuing challenges for women with chronic pain: Eecovery through recognition.' Qualitative Health Research 13(4): 491509.

Werner, A., \& Malterud, K. (2003) 'It is hard work behaving as a credible patient: Encounters between women with chronic pain and their doctors.' Social Science and Medicine 57: 1409-1419. 
Werner, A., \& Malterud, K. (2005) 'The pain isn't as disabling as it used to be: How the patient experience empowerment instead of vulnerability in the consultation?' Scandinavian Journal of Public Health 33 (Suppl 66): 41-46.

West, C., \& Stewart, L. (2013) 'Accidental insider: Living the PhD study.' Collegian 20: 61-65.

White, J., Hunter, M. \& Holttum, S. (2007) 'How do women experience myocardial infarction? A qualitative exploration of illness perceptions, adjustments and coping.' Psychology, Health and Medicine 12(3): 278-288.

Williams, S. J. (2000) 'Chronic illness as biographical disruption or biographical disruption as chronic illness? Reflections on a core concept.' Sociology of Health and Illness, 22(1): 40-67.

Williams, S. J. (2003) 'Medicine and the body.' London: Sage.

Wilson, S. (2007) 'When you have children, you're obliged to live: Motherhood, chronic illness and biographical disruption.' Sociology of Health and Illness 29(4): 610-626.

Winstone, H. V., \& Freeth, Z. (1972) 'Kuwait: prosperity and reality.' London:

George Allen and Unwin.

Woby, S. R., Watson, P. J., Roach, N. K., \& Urmston, M. (2004) 'Adjustment to chronic low back pain - the relative influence of fear-avoidance beliefs, catastrophising, and appraisals of control.' Behaviour Research and Therapy 42: 761-774.

Woodward, K. (2002) 'Understanding identity.' London: Arnold.

Woodward, K. (2004) 'Questioning identity: Gender, class, ethnicity.' London: Routledge.

Zepp, I. G. (1992) 'A Muslim primer.' Westminster: Wakefield Editions. 


\section{Appendix 1 - Position of the Literature and Development of the}

\section{Conceptual Framework in this Study}

\begin{tabular}{|c|c|c|}
\hline Stage of Study & Literature reviewed & Aims \\
\hline \multirow[t]{2}{*}{ Stage 1} & $\begin{array}{l}\text { Preliminary literature review } \\
\text { - Theoretical notions of chronic } \\
\text { illness, disability, self and } \\
\text { identity } \\
\text { - Qualitative studies investigating } \\
\text { the subjective experiences of } \\
\text { people with CLBP } \\
\text { - Qualitative studies investigating } \\
\text { the concepts of self and identity } \\
\text { amongst people with chronic } \\
\text { illness }\end{array}$ & $\begin{array}{l}\text { Exploring significance of } \\
\text { area of research } \\
\text { - Identifying gaps in the } \\
\text { current literature } \\
\text { - Developing and refining } \\
\text { research question and } \\
\text { objectives } \\
\text { - Developing theoretical } \\
\text { sensitivity }\end{array}$ \\
\hline & $\begin{array}{l}\text { Methodological literature review } \\
\text { - Qualitative research methods } \\
\text { - The various grounded theory } \\
\text { approaches } \\
\text { - Symbolic interactionism } \\
\text { - Social constructionism }\end{array}$ & $\begin{array}{l}\text { Developing ontological, } \\
\text { epistemological and } \\
\text { theoretical assumptions } \\
\text { - Selecting the } \\
\text { methodological approach } \\
\text { - Designing the study } \\
\text { - Preparing for data collection } \\
\text { and analysis }\end{array}$ \\
\hline \multirow[t]{2}{*}{ Stage 2} & $\begin{array}{l}\text { Ongoing engagement and review } \\
\text { guided by data analysis and } \\
\text { developing theory } \\
\text { - Symbolic interactionist notions } \\
\text { of self and identity } \\
\text { - Sociology of emotions } \\
\text { - Qualitative studies focusing on } \\
\text { the gendered experiences of } \\
\text { women with chronic illness }\end{array}$ & $\begin{array}{l}\text { Developing various } \\
\text { perspectives to view the } \\
\text { data with increasing levels } \\
\text { of abstraction } \\
\text { - Conceptual leverage from } \\
\text { the literature } \\
\text { - Enhancing theoretical } \\
\text { sensitivity } \\
\text { - Updating the preliminary } \\
\text { literature review }\end{array}$ \\
\hline & $\begin{array}{l}\text { Integrative literature } \\
\text { - Revisiting key concepts and } \\
\text { theories: } \\
\text { Biographical disruption } \\
\text { Seminal work on the social self } \\
\text { (Mead, Goffman) } \\
\text { Seminal work on self and identity in } \\
\text { chronic illness (Charmaz) } \\
\text { - Transitions in chronic illness }\end{array}$ & $\begin{array}{l}\text { - Engaging the study's theory } \\
\text { with empirical research and } \\
\text { with formal theories } \\
\text { - Testing and developing the } \\
\text { central dimension } \\
\text { - Developing the explanatory } \\
\text { power of the theory } \\
\text { - Identifying original } \\
\text { contributions }\end{array}$ \\
\hline
\end{tabular}




\section{Appendix 2 - Faculty of Health and Social Science Research}

\section{Ethics and Governance Committee, University of Brighton}

\section{Ethics Committee Approval}

10-Nov-2011

Dear Miss Abdal,

I am pleased to inform you that your application entitled "Chronic Low Back Pain and the Construction of Illness Identities in Kuwait" has been approved by the Faculty of Health and Social Science Research Ethics and Governance Committee. The comments of the reviewer(s) who reviewed your manuscript are included at the foot of this letter.

Please notify The Chair of FREGC immediately if you experience an adverse incident whilst undertaking the research or if you need to make amendments to the original application.

We shall shortly issue letters of sponsorship and insurance for appropriate external agencies as necessary.

We wish you well with your research. Please remember to send annual updates on the progress of your research or an end of study summary of your research.

Sincerely,

Prof. Julie Scholes

CHair, Faculty of Health and Social Science Research Ethics and Governance Committee J.Scholes@brighton.ac.uk 


\section{Appendix 3 - Kuwait Institute for Medical Specialisations and}

\section{Ministry of Health Ethical and Study Approval (English and}

\section{Arabic versions)}

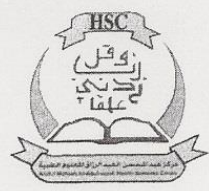

\section{JOINT COMMITTEE FOR THE PROTECTION OF HUMAN SUBJECTS IN RESEARCH}

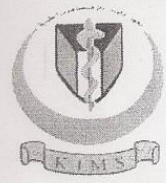

Ref.: VDR/JC/162

Date: December 4, 2011

To:

Noor Abdal

PhD Student - Physiotherapist University of Brighton - UK

From:

Dr. Ibrahim A. Hadi Secretary General KIMS

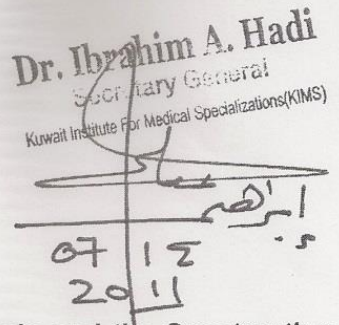

Sub: $\quad$ Project title: Chronic Low Back Pain and the Construction of IIIness Identities in Kuwait

Decision: Ethical approval granted.

Since the information required in the Consent forms from this Committee and University of Brighton are almost the same, it is advised that the Consent form from University of Brighton and the Arabic consent form from this Committee may be used. 


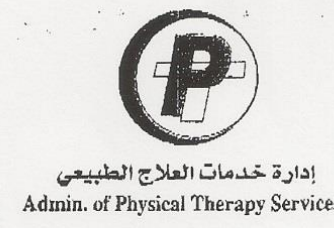

Reference :

Date:

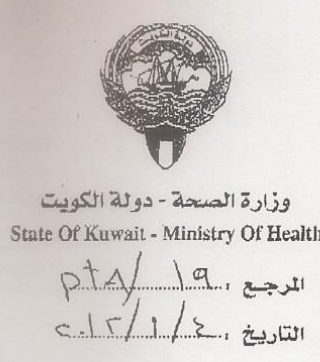

المبديد / مدير منطقة الصباح الطبية التخصصية

المحترمة المترمة

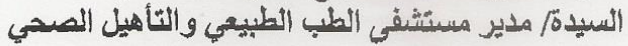

تحبية طرية.. ويتث ،

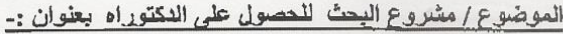

(Chronic Low Back Pain and the Construction of Self) المقلم من ألطالبة / نئ عبدال - جامعة بر ايتون - بالمملكة المتحدة

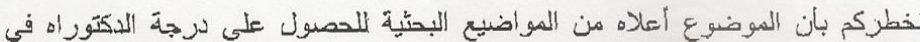

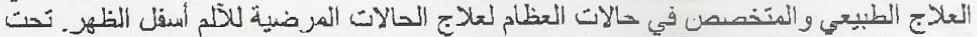

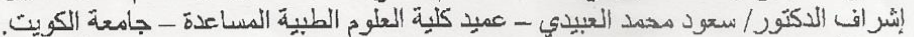

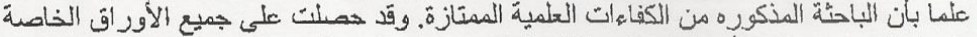

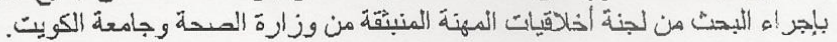

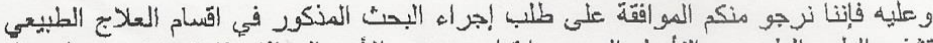

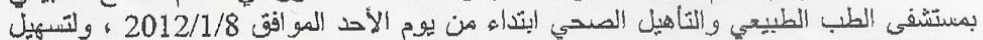

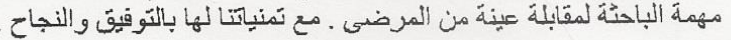

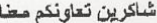

وتفضلو ا بقَبرل فائق الاحتر مغام

مرفقات: كتاب كلية العلوم الطببة المساعدة

مدير إلدارة خدمات العلاج الطبيعي

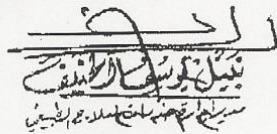

P.O.Box (5), Safat Zip Code (13001), Kuwait

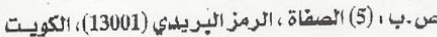
Tel.: 24860574 - 24860749 - Fax : 24860167

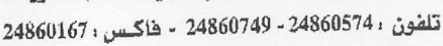




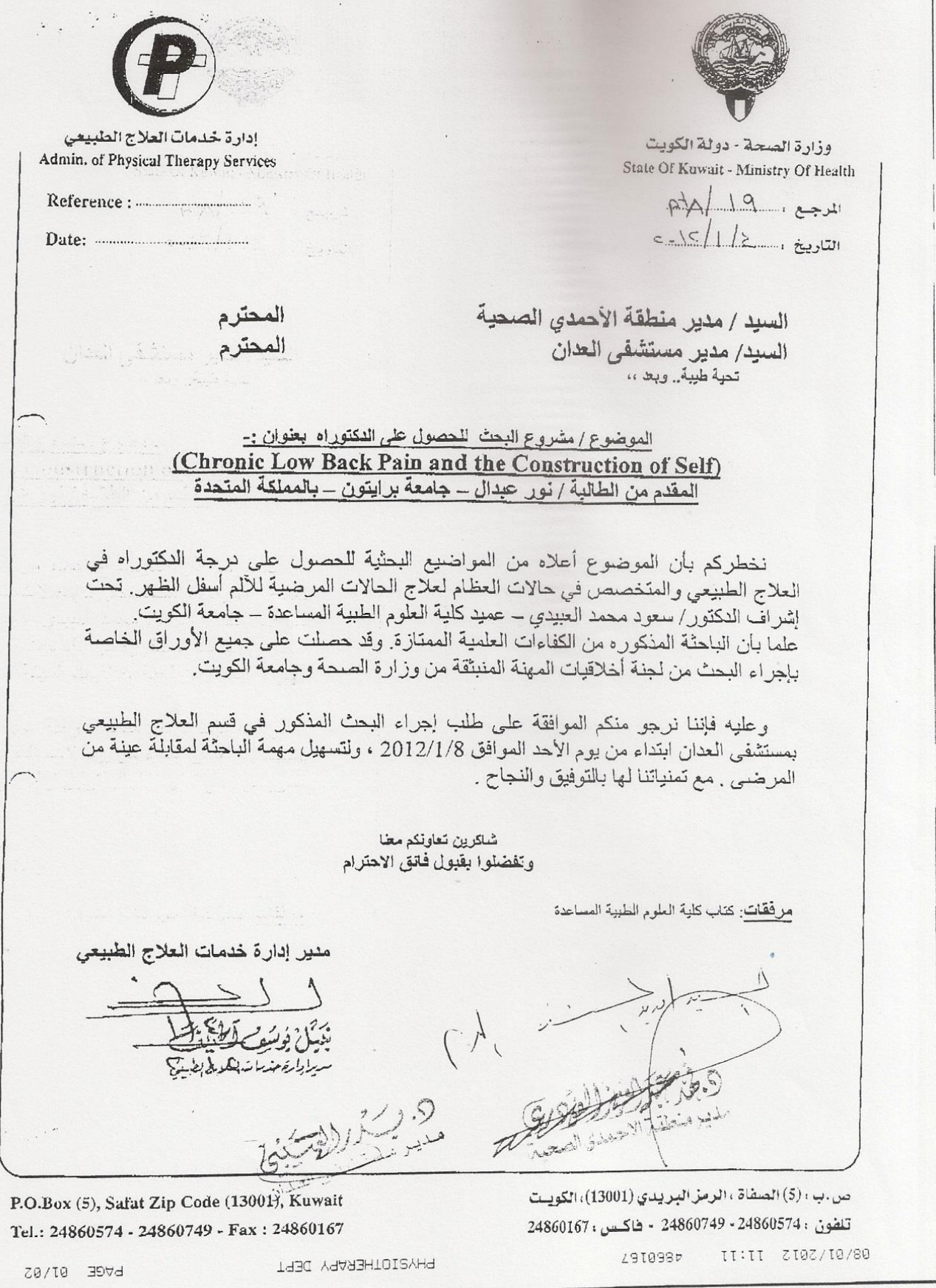




\section{Appendix 4 - Participant Information Sheet, Consent Form and}

\section{Participant Contact Form}

Title of the study: Chronic Low Back Pain (CLBP) and the Construction of Illness Identities

\section{Invitation}

My name is Noor Abdal and I am a PhD student at the University of Brighton, UK. I would like to invite you to participate in a research study. Please take some time to read this information sheet to familiarise yourself with the aims of the research, and what will be required from you if you choose to participate. You can discuss it with others if you wish; please feel free to contact me if you have any further enquiries or would like additional information. After you have read this information sheet thoroughly, have had all your queries cleared and have decided to participate, please contact me.

\section{What is the purpose of the study?}

The aim of my study is to investigate the experience of patients who have been suffering from low back pain for more than six weeks in order to produce a theory which explains how physiotherapists and patients develop the meaning of CLBP, and what factors may influence those meanings.

\section{Why have I been invited?}

You have been invited because I aim to recruit patients who have been suffering from CLBP for more than six weeks and do not suffer from conditions causing problems with cognition such as mental illnesses.

\section{Do I have to take part?}

Taking part in this study is completely voluntary and it is entirely up to you to decide whether or not you want to take part. The study is explained in this information sheet; I am also happy to answer any further questions or queries you may have. Once you decide to participate, you will be given a consent form to sign to show that you agreed to take part in the study. You may withdraw from the study at any time without offering a reason.

\section{What will happen to me if I take part?}

You will be invited to participate in up to three interviews: one after your initial physiotherapy session, one after you have been discharged, and a follow-up interview six weeks after you have been discharged from physiotherapy. Each is anticipated to last one hour, but may possibly take longer if you wish to share further information or elaborate on information you have chosen to disclose. Moreover, I will observe your initial physiotherapy session. During the interview, some questions will be asked but there will also be room for some open discussion. The interviews will be audiotaped and the information will be transcribed. However, no personal information that may identify you will be requested or used in this study. You will not be required to provide information such as your name. I will provide you with a copy of the transcript so that you can check it for accuracy and remove 
any information you feel may threaten your anonymity. You will be asked questions related to your experience with CLBP and how physiotherapy intervention may have influenced your experience.

\section{Will my taking part in the study be kept confidential?}

All the information you provide will remain anonymous and kept strictly confidential unless a disclosure is made which signifies poor or unethical practice in which case the researcher will have to notify the relevant authority. The information you disclose will be stored in a password protected external memory drive and password protected laptop, and will only be accessed and viewed by the researcher. Transcript documents will be stored in a locked drawer only accessible by the researcher, however your transcript may need to be viewed by my academic supervisors, in which case any identifying information will be removed. The data will not be retained for use in future studies and will be destroyed after it has been used in this study.

In the case of unprofessional or dangerous behaviours, disclosure of negligence or harm from the interview, the researcher will be required to break confidentiality and pass the information to the appropriate authority.

\section{What will happen if I wish to withdraw from the study?}

If you do not wish to carry on with the study, you may withdraw at anytime without giving any reason. However, since interviewing, observing and analysing interview transcripts will occur concurrently, it may be impossible to disaggregate and remove the data which you had already contributed. If any data you have provided has not been analysed at the point of your decision to withdraw from the study, you may be asked whether the data collected from you can still be used; however, you retain the right to decide whether that data can be used.

\section{What are the potential benefits of taking part in this study?}

You will not benefit directly from participating in the study, however, the information you provide will aid in developing a theory which may be beneficial in increasing your awareness of the condition, reduce uncertainty and help in revising dysfunctional beliefs and negative coping strategies which may be worsening your illness. Moreover, the results of the study may provide you with support, as reading the experiences of other people with CLBP may give you a sense that others understand what you are going through.

\section{What are the potential risks and disadvantages of taking part in this study?}

There is a risk that you may become distressed as you reflect on your experiences. If this happens, I will ask whether you wish to continue, pause or stop the interview. If you wish, I will refer you to support services provided by the hospital. You are free to stop the interview any time without giving reasons. 


\section{How will the findings of this study be disseminated?}

A summarised version of findings of the study will be provided to physiotherapists who participate in the study.

Dissemination of the research findings will take place at workshops and seminars and at national and international conferences. Publications will be disseminated in professional and peer-reviewed international journals. A copy of the final thesis produced from this study will be provided to the Kuwait Cultural Office; this is a normal procedure for students to follow after completing their study programmes. Moreover, any publications from the study will be available on the Internet.

\section{What if I change my mind about taking part?}

Your participation in this study is voluntary. There is absolutely no detriment in not taking part. If you choose to take part, you can still withdraw from the study at any time without giving a reason and it will not affect your care in any way.

\section{Contact Information}

Dr. Nikki Petty

Principal Lecturer

Address: University of Brighton

Aldro Building

49 Darley Road, Eastbourne

East Sussex BN20 7UR

United Kingdom

Email: N.J.Petty@bton.ac.uk

Telephone number: +441273641806

Mrs. Lynne Caladine

Head of School of Health Professions

Address: University of Brighton

Robert Dodd building

49 Darley Road, Eastbourne

East Sussex BN 20 7UR

United Kingdom

Email: L.Caladine@ brighton.ac.uk

Telephone number: +441273643773

If you would like to discuss this study further, please do not hesitate to contact me:

Noor Abdal

Email: noor.h.abdal@gmail.com 
Telephone number: +96599109955 


\section{What if there is a problem?}

Any complaint about the way you have been dealt with during the study or any possible harm you might have suffered can be addressed by contacting any of the following people: Dr. Nikki Petty or Lynne Calidyne. Please see the bottom of the information sheet for their contact details.

\section{Who is sponsoring this study?}

The study is being sponsored by the Civil Services Commission, a governmental institution in Kuwait.

\section{Who has reviewed this study?}

The study has been reviewed by the University of Brighton Faculty of Health and Social Science Research Ethics and Governance Committee and the Ministry of Health in Kuwait. 


\section{Consent Form}

Title of Project: Chronic Low Back Pain and the Construction of Illness Identities Name of Researcher: Noor Abdal

Please initial box

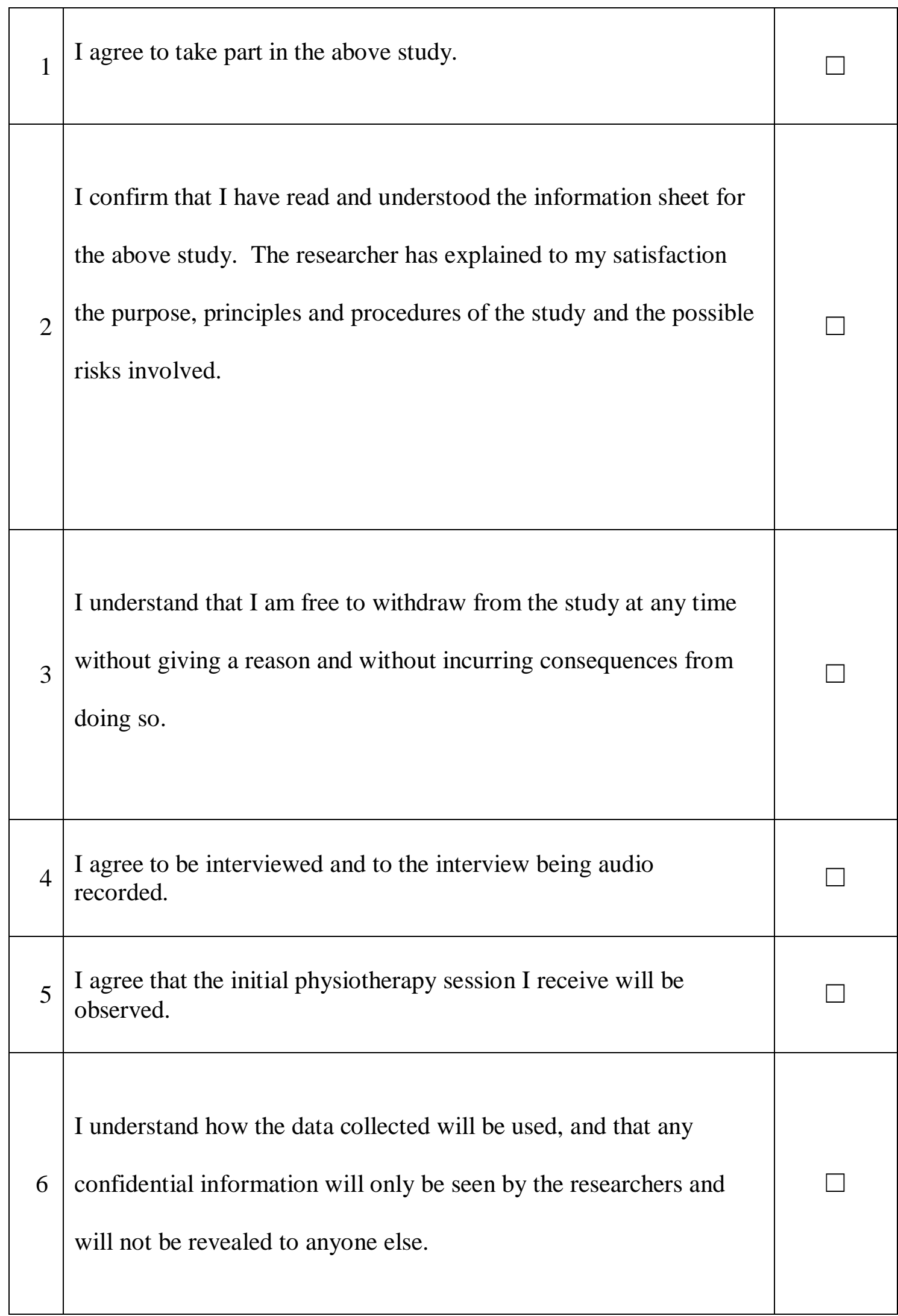




\begin{tabular}{|l|l|l|}
\hline 7 & $\begin{array}{l}\text { I agree that should I withdraw from the study, the data collected up } \\
\text { to that point may be used by the researcher for the purposes } \\
\text { described in the information sheet. }\end{array}$ \\
\hline 8 & $\begin{array}{l}\text { I agree that anonymised quotes from interviews may be used in the } \\
\text { thesis and any publications from this study. }\end{array}$ \\
\hline
\end{tabular}

Name of Patient

Name of Researcher
Date

Date

Signature
Signature

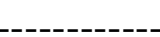


$\underline{\text { Participant Contact Form }}$

Name:

Preferred method of contact (please choose one or more and provide the relevant details):

Address:

Landline number:

Mobile number:

Email:

Please specify the most appropriate time to contact you: 


\title{
Appendix 5 - The Participant Information Sheet, Consent Form
}

\section{and Participant Contact Form (Arabic Version)}

\author{
ورقة معلومات للمرضى الراغبين بالمشاركه في الدراسه

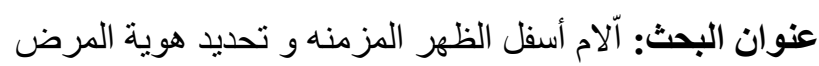

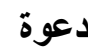

اسمي نور عبدال, طالبة دكتور اه في جامعة بر ايتون في المملكة المتحدة. اود دعوتكم للمشاركه في البحث الخاص

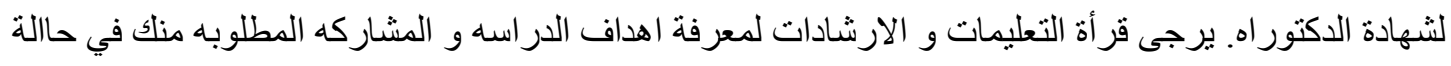
مو افقتلك للمشاركه. يمكنك الاتصال بي مباشرة على الرقم التالي للرد على استفسار اتك و نوضيحها للك. noor.h.abdal@gmail.com بور عبدال, تلفون: 965 9910995+, البريد الاكتروني:

ما هو الهرف من الاراسه؟

در اسة التجربه التي يمر بها مرضى آلام أسفل الظهر الذي يعاني منه المريض لمدة تزيد عن 6 اسابيع. و بالتالي

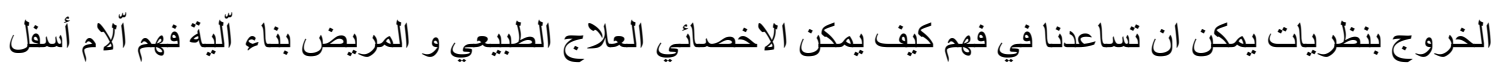

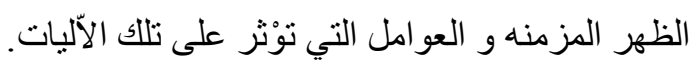

لم تم دعوتلك للمشاركه؟

تم دعو تك للحاجه لمشاركة مرضى يعانون من آلام أسفل الظهر لمدة تزيد عن 6 اسابيع. اذا كنت تعني من حالة تؤثر

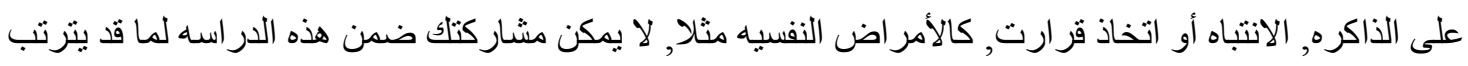
عليها من مضايقات أو ازعاج للك و بالتالي يمكنك التوقف عن استمر اريه في فر أة هذه الورقاه. ماذا سيحدث لك في حالة مشاركتي؟

سينم دعونلك للمشاركه في ثلاثه مقابلات, الاولى بعد فحص العلاج الطبيعي الاول, الثانيه بعد انتهاء فترة العلاج الطبيعي المحدده للك من قبل الاخصائي, و الثالثه بعد 6 اسابيع من انتهاء فترة العلاج الطبيعي. ستكون كل مقابله ساعه الهابه واحده على الأقل. إضافة لذلك سأقوم بملاحظة جلسة العلاج الطبيعي الأولى. خلال المقابلات سيتم طرح الاسئله كما

سيكون هنالك وقت كافي للمناقشه. كما اود ان اقوم بتسجيل المقابله ليساعدني في كتابتها لاحقا بصوره يمكن من

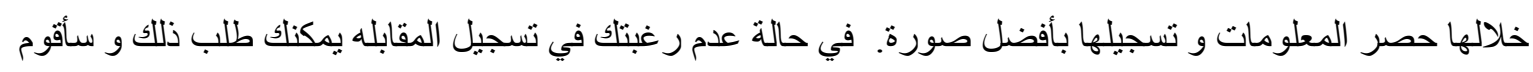
بكتابة ملاحظات أثناء المقابله بدلا من تسجيلها. و لن يتم ادراج اي معلومات عن هوية المريض أو أخصائي العلاج

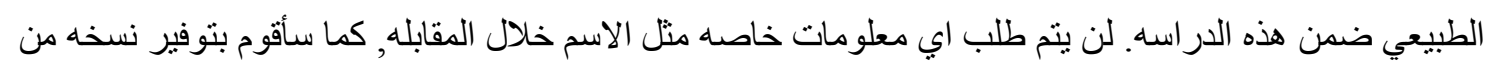
مضمون المقابله لأي مريض راغب بالمر اجعة و للتأكيد من صحتها و حذف المعلومات قد تكثف هويته. ستتضمن المقابله أسئله عن تجربتك التي تمر بها بسبب آلام أسفل الظهر و نأثير تدخل أخصائي العلاج الطبيعي للمعالجها.

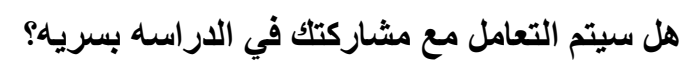

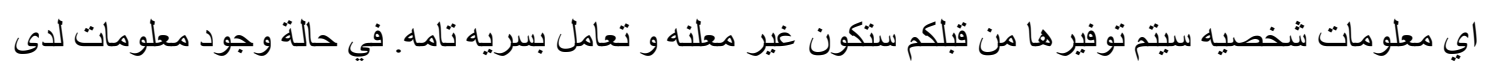

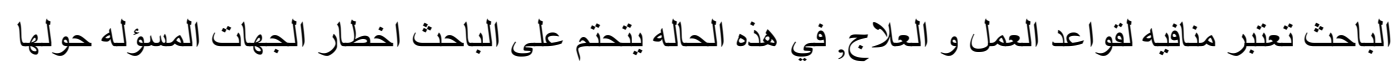
ما يسحدث في حالة تغيير رأيك في المشاركه بالدر اسه؟ 
في حاله مشار كتك يمكنك الانسحاب في أي وقت دون ابداء الاسباب كما ان لن يكون لذلك تأثثر على العنايه بالمشارك بأي شكل.

ما هي الفوائد المتوقعه من المشاركه في الدراسه؟ المعلومات التي سيتم تحصيلهاو تحليلها ضمن الدراسه من خلال مشاركتلك قد تسهم في تطوير النظريات اللازمه و

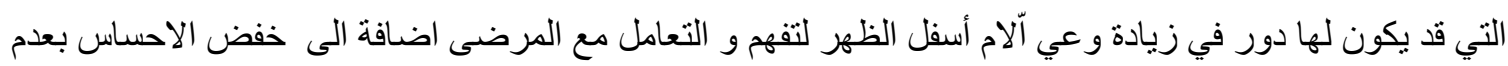
اليقيين و معالجة المعتقدات الغير صائبه و كيفية التعامل مع المرض بصوره سلبيه و التي قد تؤدي الى زيادة حدة المرض و آلامه. كما ان نتائج الدراسه قد نوفر آلّه دعم من خلال قرأة تجارب آخرين يعانون من مرض آلام أسفل

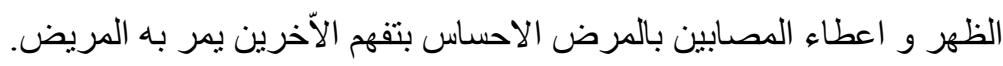

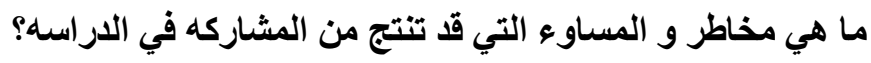
من المخاطر هو ما قد تتسب للك المقابله من ضغوط نتيجة نوضيح ما تمر به من تجربه مرضيه و في حال حدوث مثل هذا الثيء سيتم سؤالكم عن رغبتك في الاستمر اريه او التوقيف المؤقت او الغاء المقابله. و بناءا على رغبتلك سيتم تحويلك لجهات الدعم في المستشفى في هذه الحاله. كما يمكنك وقف المقابله في اي وقت دون ابداء الاسباب. ما سيحدث في حالة وجود اي مشكله؟ في حالة وجود اي شكوى عن كيفيه التعامل معلك خلال الدراسه او اي اذى لحق بك نتيجه الدراسه يمكنك توجيهها الى الى اي من الاشخاص المذكورين ادناه.

د. سعود العبيدي, عميد كليه العلوم الطبيه المساعدة في جامعه الكويت و المشرف المحلي, -

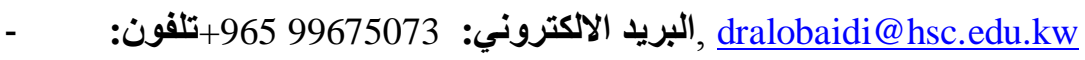

د. نيكي بتي, محاضر رئيسي في جامعة برايتون في المملكه المتحده و المشرف العالمي, -

- البريد الاكتروني: 44.,petty@bton.ac.uk 
نموذج الموافقة للمرضى

عنوان البحث: آلام الظهر السفلي المزمنة وهوية المرض

اسم الباحث: نور عبدال

يرجى وضع علامه على المربع

\begin{tabular}{|c|c|c|}
\hline$\square$ & 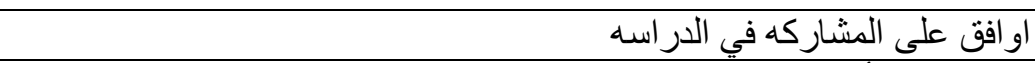 & 1 \\
\hline$\square$ & 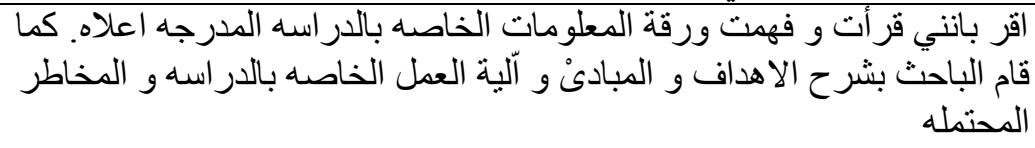 & 2 \\
\hline$\square$ & 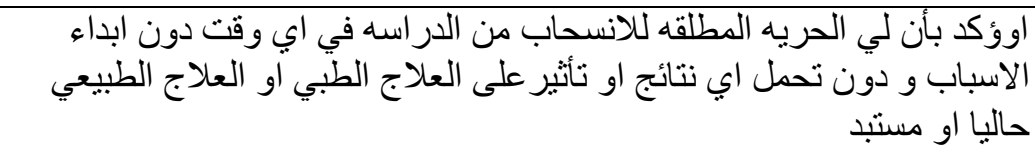 & 3 \\
\hline$\square$ & انا او افق على ان المشاركه في جلسات المقابله و تسجيل تللك الجلسات. & 4 \\
\hline$\square$ & انا او افق على تواجد الباحث خلال حلسة العلاج الطبيعي الأولى للملاحظه. & 5 \\
\hline$\square$ & 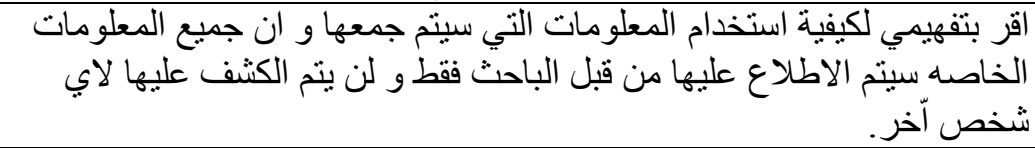 & 6 \\
\hline$\square$ & 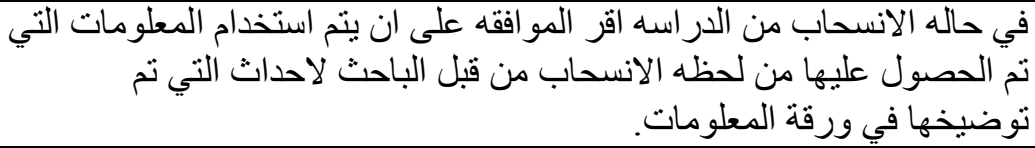 & 7 \\
\hline$\square$ & 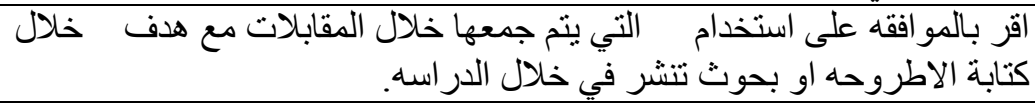 & 8 \\
\hline
\end{tabular}

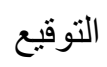

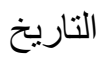

اسم المريض

التوقيع

التاريخ 
نموذج معلومات الاتصال بالمشارك

الاسم:

طريقة الاتصال المفضلة (يرجى اختيار واحدة أو أكثر من طرق الاتصال و توفير المعلومات المطلوبة) العنوان:

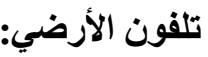

تلفون النقال: - 20 - n

البريد الاكتروني:

يرجى تحديد أفضل الأوقات للاتصال: 